Murilo da Silva

\title{
LOCALIZAÇÃO DE FALTAS EM LINHAS DE TRANSMISSÃO UTILIZANDO A TEORIA DE ONDAS VIAJANTES E TRANSFORMADA WAVELET
}

Dissertação apresentada à Escola de Engenharia de São Carlos da Universidade de São Paulo, como parte dos requisitos para obtenção do Título de Mestre em Engenharia Elétrica.

Orientador: Prof. Tit. Denis Vinicius Coury

São Carlos

2003 
Aos meus pais, Dorival e Maria, por tudo o que fizeram e fazem por mim, a minha queridíssima irmã, Patrícia e, a minha tia Magda, por seu constante apoio. 


\section{AGRADECIMENTOS}

Em primeiro lugar a DEUS, sem o qual nada seria possível de se realizar.

À minha família, meu pai Dorival, minha mãe Maria, minha irmã Patrícia, minha sobrinha Thais, pelo amor, pelo carinho, pela educação, por sempre acreditarem em mim e pelo constante incentivo.

Aos meus familiares, em especial a minha tia Magda pelo apoio e incentivo.

Em especial ao Prof. Titular Denis Vinicius Coury, pelo apoio, confiança, amizade e por sua sábia e segura orientação no desenvolvimento deste trabalho.

A Karla, pela paciência, compreensão, apoio, carinho e por ser essa pessoa tão especial que me faz sentir tão feliz.

Ao Doutor Mário Oleskovicz, pela amizade e por seu importante auxílio no desenvolvimento deste trabalho.

A todos os meus amigos e amigas que tive a honra de conhecer graças a este trabalho, em especial aos integrantes do LSEE - "O LAB", pela ajuda nos momentos de trabalho sério, assim como pelos momentos de descontração e alegria.

Ao Departamento de Engenharia Elétrica da Escola de Engenharia de São Carlos - USP, por colocar a minha disposição sua estrutura.

Aos professores e funcionários do Departamento de Engenharia Elétrica (EESCUSP) que sempre estiveram dispostos a colaborar.

A todos aqueles que direta ou indiretamente contribuíram para realização deste trabalho.

À CAPES - Coordenação de Aperfeiçoamento de Pessoal de Nível Superior, pelo auxílio financeiro fornecido no período da realização deste trabalho, sem o qual o mesmo não seria possível. 


\section{RESUMO}

SILVA, M. (2003). Localização de faltas em linhas de transmissão utilizando a teoria de ondas viajantes e transformada wavelet. Dissertação (Mestrado) - Escola de Engenharia de São Carlos, Universidade de São Paulo, São Carlos, 2003.

Este trabalho traz a aplicação da Transformada Wavelet (TW) para analisar os transitórios de alta freqüência em um sistema de transmissão causados por uma falta sustentada, com o objetivo de se determinar a precisa localização da mesma. A TW, ferramenta matemática empregada neste trabalho, é uma transformação linear muito parecida com a transformada de Fourier, com uma importante diferença: ela permite a localização no tempo de diferentes componentes de freqüência de um dado sinal. Esta localização permite a detecção no tempo da ocorrência de distúrbios abruptos, tais como os transitórios ocasionados por situações de faltas. Os sinais de ondas viajantes geradas pela ocorrência da falta aparecem como distúrbios superpostos aos sinais de freqüência fundamental que são registrados pelos relés. Processando-se estes sinais pelo emprego da TW, esta pode revelar o tempo de propagação dos sinais analisados entre o ponto de ocorrência do distúrbio e a localização física do relé. Conseqüentemente, dispondo-se do intervalo de tempo entre as ondas sobre uma dada linha de transmissão, a distância do ponto de falta pode então ser facilmente determinada, sendo esta a filosofia adotada neste trabalho. O problema delineado é abordado através da implementação prática de um algoritmo computacional. Nesta implementação, o usuário pode escolher a técnica de localização a ser empregada, utilizando-se de dados registrados em um ou em ambos os terminais da linha, conforme a sua necessidade e/ou disponibilidade dos recursos necessários. Com o objetivo de testar e validar a aplicabilidade do algoritmo de localização de faltas, utilizou-se de dados de sinais faltosos obtidos através de simulações do software ATP (Altenative Transients Program), levando-se em conta vários tipos de falta em diferentes localizações ao longo da linha, com diferentes ângulos de incidência, resistências de falta, freqüência de amostragem do sinal, etc. Também foi verificada a influência do acoplamento mútuo em caso de circuitos duplos 
de transmissão. Os resultados alcançados pelo algoritmo são promissores e demonstram uma ótima precisão e aplicabilidade do método proposto.

Palavras chave: Localização de faltas, ondas viajantes, transformada wavelet, sistemas elétricos de potência. 


\section{ABSTRACT}

SILVA, M. (2003). Fault Location in Transmission Lines Using Traveling Waves and Wavelet Transform Theory. Dissertation (Masters Degree) - Escola de Engenharia de São Carlos, Universidade de São Paulo, São Carlos, 2003.

This work presents a Wavelet Transform (WT) application to analyze the high frequency transients in a transmission line caused by a fault, with the purpose of determining its accurate location. The WT is very similar to Fourier Transform (FT), with an important difference: it allows the time determination of different frequency components of a signal. This skill allows the detection of the time of the disturbance occurrence, such as fault transients. The traveling waves generated by the fault occurrence appear as superimposed disturbances on the power frequency signals recorded by the relay. By processing these signals using the WT, the propagation time between the fault point and the relay location can be determined. Consequently, the distance of the fault point can be easily calculated. The delineated problem is boarded through the practical implementation of a computational algorithm. In this implementation, the user can choose the location technique to be employee, using data registered in one or both the terminals of the line, according to the necessity and/or availability of the data. In order to evaluate the applicability of the proposed scheme, the simulation of the transmission line in a faulty condition was utilized. This work makes use of a digital simulator of a faulted EHV (Extra High Voltage) transmission lines known as Alternative Transients Program (ATP). A typical transmission line from CESP (Companhia Energética de São Paulo) were utilized. The simulated data obtained was very close to that found in practice. This study takes into account single phase to ground faults, phase-to-phase faults, phase-phase to ground and three phase faults. The data set was composed of various fault situations considering different fault locations, fault resistances and fault inception angles. The influence of the sampled rate used was also verified as well as the mutual coupling in case of double transmission circuits. The test results reached for the algorithm are promising and demonstrate a highly satisfactory degree of accuracy and applicability of the proposed method. 
Keywords: Fault location, traveling waves, wavelet transform, power system. 


\section{LISTA DE FIGURAS}

FIGURA 1 - Diagrama Lattice representando as sucessivas reflexões de um sinal

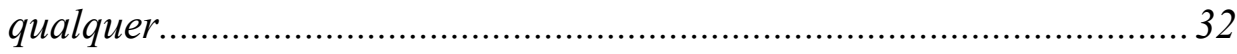

FIGURA 2 - Escalamento de uma função Wavelet ..................................................... 36

FIGURA 3 - Translação aplicada a uma Wavelet ........................................................ 37

FIGURA 4 - Processo de filtragem de um sinal no primeiro nível.................................. 38

FIGURA 5 - Processo de diminuição do número de amostras do sinal

(Downsampling)

FIGURA 6 - Exemplo de filtragem com downsampling de um sinal senoidal ruidoso. 39

FIGURA 7 - Processo de decomposição de um sinal em AMR 40

FIGURA 8 - Processo de reconstrução de um sinal filtrado. 41

FIGURA 9 - Processo de aumento do número de amostras para reconstrução de um sinal

FIGURA 10 - Processos de decomposição e reconstrução de um sinal. 42

FIGURA 11 - Reconstrução de um sinal a partir de seu coeficientes de aproximação

FIGURA 12 - Reconstrução do primeiro nível de detalhe do sinal. 43

FIGURA 13 - Diferentes formas para se reconstruir o sinal a partir de seus coeficientes

FIGURA 14 - Áreas de aplicação da TW em sistemas elétricos de potência. 44

FIGURA 15 - Representação do sistema elétrico analisado 46

FIGURA 16 - Situações de faltas sobre o sistema ........................................................... 47

FIGURA 17 - Silhueta de torre da linha de $440 \mathrm{kV}$.................................................... 49

FIGURA 18 - Transposição de uma linha de transmissão............................................... 50

FIGURA 19 - Representação de um trecho de uma linha de transmissão por parâmetros distribuídos. 50

FIGURA 20 - Rotina Line Constant para o sistema simples vertical tipo VVV ............. 51

FIGURA 21 - Arquivo de entrada de dados do ATP para uma falta fase-terra ............ 53

FIGURA 22 - Formas de onda de tensão para uma falta fase-terra aplicada a 40 km da barra $E$. 
FIGURA 23 - Formas de onda de corrente para uma falta fase-terra aplicada a 40 km da barra E. 54

FIGURA 24 - Configuração do sistema com circuito duplo vertical. 56

FIGURA 25 - Silhueta da torre de um circuito de transmissão duplo vertical de $440 \mathrm{kV}$.

FIGURA 26 - Arquivo de entrada para a rotina Line Constant referente ao circuito duplo 58

FIGURA 27 - Arquivo de entrada do ATP para uma falta fase-fase no circuito 1. 59

FIGURA 28 - Formas de ondas de tensão para uma falta fase-fase na linha E-F do circuito 1 .

FIGURA 29 - Formas de ondas de corrente para uma falta fase-fase na linha E-F do circuito 1 60

FIGURA 30 - Sistema Elétrico e diagrama Lattice 64

FIGURA 31 - Fluxograma do algoritmo de localização de faltas 65

FIGURA 32 - Sub-rotina para classificação do tipo da falta . 68

FIGURA 33 - Classificação dos diversos tipos de faltas ..... 69

FIGURA 34 - Menu de escolha da técnica de localização de faltas............................... 72

FIGURA 35 - Exemplo de deteç̧ão dos picos iniciais.................................................. 74

FIGURA 36 - Exemplo 1: Detecção de T2 para uma falta fase-terra sem necessidade do limiar 3.

FIGURA 37 - Exemplo 2: Detecção de T2 para uma falta fase-terra com necessidade do limiar 3.

FIGURA 38 - Fluxograma referente as etapas para determinação dos tempos $t_{1} e$ $t_{2}$

FIGURA 39 - (a) Falta fase-terra na segunda metade da linha, (b) falta fase-terra na primeira metade da linha

FIGURA 40 - Sinais de detalhe 1 dos modos aéreo 1 e terra para uma falta faseterra na segunda metade da linha

FIGURA 41 - Coeficientes wavelet para uma falta fase A-terra a $110 \mathrm{~km}$ da barra E, com resistência de falta de 100 ohms e ângulo de incidência de $0^{\circ}$.

FIGURA 42 - Histograma referente as faltas $(A B)$ com ângulo de incidência de 0 e $90^{0}$ 
FIGURA 43 - Histograma referente as faltas $(A B C)$ com ângulo de incidência de 0 e $90^{\circ}$ 88

FIGURA 44 - Histograma referente as faltas (AT) com ângulo de incidencia de $0^{0} \ldots . .93$ FIGURA 45 - Histograma referente as faltas (AT) com ângulo de incidencia de $90^{0} \ldots 93$ FIGURA 46 - Histograma referente as faltas (BCT) com ângulo de incidência de $0^{0} \ldots 93$ FIGURA 47 - Histograma referente as faltas (BCT) com ângulo de incidência de $90^{\circ}$ 93

FIGURA 48 - Influência da distância para faltas fase-fase $(A B)$................................. 94

FIGURA 49 - Influência da distância para faltas trifásicas........................................ 94

FIGURA 50 - Influência do tipo da falta na precisão do algoritmo ............................... 95

FIGURA 51 - Influência da resistência de falta em situações de faltas fase-terra (AT), com resistências de falta de 0, 50 e $100 \Omega$ e ângulo de incidência de falta de $90^{\circ}$..... 96

FIGURA 52 - Influência da resistência de falta em situações de faltas fase-faseterra (BCT), com resistências de falta de 0, 50 e $100 \Omega$ e ângulo de incidência de falta de $90^{\circ}$

FIGURA 53 - Influência da resistência de falta em situações de faltas fase-faseterra (ACT), ), com resistências de falta de 200 e $400 \Omega$ e ângulo de incidência de falta de $90^{\circ}$. 98

FIGURA 54 - Falta AT a $80 \mathrm{~km}$ da barra E, com ângulo de incidência de falta de $0^{0}$ e resistência de falta de $400 \Omega$......

FIGURA 55 - Influência da perda de sincronismo (1 amostra) considerando situações de faltas fase-terra com ângulo de incidência de $90^{\circ}$.

FIGURA 56 - Influência da imprecisão dos parâmetros de linha (L e C) em situações de falta fase-terra.

FIGURA 57 - Histograma referente aos casos de faltas fase-terra aplicadas sobre um circuito duplo. 103

FIGURA 58 -Dados registrados na barra E e F para uma falta fase-terra (AT) aplicada no circuito 2 a $50 \mathrm{~km}$ da barra I sobre a linha I-G. 105

FIGURA 59 - Coeficientes wavelet para uma falta-fase fase(AB) a $70 \mathrm{~km}$ da barra E, com ângulo de incidência de $90^{\circ}$ 109

FIGURA 60 - Histograma referente as situações de faltas fase-fase (AB). 110

FIGURA 61 - Histograma referente as situações de faltas trifásicas (ABC) 110 
FIGURA 62 - Histograma referente as situações de falta fase-fase-terra (ACT) 112

FIGURA 63 - Coeficientes wavelet para uma falta fase A-terra a $25 \mathrm{~km}$ da barra E, com resistência de falta de 0 ohms e ângulo de incidência de $90^{\circ} \ldots . . .113$

FIGURA 64 - Coeficientes wavelet para uma falta fase A-terra a $125 \mathrm{~km}$ da barra E, com resistência de falta de 0 ohms e ângulo de incidência de $90^{\circ} .114$

FIGURA 65 - Histograma referente as faltas fase-terra (AT), com ângulo de incidência de $00^{0}$

FIGURA 66 - Histograma referente as faltas fase-terra (AT), com ângulo de incidência de falta de $90^{\circ}$

FIGURA 67 - Influência do tipo da falta na precisão da técnica de localização utilizada.... 118

FIGURA 68 - Influência do ângulo de incidência da falta para faltas fase-terra ....... 119

FIGURA 69 - Influência da resistência de falta para faltas fase-fase-terra (ACT)..... 120

FIGURA 70 - Influência da imprecisão dos parâmetros de linha (L e C) sobre a técnica de um terminal em situações de falta fase-terra.

FIGURA 71 - Histograma referente as situações de falta fase-fase aplicadas ao circuito duplo

FIGURA 72 - Comparação entre a aplicação do localizador sobre diferentes configurações de linhas de transmissão. 


\section{LISTA DE TABELAS}

TABELA 1 Distribuição de faltas em um sistema de $500 \mathrm{kV}$, em um periodo de dez anos, com a ocorrência de noventa e nove faltas.................................... 2

TABELA 2 - Parâmetros da linha de transmissão de $440 \mathrm{kV}$........................................51

TABELA 3 - Parâmetros dos equivalentes de geração das barras $D$ e $G$..................... 52

TABELA 4 - Dados das barras de geração $D$ e $G$.............................................................52

TABELA 5 - Parâmetros de seqüência da linha de transmissão para o circuito

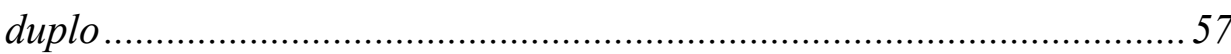

TABELA 6 - Parâmetros dos equivalentes de geração das barras $D$ e $G$....................... 58

TABELA 7 - Dados de barra referentes ao circuito duplo........................................... 58

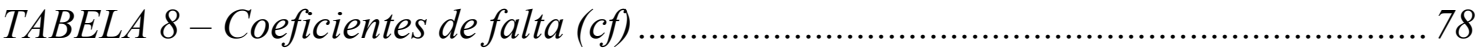

TABELA 9 - Falta fase-fase (AB), com ângulo de incidência de falta de $0^{0}$..................8 87

TABELA 10 - Falta fase-fase (AB), com ângulo de incidência de falta de $90^{\circ}$..............87

TABELA 11 - Falta trifásica $(A B C)$, com ângulo de incidência de falta de $0^{0}$................87

TABELA 12 - Falta trifásica $(A B C)$, com ângulo de incidência de falta de $90^{\circ}$.............87

TABELA 13 - Faltas fase-terra (AT), com resistências de falta de 0, 50 e $100 \Omega$ e ângulo de incidência de falta de $0^{0}$.

TABELA 14 -Faltas fase-terra (AT), com resistências de falta de 0, 50 e $100 \Omega e$ ângulo de incidência de falta de $90^{\circ}$.

TABELA 15 - Faltas fase-fase-terra (BCT), com resistências de falta de 0, 50 e 100 $\Omega$ e ângulo de incidência de falta de $0^{0}$ 91

TABELA 16 - Faltas fase-fase-terra (BCT), com resistências de falta de 0, 50 e 100 $\Omega$ e ângulo de incidência de falta de $90^{\circ}$............................................. 92

TABELA 17 -Influência da taxa amostral em situações de falta fase-terra .................... 99

TABELA 18 -Influência da taxa amostral em situações de falta fase-fase .................. 100

TABELA 19 -Faltas fase-terra (AT) aplicadas no circuito duplo ............................... 104

TABELA 20 - Faltas fase-terra e fase-fase aplicadas no circuito 1 da linha dupla .... 107

TABELA 21 - Faltas fase-terra aplicadas no circuito 2 da linha dupla ....................... 108

TABELA 22 -Falta fase-fase (AB), com ângulo de incidência de falta de $0^{0}$............... 110

TABELA 23 - Falta fase-fase (AB), com ângulo de incidência de falta de $90^{\circ} \ldots \ldots \ldots . . .110$

TABELA 24 -Faltas trifásica $(A B C)$, com ângulo de incidência de falta de $0^{0} \ldots \ldots \ldots . . .110$ 
TABELA 25 -Faltas trifásicas (ABC), com ângulo de incidência de falta de $90^{\circ}$ 110

TABELA 26 - Faltas Fase-Fase-Terra (ACT), com ângulo de incidência de falta de $0^{0}$ e resistência de falta de 0, 50 e $100 \mathrm{ohms}$.

TABELA 27 - Falta fase-terra (AT), com ângulo de incidência de falta de $0^{0}$. 115

TABELA 28 - Faltas fase-terra (AT), com ângulo de incidência de falta de $90^{\circ}$. 116

TABELA 29 - Resultados obtidos para casos de faltas fase-terra com ângulo de incidência de $0^{\circ}$ e variação da freqüência de amostragem do sinal..... 122

TABELA 30 - Resultados obtidos para casos de faltas fase-terra com ângulo de incidência de $90^{\circ}$ e variação da freqüência de amostragem do sinal... 122

TABELA 31 - Faltas fase-fase (AB) aplicadas no circuito duplo. 124

TABELA 32 - Faltas fase-terra e fase-fase aplicadas no circuito 1 da linha dupla..... 126

TABELA 33 - Faltas fase-terra aplicadas no circuito 2 da linha dupla. 127

TABELA 34 - Resultados gerais alcançados pela técnica de um terminal. 129

TABELA 35 - Resultados gerais alcançados pela técnica de um terminal aplicada a um circuito duplo.

TABELA 36 - Resultados gerais alcançados pela técnica de dois terminais aplicada a um circuito simples.

TABELA 37 - Resultados gerais alcançados pela técnica de dois terminais aplicada a um circuito duplo

TABELA 38 - Resultados para faltas fase-fase(AC) com ângulo de incidência de $0^{\circ}$

TABELA 39 - Resultados para faltas fase-fase(AC) com ângulo de incidência de $90^{\circ}$.

TABELA 40 - Resultados para faltas fase-fase (BC) com ângulo de incidência de $0^{\circ} .143$

TABELA 41 - Resultados para faltas fase-fase $(B C)$ com ângulo de incidência de $90^{\circ}$.

TABELA 42 - Resultados para faltas trifásicas (ABC) com ângulo de incidência de $0^{\circ}$. 143

TABELA 43 - Resultados para faltas trifásicas (ABC) com ângulo de incidência de $90^{\circ}$

TABELA 44 - Resultados para faltas fase-terra(BT) com ângulo de incidência de $0^{\circ}$ e resistência de falta de 0, 50 e 100 ohms. 144

TABELA 45 - Resultados para faltas fase-terra(BT) com ângulo de incidência de $90^{\circ}$ e resistência de falta de 0, 50 e $100 \mathrm{ohms}$ 
TABELA 46 - Resultados para faltas fase-terra(CT) com ângulo de incidência de $0^{\circ}$ e resistência de falta de 0,50 e $100 \mathrm{ohms}$

TABELA 47 - Resultados para faltas fase-terra(BT) com ângulo de incidência de $90^{\circ}$ e resistência de falta de 0,50 e $100 \mathrm{ohms}$

TABELA 48 - Resultados para faltas fase-fase-terra(ABT) com ângulo de incidência de $0^{\circ}$ e resistência de falta de 0, 50 e $100 \mathrm{ohms}$ 148

TABELA 49 - Resultados para faltas fase-fase-terra(ABT) com ângulo de incidência de $90^{\circ}$ e resistência de falta de 0, 50 e $100 \mathrm{ohms}$

TABELA 50 - Resultados para faltas fase-fase-terra(ACT) com ângulo de incidência de $0^{\circ}$ e resistência de falta de 0, 50 e $100 \mathrm{ohms}$

TABELA 51 - Resultados para faltas fase-fase-terra(ACT) com ângulo de incidência de $90^{\circ}$ e resistência de falta de 0, 50 e $100 \mathrm{ohms}$

TABELA 52 - Resultados para faltas fase-terra(AT) com ângulo de incidência de $45^{\circ}$ e resistência de falta de 100, 200 e $400 \mathrm{ohms}$.

TABELA 53 - Resultados para faltas fase-terra(AT) com ângulo de incidência de $70^{\circ}$ e resistência de falta de 100, 200 e $400 \mathrm{ohms}$.

TABELA 54 - Resultados para faltas fase-terra(AT) com ângulo de incidência de $0^{\circ}$ e resistência de falta de 200 e $400 \mathrm{ohms}$.

TABELA 55 - Resultados para faltas fase-terra(AT) com ângulo de incidência de $90^{\circ}$ e resistência de falta de 200 e $400 \mathrm{ohms}$

TABELA 56 - Resultados para faltas fase-fase-terra(ACT) com ângulo de incidência de $0^{\circ}$ e resistência de falta de 200 e $400 \mathrm{ohms}$

TABELA 57 - Resultados para faltas fase-fase-terra(ACT) com ângulo de incidência de $90^{\circ}$ e resistência de falta de 200 e 400 ohms.

TABELA 58 - Resultados da perda de sincronismo (1 $\mu$ s) para faltas AT com ângulo de incidência de $0^{\circ}$.

TABELA 59 - Resultados da perda de sincronismo (1 1 s) para faltas AT com ângulo de incidência de $90^{\circ}$.

TABELA 60 - Resultados da perda de sincronismo (1 amostra) para faltas AT com ângulo de incidência de $0^{\circ}$.

TABELA 61 - Resultados da perda de sincronismo (1 amostra) para faltas AT com ângulo de incidência de $90^{\circ}$. 
TABELA 62 - Resultados da perda de sincronismo (1 $\mu$ s) para faltas AB com ângulo de incidência de $0^{\circ}$ e $90^{\circ}$.

TABELA 63 - Resultados da perda de sincronismo (1 amostra) para faltas AB com ângulo de incidência de $0^{\circ}$ e $90^{\circ}$. 162

TABELA 64 - Efeito da taxa de amostragem para faltas fase-terra (AT) com ângulo de incidência de $0^{\circ}$ e resistência de falta de 0, 50 e 100 ohms .163

TABELA 65 - Efeito da taxa de amostragem para faltas fase-fase-terra (ABT) com ângulo de incidência de $0^{\circ}$ e resistência de falta de 0, 50 e 100 ohms . 164

TABELA 66 - Efeito da taxa de amostragem para faltas fase-terra (ABT) com ângulo de incidência de $90^{\circ}$ e resistência de falta de 0, 50 e 100 ohms. 165

TABELA 67 - Efeito da taxa de amostragem para faltas fase-fase (AB) com ângulo de incidência de $90^{\circ}$. 166

TABELA 68 - Efeito da taxa de amostragem para faltas trifásicas (ABC) com ângulo de incidência de $0^{\circ}$.

TABELA 69 - Efeito da taxa de amostragem para faltas trifásicas (ABC) com ângulo de incidência de $90^{\circ}$.

TABELA 70 - Efeito da imprecisão de $+5 \%$ nos parâmetros L e C da linha de transmissão considerando faltas fase-terra com ângulo de incidência da falta de $0^{\circ}$.

TABELA 71 - Efeito da imprecisão de $+5 \%$ nos parâmetros $L$ e $C$ da linha de transmissão considerando faltas fase-terra com ângulo de incidência da falta de $90^{\circ}$. 168

TABELA 72 - Efeito da imprecisão de -5\% nos parâmetros L e C da linha de transmissão considerando faltas fase-terra com ângulo de incidência da falta de $0^{\circ}$. 169

TABELA 73 - Efeito da imprecisão de-5\% nos parâmetros L e C da linha de transmissão considerando faltas fase-terra com ângulo de incidência da falta de $90^{\circ}$. 170

TABELA 74 - Resultados para faltas fase-terra (BT) com ângulo de incidência de $0^{\circ}$ e resistência de falta de 0, 50 e 100 ohms. 172

TABELA 75 - Resultados para faltas fase-terra (BT) com ângulo de incidência de $90^{\circ}$ e resistência de falta de 0, 50 e 100 ohms. 
TABELA 76 - Resultados para faltas fase-terra (CT) com ângulo de incidência de $0^{\circ}$ e resistência de falta de 0, 50 e $100 \mathrm{ohms}$

TABELA 77 - Resultados para faltas fase-terra (BT) com ângulo de incidência de $90^{\circ}$ e resistência de falta de 0, 50 e $100 \mathrm{ohms}$

TABELA 78 - Resultados para faltas fase-terra (AT) com ângulo de incidência de $90^{\circ}$ e resistência de falta de 200 e $400 \mathrm{ohms}$

TABELA 79 - Resultados para faltas fase-fase-terra (ABT) com ângulo de incidência de $0^{\circ}$ e resistência de falta de 0, 50 e $100 \mathrm{ohms}$.

TABELA 80 - Resultados para faltas fase-fase-terra (ABT) com ângulo de incidência de $90^{\circ}$ e resistência de falta de 0, 50 e $100 \mathrm{ohms}$.

TABELA 81 - Resultados para faltas fase-fase-terra (ACT) com ângulo de incidência de $90^{\circ}$ e resistência de falta de 0, 50 e $100 \mathrm{ohms}$.

TABELA 82 - Resultados para faltas fase-fase-terra (BCT) com ângulo de incidência de $0^{\circ}$ e resistência de falta de 0, 50 e $100 \mathrm{ohms}$. 180

TABELA 83 - Resultados para faltas fase-fase-terra (BCT) com ângulo de incidência de $90^{\circ}$ e resistência de falta de 0, 50 e $100 \mathrm{ohms}$.

TABELA 84 - Resultados para faltas fase-fase (AC) com ângulo de incidência de $0^{\circ}$.

TABELA 85 - Resultados para faltas fase-fase (AC) com ângulo de incidência de $90^{\circ}$ 182

TABELA 86 - Resultados para faltas fase-fase (BC) com ângulo de incidência de $0^{\circ}$

TABELA 87 - Resultados para faltas fase-fase (BC) com ângulo de incidência de $90^{\circ}$

TABELA 88 - Resultados para faltas fase-fase (AB) com ângulo de incidência de $45^{\circ}$.

TABELA 89 - Resultados para faltas fase-fase (AB) com ângulo de incidência de $70^{\circ}$

TABELA 90 - Resultados para faltas fase-fase-terra (ACT) com ângulo de incidência de $0^{\circ}$ e resistência de falta de 200 e $400 \mathrm{ohms}$. 183

TABELA 91 - Resultados para faltas fase-fase-terra (ACT) com ângulo de incidência de $90^{\circ}$ e resistência de falta de 200 e 400 ohms. 184

TABELA 92 - Resultados para faltas fase-terra (AT) com ângulo de incidência de $45^{\circ}$ e resistência de falta de 100, 200 e $400 \mathrm{ohms}$ 
TABELA 93 - Resultados para faltas fase-terra (AT) com ângulo de incidência de $70^{\circ}$ e resistência de falta de 100, 200 e 400 ohms.

TABELA 94 - Efeito da variação da taxa amostral dos dados considerando casos de faltas fase-terra com ângulo de incidência da falta de $0^{\circ}$.

TABELA 95 - Efeito da variação da taxa amostral dos dados considerando casos de faltas fase-terra com ângulo de incidência da falta de $90^{\circ}$. 187

TABELA 96 - Efeito da imprecisão de $+5 \%$ nos parâmetros L e C da linha de transmissão considerando faltas fase-terra com ângulo de incidência da falta de $0^{\circ}$. 188

TABELA 97 - Efeito da imprecisão de $+5 \%$ nos parâmetros L e C da linha de transmissão considerando faltas fase-terra com ângulo de incidência da falta de $90^{\circ}$. 189

TABELA 98 - Efeito da imprecisão de -5\% nos parâmetros L e C da linha de transmissão considerando faltas fase-terra com ângulo de incidência da falta de $0^{\circ}$.

TABELA 99 - Efeito da imprecisão de -5\% nos parâmetros L e C da linha de transmissão considerando faltas fase-terra com ângulo de incidência da falta de $90^{\circ}$.

TABELA 100 - Resultados para faltas fase-fase (AB) com ângulo de incidência de $O^{\circ}$, aplicadas na linha $E-F$.

TABELA 101 - Resultados para faltas fase-fase (AB) com ângulo de incidência de $90^{\circ}$, aplicadas na linha $E-F$.

TABELA 102 - Resultados para faltas trifásicas $(A B C)$ com ângulo de incidência de $0^{\circ}$, aplicadas na linha $E-F$.

TABELA 103 - Resultados para faltas trifásicas $(A B C)$ com ângulo de incidência de $90^{\circ}$, aplicadas na linha $E-F$.

TABELA 104 - Resultados para faltas fase-terra (AT) com ângulo de incidência de $90^{\circ}$ e resistência de falta de 0, 50 e $100 \mathrm{ohms}$, aplicadas na linha EF.

TABELA 105 - Resultados para faltas fase-fase-terra (ABT) com ângulo de incidência de $0^{\circ}$ e resistência de falta de 0, 50 e $100 \mathrm{ohms}$, aplicadas na linha $E-F$. 
TABELA 106 - Resultados para faltas fase-fase-terra (ABT) com ângulo de incidência de $90^{\circ}$ e resistência de falta de 0, 50 e $100 \mathrm{ohms}$, aplicadas na linha E-F.

TABELA 107 - Resultados referentes a situações de faltas aplicadas nas linhas do circuito 1

TABELA 108 - Resultados referentes a situações de faltas aplicadas nas linhas do circuito 2 .

TABELA 109 - Resultados para faltas fase-terra (AT) com ângulo de incidência de $0^{\circ}$ e resistência de falta de 0, 50 e 100 ohms, aplicadas sobre linha $E-F$.

TABELA 110 - Resultados para faltas fase-terra (AT) com ângulo de incidência de $90^{\circ}$ e resistência de falta de 0, 50 e $100 \mathrm{ohms}$, aplicadas sobre linha $E-F$.

TABELA 111 - Resultados para faltas fase-fase-terra (ABT) com ângulo de incidência de $0^{\circ}$ e resistência de falta de 0, 50 e $100 \mathrm{ohms}$, aplicadas sobre linha $E-F$.

TABELA 112 - Resultados para faltas fase-fase-terra (ABT) com ângulo de incidência de $90^{\circ}$ e resistência de falta de 0, 50 e $100 \mathrm{ohms,}$ aplicadas sobre linha E-F.

TABELA 113 - Resultados para faltas fase-fase $(A B)$ com ângulo de incidência de $90^{\circ}$, aplicadas sobre linha $E-F$.

TABELA 114 - Resultados para faltas trifásicas (ABC) com ângulo de incidência de $0^{\circ}$, aplicadas sobre linha $E-F$.

TABELA 115 - Resultados para faltas trifásicas $(A B C)$ com ângulo de incidência de $90^{\circ}$, aplicadas sobre linha E-F.

TABELA 116 - Resultados referentes a situações de faltas aplicadas nas linhas do circuito 1 , utilizando dados registrados localmente.

TABELA 117 - Resultados referentes a situações de faltas aplicadas nas linhas do circuito 2, utilizando dados registrados localmente. 


\section{LISTA DE SIGLAS E ABREVIATURAS}

\begin{tabular}{ll} 
SEP & Sistemas Elétricos de Potência \\
LT & Linha de Transmissão \\
A/D & Analógico/Digital \\
PSD & Processadores de Sinais Digitais \\
RNA & Rede Neural Artificial \\
TW & Transformada Wavelet \\
ATP & Alternative Transients Program \\
TDF & Transformada Discreta de Fourier \\
CC & Corrente Contínua \\
FDC & Fator de Distribuição de Corrente \\
MLP & MultiLayer Perceptron \\
EAT & Extra Alta Tensão \\
AMR & Análise Multiresolução \\
GPS & Global Positioning Satellite \\
RBF & Radial Basis Function \\
TPs & Transformadores de Potêncial \\
TCs & Transformadores de Corrente \\
TWC & Transformada Wavelet Contínua \\
TWD & Transformada Wavelet Discreta \\
TF & Transformada de Fourier \\
STFT & Short-Time Fourier Transform \\
TFJ & Transformada de Fourier Janelada \\
TWDI & Transformada Wavelet Discreta Inversa \\
CESP & Companhia Energética de São Paulo \\
CEPEL & Centro de Pesquisa de Engenharia Elétrica \\
SINAPE & Sistemasegrado de Apoio à Análise de Perturbações \\
AT & Falterra \\
\hline CT)-terra
\end{tabular}




$\begin{array}{ll}\text { ACT } & \text { Falta-fase(A)-fase(C)-terra } \\ \text { BCT } & \text { Falta-fase(B)-fase(C)-terra } \\ \text { AB } & \text { Falta-fase(A)-fase(B) } \\ \text { AC } & \text { Falta-fase(A)-fase(C) } \\ \text { BC } & \text { Falta-fase(B)-fase(C) } \\ \text { ABC } & \text { Falta-fase(A)-fase(B)-fase(C) }\end{array}$




\section{LISTA DE SÍMBOLOS}

\begin{tabular}{|c|c|}
\hline $\mathrm{V}_{\mathrm{F}}, \mathrm{I}_{\mathrm{F}}$ & tensão e corrente no ponto de falta \\
\hline $\mathrm{V}_{\mathrm{S}}^{\prime}, \mathrm{I}_{\mathrm{S}}{ }^{\prime}$ & tensão e corrente pós-falta no terminal S \\
\hline $\mathrm{V}_{\mathrm{S}}, \mathrm{I}_{\mathrm{S}}$ & tensão e corrente pré-falta no terminal S \\
\hline $\mathrm{V}_{\mathrm{S}}{ }^{\prime}, \mathrm{I}_{\mathrm{S}} "$ & componentes superpostos de tensão e corrente em S \\
\hline $\mathrm{I}_{\mathrm{SF}}$ & componente superposto da corrente de falta do terminal $\mathrm{S}$ ao ponto $\mathrm{F}$ \\
\hline$V_{R}^{\prime}, I_{R}^{\prime}$ & tensão e corrente pós-falta no terminal $\mathrm{R}$ \\
\hline$V_{R}, I_{R}$ & tensão e corrente pré-falta no terminal $\mathrm{R}$ \\
\hline$V_{R}^{\prime \prime}, I_{R}^{\prime \prime}$ & componentes superpostos de tensão e corrente em $\mathrm{R}$ \\
\hline $\mathrm{R}_{\mathrm{F}}$ & resistência de falta \\
\hline $\mathrm{Z}_{\mathrm{F}}$ & impedância de falta \\
\hline $\mathrm{p}$ & distância da falta em porcentagem da extensão da linha \\
\hline$Z_{\mathrm{L}}$ & impedância da linha de transmissão por unidade de comprimento \\
\hline $\mathrm{Z}_{\mathrm{LS}}$ & impedância da linha entre a falta e o terminal $\mathrm{S}$ \\
\hline 1 & comprimento da linha \\
\hline$Z_{0}$ & impedância característica \\
\hline $\mathrm{Z}_{\mathrm{S}}, \mathrm{Z}_{\mathrm{R}}$ & impedância das fontes dos terminais local e remoto \\
\hline $\mathrm{Z}_{\mathrm{th}}$ & impedância de Thévenin vista no ponto de falta \\
\hline $\mathrm{V}_{\mathrm{Fd}}$ & componente de tensão superposta de seqüência positiva no ponto de falta \\
\hline $\mathrm{I}_{\mathrm{Fd}}$ & $\begin{array}{l}\text { componente de corrente superposta de seqüência positiva no ponto de } \\
\text { falta }\end{array}$ \\
\hline$\left[\mathrm{V}_{\mathrm{F}}\right]$ & vetor de tensões trifásicas no ponto de falta \\
\hline$\left[\mathrm{V}_{\mathrm{L}}\right]$ & vetor de tensões trifásicas no terminal local \\
\hline$\left[\mathrm{V}_{\mathrm{R}}\right]$ & vetor de tensões trifásicas no terminal remoto \\
\hline$\left[\mathrm{I}_{\mathrm{L}}\right]$ & vetor de correntes trifásicas no terminal local \\
\hline$\left[\mathrm{I}_{\mathrm{R}}\right]$ & vetor de correntes trifásicas no terminal remoto \\
\hline$\left[\mathrm{Z}_{\mathrm{a}, \mathrm{b}, \mathrm{c}}\right]$ & matriz trifásica de impedâncias série da linha \\
\hline $\mathrm{K}_{\mathrm{p}}$ & fator de distribuição de corrente \\
\hline$\lambda$ & constante de propagação da linha \\
\hline$v_{0}, v_{1}$ & velocidade de propagação do modo terra e aéreo 1 \\
\hline
\end{tabular}


$v_{m 0}, v_{m 1} \quad$ velocidades de propagação do modo terra (modo 0) e aéreo 1 (modo 1 )

d distância ao ponto de falta

A, B, C e D parâmetros do quadripólo representativo da linha

$\mathrm{T}$ matriz de transformação modal de Clarke

$\mathrm{X}_{\mathrm{S}} \quad$ reatância no terminal S

$\mathrm{Z}_{\mathrm{abc}} \quad$ matriz de impedância série

$\mathrm{D}_{\mathrm{x}} \quad$ distância entre dois pontos consecutivos da linha de transmissão.

a fator de escala para a Transformada Wavelet Contínua

A versão aproximada de um sinal

b fator de translação para a Transformada Wavelet Contínua

cA versão aproximada de um sinal com operador downsampling

cD versão de detalhes de um sinal com operador downsampling

D versão de detalhes de um sinal

$\mathrm{h}_{0} \quad$ filtro passa baixa

$\mathrm{h}_{1} \quad$ filtro passa alta

k fator de translação relacionado a Análise Multiresolução

m parâmetro de escala para Transformada Wavelet Discreta

$\mathrm{n} \quad$ parâmetro de translação para Transformada Wavelet Discreta

$\mathrm{t} \quad$ variável tempo

X variável correspondente a tempo ou espaço

$\varphi \quad$ Função escala

$\psi \quad$ Função Wavelet

a,b,c fases da linha

$0, \alpha, \beta \quad$ índices modais 


\section{SUMÁRIO}

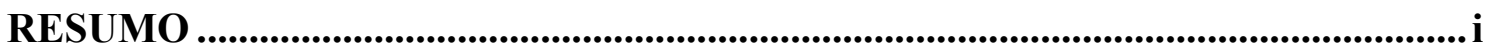

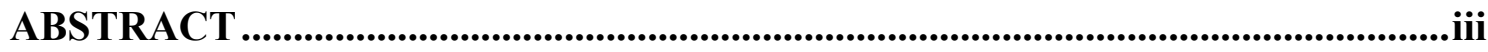

LISTA DE FIGURAS ..............................................................................................................

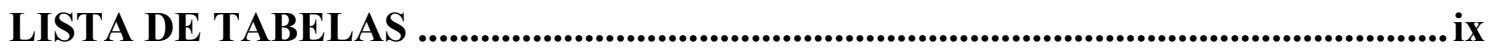

LISTA DE SIGLAS E ABREVIATURAS .........................................................

LISTA DE SÍMBOLOS ............................................................................................... Xviii

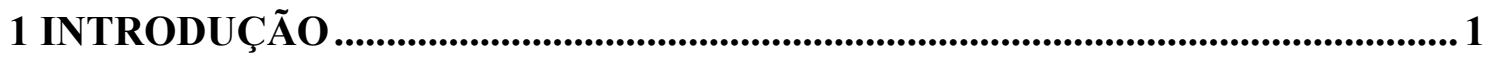

1.1 Localizadores de Faltas para Linhas de Transmissão ........................................... 2

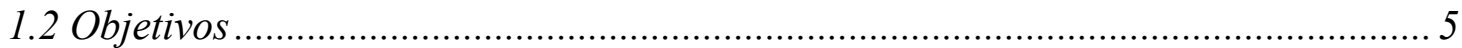

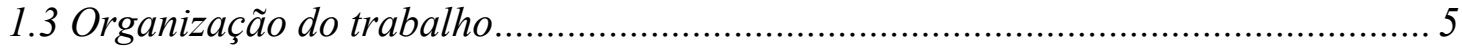

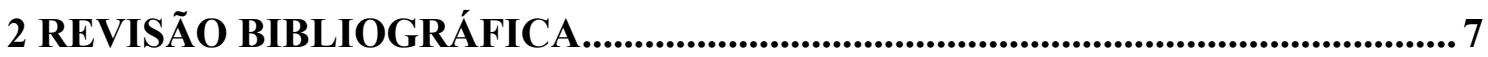

2.1 Métodos baseados nos componentes de freqüência fundamental ............................ 7

2.1.1 Algoritmos que utilizam dados somente do terminal local da linha ................... 7

2.1.2 Algoritmos que utilizam dados de mais de um terminal da linha .................... 15

2.2 Métodos baseados nos componentes de alta freqüência gerados por uma falta ... 22

2.2.1 Algoritmos que utilizam dados somente do terminal local da linha .................22

2.2.2 Algoritmos que utilizam dados de múltiplos terminais da linha ...................... 27

3 FUNDAMENTOS SOBRE ONDAS VIAJANTES E TRANSFORMADA

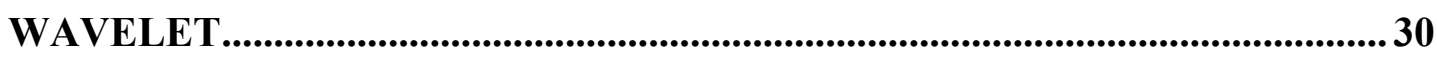

3.1 Ondas Viajantes em Sistemas de Transmissão ..................................................... 30

3.1.1 Reflexões e Refrações de Ondas Viajantes....................................................... 31

3.1.2 Reflexões Sucessivas e Diagrama Lattice ....................................................... 31

3.1.3 Atenuação e Distorção das Ondas Viajantes .................................................... 32

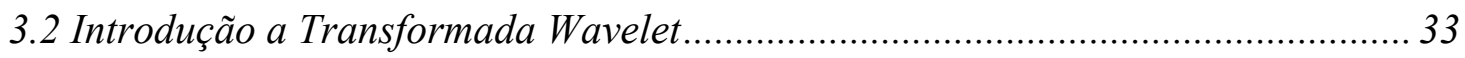

3.2.1 A Transformada Wavelet Contínua .............................................................. 35

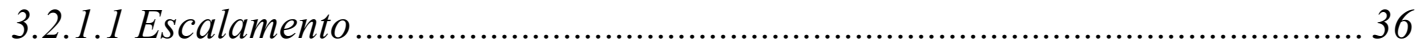

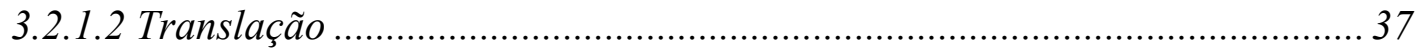


3.2.2 A Transformada Wavelet Discreta 37

3.2.3 Filtragem e Análise Multiresolução .................................................................. 38

3.2.3.1 Decomposição em Múltiplos Níveis ou Análise Multiresolução ................. 40

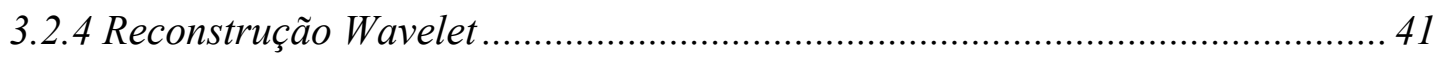

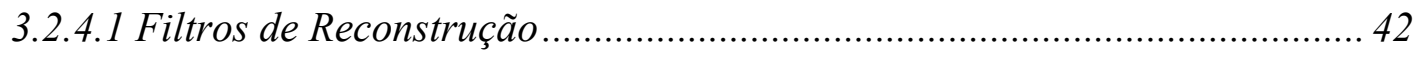

3.2.4.2 Aproximações e Detalhes na Reconstrução............................................... 42

3.2.5 Aplicações da Transformada Wavelet em Sistemas Elétricos de Potência....... 44

4 SISTEMA ELÉTRICO ANALISADO_................................................................ 46

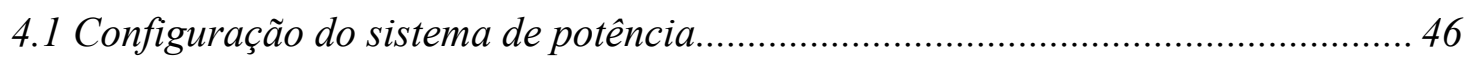

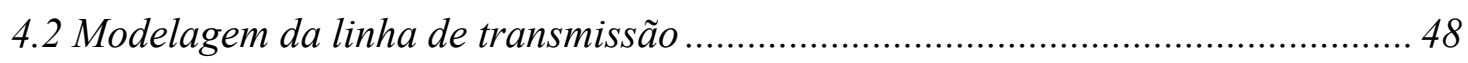

4.2.1 Parâmetros do sistema elétrico .......................................................................... 48

4.2.2 Rotina Line Constant e arquivo de entrada para o software ATP .................... 50

4.3 Variações nas simulações das condições de faltas aplicadas ao circuito de

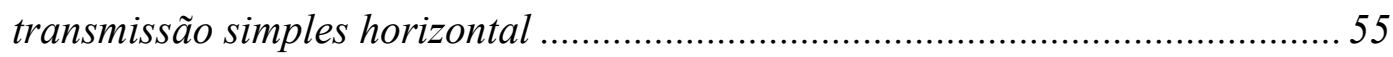

4.4 Modelagem e dados referentes ao circuito duplo vertical ...................................... 56

4.4.1 Variações nas simulações das condições de faltas aplicadas ao circuito de transmissão duplo.

\section{LOCALIZAÇÃO DE FALTAS UTILIZANDO A TRANSFORMADA}

WAVELET - ABORDAGEM TEÓRICA ..........................................................63

5.1 Princípio básico do método de localização de faltas ................................................ 63

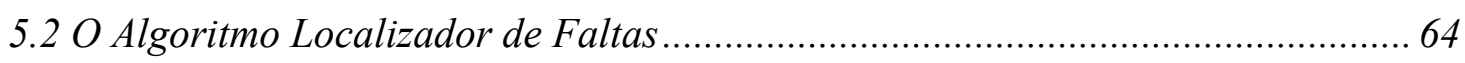

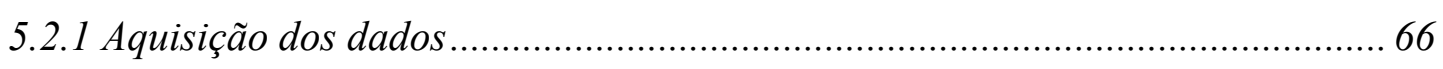

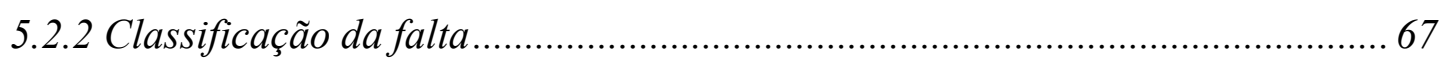

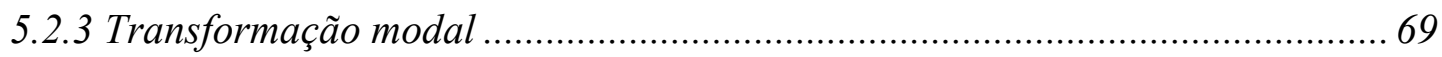

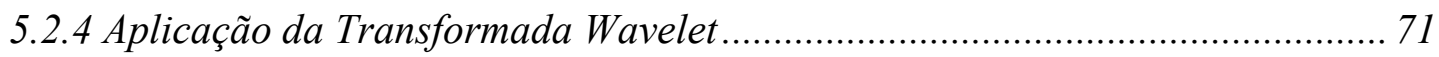

5.2.5 Técnica de localização de faltas ......................................................................... 72

5.2.6 Formulação para localização de faltas com dados provenientes de dois

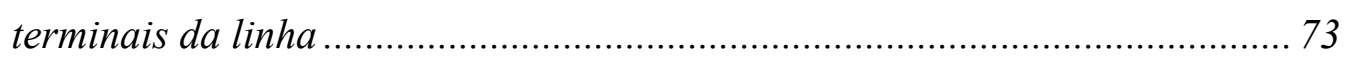

5.2.6.1 Determinação dos tempos de reflexão ...................................................... 73

5.2.6.2 Cálculo da distância da falta envolvendo dados de dois terminais............. 74

5.2.7 Formulação para localização de faltas com dados provenientes de um terminal da linha. 
5.2.7.1 Determinação dos tempos de reflexão no terminal local 76

5.2.7.2 Pré-Localização para faltas fase-terra..... 79

5.2.7.3 Cálculo da distância para faltas fase-fase-terra, fase-fase e trifásica 82

5.2.7.4 Cálculo da distância para faltas fase-terra. 82

\section{LOCALIZAÇÃO DE FALTAS UTILIZANDO A TRANSFORMADA} WAVELET - TESTES E RESULTADOS OBTIDOS .84

6.1 Resultados alcançados utilizando-se dados provenientes de dois terminais 85

6.1.1 Influência da variação da distância da falta..... 93

6.1.2 Influência dos diferentes tipos de faltas..... 94

6.1.3 Influência do ângulo de inserção da falta. 95

6.1.4 Influência da resistência de falta 96

6.1.5 Influência da taxa amostral. 98

6.1.6 Influência da perda de sincronismo dos dados..... 100

6.1.7 Influência da imprecisão na determinação dos parâmetros da linha. 101

6.1.8 Comportamento do algoritmo frente ao acoplamento mútuo das fases em circuitos duplos de transmissão.

6.1.9 Comportamento do algoritmo frente à faltas fora da zona de cobertura considerando circuitos duplos de transmissão.

6.2 Resultados alcançados utilizando-se dados provenientes de um terminal da linha. 108

6.2.1 Resultados alcançados para faltas fase-fase terra, fase-fase e trifásicas. 109

6.2.2 Resultados alcançados para faltas fase-terra. 112

6.2.3 Influência da variação da distância da falta...... 118

6.2.4 Influência dos diferentes tipos de faltas..... 118

6.2.5 Influência do ângulo de inserção da falta. 119

6.2.6 Influência da resistência de falta 120

6.2.7 Influência da variação da Taxa de Amostragem do sinal.

6.2.8 Influência da imprecisão na determinação dos parâmetros da linha. 122

6.2.9 Comportamento da técnica frente ao acoplamento mútuo entre circuitos de uma linha de transmissão dupla

6.2.10 Comportamento da técnica de localização frente à faltas fora da zona de cobertura considerando circuitos duplos de transmissão 
7 CONCLUSÕES

7.1 Considerações sobre a técnica que utiliza dados somente de um terminal da linha.

7.2 Considerações sobre a técnica que utiliza dados de ambos os terminais da linha.

7.3 Considerações gerais sobre o algoritmo de localização de faltas. 132

7.4 Continuidade da pesquisa 133

REFERÊNCIAS BIBLIOGRÁFICAS

APÊNDICE A - Resultados dos testes sobre o circuito simples de transmissão... 142

APÊNDICE B - Resultados dos testes para o circuito duplo 192 


\section{INTRODUÇ̃̃O}

A energia elétrica é um dos recursos fundamentais para o desenvolvimento econômico de um país, bem como, para promover a satisfação e o bem-estar da sociedade. Dessa forma, os Sistemas Elétricos de Potência (SEP) devem garantir um alto grau de confiabilidade na continuidade do fornecimento de energia elétrica. Contudo, interrupções no fornecimento de energia elétrica podem ser provocadas pela ocorrência de diferentes tipos de fenômenos eletromagnéticos no sistema elétrico que podem afetar classes de consumidores distintas. Faltas podem ocorrer nos diversos componentes de um SEP, dentre os quais podemos destacar as Linhas de Transmissão (LTs) como o elemento mais susceptível, especialmente se considerarmos suas dimensões físicas, complexidade funcional e o ambiente que se encontram, apresentando assim, maior dificuldade para manutenção e monitoramento. Podemos ilustrar a predominância de faltas em linhas de transmissão, observando a Tabela 1, de acordo com VAN ZEE apud COURY [1], que mostra o registro da distribuição de faltas, em um sistema de $500 \mathrm{kV}$, em um período de dez anos.

Observações práticas também mostram que entre $70 \%$ a $80 \%$ das faltas nas linhas de transmissão ocorrem entre um só condutor e a terra, conforme STEVENSON [2]. Um menor número de faltas refere-se às que envolvem todas as fases, em torno de $5 \%$.

O crescente aumento em complexidade dos SEP devido ao aumento constante da demanda de energia e a interligação dos sistemas existentes, tem exigido uma considerável melhora dos equipamentos de controle, proteção e localização de faltas, a fim de possibilitar a redução do período de interrupção do fornecimento de energia, em caso de falhas, e garantir a operação confiável e econômica do sistema de potência, seja em condições normais de operação ou em contingência. Além disto, podemos destacar 
TABELA 1 Distribuição de faltas em um sistema de $500 \mathrm{kV}$, em um período de dez anos, com a ocorrência de noventa e nove faltas.

\begin{tabular}{cc}
\hline EQUIPAMENTOS FALTOSOS & NÚMERO DE FALTAS \\
\hline Linha de transmissão & 82 \\
Circuitos disjuntores & 4 \\
Autotransformadores & 6 \\
Barramentos & 1 \\
Geradores & 1 \\
Erro humano & 5 \\
\hline
\end{tabular}

também, como por exemplo no caso do Brasil, o crescimento da competição no mercado de energia devido ao processo de desestatização pelo qual vem passando o nosso setor elétrico, o que tem levado as empresas de energia elétrica a investirem em modernos sistemas de gerenciamento e proteção, a fim de assegurar uma fatia significativa do mercado, através da oferta de energia a um menor custo e com alto padrão de qualidade.

Nas últimas duas décadas, utilizar dispositivos baseados em microprocessadores nas soluções de problemas de sistemas elétricos de potência tem sido assunto de grande interesse por parte de engenheiros e pesquisadores. Esse interesse se deve ao rápido avanço da tecnologia dos microprocessadores, aliado ao desenvolvimento na área de software, tornando estes cada vez mais apropriados para aplicações em sistemas elétricos de potência, especialmente onde é necessária uma grande precisão, como na localização de faltas, assunto este a ser abordado no que segue.

\subsection{Localizadores de Faltas para Linhas de Transmissão}

Um localizador digital de faltas, como o próprio nome diz, tem por objetivo determinar, o mais precisamente possível, o ponto de ocorrência de uma falta em uma linha de transmissão, o que é de suma importância para uma operação confiável e econômica do sistema de potência. Conhecendo-se a localização da falta, um menor tempo é despendido nos serviços de manutenção e reparo, o que permite uma rápida restauração da operação após a ocorrência de uma falta sustentada. Além de prover a localização de faltas sustentadas, um localizador pode também estimar faltas transitórias, que podem alertar para possíveis pontos fracos nos sistemas de transmissão, evitando futuros problemas de maior grandeza. 
Um localizador de faltas pode ser implementado de três maneiras distintas, sendo essas:

1) como um dispositivo stand-alone: o localizador de faltas possui um hardware, similar ao de um relé digital;

2) como parte de um relé digital de proteção: neste caso, o algoritmo de um localizador de faltas é incluído juntamente com o algoritmo do relé de proteção e

3) como um algoritmo independente: usando dados obtidos através de registradores digitais de faltas.

Os localizadores de faltas processam dados registrados digitalmente de modo off-line e, por essa razão, não estão sujeitos às restrições de processamento impostas aos relés de proteção, que devem operar em modo on-line. Isso permite um aumento na sofisticação dos algoritmos e portanto, na precisão relacionada à localização de faltas, o que é particularmente desejável para linhas longas ou localizadas em terrenos acidentados, onde poucos quilômetros de imprecisão podem comprometer a continuidade do fornecimento de energia (GAUTIER, 1996) [3].

O projeto dos localizadores de faltas microprocessados inclui a escolha de um hardware e de um método de localização para implementação do algoritmo de localização.

Os métodos de localização tem sido classificados em duas diferentes categorias, como segue:

1) métodos baseados em componentes de freqüência fundamental e

2) métodos baseados nos transitórios de altas freqüências gerados por uma situação de falta, também conhecidos na literatura como métodos de ondas viajantes.

Essas metodologias de localização, por sua vez, podem ser classificadas de acordo com o modo de obtenção dos dados em técnicas: (i) dispondo de dados provenientes de um único terminal e (ii) de dados provenientes de múltiplos terminais da linha de transmissão.

Os algoritmos de localização de faltas que utilizam dados provenientes de um terminal da linha, os quais consideram as componentes de freqüência fundamental, são em sua maioria, baseados na determinação da impedância aparente da linha de transmissão vista do local de medida durante a falta. Esta impedância é obtida em função dos parâmetros da LT e dos fasores de freqüência fundamental de tensão e 
corrente, originados em um dos terminais da LT. As estimativas para essas localizações de faltas estão sujeitas a erros devido ao efeito combinado da corrente de carga, da resistência, tipo e ângulo de incidência da falta, dentre outros. Melhorias em tais métodos são alcançadas utilizando-se de medições sincronizadas nos terminais em questão. Sobre esse assunto, deve ser mencionado que se faz necessário um meio de comunicação entre os terminais para transmissão dos dados de falta registrados para um terminal de referência, onde será realizado o processamento para a localização da falta. Contudo, ao contrário da detecção da falta, que opera em modo on-line e, por essa razão exige alta velocidade e canais de comunicação contínuos, os requisitos de comunicação para os localizadores são bastantes simples, uma vez que o algoritmo opera em modo off-line (COURY, 1992)[4].

Os métodos que utilizam às componentes de alta freqüência dos sinais transitórios gerados por uma falta, estão fundamentados na teoria de ondas viajantes. Estes algoritmos são baseados na determinação do tempo de viagem da onda de tensão ou corrente do ponto de falta ao terminal de monitoramento e na velocidade de propagação da onda viajante na linha, a qual é função dos parâmetros da mesma.

A principal limitação encontrada na implementação dos algoritmos que consideram o emprego da teoria de ondas viajantes decorre da necessidade da utilização de elevadas taxas de freqüência de amostragem. Todavia, o progresso atual da tecnologia dos conversores $\mathrm{A} / \mathrm{D}$ de alta velocidade e dos processadores de sinais digitais (PSDs) de alto desempenho, como também dos transdutores óticos de corrente e tensão, têm tornado possível operações a elevadas taxas de amostragem. Além disso, técnicas como processamento paralelo tendem a viabilizar altas velocidades de execução de tais tarefas (SILVEIRA, 2001)[5].

Mais recentemente, tem sido proposto o emprego de ferramentas inteligentes como Redes Neurais Artificiais (RNAs), assim como, aplicação de novas ferramentas matemáticas, como por exemplo, o uso da Transformada Wavelet ao problema de localização de faltas. Encontram-se também na literatura, trabalhos associando-se ambas as ferramentas, RNAs e TW, aplicadas a solução do mesmo problema.

A característica de localização tempo-freqüência da TW permite obter alta resolução no tempo para altas freqüências e, alta resolução em freqüência para baixas freqüências, devido a sua característica de escalamento. Esta característica permite que a TW seja utilizada em um algoritmo de localização de faltas, tanto nos métodos 
baseados nos componentes de alta freqüência quanto nos métodos baseados em componentes de freqüência fundamental.

A análise wavelet é capaz de localizar com precisão os instantes de tempo de ocorrência de eventos, pontos de descontinuidades, etc, o que a torna muito adequada para a aplicação na localização de faltas, quando da utilização dos métodos baseados em ondas viajantes.

Este trabalho propõe a aplicação da TW para analisar os transitórios de alta freqüência provenientes de uma situação de falta com o intuito de terminar o tempo de reflexão das ondas entre o ponto de falta e os terminais ou barramentos e, com isso, estimar a distância de ocorrência da falta em uma linha de transmissão.

\subsection{Objetivos}

Este trabalho tem por objetivo abordar o problema da localização de faltas através da implementação prática de um algoritmo computacional de localização, recorrendo a teoria da TW. A implementação do algoritmo é baseada no método das componentes de alta freqüência dos sinais transitórios de falta registrados tanto em um terminal quanto em ambos os terminais. Tal algoritmo é implementado através do software Matlab ${ }^{\circledR}$ e posteriormente testado usando-se dados de faltas obtidos através de simulações do software ATP (Alternative Transients Program). Nas simulações aplicadas a este software, para um sistema de transmissão de $440 \mathrm{kV}$, foram considerados vários tipos de faltas em diferentes localizações ao longo da linha, com diferentes ângulos de incidência, resistências de faltas e condições de carga. Os resultados a serem apresentados evidenciarão a aplicabilidade, confiabilidade e precisão do método proposto.

\subsection{Organização do trabalho}

O trabalho está dividido em sete capítulos. No capítulo 2 é apresentada uma revisão bibliográfica referente as diferentes metodologias aplicadas à localização de faltas em linhas de transmissão. Essas metodologias são divididas em duas categorias: (i) métodos que fazem uso das componentes de freqüência fundamental e (ii) métodos que fazem uso das componentes de alta freqüência. Por sua vez, esses métodos são 
subdivididos em duas técnicas conforme obtenção dos dados que podem ser provenientes de um ou de dois terminais da linha.

No capítulo 3 são abordados os fundamentos básicos da teoria sobre ondas viajantes, Transformada Wavelet e suas aplicações no sistema elétrico de potência. A modelagem do sistema elétrico de potência a ser analisado, bem como as considerações referentes às variações nas simulações das faltas aplicadas sobre o sistema proposto são apresentadas no capítulo 4 .

O capítulo 5 aborda a formulação do problema de localização de faltas em linhas de transmissão baseado em ondas viajantes utilizando a TW, seguido da descrição do algoritmo de localização de faltas proposto. Dando seqüência, no capítulo 6 são apresentados e discutidos os resultados dos testes obtidos pelo algoritmo de localização de faltas.

Finalmente, no capítulo 7, são relatadas as conclusões e idéias para continuidade do trabalho. 


\section{REVISÃO BIBLIOGRÁFICA}

O desenvolvimento de novos métodos de localização digital de faltas para linhas de transmissão (LT) utilizando dispositivos baseados em microprocessadores é questão de interesse de pesquisadores e engenheiros de potência nos últimos anos, com um número muito grande de propostas de novas metodologias e aperfeiçoamento de outras já existentes, visando melhorar a precisão das localizações de faltas em LTs.

$\mathrm{O}$ estudo da bibliografia sugere duas diferentes categorias em que podem ser classificados os métodos de localização de falta: os métodos baseados em componentes de freqüência fundamental e o método das ondas viajantes. Neste capítulo são referenciados ambos os métodos de localização, os quais se subdividem em dois grupos segundo a obtenção e utilização de dados de um ou de mais terminais da linha.

\subsection{Métodos baseados nos componentes de freqüência fundamental}

Um dos métodos utilizados para localizar faltas em linhas de transmissão, e que considera as componentes à freqüência fundamental, está baseado na determinação da impedância aparente da linha de transmissão durante a falta. Esta impedância é obtida em função dos parâmetros da LT e dos fasores de tensão e corrente extraídos dos sinais registrados em um ou em ambos os terminais da LT.

\subsubsection{Algoritmos que utilizam dados somente do terminal local da linha}

Os algoritmos baseados nos componentes de freqüência fundamental registrados em um único terminal, geralmente fazem uso da impedância aparente calculada em relação ao ponto de falta e das correntes de pré-falta para calcular a localização da falta. Entretanto, os mesmo estão sujeitos a erros devido à contribuição de correntes provenientes dos alimentadores remotos e também devido à resistência de falta. Nesses 
métodos é necessário que se identifique o tipo de falta ocorrida, pois o equacionamento para cada tipo de falta é diferente dos demais.

SAINT \& PAITHANKAR apud GAUTIER (1996)[3] propuseram uma técnica de localização de faltas baseada no cálculo da razão entre a reatância de falta da linha $\left(\mathrm{X}_{\mathrm{LS}}\right)$ (a partir do terminal onde se encontra o localizador de falta até o ponto da falta), e a reatância total da $\mathrm{LT}\left(\mathrm{X}_{\mathrm{n}}\right)$, ou seja, $\mathrm{X}_{\mathrm{LS}} / \mathrm{X}_{\mathrm{n}}$. Como $\mathrm{X}_{\mathrm{n}}$ é um valor conhecido, a razão $\mathrm{X}_{\mathrm{LS}} / \mathrm{X}_{\mathrm{n}}$ determina a posição da falta. Do cálculo dessa razão pode ser derivada a seguinte expressão:

$$
\frac{X_{L S}}{X_{n}}=\frac{\operatorname{sen} \theta_{3} \operatorname{sen} \theta_{1}}{\operatorname{sen} \theta_{2}}
$$

onde:

$$
\begin{aligned}
& \theta_{1}=\operatorname{arctg}\left(\frac{I_{R}^{\prime} X_{n}}{V_{S}^{\prime}}\right) \\
& \theta_{2}=-\frac{V_{S}^{\prime}}{I_{R}^{\prime} X_{n}-V_{S}^{\prime}} \\
& \theta_{3}=180^{\circ}-\left(\theta_{1}+\theta_{2}\right)
\end{aligned}
$$

sendo que $I_{R}^{\prime}$ é a corrente pós-falta no terminal R e $V_{S}^{\prime}$ a tensão de pós-falta no terminal local.

A eq.(2.1) denota que a posição da falta pode ser determinada pela medida de dois quaisquer dos três ângulos $\theta_{1}, \theta_{2}$ e $\theta_{3}$. A técnica proposta é baseada na medição destes ângulos por dois contadores digitais. O localizador de faltas é analisado somente sob condições de fonte conectada em um único terminal. Contudo, as estimativas da localização de falta não são precisas se existe uma contribuição à corrente de falta pelas fontes conectadas em ambos os terminais da linha e se for levada em conta a resistência de falta.

TAKAGI et al. (1981)[6] apresentaram um algoritmo de localização baseado no uso de sinais de tensão e corrente apenas de um terminal, os quais são posteriormente filtrados através da técnica da Transformada Discreta de Fourier (TDF), a fim de obter uma medida dos fasores de tensão e corrente em regime permanente. $\mathrm{O}$ algoritmo utiliza componentes superpostos e modais de tensão e corrente, ao invés dos valores totais para 
o cálculo da distância. Isso permite que um sistema trifásico seja tratado como um sistema com três circuitos monofásicos independentes, simplificando consideravelmente os cálculos necessários. O equacionamento deste algoritmo também faz uso de quadripólos e do método de Newtow-Raphson.

Para uma linha monofásica, aplicando-se a teoria da superposição em redes lineares, isto é, separando a rede faltosa em duas redes derivadas (uma rede de pré-falta e uma rede em que a falta foi isolada) obteremos o vetor $V_{F}$ no ponto de falta:

$$
V_{F}=R_{F} I_{F}=-R_{F}\left(I_{S F}^{\prime \prime}+I_{R F}^{\prime \prime}\right)
$$

Onde $\mathrm{V}_{\mathrm{F}}$ e $I_{S F}^{\prime \prime}$ são estimados por vetores medidos no terminal local da linha:

$$
\begin{aligned}
& V_{F}=A(d) V_{S}-B(d) I_{S} \\
& I_{S F}^{\prime \prime}=C(d) V_{S}^{\prime \prime}-D(d) I_{S}^{\prime \prime}
\end{aligned}
$$

A, B, C e D são as constantes do quadripólo representativo da linha de transmissão, expresso por:

$$
\begin{aligned}
& A(d)=D(d)=\cosh (\lambda d) \\
& B(d)=Z_{0} \cdot \sinh (\lambda d) \\
& C(d)=\sinh (\lambda d)
\end{aligned}
$$

A partir de uma série de manipulações algébricas envolvendo as eq.(2.3, 2.4 e 2.5), chega-se a:

$$
R_{F}[1+K(d)]=-\frac{A(d) V_{S}-B(d) I_{S}}{C(d) V_{S}^{\prime \prime}-D(d) I_{S}^{\prime \prime}}
$$

Dadas as equações acima, temos que $V_{F}$ e $I_{F}$ é a tensão e corrente no ponto de falta respectivamente, $V_{S}$ e $I_{S}$ representam a tensão e corrente de pré-falta no terminal local, $\mathrm{R}_{\mathrm{F}}$ a resistência de falta, $I_{S F}^{\prime \prime}$ é o componente superposto da corrente de falta do terminal local ao ponto de falta, $I_{R F}^{\prime \prime}$ é o componente superposto da corrente de falta do terminal remoto ao ponto de falta, $Z_{0}$ impedância característica da linha e $K(d)$ é a relação entre $I_{R F}^{\prime \prime}$ e $I_{S F}^{\prime \prime}$.

Considerando-se as seguintes hipóteses:

- $R_{F}$ é puramente resistiva;

- Relação $K(d)$ é um número real. 
Esta segunda hipótese só é válida se os equivalentes nos terminais da linha de transmissão forem puramente indutivos e a linha sem perdas, o que em determinados casos pode ser uma boa aproximação.

A equação básica do localizador é definida como:

$$
I_{m}\left[\frac{A(d) V_{S}-B(d) I_{S}}{C(d) V_{S}^{\prime \prime}-D(d) I_{S}^{\prime \prime}}\right]=0
$$

Onde $I_{m}[$.$] representa a parte imaginária de uma variável complexa. A solução \boldsymbol{d}$ da eq.(2.8) corresponde a distância do ponto de falta ao terminal local. A eq.(2.8) é uma equação não linear, sendo necessário a técnica iterativa de Newton-Raphson para resolvê-la.

Em TAKAGI et al. (1982a)[7], continuação de [6], é apresentado uma outra possível solução para o problema de localização da falta baseado na Transformada de Laplace. Este método também utiliza o princípio da superposição aplicado a análise do estado transitório de uma rede faltosa. A equação fundamental do localizador é não linear, portanto, se faz necessário o uso de uma técnica de solução iterativa como o método de Newtow-Raphson para este método.

TAKAGI et al. (1982b)[8] desenvolveram uma técnica aproximada de localização de faltas, na qual calcula-se a reatância da linha faltosa, usando a representação dos fasores de tensão e corrente no terminal local da LT, juntamente com a teoria de quadripólos. Erros causados por vários fatores como: fluxo de carga, resistência de falta, e disposição não simétrica da linha de transmissão foram reduzidos através de correções.

Este método parte do mesmo equacionamento apresentado anteriormente em [6], mas é direcionado de forma a chegar na seguinte equação:

$$
V_{S}-I_{S} \cdot Z_{0} \cdot \tanh (\lambda d)=R_{F} \cdot K\left(\frac{V_{S}^{\prime \prime} \cdot \tanh (\lambda d)}{Z_{0}}-I_{S}^{\prime \prime}\right)
$$

Nesse caso as aproximações consideradas são:

- $\tanh (\lambda d)=\lambda d$

- $\frac{V_{S}^{\prime \prime} \cdot \tanh (\lambda d)}{Z_{0}}<<I_{S}^{\prime \prime}$ 
Considerando essas hipóteses, e novamente admitindo que a resistência de falta seja puramente resistiva e que não haja diferença entre as fases das correntes de falta isoladas na linha (em falta menos pré-falta), os valores de $\mathrm{R}_{\mathrm{F}}$ e $\mathrm{K}$ são números reais.

Dessa forma é possível chegar a uma expressão em que a distância da falta pode ser obtida por uma fórmula direta, sem a necessidade de cálculos iterativos.

$$
d=\frac{I_{m}\left(V_{S}^{\prime} I_{S}^{I^{*}}\right)}{I_{m}\left(Z_{L} I_{S}^{\prime} I_{S}^{\prime *}\right)}
$$

Onde o símbolo * indica o conjugado complexo e $d$ a distância do ponto de falta.

RICHARDS \& TAN (1982)[9] apresentaram um método de localização de faltas por estimação de parâmetros de um sistema dinâmico. O sistema de equações diferenciais é baseado no modelo de linha de parâmetros concentrados, nos equivalentes de Thévenin para transitórios em ambos os terminais e na desconhecida resistência de falta. As equações são simplificadas usando componentes simétricos. A estimação do algoritmo não exige filtragem dos componentes $\mathrm{CC}$, nem dos componentes de alta freqüência.

O problema de localização de faltas é tratado como um problema de estimação de parâmetros do sistema dinâmico, no qual, a resposta do sistema físico é comparada com o modelo de parâmetros concentrados. Os parâmetros do modelo são variados, até que uma combinação adequada seja obtida com a resposta física do sistema.

ERIKSSON et al (1985)[10] descreveram uma técnica de localização de faltas usando o Fator de Distribuição de Corrente (FDC), na qual determinam o ângulo da tensão no ponto de falta e a distância de falta. Esta técnica apresenta maiores benefícios se comparada ao método proposto por TAKAGI [8], uma vez que, considera a influência introduzida pelo terminal remoto da linha, usando para isso, o modelo completo da rede. Além disso, valores representativos para a impedância da fonte são também armazenados, para compensar as variações nos ângulos das impedâncias e determinar uma correta descrição da rede. $\mathrm{O}$ valor de $R_{F}$ desconhecido não é necessário, sendo usado somente o ângulo de $R_{F}$ x $I_{F}$ da tensão, no ponto de falta.

O cálculo da localização determina a impedância aparente da falta com uma compensação para a queda de tensão na resistência de falta, eliminando erros na 
medição convencional do tipo à reatância. Como a impedância de seqüência positiva não depende da resistência do pé de torre e nem da resistência do solo, as componentes da corrente de seqüência zero foram eliminadas e somente as componentes da corrente de seqüência positiva e negativa foram usadas. A partir de todo um equacionamento foi obtida a eq.(2.11) na qual foi introduzido o $\operatorname{FDC}\left(K_{p}\right)$ :

$$
V_{S}=I_{S} p Z_{l}+\left(\frac{I_{S F}}{K_{P}}\right) R_{F}
$$

onde $I_{S F}$ varia conforme o tipo de falta e representa a mudança na corrente produzida pela falta, que é igual a atual corrente, menos a corrente de pré-falta. O FDC $\left(K_{p}\right)$ é definido pela eq.(2.12) como função da localização da falta dos parâmetros de seqüência positiva da linha e da impedância das fontes $\left(Z_{S}\right.$ e $\left.Z_{R}\right)$ :

$$
K_{P}=\frac{(1-p) Z_{L}+Z_{S}}{Z_{R}+Z_{L}+Z_{R}}
$$

Onde $Z_{L}$ é a impedância da linha, $p$ a distância da falta em percentagem e $K p$ o fator de distribuição de corrente.

Substituindo a eq.(2.12) na eq.(2.11) foi obtida a expressão complexa (2.13) que contém as variáveis $p$ e $R_{F}$ desconhecidas:

$$
p^{2}-p K_{1}+K_{2}-K_{3} R_{F}
$$

Onde:

$$
\begin{aligned}
& K_{1}=\frac{V_{S}}{I_{S} Z_{L}}+1+\frac{Z_{R}}{Z_{L}} \\
& K_{2}=\frac{V_{S}}{I_{S} Z_{L}} \cdot\left(\frac{Z_{R}}{Z_{L}}+1\right) \\
& K_{3}=\frac{I_{S F}}{I_{S} Z_{L}} \cdot\left(\frac{Z_{S}+Z_{R}}{Z_{L}}+1\right)
\end{aligned}
$$

Separando a equação complexa (2.13) em uma parte real e outra imaginária, são obtidas duas equações simultâneas. Eliminando a resistência de falta $\mathrm{R}_{\mathrm{F}}$, que é desconhecida, resulta uma expressão simples em função de uma única variável desconhecida - $p$. Esta é resolvida através de um algoritmo que emprega os valores de pico e posições de fase, obtidos por uma rotina baseada na análise de Fourier. 
MORRISON \& YANG (1987)[11] também desenvolveram um método de localização de faltas baseado na equação diferencial da linha. A equação da falta é baseada na tensão e na corrente instantânea de um dos terminais do sistema. A técnica despreza o efeito da capacitância em paralelo.

RANJBAR et al. (1992)[12] apresentaram um técnica baseada em modelos de linha de transmissão de parâmetros distribuídos que leva em consideração o efeito da capacitância da linha. A abordagem utilizada baseia-se no cálculo da tensão ao longo da linha de transmissão. No ponto de falta, a tensão assume seu valor mínimo e, assim, uma comparação dos valores das tensões em diferentes pontos da linha fornece uma base para a localização da falta. Para isso os autores desenvolveram uma função G(x), proporcional à integral do valor absoluto da tensão sobre um intervalo de tempo limitado. Esta função, por sua vez, faz uso das ondas de tensão ao longo da linha calculadas por meio de equações telegráficas. $\mathrm{G}(\mathrm{x})$ é calculada para diversos pontos sobre a linha e possui seu valor mínimo no local de ocorrência da falta.

O método determina a localização mesmo para uma falta com ângulo de incidência igual à zero. $\mathrm{O}$ erro máximo atingido foi menor que $\mathrm{D}_{\mathrm{x}} / 2$, onde $\mathrm{D}_{\mathrm{x}}$ é a distância entre dois pontos consecutivos da linha de transmissão, sobre os quais são calculados valores para a função $G(x)$. O método faz uso da teoria modal para transformação das equações aplicadas à faltas não simétricas.

GIRGIS \& FALLOW (1992)[13] desenvolveram duas técnicas de localização de faltas baseadas no conceito de impedância aparente e uso dos fasores trifásicos de tensão e corrente. O primeiro método utiliza dados de apenas um terminal da linha e o segundo método utiliza dados de dois terminais, sendo esses dados obtidos por registradores digitais de faltas. Ambas as técnicas foram testadas utilizando registros de faltas em uma linha de $69 \mathrm{kV}$ e $115 \mathrm{kV}$, respectivamente. Tais técnicas apresentaram alto grau de precisão nos testes avaliados. Segundo os autores, as imprecisões constatadas nas técnicas são devidas a imprecisão dos parâmetros da linha, carga do sistema e comprimento da linha.

JOHNS et al. (1995)[14] apresentaram uma nova proposta para o cálculo da distância de falta com uso somente dos dados do terminal local. O método utiliza 
componentes superpostos de tensão e corrente, sendo a equação básica utilizada expressa por:

$$
Z_{F}=\frac{\left(E_{F}-V_{S}+I_{S} \cdot d \cdot Z_{L}\right) \cdot\left((1-d) \cdot Z_{L}+Z_{R}\right)}{V_{S}-I_{S} \cdot\left(Z_{L}+Z_{R}\right)}
$$

Tal que:

$$
E_{F}=-\left(V_{S}-d \cdot Z_{L} \cdot I_{L}\right)
$$

Onde $Z_{F}$ representa a impedância de falta e $E_{F}$ a tensão no ponto da falta.

Um dos objetivos do método é apresentar insensibilidade às condições de operação da rede, e para os testes realizados, considerando uma linha de $400 \mathrm{kV}$ com $100 \mathrm{~km}$, a precisão obtida foi bastante satisfatória.

PURUSHOTHAMA et al. (2000)[15] propuseram a aplicação de Redes Neurais Artificiais ao problema de localização de faltas, usando dados registrados em um terminal ou em ambos os terminais da linha. Os autores desenvolveram duas RNAs, uma utilizando a rede Multilayer Perceptron (MLP) convencional e outra, baseada na técnica de correlação em cascata de Fahlman, para localização da falta em LTs de Extra Alta Tensão (EAT). Na primeira aplicação (rede MLP), as entradas para a rede, definem dados de pré e pós-falta de corrente e pós falta das tensões trifásicas, medidas no terminal local, assim como o tipo da falta, tendo como saída a localização e a resistência da falta. Na Segunda aplicação (cascata de Fahlman's) são usados como entrada valores de seqüência positiva, negativa e zero da tensão, medidos em ambos os terminais e também apresenta como saída a distância e a resistência da falta. Ambas as aplicações são posteriormente comparadas com três métodos analíticos convencionais [7,10 e 27], apresentando promissores resultados.

SAHA et al. (2001)[16] apresentam um algoritmo de localização de faltas para linhas paralelas utilizando sinais de tensão e corrente provenientes do terminal local. $\mathrm{O}$ algoritmo faz uso de componentes simétricos. As correntes e tensões de fase em ambas as linhas, com falta e sem falta, são utilizadas pelo localizador. O algoritmo é capaz de localizar faltas quando ambas as linhas estão em operação e não requer conhecimento das impedâncias das fontes e o uso de sinais de pré-falta. As incertezas com respeito a impedância de seqüência zero da linha é parcialmente limitada, pois a queda de tensão 
gerada pela falta ao longo da linha é determinada excluindo-se a componente de seqüência zero.

YIBIN et al. (1997)[17] propuseram uma nova técnica de localização de faltas usando a Transformada Wavelet. Este método faz uso das componentes de freqüência fundamental do sistema, extraídas com o auxílio da TW, para promover a localização da falta. Com base na Análise Multiresolução (AMR) usando wavelet, sendo os sinais amostrados à freqüência de $5 \mathrm{kHz}$, os autores afirmam que as componentes fundamentais estão inclusas na sexta escala, que compreende a faixa de freqüência de 39,06 à 78,13 Hz. Porém nesta escala, os sinais são representados por menos de duas amostras/ciclo, o que pode ser considerado insuficiente para representar o sinal. Portanto, considera-se o emprego do algoritmo de codificação por sub-bandas de tempo invariante que mantém o mesmo número de amostras em todas as escalas. $\mathrm{O}$ algoritmo proposto apresentou melhores resultados quando comparado à um algoritmo baseado na extração dos fasores fundamentais por meio da Transformada de Fourier.

SOARES et al (2002)[18] descrevem uma outra aplicação da teoria wavelet ao problema de localização de faltas em linhas de transmissão seguindo o princípio apresentado em [17]. O método faz uso das componentes de freqüência fundamental dos sinais de tensão e corrente para promover a localização da falta. A partir dos sinais de tensão e corrente, suas versões aproximadas e detalhadas são obtidas através da implementação do algoritmo de codificação por sub-bandas, baseado na AMR. Porém, neste método, são consideradas as aproximações de terceira escala dos sinais de tensão e corrente para se obter as componentes na faixa de freqüência de 0 à $480 \mathrm{~Hz}$. Para a implementação deste método, considera-se que as componentes fundamentais dos sinais de tensão e corrente são obtidas ao extrair as componentes dos sinais de terceira escala, sendo a distância estimada considerando o método da impedância aparente.

\subsubsection{Algoritmos que utilizam dados de mais de um terminal da linha}

Com a finalidade de melhorar a precisão dos algoritmos de localização de faltas em linhas de transmissão, muitos autores propõem o uso de dados observados em ambos os terminais da linha. Essas técnicas, geralmente, são independentes da impedância de falta e de mudanças na configuração das fontes dos sistemas de potência. 
Por outro lado, torna-se necessário um meio de comunicação entre os terminais, bem como um método para determinação dos ângulos de fase das tensões e correntes, em relação a um eixo de referência comum. A localização da falta só poderá ser determinada precisamente se as medições em ambos os terminais forem sincronizadas.

SCHWEITZER \& JACHINOWHI (1981)[19] propuseram uma técnica usando corrente e tensão em regime permanente, provenientes dos dois terminais da linha. Uma primeira abordagem é usada para um modelo de linha curta. A tensão no ponto da falta (ponto F), usando dados de ambos os barramentos, como por exemplo, barramentos $\mathrm{S}$ e R, são dadas pelas eq.(2.16 e 2.17):

$$
\begin{aligned}
& V_{F}^{\prime}=V_{S}^{\prime}-p Z_{L} I_{S}^{\prime} \\
& V_{F}^{\prime}=V_{R}^{\prime}-(1-p) Z_{L} I_{R}^{\prime}
\end{aligned}
$$

Equacionando-as de modo a eliminar $V_{F}^{\prime}$, obtêm-se o resultado:

$$
p=\frac{\left(V_{S}^{\prime}-V_{R}^{\prime}\right)+Z_{L} I_{R}^{\prime}}{Z_{L}\left(I_{S}^{\prime}+I_{R}^{\prime}\right)}
$$

A eq.(2.18) fornece o valor de $p$, usando valores em regime permanente para correntes e tensões, e representa a distância fracional ao ponto de falta.

A aproximação para linha curta assume que as correntes em ambos os terminais da linha são as mesmas sob condições normais (sem a ocorrência de faltas). Isto produz a condição para pré-falta:

$$
I_{R}^{\prime}=-I_{S}^{\prime}
$$

Logo, a observação da corrente pré falta produz uma relação de fase entre os clocks nas duas subestações, tornando possível a sincronização dos dados para a obtenção da precisão máxima.

Onde a aproximação para linha curta não é justificada, a dedução pode ser repetida usando-se equações com parâmetros distribuídos. Portanto, as eq.(2.16 e 2.17) são substituídas por:

$$
\begin{aligned}
& V_{F}^{\prime}=V_{S}^{\prime} \cosh (\lambda p L)-Z_{0} I_{S}^{\prime} \cosh (\lambda p L) \\
& V_{F}^{\prime}=V_{R}^{\prime} \cosh [\lambda(1-p) L]-Z_{0} I_{R}^{\prime} \cosh [\lambda(1-p) L]
\end{aligned}
$$


A solução obtida para a localização, usando as equações acima definidas e as aproximações de primeira ordem para as exponenciais das funções hiperbólicas, fica:

$$
p=\frac{\left(V_{S}^{\prime}-V_{R}^{\prime}\right)-Z_{0} \lambda L I_{R}^{\prime}}{Z_{0} \lambda L\left(I_{S}^{\prime}+I_{R}^{\prime}\right)-\left(V_{S}^{\prime}-V_{R}^{\prime}\right)(\lambda L)-\left(V_{R}^{\prime}+Z_{0} I_{R}^{\prime}\right)(\lambda L)^{2}}
$$

onde: $Z_{0} \lambda L=Z_{L}$.

Uma estimativa da corrente de pré-falta $I_{R}^{\prime}$ no barramento local é necessária para sincronização dos clocks. Usando as mesmas aproximações, a estimativa é:

$$
I_{R S}^{\prime}=V_{S}^{\prime}\left[\lambda L / Z_{0}\right]-I_{S}^{\prime}
$$

onde $I_{R S}^{\prime}$ denota uma estimativa para a corrente do barramento R no barramento S.

O método para dois terminais descrito acima não requer valores para os parâmetros do sistema externo à linha de transmissão monitorada. Não são apresentados resultados com referência a nenhuma das técnicas mencionadas acima. Na realidade, a precisão pode ser limitada por alguns fatores, tais como: grau de fidelidade do modelo da linha usado na implementação, precisão com que os parâmetros da linha são determinados e pelos hardwares e softwares usados, o que inclui eficiência do método de filtragem para obtenção dos valores em regime permanente.

SACHDEV \& AGARWAL(1985)[20] propuseram uma técnica de localização de faltas não iterativa que é adequada para estimar localizações de faltas para terra. $\mathrm{O}$ método faz uso da impedância aparente local da linha, da corrente de seqüência positiva medida localmente por relés e também, de dados correspondentes ao terminal remoto. A partir dessas informações, diferentes tipos de faltas foram analisados e testados usando a teoria de componentes simétricos, a fim de obter a distância da falta para cada caso. Impedâncias das fontes, fatores de distribuição e correntes pré-falta não foram usados no processo de estimação.

A técnica foi testada para dados simulados de faltas fase-terra e fase-fase-terra. Os resultados indicaram que os erros de estimação são menores que $5 \%$ do comprimento da linha, exceto para uma porção da linha próxima do seu ponto médio, onde as contribuições da correntes de faltas dos dois terminais da linha são iguais. As medidas realizadas nos dois terminais não necessitam ser sincronizadas. O efeito da capacitância em paralelo é desprezado. 
JEYASURYA \& RAHMAN (1989)[21] tomaram por base a eq.(2.18) para estimar a localização de faltas em linhas de transmissão. Os autores também fizeram uso de um método para determinar o ângulo de fase entre as correntes dos relés relativos a um eixo de referência comum.

A eq.(2.18) despreza a capacitância em paralelo nas linhas de transmissão. Para linhas EAT longas, onde correntes de carga são substanciais, os autores afirmam que o método resultará em uma estimação altamente precisa para a localização da falta, visto que os transitórios de alta freqüência, originados pela capacitância em paralelo, são eliminados através de filtros adequados.

Uma estimativa precisa da posição da falta é obtida com um ciclo de dados pósfalta, quando a capacitância da linha é desprezada. Levando-se em conta essa capacitância, foi observado que quase dois ciclos de dados pós-falta são necessários para obter a mesma estimativa.

JOHNS \& JAMALI (1990)[22] descreveram uma técnica precisa de localização de faltas para linhas de transmissão, a qual envolve monitoramento e filtragem das ondas de tensões e correntes medidas em ambos os terminais da linha, de maneira a produzir uma medida dos fasores de tensão e corrente fundamentais em regime permanente. Eles usaram as eq.(2.20 e 2.21) para uma avaliação exata da distância à falta, calculando-a pela teoria de modos naturais e teoria de função matricial. A expressão final para o cálculo da distância da falta para o modelo em uma única etapa é dada pela eq.(2.24):

$$
d=\frac{\arctan h(-B / A)}{\lambda}
$$

Onde:

$$
\begin{aligned}
& A=I_{R}^{\prime} \cosh (\lambda L) Z_{0}-V_{R}^{\prime} \sinh (\lambda L)+Z_{0} I_{S}^{\prime} \\
& B=V_{R}^{\prime} \cosh (\lambda L)-Z_{0} V_{R}^{\prime} \sinh (\lambda L)+V_{S}^{\prime}
\end{aligned}
$$

A localização da falta independe da resistência de falta e não exige qualquer conhecimento da impedância da fonte. O método mantém um alto grau de precisão para linhas não transpostas e nenhuma identificação do tipo da falta é exigida. Em todos os casos testados, o erro produzido pelo algoritmo foi satisfatório. 
KALAM \& JOHNS (1991)[23] descrevem um novo método de localização de faltas para linhas de transmissão com três terminais, fundamentado nas idéias de [22]. Entretanto, a aplicação é estendida a dados de tensão e corrente medidos nos três terminais, os quais são filtrados de maneira a produzir uma medida dos fasores fundamentais em regime permanente. O algoritmo é independente da resistência da falta e não exige qualquer conhecimento da impedância da fonte e do tipo da falta. $\mathrm{O}$ algoritmo também não requer um pré-conhecimento da seção na qual a falta ocorreu.

Em GIRGIS et al (1992)[24] a distância da falta é obtida a partir do equacionamento dos vetores trifásicos de tensão e corrente com o uso da matriz trifásica de impedâncias série da linha, sendo desprezado o efeito da capacitância, o que é uma aproximação boa apenas para linhas curtas.

O método considera linhas de dois ou três terminais, e pode ser aplicado mesmo no caso de não haver sincronização dos dados dos terminais. Para o caso de linhas de dois terminais com dados sincronizados tem-se:

$$
\begin{aligned}
& {\left[V_{F}\right]=\left[V_{S}\right]-d \cdot\left[Z_{a, b, c}\right] \cdot\left[I_{S}\right]} \\
& {\left[V_{F}\right]=\left[V_{R}\right]-(l-d) \cdot\left[Z_{a, b, c}\right] \cdot\left[I_{R}\right]}
\end{aligned}
$$

Das duas equações acima:

$$
\left[V_{L}\right]-\left[V_{R}\right]+l \cdot\left[Z_{a, b, c}\right] \cdot\left[I_{R}\right]=d \cdot\left[Z_{a . b . c}\right] \cdot\left(\left[I_{L}\right]+\left[I_{R}\right]\right)
$$

A eq.(2.29) pode ser rescrita como:

$$
Y=M \cdot d
$$

Onde:

$$
\begin{aligned}
& Y=\left[V_{L}\right]-\left[V_{R}\right]+\left\lfloor Z_{a, b, c}\right\rfloor \cdot\left[I_{R}\right] \cdot l \\
& M=\left[Z_{a, b, c}\right] \cdot\left(\left[I_{L}\right]+\left[I_{R}\right\rfloor\right)
\end{aligned}
$$

O valor da incógnita $d$ na expressão (2.30) é obtida com o uso do método dos mínimos quadrados:

$$
d=\left(\bar{M}^{T} \cdot M\right)^{-1} \cdot \bar{M}^{T} \cdot Y
$$

Onde $\bar{M}^{T}$ é a transposta da matriz $M$ com os elementos conjugados, [ $\left.\mathrm{V}_{\mathrm{L}}\right]$ e $\left[\mathrm{I}_{\mathrm{L}}\right]$ são os vetores de tensão e corrente trifásicos no terminal local, $\left[\mathrm{V}_{R}\right]$ e $\left[\mathrm{I}_{R}\right]$ são os vetores de 
tensão e corrente trifásicos no terminal remoto, $\left[Z_{\mathrm{a}, \mathrm{b}, \mathrm{c}}\right]$ é a matriz trifásica de impedância série da linha, $l$ é o comprimento da linha e $d$ a distância da falta.

A metodologia apresentada estende-se a linhas de três terminais e permite a utilização de dados não sincronizados. A mesma independe do tipo e da resistência de falta.

AGGARWAL et al. (1993)[25] apresentaram um método para computar a localização das faltas nas linhas de transmissão de três terminais, o qual foi desenvolvido, especificamente para uma linha de dois terminais por [22]. A técnica é baseada na utilização das formas de ondas de tensão e corrente em todos os terminais de uma típica linha de três terminais de EAT, sendo as formas de ondas filtradas, usando-se a técnica da TDF a fim de se obter uma medida dos fasores de tensão e corrente em regime permanente. Essa técnica faz uso da teoria da superposição e de componentes modais, ao invés de valores totais e valores de fase para calcular a distância da falta. Alguns artifícios são também desenvolvidos para efetivamente sincronizar os dados provenientes dos três terminais e identificar exatamente o ramo faltoso, ambos requisitos necessários para se obter um alto grau de exatidão. A técnica é também virtualmente independente da resistência de falta e insensível à variações na impedância da fonte, configurações de linha, incluindo uma linha não transposta. O método em questão apresenta uma boa precisão para as condições analisadas.

NOVOSEL et al. (1995)[26] apresentam um método baseado no equacionamento com matrizes trifásicas da linha. Por ser um método off-line, não requer sincronização dos dados nos terminais, de forma a permitir a comunicação desses dados por um canal de comunicação simples, permitindo até mesmo a utilização de modem.

Em ZAMORA \& MIÑANBRES (1996)[27] a obtenção da distância de falta é feita utilizando apenas os componentes fundamentais dos sinais de tensão de falta e préfalta registrados em ambos os terminais da linha e de um novo conceito denominado fator de distância $\left(K_{v}\right)$. São considerados no equacionamento componentes superpostos e componentes simétricos de tensão e corrente para melhoria da precisão do algoritmo, que parte da seguinte equação:

$$
V_{F d}=-Z_{t h} \cdot I_{F d}
$$


Onde $Z_{t h}$ representa a impedância equivalente de Thévenin de seqüência positiva do sistema modelado como um circuito PI, $V_{F d}$ é a componente de tensão superposta de seqüência positiva e $I_{F d}$ a corrente superposta de seqüência positiva, ambas no ponto de falta.

No que segue, os autores fizeram uso de um fator de distância $\left(K_{v}\right)$, que representa a razão entre os componentes de tensão superpostas de seqüência positiva de ambos os terminais, que por sua vez é função da distância. A partir do fator de distância é obtida a distância de falta, através da consulta a uma curva $K_{v}$ versus $p$ ( $p$ é igual a distância da falta em pu), curva esta definida como uma função de $K_{v}$ e determinada em particular para a linha em análise. Para os testes apresentados, o erro máximo obtido foi de 2,25\% do comprimento da linha, considerando a entrada de dados errôneos tanto em amplitude como em ângulo. O algoritmo é independente do sincronismo de dados, tipo da falta, resistência de falta e condições de pré-falta.

GONG et al. (2000)[28] apresentam um algoritmo de localização de faltas que faz uso de sinais de tensão e corrente provenientes de dois ou três terminais. $O$ algoritmo utiliza um modelo matemático expresso por equações diferenciais, onde o efeito da resistência de falta é eliminado completamente. Os autores propõem o uso de GPS (Sistema de posicionamento global) para uma ideal sincronização dos dados e o uso de modem e linha telefônica para transferência dos mesmos.

SOLLERO et al. (2001)[29] descrevem um novo método de localização de faltas em linhas de transmissão a ser incorporado ao Sistema Integrado de Apoio à Análise de Perturbações (SINAPE - CEPEL). Este módulo faz uso dos fasores de tensão e corrente de falta de ambas as extremidades da linha, obtidos pelo processamento, via SINAPE, das amostras armazenadas por oscilógrafos digitais. O algoritmo a ser implementado é fundamentado em [22]. O SINAPE é uma ferramenta que integra uma ampla variedade de funções para análise de eventos oscilográficos. Para utilização do novo algoritmo proposto no SINAPE é necessária uma estrutura de comunicação para transferência dos dados. Os resultados obtidos indicam que o módulo de localização de falta apresentado resolve, simultaneamente, vários problemas não triviais para se estabelecer o ponto de ocorrência da falta, além de apresentar resultados mais consistentes e precisos. 


\subsection{Métodos baseados nos componentes de alta freqüência gerados por uma falta}

Os algoritmos baseados nas componentes de alta freqüência dos sinais transitórios gerados por uma situação de falta são fundamentados na teoria de ondas viajantes em um sistemas de transmissão, (BEWLEY, 1963)[30]. Estes algoritmos baseiam-se geralmente, na determinação do tempo de viagem da onda do ponto de falta ao terminal de monitoramento e na velocidade de propagação da onda viajante na linha em questão, para estimar, o mais precisamente quanto possível, o ponto de ocorrência de uma falta.

Os algoritmos fundamentados na teoria de ondas viajantes podem ser classificados em duas categorias quanto a aquisição de dados: em um ou em múltiplos terminais. A seguir são apresentados alguns trabalhos referentes a esses métodos.

\subsubsection{Algoritmos que utilizam dados somente do terminal local da linha}

GALE \& CROSSLEY (1993)[31] descrevem diversos e distintos tipos de equipamentos que foram desenvolvidos na década de 50, para localização de faltas em linhas de transmissão, baseados em ondas viajantes. Esses tipos foram classificados de acordo com o seu modo de operação em: Tipos A, B, C e D. Apesar da eficácia apresentada pelos resultados obtidos por essas técnicas serem encorajadores, o custo de instalação, operação e manutenção era alto e suas aplicações foram limitadas. Todavia, em meados dos anos 60, diversas linhas de 275 e $400 \mathrm{kV}$ do Reino Unido, foram equipadas com o localizador tipo $\mathrm{C}$, que ainda pode ser encontrado comercialmente nos dias de hoje.

Os localizadores do tipo A e D não incluem circuitos geradores de pulso. Ao invés, utilizam os transitórios viajantes produzidos pela falta para poder determinar a localização da falta. O tipos B e C necessitam de um circuito gerador de pulsos para efetuarem a localização.

- Localizador de falta tipo A: utiliza dados de um terminal e mede o tempo de viagem dos transitórios gerados por uma falta entre o ponto de falta e o terminal local.

- Localizador de falta tipo D: utiliza dados dos dois terminais e detecta o tempo de chegada da primeira onda viajante gerada por uma falta para o cálculo da distância da mesma. Esse método necessita de sincronização dos dados. 
- Localizador de faltas tipo B: estes utilizam dados provenientes de ambos os terminais e, o envio de um sinal de sincronização no tempo aos detectores de onda em cada terminal da linha. Há três variações do tipo B, sendo elas:

Tipo B1: utiliza um pulso de rádio enviado por um canal de microondas;

$>$ Tipo B2: faz uso de um sistema carrier de linha de potência;

$>$ Tipo B3: usa a injeção de um pulso CC sobre a linha.

Os três tipos detectam a chegada dos transitórios em seus terminais. Quando a onda inicial atinge o terminal mais próximo, esta dispara um contador eletrônico que será parado por um sinal enviado pelo terminal remoto, assim que o transitório inicial da falta alcançá-lo. Conhecendo-se o tempo de propagação para todo o comprimento da linha e o valor contado, determina-se a distância como no tipo D.

- Localizador de faltas tipo C: utiliza dados de um terminal e opera usando o princípio do radar. Um pulso é aplicado na linha e o tempo de viagem ao ponto de falta e deste ao terminal local é determinada e usada para calcular a distância de ocorrência.

Os autores apresentam também resultados alcançados por um localizador de faltas baseado nos modos de operação do tipo A, D e B3, implementados utilizando-se da tecnologia atual (microprocessadores, GPS, etc). Os autores concluem que idéias antigas de localização de faltas podem ser implementadas hoje em dia, com menores custos e resultados promissores.

VITINS (1978)[32] apresenta um método de proteção de distância para linhas de transmissão baseado nas equações de onda da linha. Neste método, a localização da falta é considerada como um problema de determinação do tempo de viagem das ondas entre o terminal local e o ponto de falta. O tempo de viagem é extraído das formas de ondas fundamentais de tensão e corrente na presença de transitórios superpostos, por meio de uma técnica de correlação. O método foi testado por simulações numéricas e dados experimentais, apresentando resultados satisfatórios.

CROSSLEY \& MACLAREN (1983)[33] apresentam uma técnica para uma rápida medida da distância da falta usando o princípio das ondas viajantes. A localização da falta é determinada pelo intervalo de tempo entre a primeira onda que atinge o relé e a correspondente onda refletida do ponto de falta que chega ao relé. A onda refletida é reconhecida através da correlação cruzada do sinal refletido contra o 
sinal inicial armazenado. A máxima saída da função de correlação cruzada ocorre quando o atraso da seção do sinal inicial corresponde a duas vezes a distância para a falta. A precisão da localização da falta depende do local da falta, do tipo da falta e do ângulo de incidência da falta.

RAJENDRA \& MACLAREN (1985)[34] partem do mesmo princípio apresentado em [33], estendendo a aplicação a circuitos com derivação ou de três terminais. O método utiliza a correlação cruzada entre uma seção da primeira onda viajante direta, detectada e armazenada, e a segunda onda viajante reversa que reflete do ponto de falta e retorna ao ponto do relé. Com isso, se consegue estimar o intervalo de viagem dos transitórios, determinando-se assim a distância da falta.

SHEHAB-ELKIN \& MACLAREN (1988)[35] examinam alguns problemas e sugerem novas técnicas para melhorar a proteção de distância baseada em ondas viajantes propostas em [33]. Os autores usam uma correlação composta, consistindo na correlação de uma janela de dados pequena e uma janela de dados longa para reconhecer as reflexões do ponto de falta e distingui-las de outras reflexões provenientes do terminal remoto, assim como, para aumentar a amplitude da correlação cruzada. Um fator de correção é usado para compensar a queda na amplitude dos sinais devido aos efeitos do ângulo de incidência da falta, mantendo a amplitude de saída da correlação dependente da distância da falta. A resistência da falta não afeta a precisão do localizador de faltas.

ANCELL \& PAHALAWATHTHA (1994)[36] descrevem uma aplicação para o problema de localização de faltas baseado na estimação da máxima verossimilhança dos tempos de chegada das ondas refletidas. O método da máxima verossimilhança, na maioria dos testes realizados, apresentou resultados melhores que dos métodos de correlação convencional. Para ângulos de incidência de falta próximos a zero, nenhum dos esquemas apresenta bons resultados.

BO et al. (1997)[37] descrevem uma nova técnica para uma precisa localização de faltas. Um equipamento projetado especialmente para o registro dos transitórios de falta é usado para extrair os sinais de tensão transitórios gerados por uma falta em um sistema de transmissão ou distribuição. O tempo de viagem dos sinais de alta freqüência 
são usados para determinar a posição da falta. O algoritmo é insensível ao tipo de falta, resistência e ângulo de incidência da falta e as configurações das fontes. A precisão da localização da falta é proporcional a taxa de amostragem.

MAGNAGO \& ABUR (1998)[38] descrevem o uso da Transformada Wavelet na análise dos transitórios de faltas em sistemas elétricos de potência, a fim de determinar a localização da falta. Usando a teoria das ondas viajantes, os sinais registrados são primeiramente decompostos em seus componentes modais, que por sua vez, são transformados do domínio do tempo para o domínio tempo-freqüência através da TW. Esta informação relata o tempo de viajem dos sinais transitórios para localizar a falta. Os coeficientes wavelets nas duas menores escalas (detalhe um e dois) dos sinais do modo aéreo 1 e do modo terra são usados pelo algoritmo. Os coeficientes wavelets do modo aéreo na escala 1 são utilizados para o cálculo da distância da falta, enquanto os coeficientes wavelets do modo terra em ambas as escalas só são utilizados para determinar a presença de conexão à terra e a metade da linha em que uma falta aterrada se encontra. O método proposto é independente da resistência de falta e mostra-se também adequada para aplicação em linhas com compensação série. O método pode ser usado tanto para dados provenientes de um terminal quanto para dados dos dois terminais. A precisão do algoritmo é proporcional a taxa de amostragem utilizada para o registro dos sinais transitórios de falta.

LIANG et al. (2000)[39] analisam um algoritmo de proteção baseado na função de correlação convencional usando ondas viajantes e propõem um algoritmo baseado em uma função de correlação wavelet. $\mathrm{O}$ algoritmo utiliza a transformada wavelet spline multi-escala para detectar o sinal das ondas viajantes, e então, uma função de correlação wavelet é empregada para completar a operação de correlação no domínio wavelet ao invés do domínio do tempo e determinar a localização da falta. O algoritmo apresentou melhor precisão e rejeição de ruídos se comparado a um método de correlação tradicional.

LAI et al (2000)[40] apresentam uma nova técnica para localização de faltas em linhas de transmissão com três terminais usando a Transformada Wavelet e RNAs. As formas de ondas das tensões e correntes são decompostas em 6 níveis utilizando a TW. O padrão de treinamento para uma rede Radial Basis Function (RBF) usa três tipos de 
informações estatísticas de todos os seis detalhes wavelets e para todas as formas de ondas de corrente e tensão, perfazendo uma rede com 108 entradas. $\mathrm{Na}$ análise wavelet é usado duas wavelets-mãe diferentes (bior4.4 e coif4), constituindo assim, dois padrões de treinamentos diferentes. Nos testes foram apresentados apenas faltas A-terra com baixa resistência de falta. Os melhores resultados foram apontados quando utilizado a wavelet-mãe coif4.

CHEN et al. (2000)[41] tomam por base o método proposto em [37], aliando este ao uso da Transformada Wavelet. A TW é usada para decompor os sinais transitórios de falta e desta maneira revelar o tempo de viagem deste sinais, necessário para localizar a falta em cabos de distribuição. O método proposto é insensível ao tipo da falta, resistência de falta, ângulo de incidência da falta e a configuração das fontes do sistema.

ABUR e MAGNAGO (2000)[42] apresentam um aperfeiçoamento do método de localização de faltas baseado na teoria de ondas viajantes e uso da TW, proposto pelos mesmos autores em [38]. O novo método requer o registro dos transitórios de falta em apenas um terminal da LT. Os sinais são desacoplados em seus componentes modais e então transformados no domínio tempo-freqüência usando TW, fornecendo o tempo entre as reflexões de onda para a estimação da distância da falta. O novo método faz uso da diferença entre os tempos dos modos terra e aéreo para determinar a localização de faltas aterradas na primeira ou segunda metade da linha de transmissão. São apresentados dois algoritmos diferentes para linhas com e sem acoplamento mútuo. Neste método, a precisão da localização da falta não é afetada pela impedância da falta, acoplamento mútuo, compensação série e transitórios produzidos por eventos que não caracterizam uma falta. O erro na estimação do local da falta é função da taxa de amostragem utilizada.

SILVEIRA et al. (2001)[5] descrevem uma metodologia aplicada ao problema de localização de faltas utilizando a TW. Neste método, os sinais normalizados de tensão e corrente são decompostos através da transformada wavelet, fornecendo os coeficientes wavelet de mais alta resolução no tempo. Esses coeficientes são desacoplados, utilizando-se uma matriz de pesos modais modificada descritas em SILVEIRA et al. (1999a e b)[43 e 44], obtendo-se por meio desta sete saídas, a primeira 
relacionada ao modo terra e as demais aos modos aéreos. Estas saídas são comparadas a limiares apropriados, detectando-se, em caso de falta, a primeira e segunda frentes de ondas viajantes com seus respectivos instantes de ocorrência. Pelo intervalo de onda entre duas frentes de ondas estima-se a distância da falta.

Os maiores erros encontrados, em relação a localização real da falta, foi de $2,8 \%$ para ocorrências próximas aos terminais da linha.

\subsubsection{Algoritmos que utilizam dados de múltiplos terminais da linha}

A técnica proposta por IBE \& CORY(1986 e 1987)[45 e 46], para linhas de dois terminais, baseada nos princípios das ondas viajantes, também é empregada para determinar a localização de faltas em linha de três terminais. Para linhas de dois terminais, dados amostrados somente no terminal local são suficientes para localizar a falta. No entanto, para as linhas de três terminais, um registro adicional em qualquer um dos terminais remotos pode ser necessário para confirmar o ramo faltoso. Uma localização precisa entre 0,07 e 3,2\% é encontrada para um sistema de $33 \mathrm{kV}$.

Em GALE \& CROSSLEY (1993)[31] também são apresentadas duas técnicas de localização por ondas viajantes, que fazem uso de dois terminais. Essas técnicas são classificadas de acordo com o seu modo de operação em tipos D e B, os quais foram detalhados anteriormente. Os autores demonstram que tais técnicas podem ser implementadas usando a tecnologia atual dos microprocessadores e GPS, alcançando bons resultados.

LEE \& MOUSA (1996)[47] descrevem a aplicação e operação prática de um novo sistema de localização de faltas baseado em ondas viajantes utilizado no sistema de $500 \mathrm{kV}$ da Bristish Columbia Hydro (Burnaby, Bristish Columbia, Canadá). Este sistema mede o tempo de chegada da onda viajante gerada por uma falta nos terminais do sistema, sincronizados por meio de GPS. A experiência com este localizador de faltas, tanto em caso de faltas permanentes como em descargas atmosféricas, indica uma alta precisão na maioria dos casos. Somente em alguns casos devido a descargas atmosféricas, o sistema apresentou anomalia nas medidas. 
Os autores JIAN et al. (1998)[48] apresentam um novo método de localização, com dados registrados em ambos os terminais, utilizando a Transformada Wavelet Contínua (TWC). São descritas duas técnicas para o cálculo da distância, levando-se em consideração o comprimento da linha. O novo método apresentou uma melhor precisão, em relação ao método convencional, além de ser independente da resistência de falta, posição da falta e características geográficas. A taxa de amostragem utilizada foi de 1 MHz.

O método descrito por MAGNAGO \& ABUR (1998)[38], apresentado anteriormente, pode ser utilizado com dados provenientes de dois terminais. Neste caso, o algoritmo baseado em ondas viajante e uso da TW é mais simples, porém necessita de um meio de comunicação entre os terminais e sincronização dos dados obtidos, sendo indicado neste caso, o uso de GPS. O método proposto é independente da resistência da falta, do tipo da falta e da posição da falta.

GALE et al. (2001)[49] relatam o uso e a experiência da aplicação prática de um localizador de faltas baseado em ondas viajantes no sistema de transmissão de Eskom, localizado na África do Sul. Segundo os autores, o sistema de localização de faltas por ondas viajantes (TWS, do inglês Traveling Wave Fault Location System) foi extensivamente testado e apresentou resultados promissores para localização de faltas em linhas de transmissão de corrente alternada, compensadas ou não, considerando também nos testes, sistemas de corrente contínua. Este localizador é agora utilizado em toda a rede de transmissão de Eskom e fornece níveis de precisão melhores do que os métodos de localização convencionais baseados no cálculo da impedância da linha.

KIM et al. (2001)[50] descrevem um método de localização de faltas usando como ferramenta a Transformada Wavelet para analisar os transitórios de falta e, por conseguinte, determinar a localização da falta. Os dados amostrados em ambos os terminais são sincronizados via GPS, e posteriormente analisados usando a TW. Os sinais provenientes da análise wavelet são transmitidos a um servidor principal, onde é feito o cálculo da localização da falta. Os autores apresentam também a estrutura de um possível sistema de monitoração para localização de faltas. A viabilidade do sistema proposto é mostrada através de alguns resultados experimentais. 
Mais recentemente, CHANDA et al. (2003)[51] propuseram um método de localização baseado na análise multiresolução wavelet combinada com uma técnica de interpolação cúbica. Este método utiliza sinais de correntes obtidos em ambos os terminais da linha. Os resultados obtidos por meio de extensivas simulações, demonstram que o método proposto apresenta uma elevada precisão, além de ser independente dos efeitos do ângulo de incidência, distância e resistência da falta.

É importante ressaltar que, estudos aliando a teoria de ondas viajantes e wavelets, também são encontrados em outras sub-áreas da proteção de sistemas elétricos, como por exemplo, para as situações de detecção e de classificação de faltas e em algoritmos de proteção de distância. 


\section{FUNDAMENTOS SOBRE ONDAS VIAJANTES E TRANSFORMADA WAVELET}

\subsection{Ondas Viajantes em Sistemas de Transmissão}

Quando falamos em ondas viajantes, estamos nos referindo à propagação da energia sobre um sistema, em nosso caso, a propagação da energia elétrica sobre uma linha de transmissão. Se uma variação qualquer de corrente ou de tensão ocorre em um terminal de uma linha de transmissão, o outro terminal só irá sentir tal variação quando a onda referente ao sinal elétrico percorrer todo o comprimento da linha. Portanto, o terminal remoto da linha de transmissão, não pode influenciar nas decisões sobre o sistema, até que a onda tenha viajado da fonte do terminal local ao terminal remoto, onde, através da interação deste com a linha de transmissão, seja produzida uma resposta que viaja de volta para a fonte local. Desta maneira, os sinais elétricos tendem a se propagar para frente e para trás, como ondas viajantes, normalmente dissipando energia com perdas no material (HEDMAN, 1978)[52].

Do exposto acima, temos que qualquer distúrbio em uma linha de transmissão (tal como os provocados por descargas atmosféricas, curtos-circuitos, ou uma alteração da condição de regime permanente) dá origem a ondas viajantes. Estas por sua vez, deslocam-se no sentido das extremidades da linha de acordo com a velocidade de propagação da linha, onde encontram descontinuidades físicas do sistema que provocam a sua reflexão ou refração, dependendo das características dessas descontinuidades. Este sucessivo processo continua até que as ondas sejam extintas devido ás atenuações causadas por perdas na linha, alcançando o regime permanente do distúrbio.

Salienta-se que o objetivo deste trabalho é apenas de apresentar de forma simples, clara e objetiva a teoria fundamental sobre ondas viajantes. Para informações 
mais detalhadas sobre o assunto, recomendam-se as seguintes bibliografias: BEWLEY (1933)[30], HEDMAN (1978)[52], GREENWOOD (1971)[53] e NAIDU (1985)[54].

\subsubsection{Reflexões e Refrações de Ondas Viajantes}

Quando uma onda viajante atinge uma descontinuidade, ou seja, um ponto de transição no qual há uma súbita mudança nos parâmetros do circuito, tais como num terminal aberto ou em curto-circuito, uma junção com uma outra linha, um enrolamento de uma máquina ou transformador, etc, uma parte da onda é refletida de volta, e uma parte da onda é transmitida para a outra sessão do circuito. A onda que chega na descontinuidade é chamada de onda incidente e as duas ondas oriundas da descontinuidade são chamadas de ondas $\underline{\text { refletidas }}$ e refratadas (transmitida), respectivamente. Tais ondas formadas no ponto de transição seguem as leis de Kirchhoff. Elas satisfazem a equações diferenciais das linhas de transmissão, e são condizentes com os princípios de conservação de energia (BEWLEY, 1933)[30].

\subsubsection{Reflexões Sucessivas e Diagrama Lattice}

Em muitos problemas (tais como os referentes aos cabos guarda, o efeito de cabos com pouca extensão, processo de carga e descarga em linhas e de redes extensas com muitas conexões e uma variedade de terminações) é necessário considerar as reflexões sucessivas das ondas viajantes. Para simplificar o que seria um problema complexo, BEWLEY (1933)[30] optou por utilizar uma técnica gráfica, de suma importância na análise de problemas relacionados a ondas viajantes em linhas de transmissão, denominada diagrama Lattice ou diagrama espaço-tempo. Tal diagrama mostra a posição e direção de cada onda viajante (incidente, refletida e refratada) em cada instante de tempo. Além disso, o diagrama Lattice facilita o cálculo da forma de todas as ondas refletidas e refratadas. O diagrama Lattice também mostra uma visão ampla do histórico de cada onda. Conhecendo-se as funções de atenuação e distorção, tais efeitos podem ser incluídos no diagrama (NAIDU, 1985)[54].

A finalidade do diagrama Lattice é propiciar um meio gráfico simples que denote as relações tempo-espaço dos sinais em análise sobre redes de transmissão com múltiplas descontinuidades. Por exemplo, no cálculo de surtos de descargas atmosféricas em linhas de transmissão com muitos pontos de aterramento, torna-se 
difícil o conhecimento de todas as ondas refletidas e refratadas ao longo da linha, especialmente após um intervalo de tempo relativamente longo. Isto é devido ao fato de que, à medida que cada onda atinge uma descontinuidade, uma nova onda refletida e refratada é gerada naquele ponto. A Figura 1 ilustra um diagrama Lattice onde temos três junções de linhas com diferentes comprimentos.

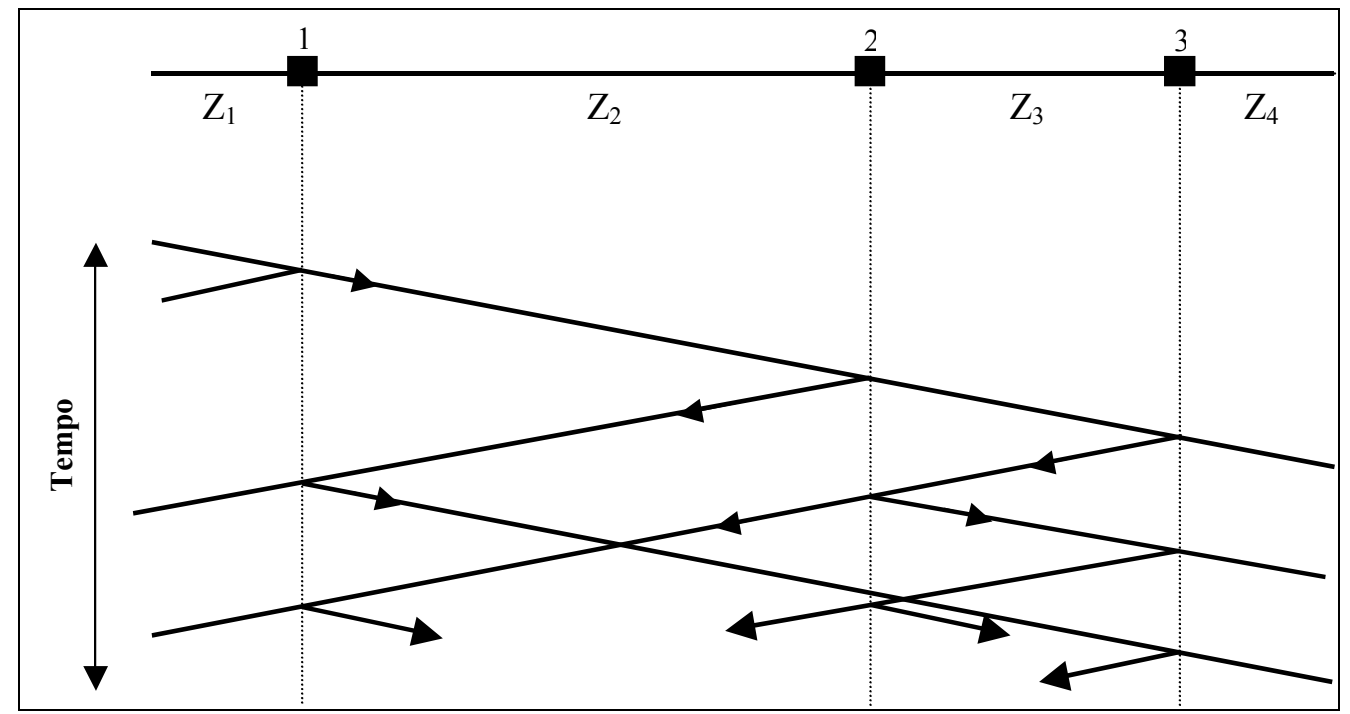

FIGURA 1 - Diagrama Lattice representando as sucessivas reflexões de um sinal qualquer

Quando temos linhas em conexão a pequenos trechos de cabos, como por exemplo, na entrada de subestações, a influência destes deve ser considerada. Geralmente, um cabo tem uma impedância de surto de aproximadamente um décimo da impedância de surto de uma linha aérea e a velocidade de viagem é aproximadamente metade da velocidade de propagação da onda em uma linha (NAIDU, 1985)[54]. Para simplificar o diagrama Lattice, emprega-se uma escala de distância diferente em cada seção, uma para a linha e outra para o cabo.

\subsubsection{Atenuação e Distorção das Ondas Viajantes}

As ondas viajantes em uma linha de transmissão são passíveis de sofrerem três diferentes alterações: (i) o valor de crista da onda decresce em amplitude, ou seja, é atenuado; (ii) as ondas mudam de forma, tornam-se mais alongadas, suas irregularidades são alisadas, e sua inclinação é reduzida; (iii) os términos das ondas de tensão e corrente tornam-se similares. Estas duas últimas mudanças ocorrem juntas e são chamadas de distorções. As distorções e atenuações das ondas ao longo da linha são 
causadas por perdas de energia, e estas estão ligadas a resistência da linha, ao efeito skin (pelicular), à dispersão sobre isoladores, à perdas dielétricas, e principalmente ao efeito corona (BEWLEY, 1933)[30].

\subsection{Introdução a Transformada Wavelet}

O tema Wavelets, muito empregado nos últimos 20 anos, é formado pela união de idéias em campos como matemática pura e aplicada, física, ciência da computação e engenharia, sendo que a sua aplicabilidade e características continuam a despertar grande interesse por parte de cientistas e pesquisadores de diversas áreas. A "Wavelet" é descrita como uma 'pequena' onda no sentido de ser de curta duração com energia finita.

A primeira menção a Wavelets apareceu no apêndice de A. Haar, em 1909 como descrito por HAAR apud (LIMA, 2002)[55]. Uma propriedade das Wavelets de Haar é possuírem suportes compactos; contudo, não são continuamente diferenciáveis, o que de certa forma limita a aplicabilidade a elas relacionadas.

As Wavelets de Haar ficaram no anonimato por muitos anos até que nos anos 30, vários grupos trabalhando de forma independente, pesquisaram a representação de funções usando uma base com escala variável. Naquela ocasião, usando a base de Haar, Paul Levy mostrou que estas funções sendo usadas como base, ofereciam melhores resultados quando comparados com os resultados obtidos com a utilização das funções bases de Fourier no estudo dos pequenos e complicados detalhes do movimento Browniano (GRAPS, 1995)[56]. Por um período muito longo, as Wavelets de Haar continuaram a ser a única base ortonormal de funções Wavelets conhecida, até que, em 1980, o termo "wavelet" foi originariamente introduzido pelo engenheiro J. Morlet, sendo a base matemática de suas idéias formalizada pelo físico teórico Alex Grossmann. Os dados sísmicos estudados por Morlet exibiam conteúdos de freqüência que mudavam rapidamente ao longo do tempo, para os quais a Transformada de Fourier não era adequada como ferramenta de análise (SCHIMIDT, 2000)[57]”.

A série de Fourier requer periodicidade de todas as funções envolvidas no tempo; isto efetivamente significa que as funções base (isto é, ondas de seno e coseno) usadas na análise de Fourier estão precisamente situadas na freqüência, mas existem para todo o tempo. A informação em freqüência de um sinal calculado pela transformada clássica de Fourier é a média durante todo o tempo do sinal. Assim, se 
existe um sinal transitório local durante algum intervalo de tempo pequeno, o transitório contribuirá para a TF (embora de modo um pouco ineficiente), mas a sua localização no eixo do tempo será perdida. A análise tradicional de Fourier não considera freqüências que variam com o tempo, ou seja, sinais não estacionários.

Com o objetivo de corrigir a deficiência mencionada da TF, Dennis Gabor a adaptou para analisar apenas uma pequena porção de tempo do sinal, originando a chamada Short-Time Fourier Transform (STFT), também conhecida como Transformada de Fourier Janelada (TFJ) que faz o mapeamento de um sinal unidimensional em duas dimensões: tempo e freqüência. No entanto, a precisão das informações obtidas por esta forma de transformação é limitada, uma vez que esta utiliza uma "janela" de dados fixa, isto é, o conteúdo de informações do sinal, amostrado seqüencialmente é analisado em um intervalo fixo de seu espaço de domínio. Com uma janela larga, por exemplo, obteremos uma boa resolução em freqüência, mas teremos uma pobre resolução no tempo, enquanto que com uma janela estreita será obtida uma boa resolução no tempo, mas uma pobre resolução em freqüência. Deve ser mencionado que a técnica da TFJ pode ser aplicada com uma seqüência de janelas de diferentes larguras para conseguir mais detalhes na localização do transitório. No entanto, esta última opção é complexa e de grande esforço computacional (KIM e AGGARWAL, 2000)[58].

Em 1985, Stephane Mallat proporcionou às Wavelets um grande impulso através de seu trabalho em processamento digital de imagens e, inspirado nos resultados deste, Y. Meyer construiu a primeira Wavelets não-trivial (suave) (DAUBECHIES, 1996)[59]. Ao contrário das Wavelets de Haar, as Wavelets de Meyer são continuamente diferenciáveis; contudo, não possuem suportes compactos. Poucos anos mais tarde, Ingrid Daubechies usou os trabalhos de Mallat para construir um conjunto de bases ortonormais de Wavelets suaves, com suportes compactos (LIMA, 2002)[55].

A Transformada Wavelet representa o próximo passo lógico: uma técnica de “janelamento" variável, permitindo o uso de uma janela de tempo maior para analisar informações de baixa freqüência de forma mais precisa, e de uma pequena janela para informações de alta freqüência (MISITI et al., 1997)[60].

De uma forma geral a família das funções

$$
\psi_{a, b}(x)=|a|^{-\frac{1}{2}} \psi\left(\frac{x-b}{a}\right) \quad a, b \in \mathfrak{R}, \quad a \neq 0,
$$


onde a variável $x$ pode corresponder a tempo ou espaço, geradas a partir das operações de dilatação (fator de escala $a$ ) e translação (fator $b$ ) da mesma função $\psi$ (Wavelets mãe), são chamadas Wavelets (DAUBECHIES, 1992)[61].

Como será visto, deve-se distinguir duas versões diferentes da Transformada Wavelet (TW), a contínua e a discreta:

- A Transformada Wavelet Contínua (TWC) faz o mapeamento de uma função de uma variável contínua em uma função de duas variáveis contínuas e a

- A Transformada Wavelet Discreta (TWD) decompõe um sinal discretizado em diferentes níveis de resolução. Esta faz o mapeamento de uma seqüência de números em outra seqüência de números (KIM e AGGARWAL, 2000) [58].

Cabe mencionar que neste trabalho será exposto somente o equacionamento matemático básico necessário para o entendimento da teoria da transformada wavelet. Para maiores informações e um estudo mais aprofundado sobre o assunto algumas bibliografias são recomendadas, entre as quais temos: DAUBECHIES (1992)[61], MEYER (1992)[62] ou CHUI (1997)[63] que trazem uma introdução matemática; BURRUS et al. (1998)[64] que apresentam uma excelente introdução do ponto de vista da engenharia e, BURKE HUBBARD (1998)[65] para uma introdução não matemática. Além destas, encontramos inúmeras publicações nacionais e internacionais sobre a teoria e implementação da TW, aplicadas a específicos problemas.

\subsubsection{A Transformada Wavelet Contínua}

A análise Wavelet emprega um protótipo de função chamado Wavelet mãe. Esta função tem média zero e parte central oscilante, a qual decai para zero em ambos os lados de sua trajetória. Matematicamente, a Transformada Wavelet Contínua (TWC) de um dado sinal $x(t)$ com respeito a Wavelet mãe $\psi(t)$ é genericamente definida como:

$$
T W C(a, b)=\frac{1}{\sqrt{a}} \int_{-\infty}^{\infty} x(t) \psi\left(\frac{t-b}{a}\right) d t
$$

onde $a$ é a dilatação ou fator de escala e $b$ é o fator de translação, e ambas as variáveis são contínuas. É claro da eq.(3.2) que o sinal original no domínio do tempo $x(t)$, com uma dimensão, é mapeado para uma nova função no espaço, de dimensão dois, através dos coeficientes de escala e de translação pela TW. O coeficiente da TW, em uma particular escala e translação - $T W C(a, b)$, representa quão bem o sinal original $x(t)$ e a 
Wavelet mãe escalada e transladada se combinam. Então, o conjunto de todos os coeficientes $T W C(a, b)$ associados a um particular sinal é a representação do sinal original $x(t)$ com respeito a Wavelet mãe $\psi(t)$ (KIM e AGGARWAL, 2000)[58].

Podemos visualizar a wavelet mãe como uma função janela. $\mathrm{O}$ fator de escala $a$ e o tamanho da janela são interdependentes, onde menores escalas implicam em menores janelas. Conseqüentemente, podemos analisar componentes de bandas estreitas de freqüência de um sinal com um pequeno fator de escala e componentes de bandas largas de freqüência com fatores de escala maiores, o que permite captar todas as características de um sinal particular.

\subsubsection{Escalamento}

Foi mencionado o fato da TW produzir um escalamento no tempo de um sinal, e agora será comentado sobre escalamento e translação de Wavelets (MISITI et al., 1997)[60]. Escalar uma Wavelet significa simplesmente dilatá-la ou contraí-la. Será detalhado aqui, o funcionamento do fator de escala que é usualmente denotado pela letra a. Em se tratando de wavelets, o efeito do fator de escala é muito facilmente observado, o que é ilustrado na Figura 2:

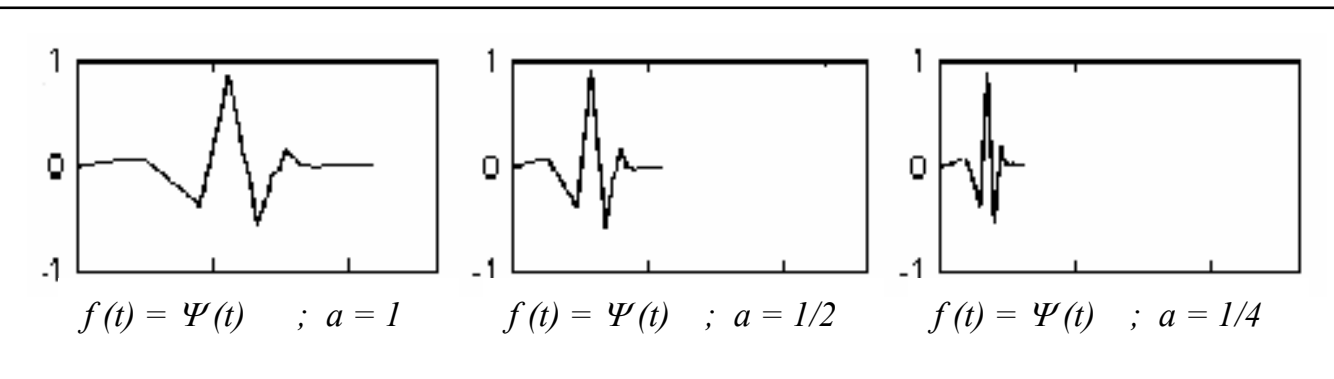

FIGURA 2 - Escalamento de uma função Wavelet

Fica claro através da Figura 2 que, quanto menor o fator de escala, mais “contraída" será a Wavelet. Na análise Wavelet, a escala é relacionada com a freqüência do sinal. O que corresponde a:

- Baixa escala $a \rightarrow$ Wavelet contraída $\rightarrow$ detalhes que mudam rapidamente $\rightarrow$ alta freqüência $w$.

- Alta escala $a \rightarrow$ Wavelet dilatada $\rightarrow$ detalhes que mudam vagarosamente $\rightarrow$ baixa freqüência $w$. 


\subsubsection{Translação}

Transladar uma Wavelet significa atrasá-la ou adiantá-la em relação ao eixo das abscissas, que é o que fazemos matematicamente quando escrevemos $f(x-k)$ como um atraso na função $f$ de um fator k, como pode ser visto abaixo na Figura 3.

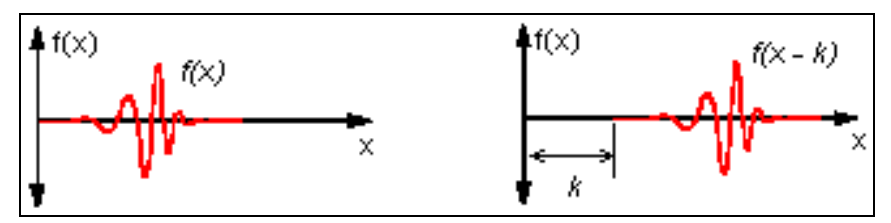

FIGURA 3 - Translação aplicada a uma Wavelet

\subsubsection{A Transformada Wavelet Discreta}

Análoga à relação existente entre a transformada contínua de Fourier e a Transformada Discreta de Fourier (TDF), a Transformada Wavelet Contínua tem uma versão digitalmente implementável, denotada como Transformada Wavelet Discreta (TWD) que é definida como segue:

$$
\operatorname{TWD}(m, k)=\frac{1}{\sqrt{a_{0}^{m}}} \sum_{n} x(n) \psi\left(\frac{k-n b_{0} a_{0}^{m}}{a_{0}^{m}}\right)
$$

onde $\psi($.) é a Wavelet mãe e os parâmetros de escala e de translação $a$ e $b$ são funções de um parâmetro inteiro $m$, isto é, $a=a_{o}^{m}$ e $b=n b_{o} a_{o}^{m}$, que permite uma expansão da família originada pela Wavelet mãe, gerando as Wavelets filhas. Nesta equação, $k$ é uma variável inteira que se refere a um número particular de amostra de um determinado sinal de entrada. O parâmetro de escala permite o aumento da escala geométrica, isto é, $1,1 / \mathrm{a}_{0}, 1 / \mathrm{a}_{\mathrm{o}}{ }^{2}, \ldots$ A saída da TWD pode ser representada em duas dimensões de maneira similar a TDF, mas com divisões muito diferentes no tempo e na freqüência. Associado com a análise Wavelet, ambas as principais características em alta e baixa freqüência nos diferentes níveis de detalhes são claramente evidenciadas. Isto é obtido aplicando-se a TWD a um determinado número de ciclos do sinal transitório (KIM e AGGARWAL, 2000)[58]. 


\subsubsection{Filtragem e Análise Multiresolução}

Filtrar um sinal implica em eliminar determinadas freqüências, ou uma banda de freqüência do mesmo. Na teoria de processamento de sinais, isto implica em realizar uma convolução do sinal para a resposta impulso do filtro ou, simplesmente, convolução.

O processo de filtragem aqui descrito, apresenta uma forma de realização da técnica de Análise Multiresolução (AMR) de uma forma bastante prática. Este processo baseia-se na filtragem de um sinal a ser analisado através de bancos de filtros passa alta e passa baixa , fornecendo versões do sinal original relativas aos coeficientes de funções Wavelets e funções escala respectivamente.

Considerando-se a Transformada Wavelet em suas formas Contínua e Discreta, fala-se usualmente em aproximações e detalhes. As aproximações são as altas escalas, isto é, as componentes de baixa freqüência do sinal. Os detalhes são as baixas escalas ou seja, as componentes de alta freqüência. O processo de filtragem é mostrado abaixo na Figura 4 em uma forma simplificada, considerando-se somente o primeiro nível de filtragem.

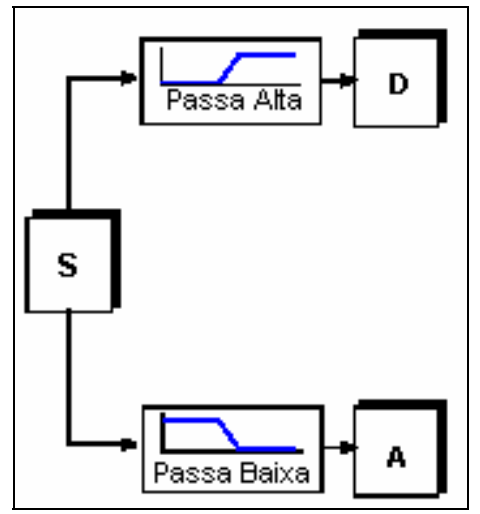

FIGURA 4 - Processo de filtragem de um sinal no primeiro nível

O sinal original $S$, passa através de dois filtros complementares que fornecem como saída dois sinais. Infelizmente, se utilizarmos esse esquema em um sinal digital real, teremos duas vezes mais a quantidade de dados em relação aos dados iniciais. Suponha que o sinal original S consista de 1000 amostras de dados. Sendo assim as versões aproximadas (A) e detalhadas (D) do sinal original terão 1000 amostras cada uma, totalizando 2000 amostras. 
Para corrigir este problema, foi introduzido um operador que diminui o número de amostras (operador downsampling) (BURRUS et al., 1998)[64] e (MISITI et al, 1997)[60], que considera dados intercalados, ou seja, considera o primeiro dado, rejeita o segundo, e assim por diante. A Figura 5 ilustra a operação do operador downsampling representado pelo símbolo $($ ).

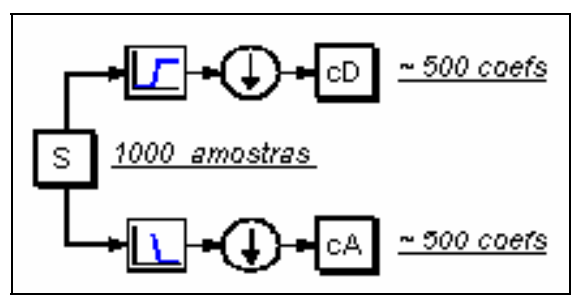

FIGURA 5 - Processo de diminuição do número de amostras do sinal (Downsampling)

Com o intuito de se obter uma melhor visualização do processo de filtragem com a diminuição do número de amostras do sinal, é mostrado na Figura 6, um exemplo do desenvolvimento da TWD de um sinal. Neste caso, o sinal é uma senóide pura com ruído de alta freqüência adicionado ao mesmo.

Observe na Figura 6 que o coeficiente de detalhe $c D$ consiste principalmente do ruído de alta freqüência, enquanto que os coeficientes $c A$ contém muito menos ruído que o sinal original.

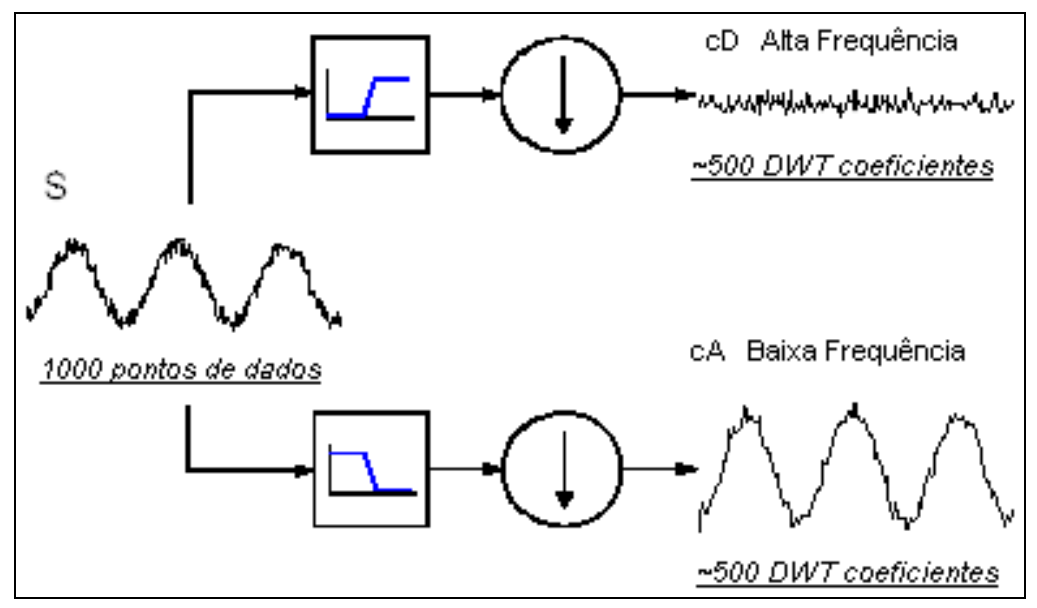

FIGURA 6 - Exemplo de filtragem com downsampling de um sinal senoidal ruidoso. 


\subsubsection{Decomposição em Múltiplos Níveis ou Análise Multiresolução}

A análise multiresolução (AMR) refere-se ao procedimento para obter aproximações de filtros passa baixa e detalhes de filtros passa alta do sinal original. Uma aproximação é a representação em baixa resolução de um sinal, enquanto um detalhe é a diferença entre duas sucessivas representações em baixa resolução do sinal original. A aproximação compreende as baixas freqüência do sinal original, enquanto um detalhe engloba o conteúdo de alta freqüência do sinal original. Aproximações e detalhes são obtidos através de um processo sucessivo de convolução. O sinal original é dividido em diferentes escalas de resolução, particularmente em diferentes freqüências, como no caso da análise de Fourier.

O algoritmo de decomposição de um sinal em análise multiresolução é ilustrado na Figura 7, o qual apresenta três níveis de decomposição. Os detalhes e aproximações do sinal original S são obtidos por meio de bancos de filtros, os quais são formados por filtros passa-baixa $\left(h_{0}\right)$ e passa-alta $\left(h_{1}\right)$. Um filtro passa-baixa remove os componentes de altas freqüências, enquanto o filtro passa alta separa o conteúdo de alta freqüência no sinal sendo analisado (KIM e AGGARWAL, 2001)[66].

Resumindo, a idéia básica da decomposição em múltiplos níveis, também conhecida como Análise Multiresolução (AMR) é dividir o espectro de um sinal em sub-bandas e então tratar individualmente cada uma das sub-bandas, considerando o propósito desejado.

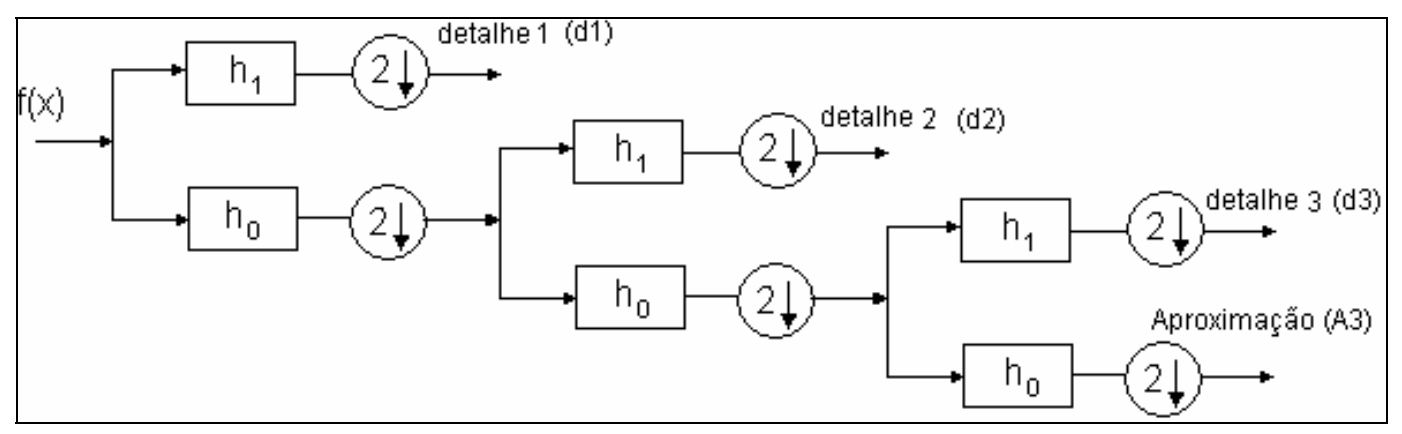

FIGURA 7 - Processo de decomposição de um sinal em AMR

A fim de se conseguir uma representação não redundante e reconstrução perfeita do sinal original, são requeridos bancos de filtros ortogonais e, conseqüentemente, uso de wavelets ortogonais. 
O número máximo de níveis de decomposição wavelet é determinado pelo comprimento do sinal, pela wavelet mãe selecionada e, pelo nível de detalhe exigido. $\mathrm{Na}$ prática, selecionamos um número satisfatório de níveis baseado na natureza do sinal (KIM e AGGARWAL, 2001)[ [66].

As famílias wavelets freqüentemente mais usadas para processamento de sinais são as wavelets Daubechies (db), Morlets, Coiflets (coif) e Symlets (sym). Estas wavelets exibem diferentes atributos e critérios de performance quando utilizadas em aplicações específicas, tais como: detecção de transitórios, compressão de sinais e filtragem de ruído. Apesar de não existir um critério definido para a escolha das wavelets, a melhor escolha é uma wavelet, que melhor caracteriza o fenômeno ou o problema a ser estudado (KIM e AGGARWAL, 2001)[ [66].

\subsubsection{Reconstrução Wavelet}

Já vimos como a TDW pode ser usada para analisar, ou decompor, sinais ou imagens. Uma outra etapa é saber como aquelas componentes podem ser reagrupadas para montar o sinal original, sem perder informações. Este processo é chamado reconstrução, ou síntese. Esta manipulação que efetua a reconstrução do sinal é chamada de Transformada Wavelet Discreta Inversa (TWDI).

Para reconstruir um sinal, o fazemos a partir dos coeficientes Wavelets, como ilustrado na Figura 8:

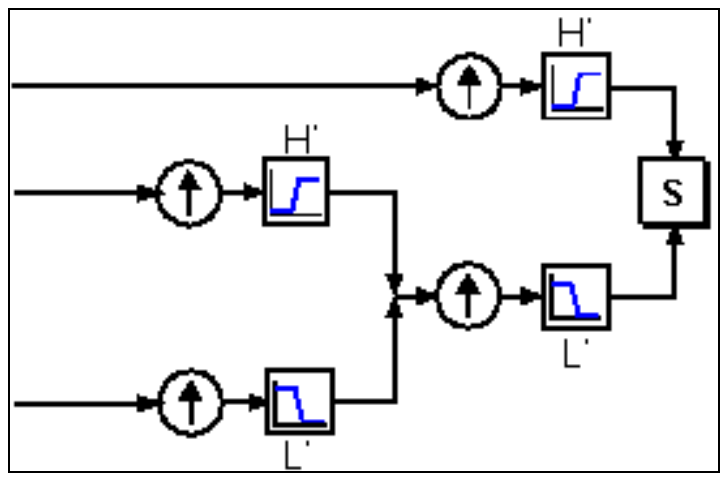

FIGURA 8 - Processo de reconstrução de um sinal filtrado

Como a análise Wavelet envolve filtragem e diminuição do número de amostras, a reconstrução Wavelet consiste em aumentar o número de amostras na filtragem. Aumentar o número de amostras é o processo de elevar o número de componentes do sinal pela inserção de zeros entre as amostras, o que está ilustrado na Figura 9. 


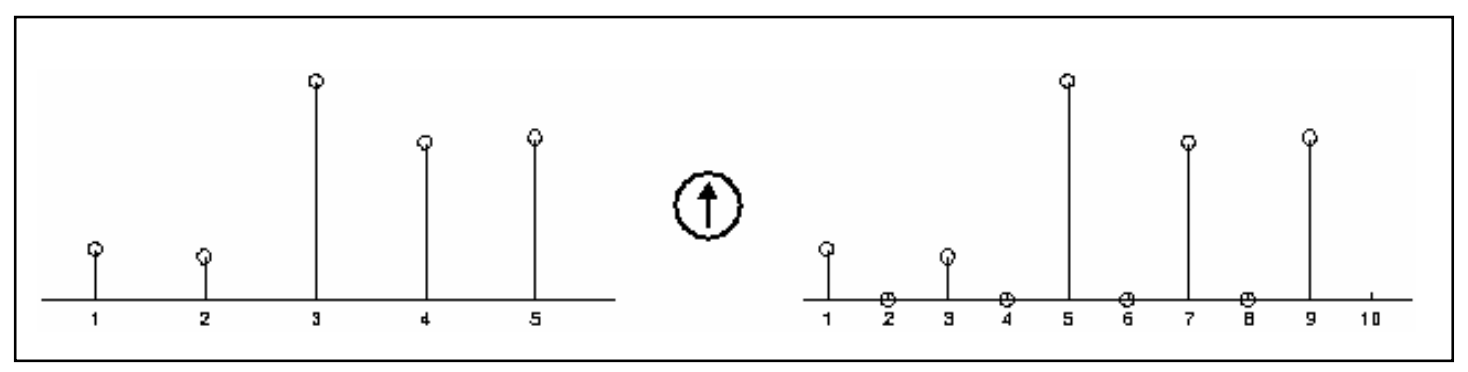

FIGURA 9 - Processo de aumento do número de amostras para reconstrução de um sinal

\subsubsection{Filtros de Reconstrução}

A parte de filtragem para a reconstrução do sinal também merece algumas considerações, devido ao fato de a escolha do filtro ser crucial para uma perfeita reconstrução do sinal original.

O processo de diminuição do número de amostras do sinal introduz neste, distorções de aliasing que podem ser canceladas pela escolha correta do filtro de reconstrução. Esta foi a grande descoberta feita pelo trabalho de Ingrid Daubechies como descrito em [60].

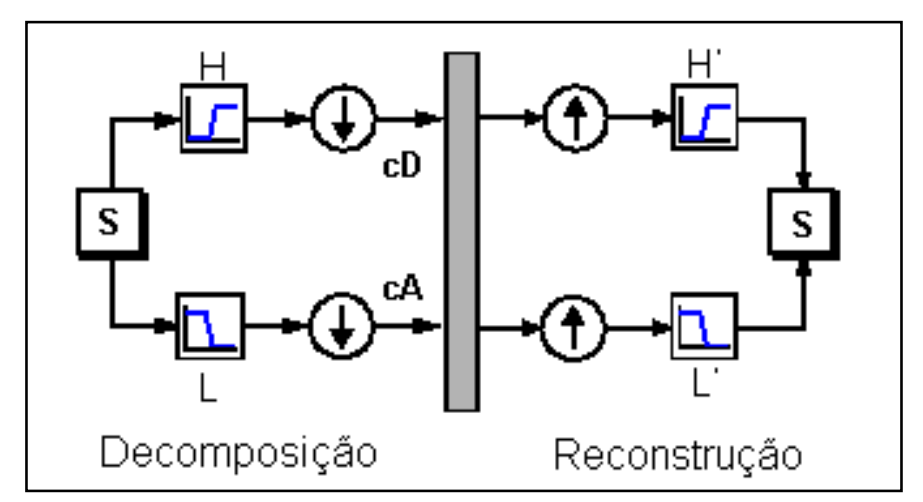

FIGURA 10 - Processos de decomposição e reconstrução de um sinal

\subsubsection{Aproximações e Detalhes na Reconstrução}

Também é possível reconstruir as aproximações e detalhes em si, a partir dos vetores de coeficientes. Como exemplo, veremos como reconstruir o primeiro nível de aproximação A1, do vetor de coeficientes cA1.

$\mathrm{O}$ vetor dos coeficientes cA1 passa pelo mesmo processo usado para reconstruir o sinal original. No entanto, ao invés de combiná-los com o nível um (1) de detalhes cD1, alimentamos com um vetor de zeros no lugar dos detalhes, como indicado na Figura 11. 


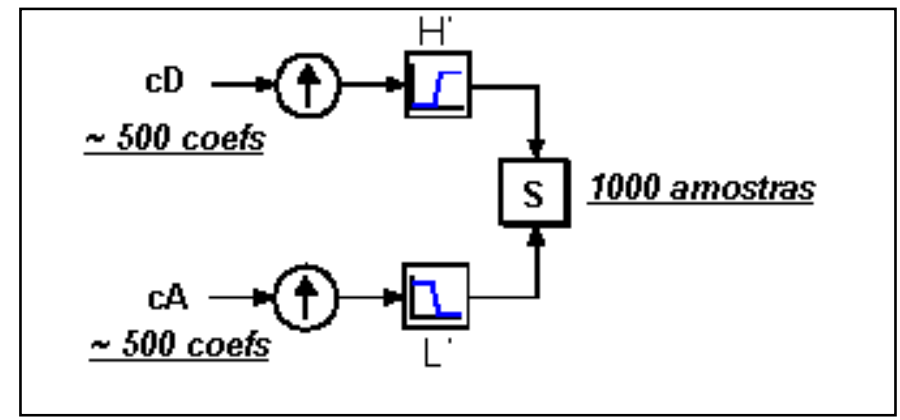

FIGURA 11 - Reconstrução de um sinal a partir de seu coeficientes de aproximação

Este processo produz a reconstrução do sinal de aproximação A1, que possui o mesmo tamanho que o sinal original $\mathrm{S}$, sendo uma aproximação real.

Similarmente, podemos reconstruir o primeiro nível de detalhe D1, usando o processo análogo, como na Figura 12.

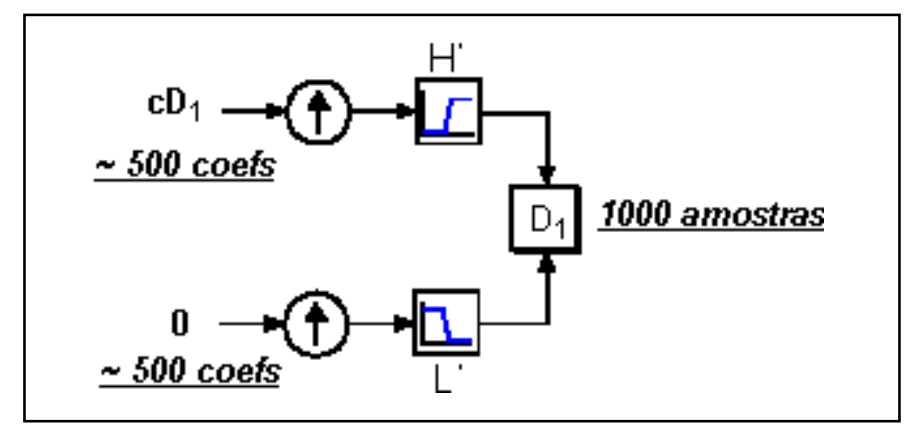

FIGURA 12 - Reconstrução do primeiro nível de detalhe do sinal

Os detalhes e aproximações reconstruídos são verdadeiramente constituintes dos sinais originais. De fato, encontramos isto quando combinamos $A_{1}+D_{1}=S$.

Note que os vetores de coeficientes cA1 e cD1, por serem produzidos pela diminuição do número de amostras, contém distorção aliasing, e suas dimensões são somente a metade da dimensão do sinal original. Assim, não podem ser combinados diretamente para reproduzir o sinal original. É necessário reconstruir as aproximações e detalhes antes de combiná-los.

Estendendo esta técnica para componentes de uma análise multi-nível, encontramos relações similares, como mostrado na Figura 13, para todo o sinal reconstruído. Deve ser observado que existem vários caminhos para reconstruir o sinal original. 


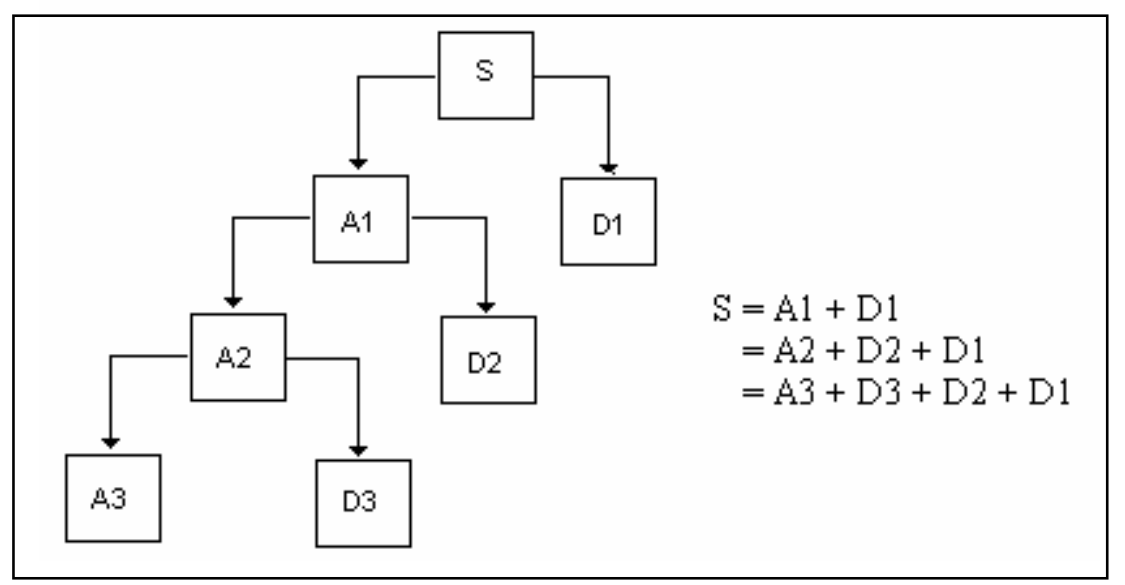

FIGURA 13 - Diferentes formas para se reconstruir o sinal a partir de seus coeficientes

\subsubsection{Aplicações da Transformada Wavelet em Sistemas Elétricos de Potência}

Na última década, houve um maior número de publicações sobre a aplicação da Transformada Wavelet em sistemas elétricos de potência. Diferentes propostas de aplicações foram introduzidas com objetivo principal de avaliar aspectos de qualidade da energia, destacando neste contexto o trabalho de SANTOSO et al. (1996)[67]. A Figura 14 ilustra as áreas de aplicação da TW em sistemas elétricos de potência (KIM e AGGARWAL, 2001)[66].

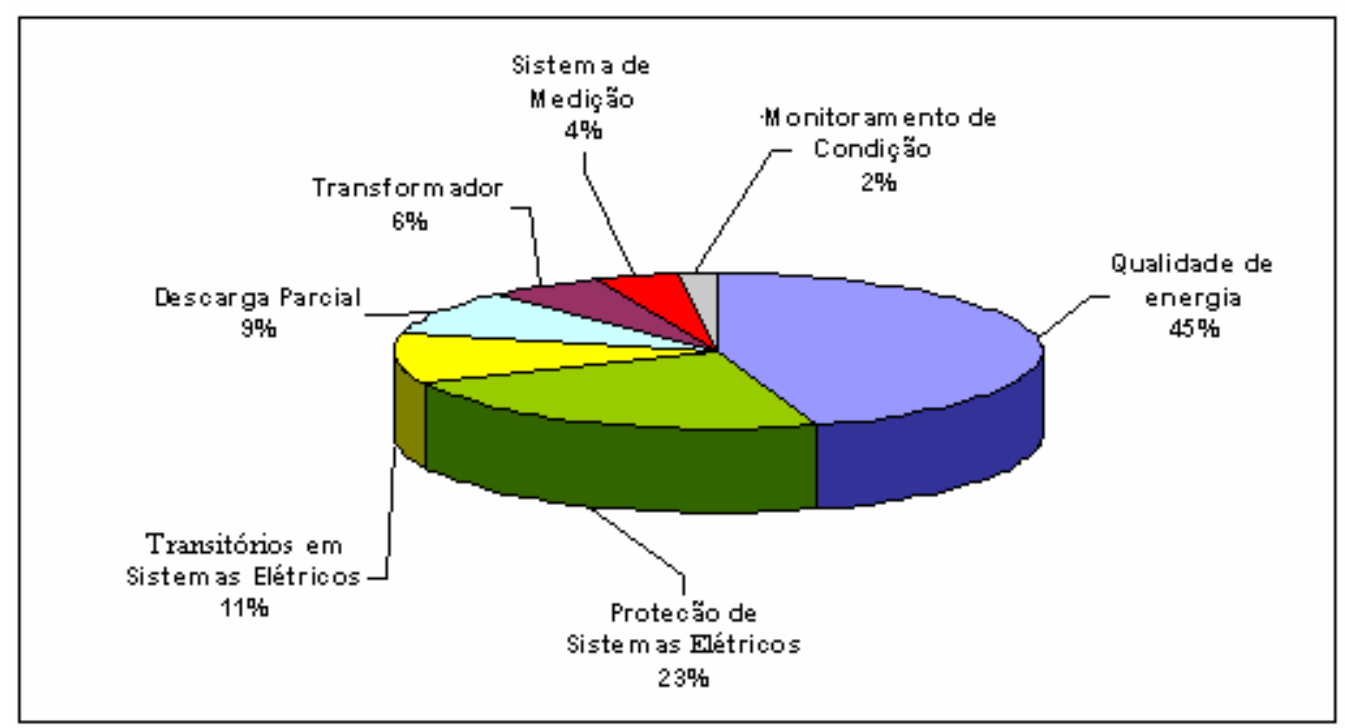

FIGURA 14 - Áreas de aplicação da TW em sistemas elétricos de potência. 
Relacionado à área de proteção/supervisão, poucas contribuições foram apresentadas até o momento, destacando-se o emprego da TW na: detecção, classificação e localização de faltas.

Quando aplicada, a TW pode ser implementa através do uso de uma linguagem de programação, como por exemplo $\mathrm{C}, \mathrm{C}++$ e mais recentemente Java, ou através da utilização de pacotes computacionais, como é o caso do "Toolbox" incluído no software Matlab $^{\odot}$. 


\section{SISTEMA ELÉTRICO ANALISADO}

Com o objetivo de testar e validar a aplicabilidade do algoritmo de localização de faltas proposto, utilizou-se da simulação de um sistema de transmissão em condição faltosa. Para tal, o software ATP (Alternative Transient Program)[68] foi empregado. Deve ser mencionado que a técnica descrita é baseada em simulações computacionais e que considerações práticas foram também incluídas na simulação, fazendo com que os dados obtidos aproximem-se dos reais. Foram também consideradas as características dos condutores e suas respectivas disposições geométricas nas torres de transmissão.

\subsection{Configuração do sistema de potência}

Observa-se na Figura 15 a representação do sistema elétrico estudado, o qual é encontrado em OLESKOVICZ (2001)[69], com a especificação das fontes, barramentos (D, E, F e G) e comprimento das linhas de transmissão.

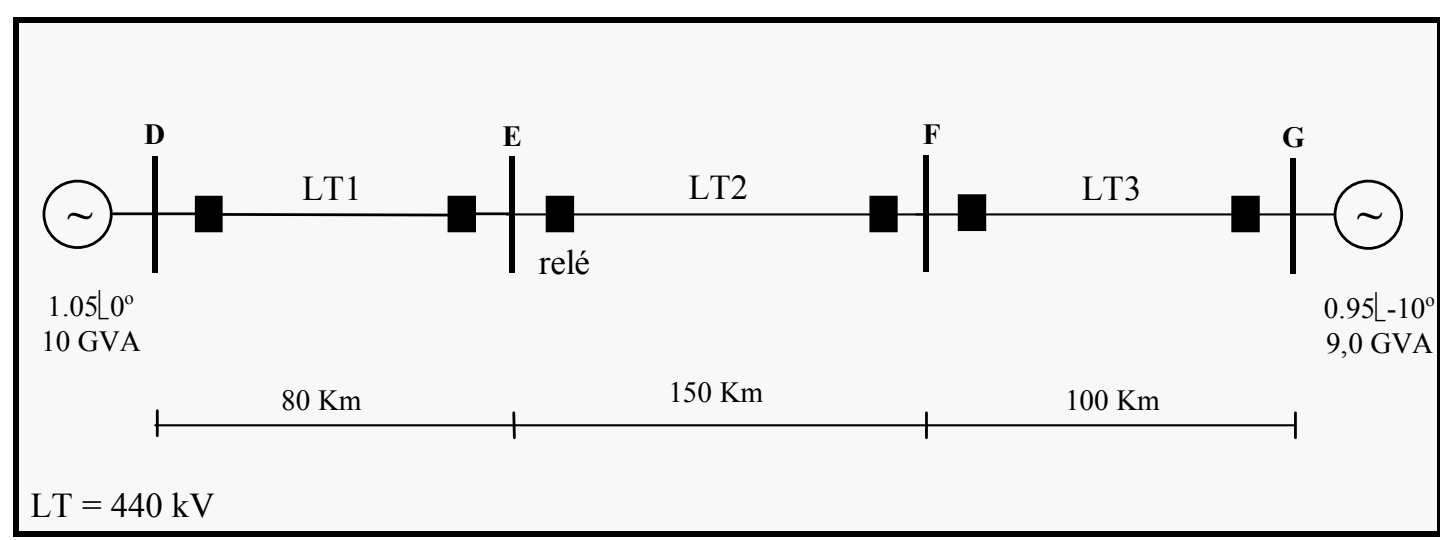

FIGURA 15 - Representação do sistema elétrico analisado 
Considerando-se os diferentes tipos de faltas que podem ocorrer sobre as linhas de transmissão, as simulações sobre o sistema apresentado foram geradas tomando-se as faltas entre:

- Algum condutor à terra (faltas fase-terra);

- Entre dois condutores à terra (faltas fase-fase-terra);

- Entre dois condutores (faltas fase-fase) ou

- Faltas trifásicas.

Tais situações de faltas foram implementadas no software ATP conforme as combinações apresentadas na Figura 16.

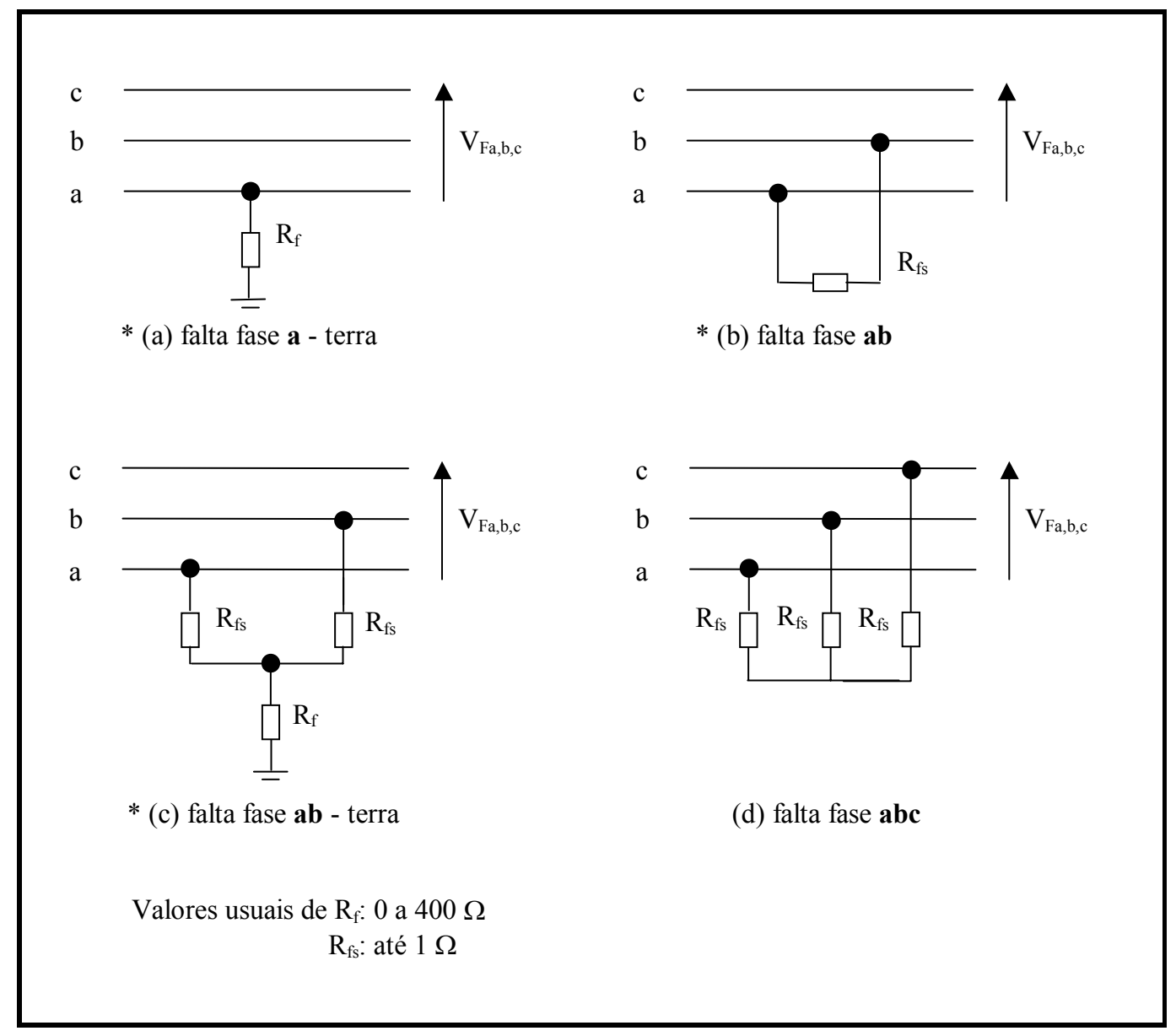

FIGURA 16 - Situações de faltas sobre o sistema

* Combinações obtidas da tese de doutorado "A practical approach to accurate fault location on extra high voltage teed feeders", Denis Vinicius Coury, Tese C858p Biblioteca Central da Escola de Engenharia de São Carlos - Figura B.5. 


\subsection{Modelagem da linha de transmissão}

A estrutura da linha de transmissão de $440 \mathrm{kV}$ (Figura 17) corresponde a uma linha típica da CESP (Companhia Energética de São Paulo), empregada entre as cidades de Araraquara - Bauru e Jupiá - Ilha Solteira. Apresentam-se, no que segue, as especificações referentes aos condutores, denotando-se as suas principais características, bem como a resistividade do solo considerada.

Condutor de fase: cabo Grosbeak

a) raio externo do condutor: $12,57 \mathrm{~mm}$;

b) raio interno do condutor: $4,635 \mathrm{~mm}$;

c) resistência em corrente contínua: $0,08998 \Omega / \mathrm{km}$.

Cabos Pára-raios: EHS 3/8"

a) raio externo do condutor: $4,572 \mathrm{~mm}$;

b) resistência em corrente contínua: $4,188 \Omega / \mathrm{km}$.

$\underline{\text { Resistividade do solo }}$

$\mathrm{R}_{\text {solo }}: 1000 \Omega . \mathrm{km}$

Flecha a meio vão

fase: $13,43 \mathrm{~m}$

pára-raios: $6,4 \mathrm{~m}$

\subsubsection{Parâmetros do sistema elétrico}

Para se efetuar as devidas simulações do sistema elétrico proposto, utilizando-se do software ATP, adotaram-se considerações necessárias para os cálculos dos parâmetros da linha de transmissão, considerando-se as características dos condutores e suas respectivas disposições geométricas nas torres de transmissão, como mostrado na Figura 17, que representa uma torre de transmissão de um circuito simples vertical tipo VVV. Dentre as considerações, optou-se por linhas transpostas, já que a transposição compensa os desequilíbrios dos campos magnéticos entre fases, cabo de cobertura, ferragens e solo sob a linha de transmissão. O resultado esperado da transposição, 
segundo (STEVENSON)[2], será a mesma indutância média para cada condutor. Uma observação prática nos diz que raramente as linhas são transpostas em intervalos regulares, sendo a transposição executada onde for fisicamente conveniente, como por exemplo, em subestações. A transposição de uma linha de transmissão qualquer é ilustrada na Figura 18.

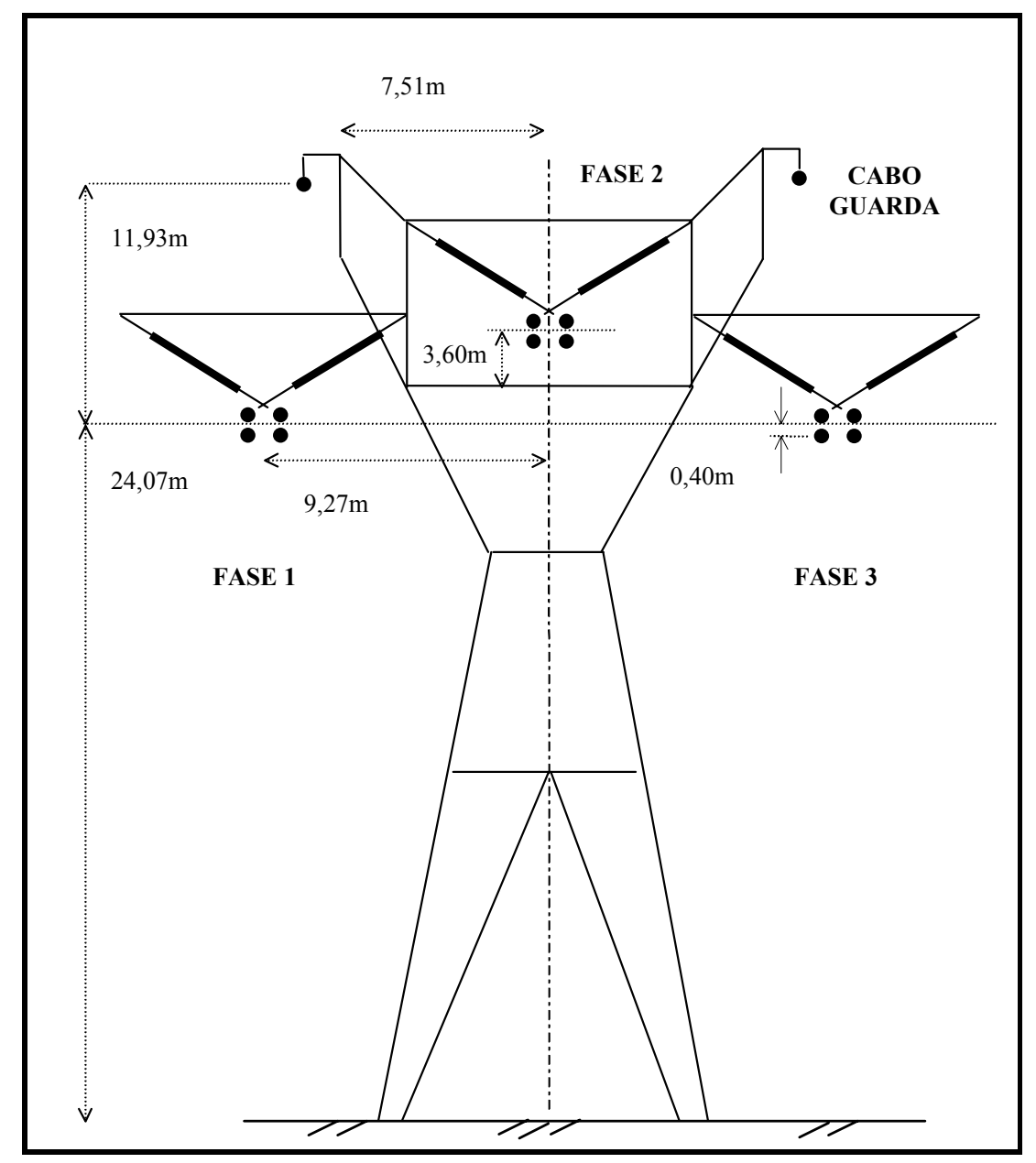

FIGURA 17 - Silhueta de torre da linha de $440 \mathrm{kV}$.

A linha de transmissão foi modelada com parâmetros distribuídos e constantes em relação à freqüência, utilizando-se para isso, a rotina Line Constants apresentada pelo software ATP, a qual será abordada posteriormente.

Para se obter uma solução exata para os parâmetros de qualquer linha de transmissão, bem como um alto grau de precisão, deve-se considerar o fato de que os parâmetros de uma linha não estão concentrados em um ponto, e sim, uniformemente distribuídos ao longo de todo o seu comprimento. Na Figura 19 mostra-se um esquema monofásico representando um pequeno trecho $(\Delta \mathrm{x})$ de uma linha de transmissão, sendo os parâmetros ( $\mathrm{R}, \mathrm{L}$ e $\mathrm{C})$, distribuídos e constantes, determinados pela rotina Line 
Constants do software ATP. Nesta, L é a indutância da linha por unidade de comprimento, $\mathbf{R}$ é a resistência por unidade de comprimento em corrente alternada e $\mathbf{C}$ é a capacitância da linha por unidade de comprimento.

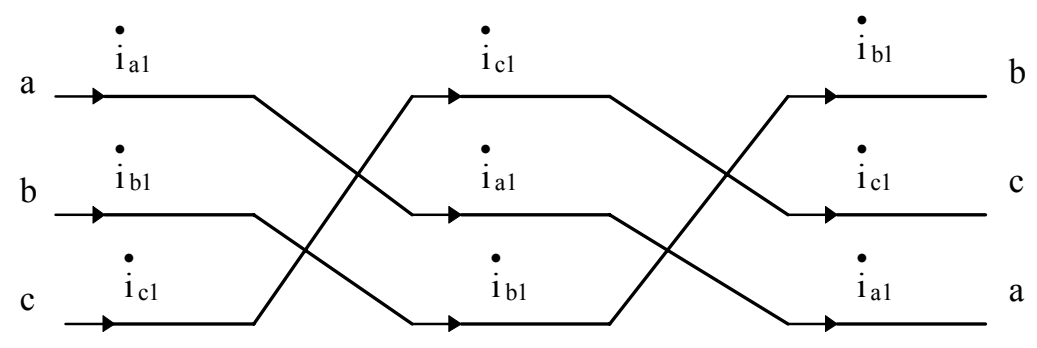

FIGURA 18 - Transposição de uma linha de transmissão

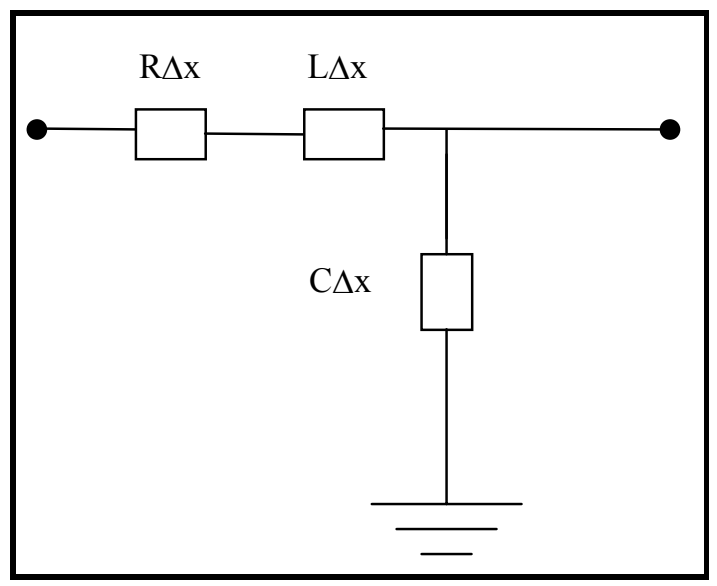

FIGURA 19 - Representação de um trecho de uma linha de transmissão por parâmetros distribuídos.

Uma observação importante a ser feita diz respeito a modelagem dos barramentos $\mathrm{E}$ e $\mathrm{F}$, pois os mesmo foram modelados como uma pequena linha de transmissão em circuito PI, sendo os seus parâmetros R, L e C obtidos também através da rotina Line-Constant.

\subsubsection{Rotina Line Constant e arquivo de entrada para o software ATP}

Após a caracterização da topologia das linhas de transmissão desejadas, passa-se ao início dos cálculos dos parâmetros das mesmas, através da rotina Line Constant, presente no software ATP, onde é considerado toda a topologia do sistema analisado, como: os espaçamentos e alturas relativas entre condutores, número de condutores por fase, resistividade do solo, freqüência em que os parâmetros foram calculados, 
condições da linha ( com ou sem transposição), etc. O arquivo de entrada da rotina Line Constant para o sistema apresentado anteriormente (linha de transmissão tipo simples horizontal - VVV) é dado na figura 20.

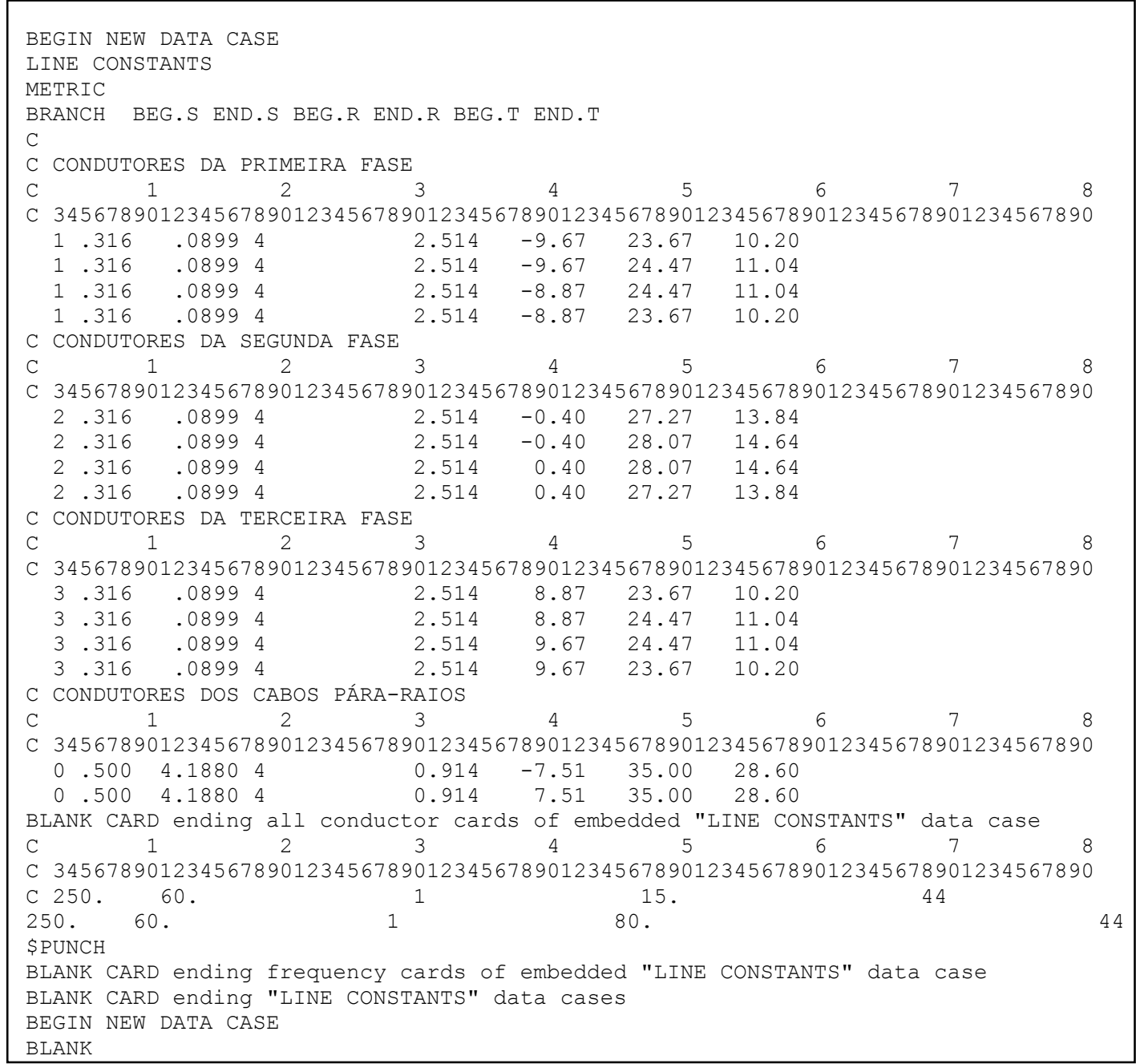

FIGURA 20 - Rotina Line Constant para o sistema simples vertical tipo VVV

Da execução da rotina Line Constant interessa-nos, dentre as inúmeras informações, os valores de seqüência zero e positiva das grandezas referentes à resistências, reatâncias e susceptâncias, considerando a linha de transmissão com transposição e as características dos barramentos E e F, os quais são mostrados na Tabela 2.

TABELA 2 - Parâmetros da linha de transmissão de $440 \mathrm{kV}$

\begin{tabular}{ccc|ccc}
\hline \multicolumn{3}{c|}{ Sequência Positiva } & \multicolumn{3}{c}{ Sequência Negativa } \\
$\mathbf{R}$ (ohms/km) & $\mathbf{L}$ (mH/km) & $\mathbf{C}(\mathbf{u F} / \mathbf{k m})$ & $\mathbf{R}(\mathrm{ohms} / \mathbf{k m})$ & $\mathbf{L}(\mathbf{m H} / \mathbf{k m})$ & $\mathbf{C}(\mathbf{u F} / \mathbf{k m})$ \\
\hline $3,853 \mathrm{E}-02$ & $7,410 \mathrm{E}-01$ & $1,570 \mathrm{E}-02$ & $1,861 \mathrm{E}+00$ & $2,230 \mathrm{E}+00$ & $9,034 \mathrm{E}-03$ \\
\hline
\end{tabular}


Nas Tabelas 3 e 4, são apresentados os parâmetros e dados de barra para os equivalentes nos terminais da linha de $440 \mathrm{kV}$ da CESP.

TABELA 3 - Parâmetros dos equivalentes de geração das barras $D e$ e

\begin{tabular}{lcc|cc}
\hline & \multicolumn{2}{c|}{ Gerador 1 - Barra D } & \multicolumn{2}{c}{ Gerador 2 - Barra G } \\
& Sequência Positiva & Sequência Negativa & Sequência Positiva & Sequência Negativa \\
\hline $\mathbf{R}(\mathbf{o h m s} / \mathbf{k m})$ & 1,6982 & 0,358 & 1,7876 & 0,4052 \\
\hline $\mathbf{L}(\mathbf{m H} / \mathbf{k m})$ & $5,14 \mathrm{E}+01$ & $1,12 \mathrm{E}+01$ & $5,41 \mathrm{E}+01$ & $1,23 \mathrm{E}+01$ \\
\hline
\end{tabular}

TABELA 4 - Dados das barras de geração De G

\begin{tabular}{lcc}
\hline & Gerador 1 - Barra D & Gerador 2 - Barra G \\
\hline Pot. (GVA) & 10 & 9 \\
\hline Tensão (pu) & 1,05 & 0,95 \\
\hline Ângulo (graus) & 0 & -10 \\
\hline
\end{tabular}

Com os resultados obtidos através da rotina Line Constant, considerando as linhas de transmissão com transposição e parâmetros distribuídos e os barramentos como pequenas linhas em circuito PI, elaborou-se um arquivo de entrada (Figura 21) a ser executado pelo software ATP, o qual descreve a situação em que se encontra o sistema elétrico. Neste arquivo de entrada, todas as conexões do sistema estão representadas, bem como as condições referentes ao tipo de falta aplicada (localização, resistência e ângulo de incidência da falta, fluxo de energia no sistema) e demais considerações adotadas.

Com respeito aos Transformadores de Corrente (TC) e Potencial (TP), não se considerou uma precisa modelagem dos mesmos. Para a atenuação das amplitudes dos sinais analisados, somente a relação de transformação dos TPs e TCs foi considerada, sem entrar em pormenores com relação ao seu efeito de saturação. 


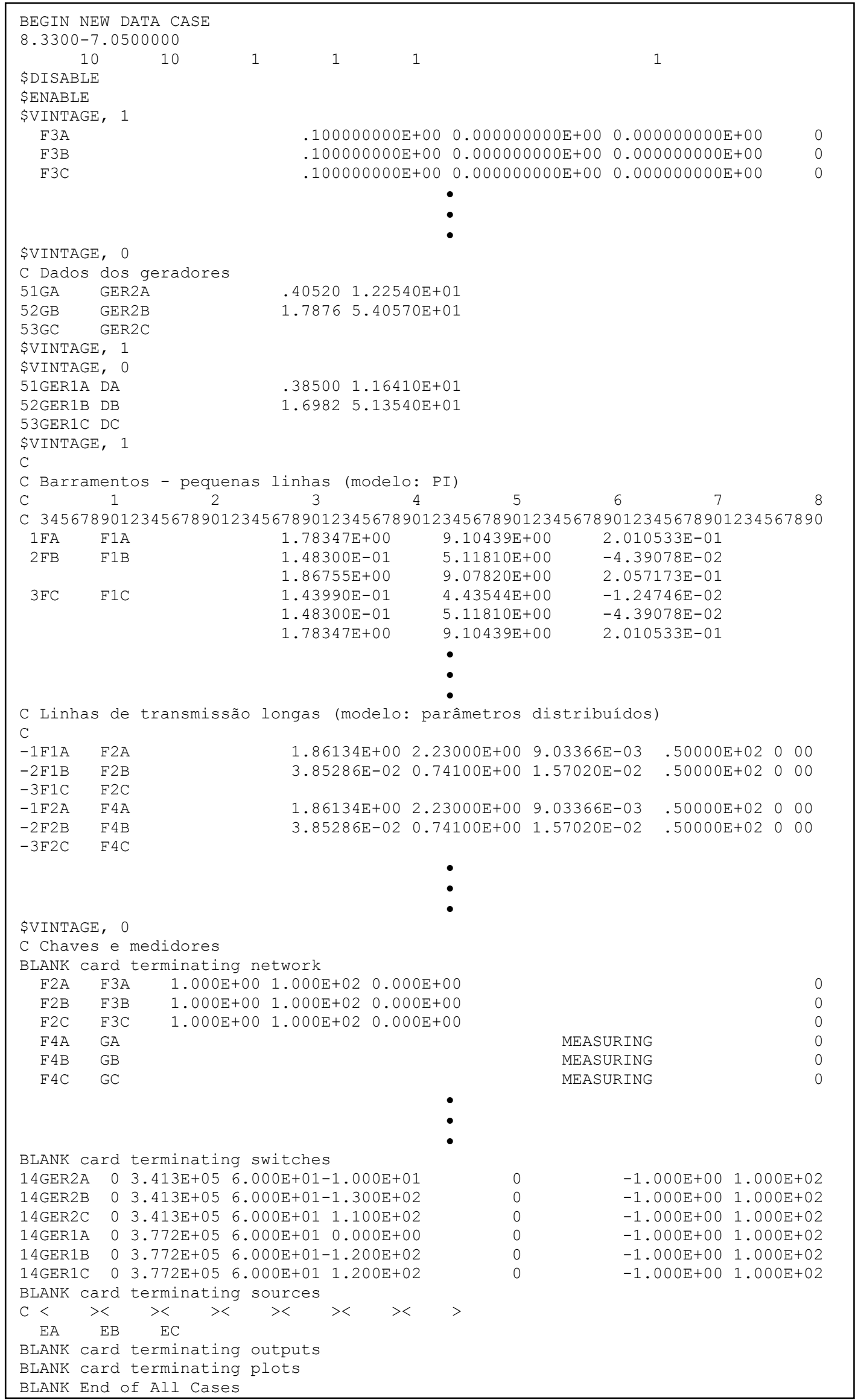

Figura 21 - Arquivo de entrada de dados do ATP para uma falta fase-terra 
Executando o arquivo da Figura 21, o qual refere-se a uma falta fase-terra com ângulo de incidência de $90^{\circ}$ aplicada a $40 \mathrm{~km}$ da barra $\mathrm{E}$ com relação a barra $\mathrm{F}$, obtemos as seguintes formas de ondas de tensão e corrente registrados na barra E (Figura 22 e 23), respectivamente.

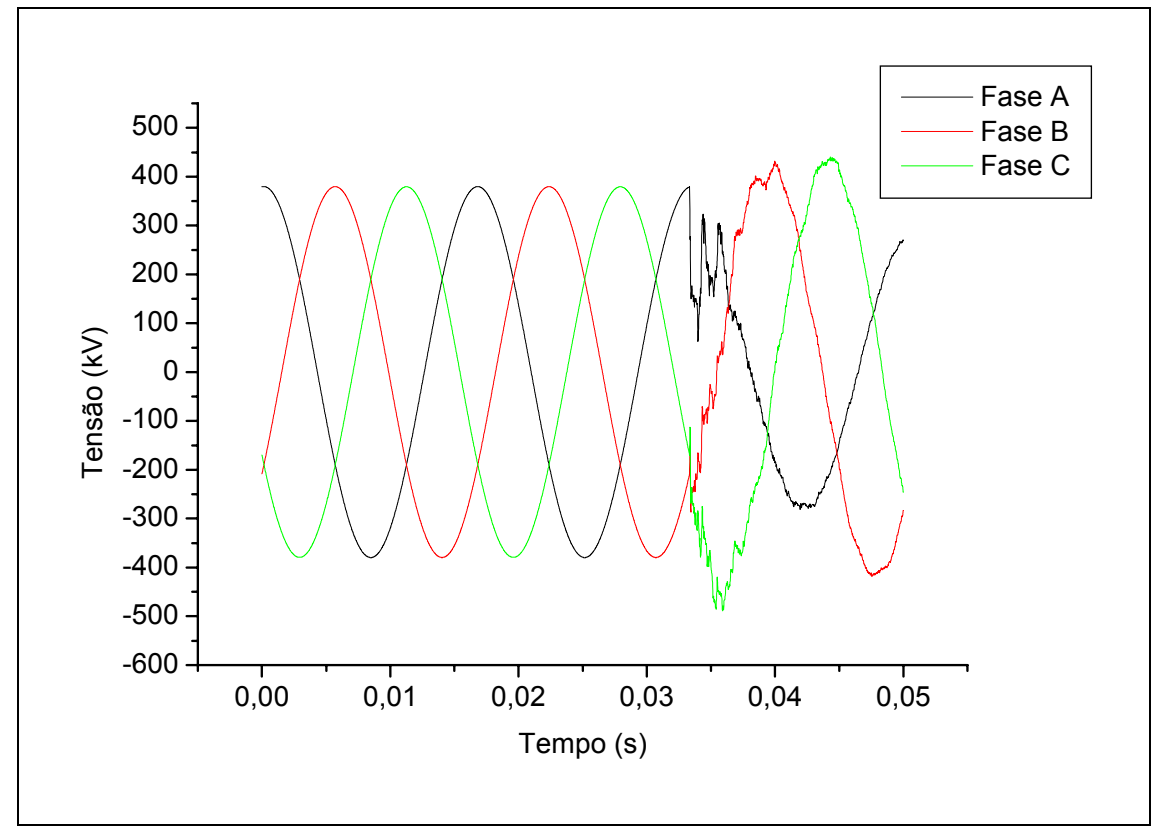

FIGURA 22 - Formas de onda de tensão para uma falta fase-terra aplicada a $40 \mathrm{~km}$ da barra $\mathrm{E}$

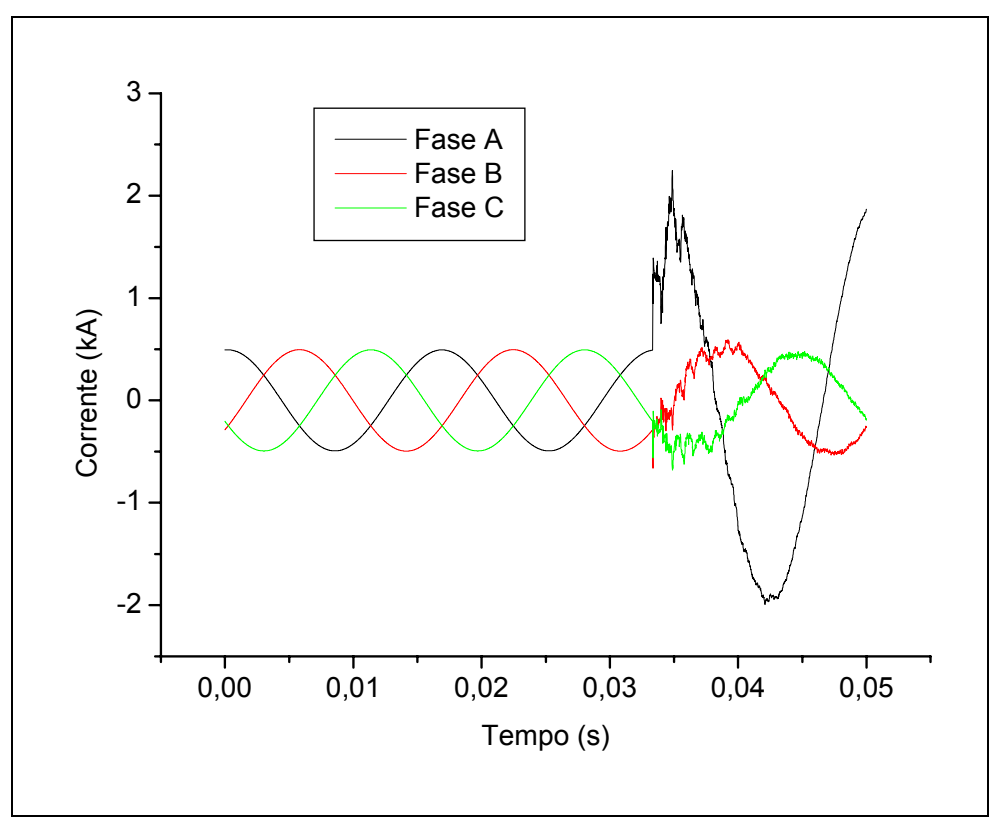

FIGURA 23 - Formas de onda de corrente para uma falta fase-terra aplicada a $40 \mathrm{~km}$ da barra E 


\subsection{Variações nas simulações das condições de faltas aplicadas ao circuito de transmissão simples horizontal}

Os dados dos sinais faltosos foram obtidos utilizando-se o software ATP Altenative Transients Program, levando-se em conta vários tipos de falta em diferentes localizações ao longo da linha entre os barramentos $\mathrm{E}$ e $\mathrm{F}$, com diferentes ângulos de incidência e resistências de falta. As variações consideradas são descritas a seguir:

a) tipos de faltas aplicadas:

- Fase-terra (A-terra, B-terra e C-terra);

- Fase-Fase-terra (AB-terra, AC-terra e BC-terra);

- $\quad$ Fase-Fase (AB, AC e BC);

- Trifásica $(\mathrm{ABC})$.

b) distâncias em que as faltas foram aplicadas entre os barramentos E e F:

- $10,25,40,55,70,75,80,95,110,125$ e $140 \mathrm{~km}$ (referência barramento E).

c) ângulo de incidência de falta:

- 0 e 90 graus.

d) Resistências de faltas consideradas:

- $0,50,100,200$ e 400 ohms

Como resposta da simulação de cada situação de falta no software ATP, obtêmse os valores de tensão e corrente trifásicos amostrados em relação aos barramentos $\mathrm{E}$ e F. O arquivo de dados descrevendo cada situação de falta é apresentado pelo software a um intervalo de amostragem de $8,33 \mu$ s, o que corresponde a uma freqüência amostral de $120 \mathrm{kHz}$, freqüência esta estabelecida pelo usuário de acordo com suas necessidades.

No desenvolvimento do trabalho, também foi analisada a influência da freqüência de amostragem, assim como, a influência do acoplamento mútuo quando da utilização de um circuito de transmissão duplo. Dados referentes ao circuito duplo utilizado são descritos no próximo item.

Os dados dos sinais faltosos obtidos através das simulações não requerem a aplicação de técnicas de filtragem, seja ela analógica ou digital, uma vez que os algoritmos de localização de faltas a serem propostos são baseados em componentes de alta freqüência. 


\subsection{Modelagem e dados referentes ao circuito duplo vertical}

Como comentado anteriormente, no desenvolvimento da pesquisa foram realizados testes em outro tipo de linha, mais precisamente em uma linha de transmissão de $440 \mathrm{kV}$ com circuito duplo vertical. Tais testes buscam validar a aplicabilidade do algoritmo em diferentes linhas de transmissão, levando-se em conta os diferentes efeitos produzidos por cada tipo de linha em específico.

Estes testes também seguiram os procedimentos descritos anteriormente para o caso de uma linha de transmissão com circuito simples horizontal VVV. O modelo do sistema proposto para estes testes, assim como a silhueta da torre de transmissão utilizada, podem ser observadas através das Figuras 24 e 25, respectivamente.

Através da modelagem e simulações do sistema de transmissão duplo vertical em condição faltosa, feitas também através do software ATP, objetivou-se analisar os seguintes pontos: a influência do acoplamento mútuo entre as fases de ambos os circuitos e o comportamento do algoritmo frente as faltas fora da sua área de cobertura.

Foram realizados testes variando-se a localização da falta no circuito 1 e 2 , o tipo da falta, ângulo de incidência da falta, a resistência de falta e a maneira de obtenção dos dados em um ou em ambos terminais da linha coberta pelo localizador.

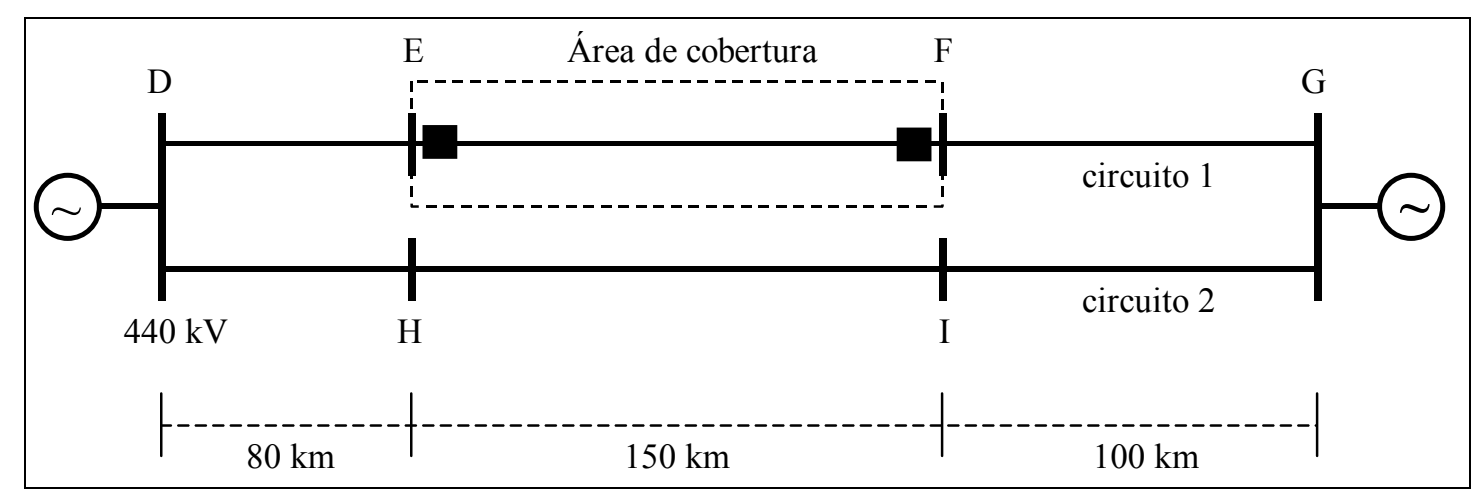

FIGURA 24 - Configuração do sistema com circuito duplo vertical

A Figura 25 traz as disposições geométricas entre os cabos (fase e pára-raios) e o afastamento em relação ao solo. As alturas médias são indicadas entre parênteses e o espaçamento entre os condutores de uma mesma fase é de $0,4 \mathrm{~m}$. 


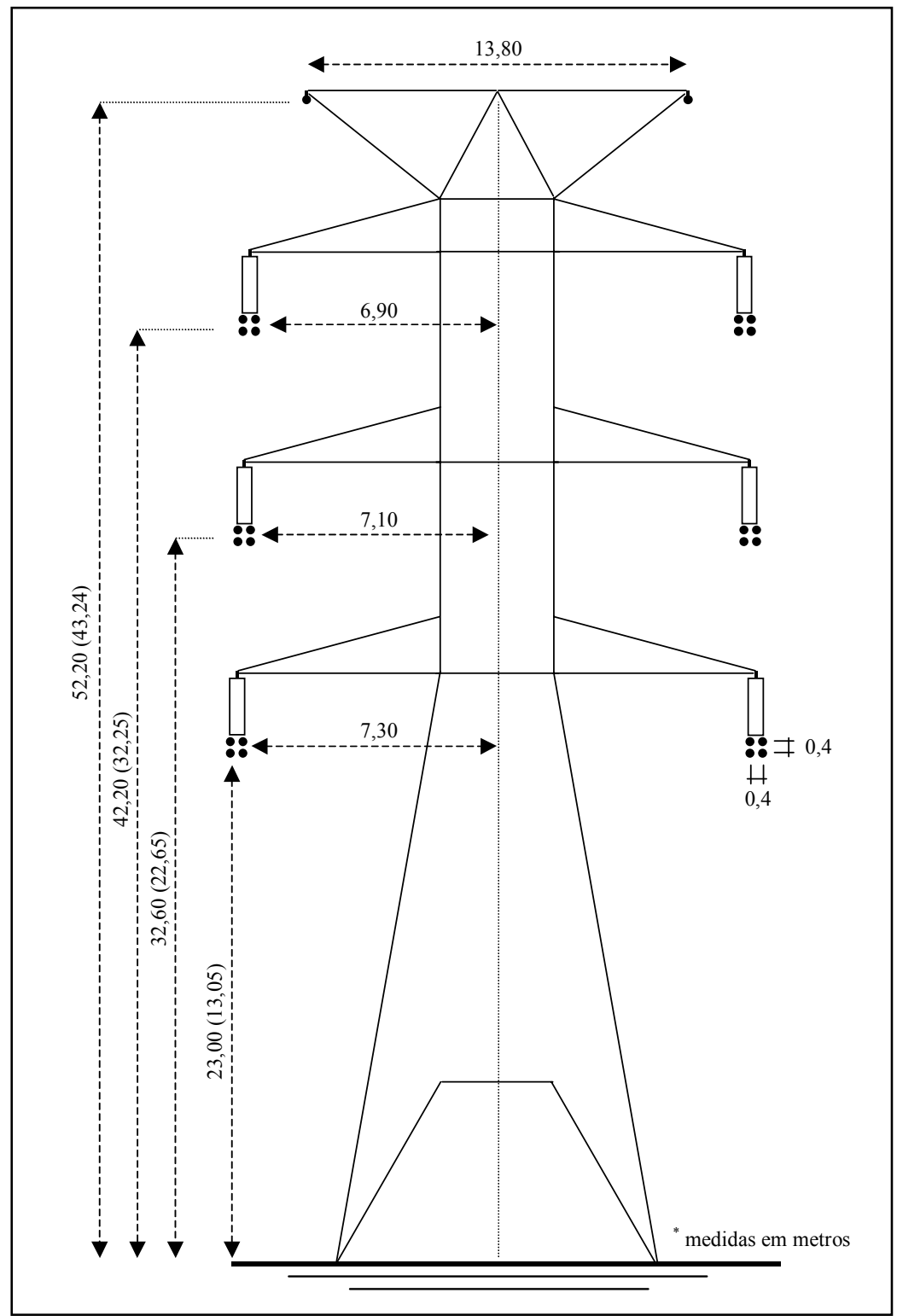

FIGURA 25 - Silhueta da torre de um circuito de transmissão duplo vertical de $440 \mathrm{kV}$.

As especificações referentes aos condutores, denotando-se as suas principais características, bem como a resistividade do solo considerada, são as mesmas do circuito simples vertical, as quais foram apresentadas na seção 4.2. Em se tratando dos dados referentes ao sistema com circuito duplo, estes são apresentados nas Tabelas 5, 6 e 7.

TABELA 5 - Parâmetros de seqüência da linha de transmissão para o circuito duplo

\begin{tabular}{ccc|ccc}
\hline \multicolumn{3}{c|}{ Sequência Positiva } & \multicolumn{3}{c}{ Sequência Negativa } \\
$\mathbf{R}(\mathbf{o h m s} / \mathbf{k m})$ & $\mathbf{L}(\mathbf{m H} / \mathbf{k m})$ & $\mathbf{C}(\mathbf{u F} / \mathbf{k m})$ & $\mathbf{R}(\mathbf{o h m s} / \mathbf{k m})$ & $\mathbf{L}(\mathbf{m H} / \mathbf{k m})$ & $\mathbf{C}(\mathbf{u F} / \mathbf{k m})$ \\
\hline $1,178 \mathrm{E}-02$ & $4,531 \mathrm{E}-01$ & $2,629 \mathrm{E}-02$ & $2,916 \mathrm{E}-01$ & $2,946 \mathrm{E}+00$ & $1,092 \mathrm{E}-02$ \\
\hline
\end{tabular}


TABELA 6 - Parâmetros dos equivalentes de geração das barras $D$ e $G$

\begin{tabular}{lcc|cc}
\hline & \multicolumn{2}{c|}{ Gerador 1 - Barra D } & \multicolumn{2}{c}{ Gerador 2 - Barra G } \\
& Seq. Positiva & Seq. Negativa & Seq. Positiva & Seq. Negativa \\
\hline $\mathbf{R}(\mathbf{o h m s} / \mathbf{k m})$ & 1,6982 & 0,358 & 1,7876 & 0,4052 \\
\hline $\mathbf{L}(\mathbf{m H} / \mathbf{k m})$ & $5,14 \mathrm{E}+01$ & $1,12 \mathrm{E}+01$ & $5,41 \mathrm{E}+01$ & $1,23 \mathrm{E}+01$ \\
\hline
\end{tabular}

TABELA 7 - Dados de barra referentes ao circuito duplo

\begin{tabular}{lcc}
\hline & Gerador 1 - Barra D & Gerador 2 - Barra G \\
\hline Pot. (GVA) & 10 & 9 \\
\hline Tensão (pu) & 1,05 & 0,95 \\
\hline Ângulo (graus) & 0 & -10 \\
\hline
\end{tabular}

A seguir são ilustrados através das Figuras 24 e 25 partes do arquivo de entrada da rotina Line Constant, assim como partes de um arquivo de entrada do ATP referente a uma condição de falta fase-fase aplicada a $80 \mathrm{~km}$ da barra $\mathrm{E}$ do circuito 1, respectivamente

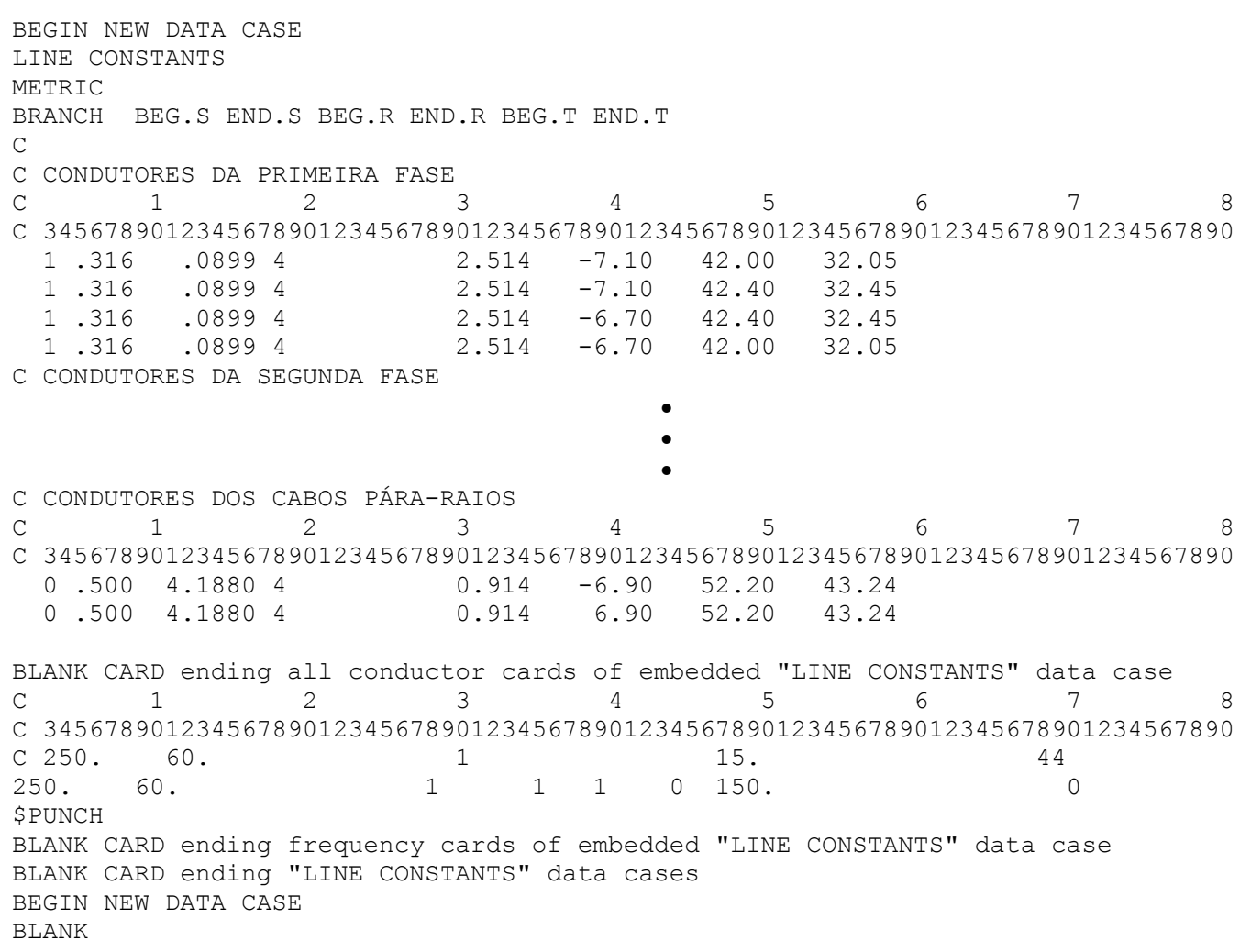

FIGURA 26-Arquivo de entrada para a rotina Line Constant referente ao circuito duplo 


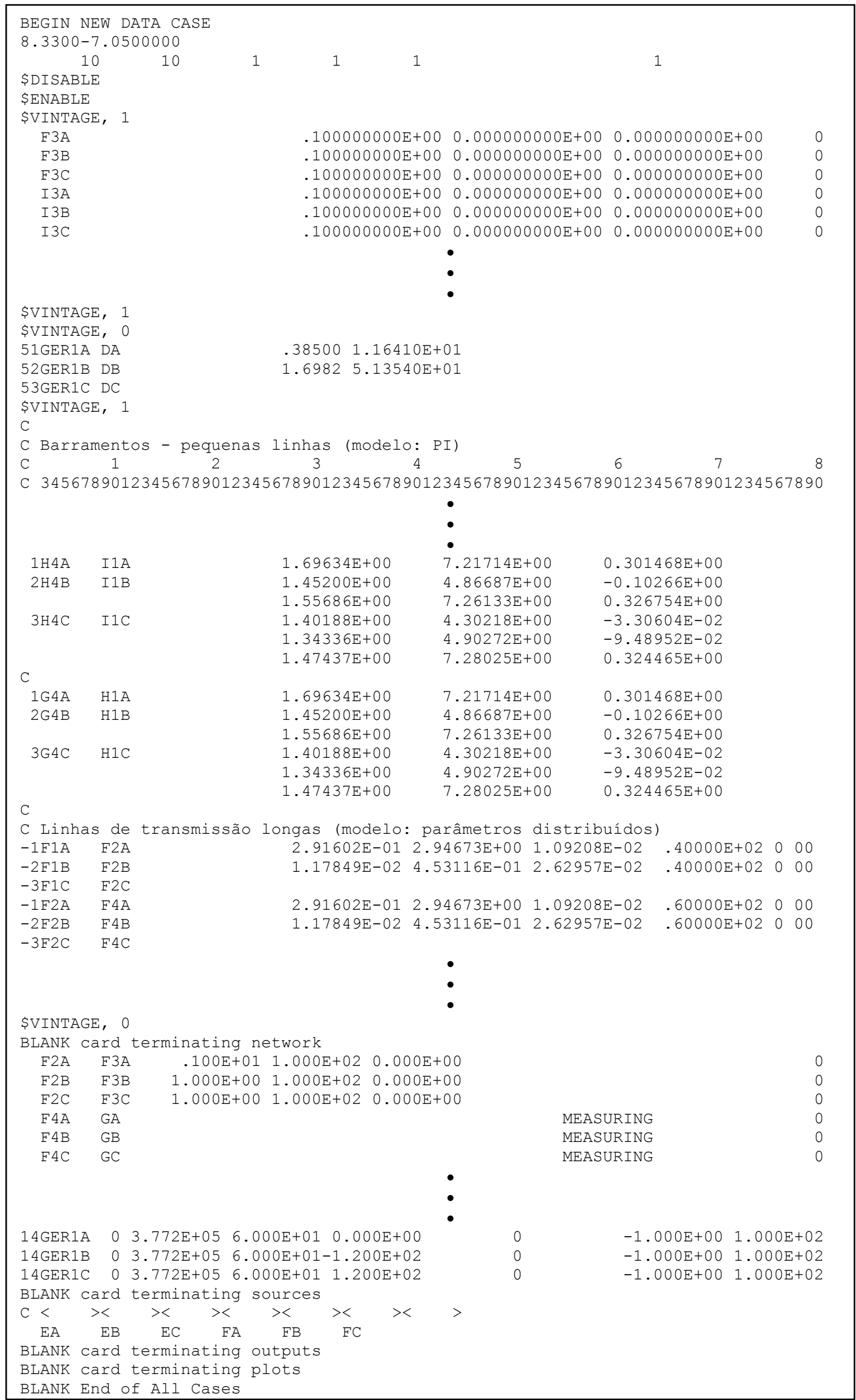

FIGURA 27 - Arquivo de entrada do ATP para uma falta fase-fase no circuito 1 
Uma vez gerado os arquivos de dados de entrada para o ATP conforme a situação de falta desejada, podemos obter os valores amostrados de tensão e corrente medidos no terminal local, remoto ou em ambos. Por exemplo, apresentando o arquivo de entrada ilustrado na Figura 27, o qual refere-se a uma falta fase-fase aplicada a 80 $\mathrm{km}$ da barra $\mathrm{E}$ do circuito 1, obtemos as seguintes formas de ondas de tensão e correntes (Figuras 28 e 29) registradas na Barra E:

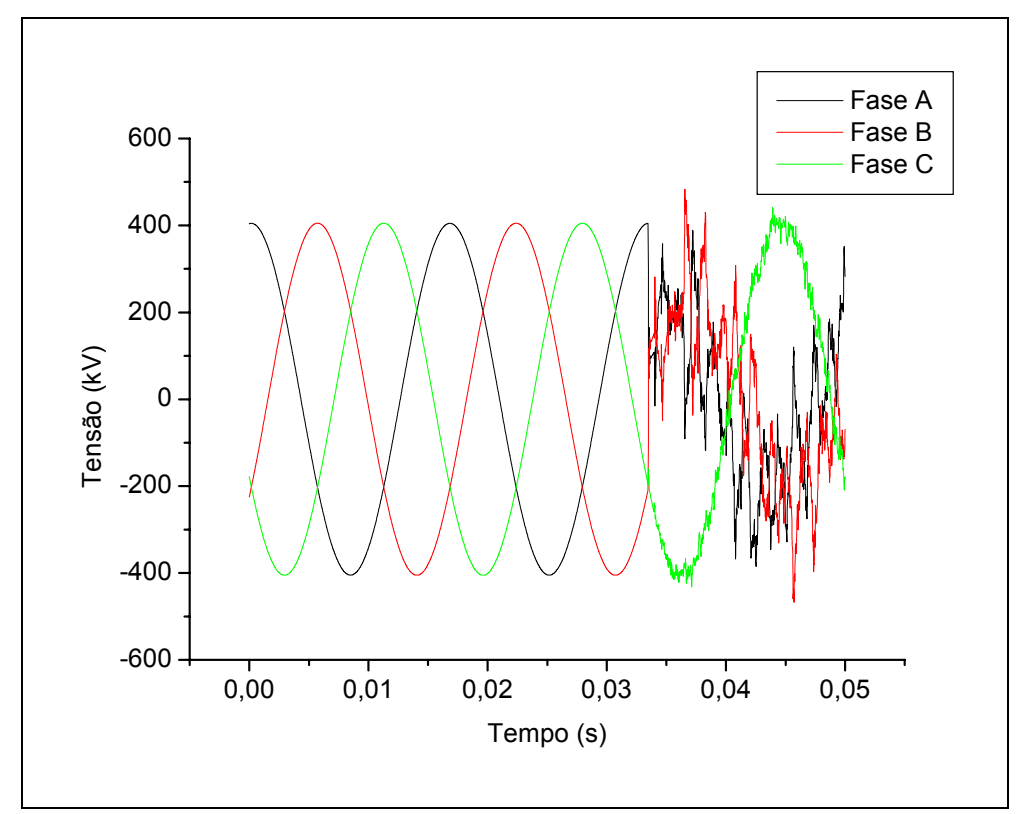

FIGURA 28 - Formas de ondas de tensão para uma falta fase-fase na linha E-F do circuito 1

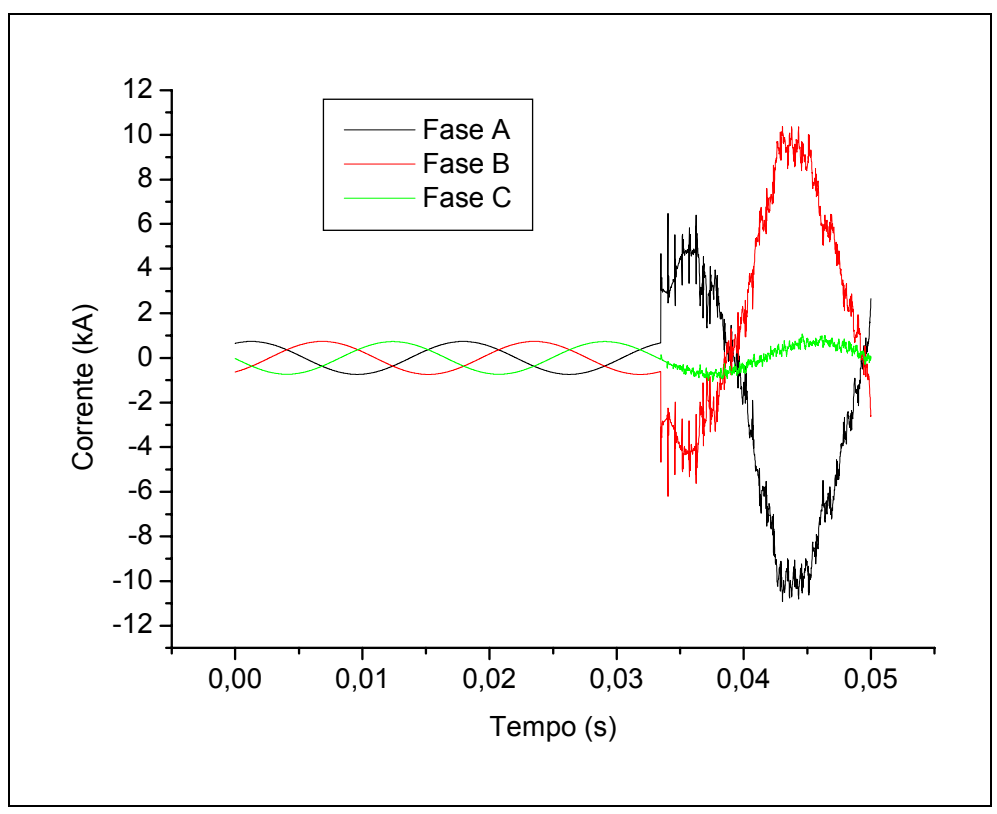

FIGURA 29 - Formas de ondas de corrente para uma falta fase-fase na linha E-F do circuito 1 


\subsubsection{Variações nas simulações das condições de faltas aplicadas ao circuito de transmissão duplo}

Seguindo a analogia aplicada à linha com circuito simples, os dados dos sinais faltosos referentes ao circuito duplo também foram obtidos utilizando-se o software ATP - Altenative Transients Program, levando-se em conta vários tipos de falta em diferentes localizações ao longo das linhas de ambos os circuitos, com diferentes ângulos de incidência e resistências de falta. As variações consideradas são descritas a seguir:

e) tipos de faltas aplicadas:

- Fase A-terra;

- Fase-Fase-terra (fases A e B para terra);

- Fase-Fase (fases A e B);

- Trifásica (fases A, B e C).

f) distâncias em que as faltas foram aplicadas:

\section{Circuito 1:}

- Entre os barramentos E e F:

$\checkmark 10,25,40,55,70,75,80,95,110,125$ e $140 \mathrm{~km}$ (referência barra E).

- Entre os barramentos D e E:

$\checkmark \quad 15,40$ e $50 \mathrm{~km}$ (referência barra D).

- Entre os barramentos F e G:

$\checkmark 10,50$ e $80 \mathrm{~km}$ (referência barra F).

\section{Circuito 2:}

- Entre os barramentos D e H:

$\checkmark \quad 15,40$ e $50 \mathrm{~km}$ (referência barra D).

- Entre os barramentos H e I:

$\checkmark 20,80$ e $130 \mathrm{~km}$ (referência barra $\mathrm{H}$ ).

- Entre os barramentos I e G:

$\checkmark 10,50$ e $80 \mathrm{~km}$ (referência barra I).

g) ângulo de incidência de falta:

- 0 e 90 graus.

h) Resistências de faltas consideradas:

- 0,50 e 100 ohms 
A freqüência de amostragem do sinal utilizada nestes testes foi de $120 \mathrm{kHz}$. 


\section{LOCALIZAÇÃO DE FALTAS UTILIZANDO A TRANSFORMADA WAVELET - ABORDAGEM TEÓRICA}

Nesta seção será abordado o problema da localização de faltas em linhas de transmissão fundamentado na teoria de ondas viajantes e da Transformada Wavelet, seguido da descrição das técnicas de localização de faltas que constituem o algoritmo desenvolvido.

\subsection{Princípio básico do método de localização de faltas}

Inicialmente para um melhor entendimento, vamos considerar uma LT monofásica de comprimento $\underline{l}$, conectada entre as barras A e B, com uma impedância característica $\mathrm{Z}_{\mathrm{c}}$ e velocidade de propagação $v$, como ilustrado na Figura 30 juntamente com o diagrama Lattice, para posteriormente abordarmos um sistema trifásico.

Na ocorrência de uma falta a uma distância $d$ da barra A, baseado na teoria de ondas viajantes (BEWLEY, 1963)[30], esta aparecerá como uma abrupta injeção de corrente e tensão no ponto de falta. Esta injeção viajará como uma onda sobreposta ao sinal fundamental do sistema ao longo da linha em ambas as direções, a partir do ponto de ocorrência da falta. Ao encontrar uma descontinuidade, essas ondas se refletem e retornam ao ponto de falta onde haverá novas reflexões e assim sucessivamente até ser alcançado o estado permanente de falta. Os transitórios de falta registrados nos terminais da linha conterão abruptas mudanças em intervalos comensurados com o tempo de excursão dos sinais entre o ponto de falta e os terminais. Determinando-se o intervalo de tempo dos sinais entre o ponto de falta e o terminal de referência e, usando a velocidade de propagação (v) das ondas, a qual é função dos parâmetros da linha em questão, a distância da falta pode ser facilmente estimada. Diferente do método de correlação, onde as ondas viajantes são computadas e usadas para correlação cruzada, 
na aplicação wavelet, o sinal decomposto (tensão ou corrente) é diretamente analisado e as reflexões determinadas através de limiares apropriados.

O algoritmo de localização utiliza componentes de alta freqüência gerados por uma situação de falta, não necessitando de técnicas de filtragem. As técnicas também utilizam componentes modais de tensão, ao invés dos valores totais (de fase), os quais são decompostos em dois níveis pela análise multiresolução wavelet.

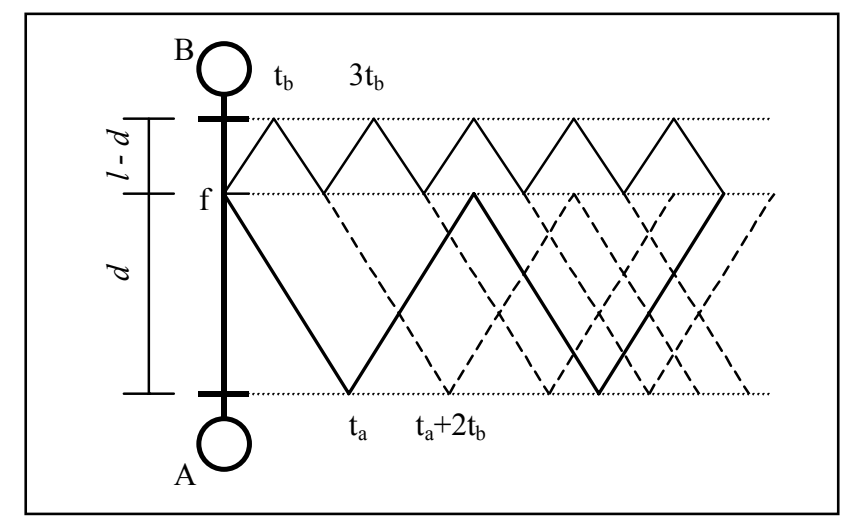

FIGURA 30 - Sistema Elétrico e diagrama Lattice

\subsection{O Algoritmo Localizador de Faltas}

Neste item é descrito o algoritmo de localização de faltas baseado em componentes de alta freqüência gerados por uma situação de falta. Como já foi mencionado anteriormente, o algoritmo é fundamentado na determinação do tempo de viagem das ondas de tensão do ponto de falta aos terminais da linha. Para se determinar os instantes de viagem das ondas é utilizado a Transformada Wavelet, aplicando-se a análise multiresolução wavelet (AMR) com dois níveis de decomposição. Uma vez determinado os intervalos de reflexão das ondas, a distância da falta pode ser estimada em função destes intervalos e da velocidade de propagação da onda na linha em questão.

O algoritmo a ser descrito foi desenvolvido de maneira que o usuário possa escolher a técnica de localização (dados de um ou dois terminais) a ser utilizada.

A Figura 31 exibe o fluxograma do algoritmo localizador de faltas, o qual envolve diferentes estágios. O primeiro estágio é a obtenção dos dados digitalizados de tensão e corrente registrados em um terminal ou se for o caso em dois terminais, através de registradores digitais de faltas de alta freqüência. Cabe ressaltar que, no caso da 
utilização de dados provenientes de dois terminais é necessária a sincronização destes dados, assim como um meio de comunicação para transmissão dos dados do terminal remoto para o terminal local, onde será feito o processamento para localizar a falta.

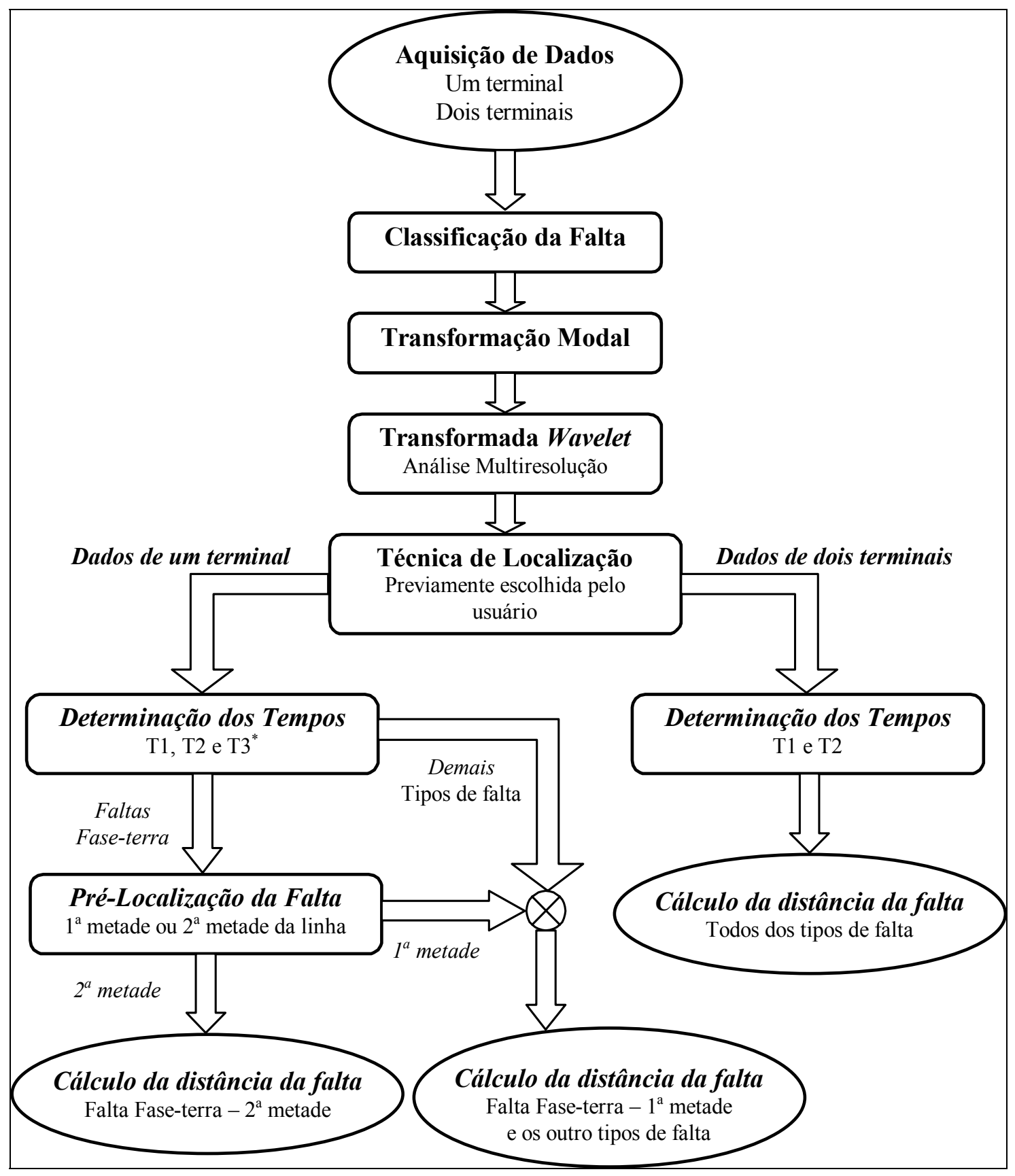

FIGURA 31 - Fluxograma do algoritmo de localização de faltas

Como pode ser observado na Figura 31, as etapas que compõem o algoritmo para determinação da posição da falta são as seguintes: aquisição dos dados, classificação da falta, transformação modal, Transformada Wavelet, técnica de 
localização a ser utilizada (dados provenientes de um terminal ou de dois terminais), determinação dos tempos de reflexão e, por último, o cálculo da distância da falta. No caso da utilização da técnica de localização com dados provenientes de um terminal, é acrescentada mais uma etapa ao algoritmo, denominada de pré-localização da falta. Essas etapas ou estágios serão descritos detalhadamente a seguir:

\subsubsection{Aquisição dos dados}

Como descrito anteriormente, os dados podem ser obtidos através de registradores digitais de sinais de alta freqüência posicionados no terminal local ou em ambos os terminais, local e remoto. Contudo, utilizando-se a técnica de localização com dados registrados em ambos os terminais, torna-se necessário que haja um meio de comunicação entre os terminais para transferência dos dados, bem como um método para sincronização das medições nos mesmos.

Para resolver o problema de sincronização de dados, temos como proposta a utilização do GPS (Global Positioning Satellite) como apresentado em (KIM et al., 2001; ZHAO et al, 2001; )[50 e 70], no qual um sinal de referência de tempo, transmitido via satélite, fica disponível nos diversos pontos de uma rede elétrica, permitindo que os sinais sejam sincronizados considerando qualquer esquema de comunicação de dados entre os terminais da linha. Em cada terminal, para cada amostra dos sinais, poderá ser armazenado o tempo real em que ela foi obtida, utilizando a referência de tempo obtida do GPS, de forma que um atraso na chegada dos dados do terminal remoto ao terminal local, poderá ser corrigido verificando-se os instantes em que as amostras foram obtidas. Segundo a literatura sobre o uso de GPS, este pode introduzir um erro máximo de $1 \mu \mathrm{s}$, o que corresponderia a aproximadamente a apenas 300 metros de imprecisão na localização da falta.

Quanto ao meio de comunicação para transferência dos dados entre os dois terminais, pode-se empregar um meio que não exija tanta velocidade e canais de comunicação contínuos, uma vez que o nosso localizador opera off-line. A comunicação dos dados pode ser feita via rádio, satélite, modem ou microondas. Outro meio de transmissão de dados que vem sendo utilizado atualmente é por meio de fibra óptica no interior dos cabos guarda (URUSAWA et al., 1989)[71], conhecido como OPGW (do inglês, fiber optic overhead ground wire), que garantem alta velocidade de transmissão e imunidade à interferências eletromagnéticas. 
Os dados obtidos via simulações, não precisam ser filtrados, uma vez que o método é baseado em componentes de alta freqüência. Segundo a literatura, a precisão do algoritmo está relacionada a taxa de amostragem utilizada, sendo usada na maioria dos trabalhos consultados, taxas que variam de $100 \mathrm{kHz}$ à dezenas de megahertz $(\mathrm{MHz})$. A freqüência de amostragem utilizada neste trabalho foi de $120 \mathrm{kHz}$. Foram realizados também testes com outras taxas de amostragem, com o intuito de se verificar a influência desta na precisão do algoritmo.

\subsubsection{Classificação da falta}

Em se tratando da técnica que utiliza dados registrados localmente, a identificação do tipo de falta ocorrido na linha de transmissão é indispensável, pois nesta técnica o equacionamento básico para obtenção da distância da falta é diferenciado conforme o tipo da falta (fase-terra ou outro tipo de falta), devido a certas peculiaridades pertinentes a esta técnica, as quais serão esclarecidas posteriormente. No método que utiliza dados de dois terminais o algoritmo de classificação de faltas pode ser incorporado como um dispositivo opcional, uma vez que este facilita a restauração e manutenção da linha, pela identificação do tipo de falta e das fases envolvidas.

O método de classificação da falta aplicado nesta pesquisa é baseado em uma comparação entre os fasores de corrente superpostos e de seqüência zero fundamental $\left(I_{a}^{\prime \prime}, I_{b}^{\prime \prime}, I_{c}^{\prime \prime}\right.$ e $\left.I_{0}^{\prime \prime}\right)$ registrados em um terminal de referência, conforme apresentado por COURY (1987)[1]. A Figura 32, ilustra a rotina de classificação da falta implementado neste trabalho.

O parâmetro $K$ é a razão entre as correntes de fase sã e faltosa. Este parâmetro depende da configuração da falta e pode ser determinado empiricamente. Neste estudo $K$ equivale a 0,5 .

Na prática é necessário também aplicar um pequeno limiar $I_{\min }$ para as medidas, devido à existência de linhas não balanceadas, transdutores, etc. Neste trabalho é considerado um $I_{\min }=0,02$, valor este também determinado empiricamente.

Os valores dos fasores de $I_{a}^{\prime \prime}, I_{b}^{\prime \prime}, I_{c}^{\prime \prime}$ e $I_{0}^{\prime \prime}$ são normalizados para a fase que possui o maior valor. Considera-se que os fasores de corrente inferiores a 0,3 são não faltosos e os fasores de valor superior a 0,6 são faltosos. A existência ou não do componente de seqüência zero, indica se a falta envolve terra. Os testes demonstram que a sub-rotina de 
classificação foi capaz de classificar corretamente os tipos de faltas para todos os testes analisados neste trabalho.

\begin{tabular}{|c|c|}
\hline SE & FALTA TIPO \\
\hline$I_{b}^{\prime \prime}<K I_{a}^{\prime \prime} \quad e \quad I_{c}^{\prime \prime}<K I_{a}^{\prime \prime}$ & Falta A-terra \\
\hline$I_{a}^{\prime \prime}<K I_{b}^{\prime \prime} \quad e \quad I_{c}^{\prime \prime}<K I_{b}^{\prime \prime}$ & Falta B-terra \\
\hline$I_{a}^{\prime \prime}<K I_{c}^{\prime \prime} \quad e \quad I_{b}^{\prime \prime}<K I_{c}^{\prime \prime}$ & Falta C-terra \\
\hline$I_{c}^{\prime \prime}<K I_{a}^{\prime \prime} \quad e \quad I_{b}^{\prime \prime} \cong I_{a} \quad e$ & \\
\hline$I_{0}^{\prime \prime}>I_{\min }$ & Falta AB-terra \\
\hline caso contrário & Falta AB \\
\hline$I_{a}^{\prime \prime}<K I_{b}^{\prime \prime} \quad e \quad I_{c}^{\prime \prime} \cong I_{b} \quad e$ & \\
\hline$I_{0}^{\prime \prime}>I_{\min }$ & Falta BC-terra \\
\hline caso contrário & Falta BC \\
\hline$I_{b}^{\prime \prime}<K I_{a}^{\prime \prime} \quad e \quad I_{a}^{\prime \prime} \cong I_{c} \quad e$ & \\
\hline$I_{0}^{\prime \prime}>I_{\min }$ & Falta AC-terra \\
\hline caso contrário & Falta AC \\
\hline$I_{a}^{\prime \prime} \cong I_{b}^{\prime \prime} \cong I_{c}^{\prime \prime}$ & Fase ABC \\
\hline
\end{tabular}

FIGURA 32 - Sub-rotina para classificação do tipo da falta

No que segue, Figura 33, são apresentados alguns resultados da técnica de classificação de falta para diferentes tipos de faltas aplicadas a uma distância de $55 \mathrm{~km}$ do barramento E na linha E-F com ângulo de incidência de $0^{\circ}$, para a configuração da linha em circuito simples horizontal. 


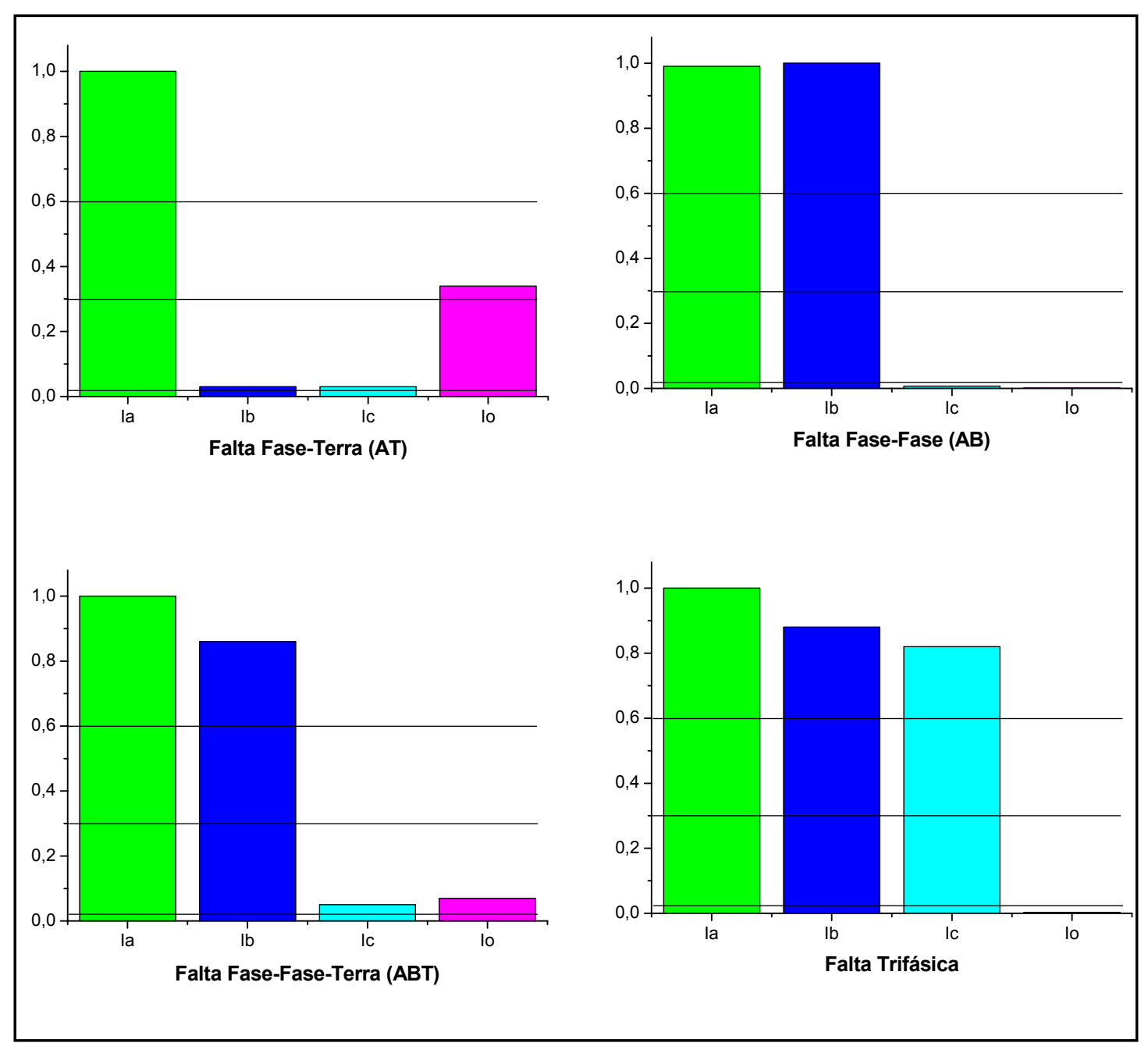

FIGURA 33 - Classificação dos diversos tipos de faltas

\subsubsection{Transformação modal}

Em linhas de transmissão trifásicas, as fases são mutuamente acopladas e, por conseguinte, as perturbações de alta freqüência geradas durante uma falta podem também aparecer nas fases não faltosas. Portanto, para implementar o método das ondas viajantes em sistemas trifásicos, os sinais no domínio do tempo são primeiramente decompostos em seus componentes modais.

A transformação modal permite que o sistema trifásico seja tratado como um sistema com três circuitos monofásicos independentes. Os valores de fase são transformados em três modos desacoplados: um modo terra (modo 0) e dois modos aéreos (modo $\alpha$ e modo $\beta$ ), também conhecidos como modo aéreo 1 e modo aéreo 2 . $\mathrm{O}$ modo zero apresenta impedância característica e velocidade de propagação distinta em relação aos modos aéreos. 
Uma vez que, na modelagem do sistema, as linhas de transmissão são totalmente transpostas, podem ser utilizadas as bem conhecidas transformações modais de Clarke ou de Wedepohl. Neste trabalho foi utilizada a matriz de transformação de CLARKE (1943)[72] dada por:

$$
T=\frac{1}{3} \cdot\left[\begin{array}{ccc}
1 & 1 & 1 \\
2 & -1 & -1 \\
0 & \sqrt{3} & -\sqrt{3}
\end{array}\right]
$$

Os sinais de fase (tensão e/ou corrente) são transformados em seus componentes modais pelo uso da matriz de transformação como segue:

$$
\left[\begin{array}{c}
V_{0} \\
V_{\alpha} \\
V_{\beta}
\end{array}\right]=T \cdot\left[\begin{array}{l}
V_{a} \\
V_{b} \\
V_{c}
\end{array}\right]
$$

Para as correntes temos:

$$
\left[\begin{array}{c}
I_{0} \\
I_{\alpha} \\
I_{\beta}
\end{array}\right]=T \cdot\left[\begin{array}{c}
I_{a} \\
I_{b} \\
I_{c}
\end{array}\right]
$$

onde $\mathrm{V}_{0, \alpha, \beta} ; \mathrm{I}_{0, \alpha, \beta}$ são os vetores modais de tensão e corrente e, $\mathrm{V}_{\mathrm{a}, \mathrm{b}, \mathrm{c}} ; \mathrm{I}_{\mathrm{a}, \mathrm{b}, \mathrm{c}}$ são os vetores de fase da tensão e corrente.

A velocidade de propagação do modo terra $\left(v_{0}\right)$ e do modo aéreo $1\left(v_{l}\right)$ são dadas respectivamente por:

$$
\begin{aligned}
& v_{0}=\frac{1}{\sqrt{\left(L_{0} C_{0}\right)}} \\
& v_{1}=\frac{1}{\sqrt{\left(L_{1} C_{1}\right)}}
\end{aligned}
$$

onde $L_{0}, C_{0}, L_{1}$ e $C_{1}$ são as indutâncias e capacitâncias de seqüência zero e positiva das linhas de transmissão.

Neste trabalho a transformação modal é utilizada para desacoplar o sinal trifásico de tensão. Uma vez feito o desacoplamento dos sinais de tensão, são usados no algoritmo de localização os sinais dos modos aéreo 1 (modo 1 ou M1) e em casos especiais o sinal do modo terra (modo 0 ou M0). Como os sinais do modo 1 estão presentes em todos os tipos de falta, este será essencialmente utilizado para a 
determinação dos tempos de viagem do sinais e conseqüentemente para o cálculo da distância da falta.

O sinal do modo terra só é significante durante faltas com envolvimento do terra, ou seja, durante faltas fase-terra e fase-fase-terra, portanto não será utilizado diretamente na estimação da distância da falta. Contudo, o modo terra será usado ocasionalmente com o propósito de distinguir certas situações peculiares pertinentes a técnica de localização com dados registrados em um terminal, na ocorrência de uma falta fase-terra.

Neste trabalho, avaliou-se também a utilização do sinal do modo terra para o cálculo da distância da falta em situações que envolveram uma conexão à terra. Estes testes porém, demonstraram resultados insatisfatórios, pois estes sinais não caracterizavam bem a chegada das ondas nos terminais, justificando a sua não utilização direta para o cálculo da distância.

\subsubsection{Aplicação da Transformada Wavelet}

Considerando a excelente capacidade da TW em discriminar e identificar com precisão os instantes de descontinuidade sobre formas de ondas, a ferramenta mostra-se propícia a aplicação na localização de faltas sobre sistemas elétricos. Tal localização é possível em virtude da TW detectar (acusar) os instantes de reflexão das ondas nos terminais, necessário para se estimar a distância do ponto de falta.

Os sinais modais de tensão, modo aéreo 1 e em certas ocasiões modo terra, são decompostos em dois níveis através da análise multiresolução wavelet, utilizando como wavelet mãe a symlet3 (sym3). Esta foi escolhida como wavelet mãe por melhor representar o problema de localização, evidenciada através de testes comparando as wavelets das famílias Daubechies da ordem 2 à 10 e Symlet da ordem 2 à 8.

Uma vez decompostos os sinais modais, foram utilizados pelo algoritmo apenas os sinais dos coeficientes wavelets (CWs) de detalhe um, ou simplesmente detalhe 1 (D1), referente ao modo 1 e ao modo terra, sendo que os mesmos compreendem uma faixa de freqüência de 60-120 kHz. Estes sinais contêm os instantes de reflexão das ondas viajantes do ponto de falta aos barramentos, necessários para estimação da falta. É importante lembrar que, para o cálculo da distância da falta, será essencialmente usado o tempo de reflexão das ondas, obtido através dos sinais de detalhe 1 do modo aéreo 1 . Durante os testes também se considerou a utilização do sinal de detalhe 2 (D2), 
entretanto, não foram alcançados resultados satisfatórios, basicamente por estes sinais conterem um faixa de freqüência não muito adequada para o método proposto.

Além disso, os sinais dos CW de detalhe 1 e 2 de ambos os modos (modo 0 e modo 1) são elevados ao quadrado com o intuito de minimizar o ruído presente no sinal, como proposto em SANTOSO (1996)[67].

\subsubsection{Técnica de localização de faltas}

Como foi descrito em seções anteriores, as técnicas de localização de faltas são divididas em: técnicas que utilizam dados registrados em apenas um terminal e técnicas que utilizam dados registrados em múltiplos terminais, em nosso caso dois terminais.

Tendo em vista as diferentes técnicas de localização, o algoritmo proposto aqui, foi desenvolvido de tal maneira que o usuário possa escolher a técnica de localização que achar mais conveniente ou que melhor se adapte ao seu sistema.

A escolha da técnica é feita previamente pelo usuário através de uma interface gráfica (menu) apresentada pelo programa, conforme ilustra a Figura 34.

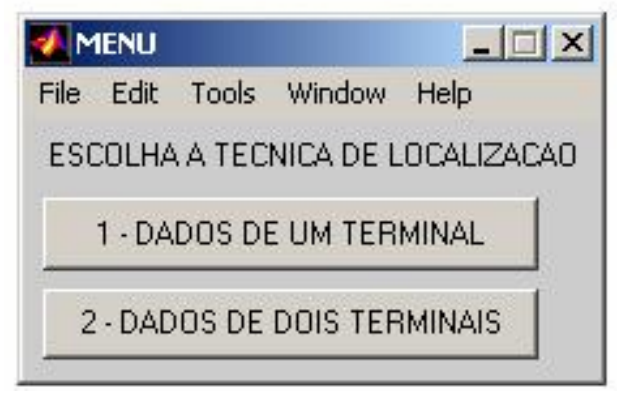

FIGURA 34 - Menu de escolha da técnica de localização de faltas

Definida a técnica de localização, obtidos os dados, classificado a situação de falta, desacoplados os sinais trifásicos de tensão através da transformação modal e, por fim, decompostos os sinais do modo aéreo e terra (quando necessário) pelo uso da análise multiresolução wavelet, passaremos agora a localização da falta propriamente dita.

Primeiramente, serão descritos os estágios que compõem a técnica de localização que utiliza dados de dois terminais. Logo em seguida, será descrita a técnica que utiliza dados provenientes de um terminal. 


\subsubsection{Formulação para localização de faltas com dados provenientes de dois terminais da linha}

Partindo do pressuposto que os estágios vistos anteriormente tenham sido executados, teremos então, a partir deste ponto, os sinais de detalhe 1 do modo 1 , referentes ao terminal local e remoto. Analisando os sinais de detalhe 1, podemos determinar os instantes de tempo de reflexão da primeira onda em ambos os terminais e com isso estimar a localização da falta. Esses estágios são detalhados a seguir. Como poderemos perceber, esta técnica é de fácil aplicação e não envolve tantos cálculos. A única desvantagem, seria da necessidade de sincronização e transmissão dos dados, o que acaba por aumentar os custos.

\subsubsection{Determinação dos tempos de reflexão}

A estimação da distância da falta nesta técnica é baseada no primeiro instante de reflexão em ambos os barramentos. Esses instantes são relatados pelos sinais de detalhe 1 do modo 1 de ambas as barras e são representados por picos presentes nos mesmos.

A detecção desses instantes é feita através da comparação dos sinais do detalhe 1 com um limiar (limiar 1). O sinal do detalhe 1 de ambas as barras é comparado amostra por amostra com o limiar 1. Este limiar 1 é definido como sendo o maior valor do sinal de detalhe 1 obtido pela análise multiresolução wavelet em dois níveis dos sinais de tensão em regime permanente medidos na barra E. Para evitar algum erro devido a grandeza dos valores e alguma imprecisão dos sinais, o valor do limiar 1 foi acrescido de $2 \%$ do seu próprio valor, o que corresponde a 1,02*1,1017e-6. Detectado a variação do sinal, são considerados mais quatro amostras consecutivas, perfazendo um conjunto de cinco amostras dos sinais de ambas as barras. Dessas cinco amostras, o maior valor corresponderá ao instante da primeira reflexão nas barras, representado na Figura 30 por $T a$ e $T b$. O número de amostras a partir da deteç̧ão da primeira amostra foi escolhido empiricamente.

A Figura 35 ilustra o processo de detecção dos tempos de reflexão, considerando uma situação de falta fase-fase. Pode-se observar pela mesma Figura que o distúrbio é detectado e os picos escolhidos adequadamente pelo algoritmo.

Determinado os tempos, passamos ao próximo e último passo desta técnica que consiste no cálculo da distância da falta. 


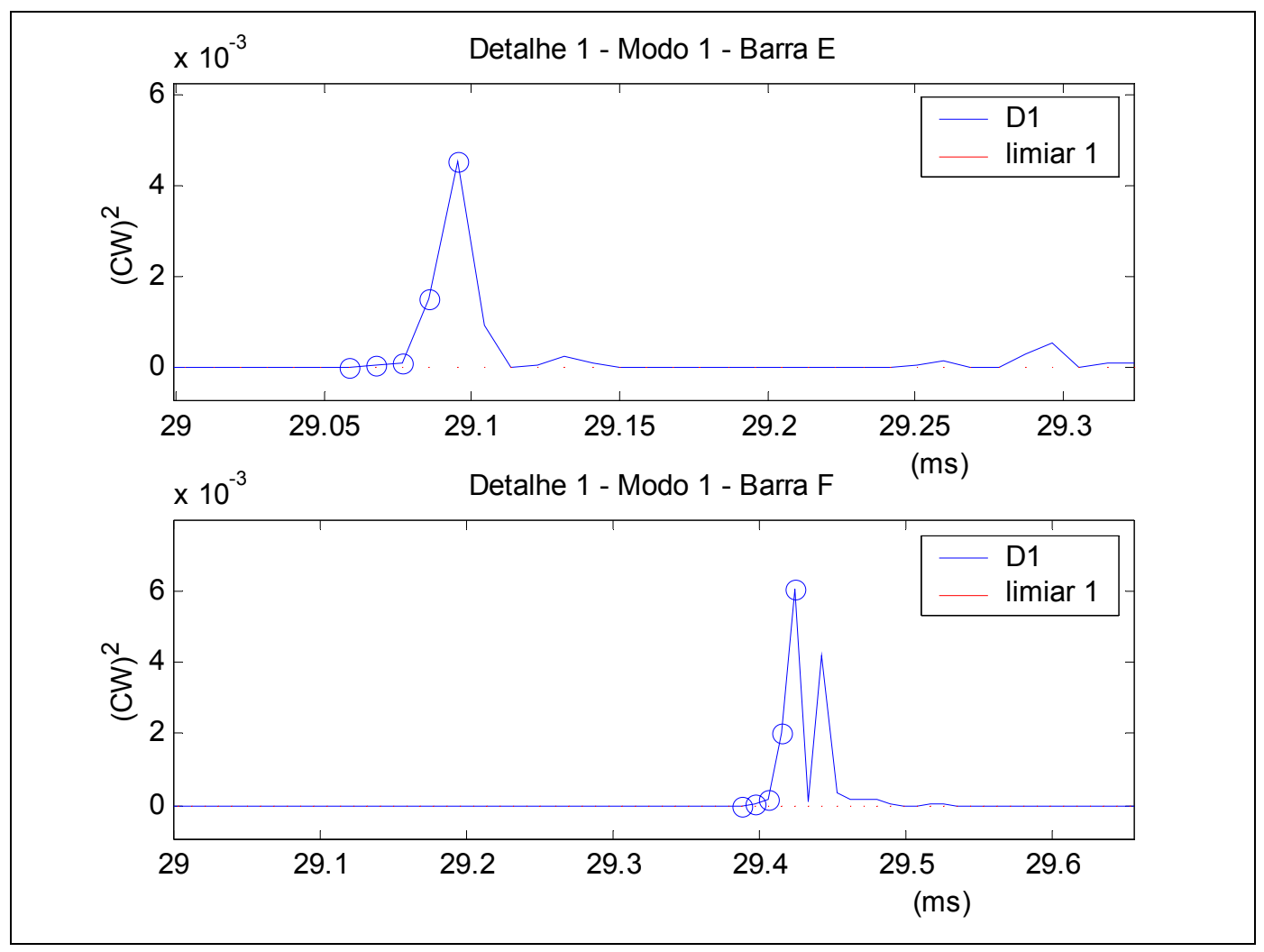

FIGURA 35 - Exemplo de detecção dos picos iniciais

\subsubsection{Cálculo da distância da falta envolvendo dados de dois terminais}

Considerando que $t_{a}$ e $t_{b}$ (Figura 30) correspondem ao tempo dos picos iniciais dos coeficientes wavelets de detalhe 1 do modo 1 (D1M1), para os sinais registrados nas barras A e B respectivamente, podemos calcular o atraso entre os tempos de detecção da falta nos dois terminais dado por:

$$
t_{d}=t_{B}-t_{A}
$$

Uma vez determinado $t_{d}$, a distância entre o ponto da falta e o terminal A é calculado pela seguinte equação:

$$
d=\frac{l-v_{m 1} \cdot t_{d}}{2}
$$

onde $l$ é o comprimento da linha de transmissão $(\mathrm{km}), v_{m l}$ é a velocidade de propagação do modo aéreo $1(\mathrm{~km} / \mathrm{s})$ e $d$ a distância da falta em relação ao barramento $\mathrm{A}(\mathrm{km})$. 


\subsubsection{Formulação para localização de faltas com dados provenientes de um terminal da linha}

Esta seção descreve a parte do algoritmo de localização de faltas relativa à técnica que utiliza dados somente do terminal local.

Esta abordagem é mais robusta e econômica, uma vez que faz uso dos sinais registrados apenas em um terminal da linha, não requer meios de comunicação ou mesmo sincronização dos dados. Todavia, seu algoritmo apresenta algumas peculiaridades se comparado com o algoritmo com dados de dois terminais.

Nessa técnica, devido a carência do tempo medido no barramento remoto, todo o tempo medido será com respeito ao instante em que a falta é detectada, ou seja, em relação a primeira reflexão de onda no terminal local. Sendo assim, a princípio, o cálculo para a localização da falta é baseado no tempo de reflexão das ondas viajantes entre o ponto de falta e o terminal local. No entanto, para faltas com envolvimento do terra, não só as reflexões sobre o ponto de falta, mas também as do terminal remoto serão observadas no terminal local ou de referência. Logo, nessa técnica, a sub-rotina de classificação da falta torna-se essencial para distinguir entre faltas aterradas ou não, uma vez que essas características conduzem a equacionamentos diferentes para o cálculo da distancia da falta.

Cabe salientar que, durante o desenvolvimento e teste do algoritmo, notou-se que as reflexões provenientes do terminal remoto não eram tão significativas no caso de faltas fase-fase-terra, devido a grande atenuação das mesmas. Já no caso de faltas faseterra, constatou-se que as reflexões do terminal remoto não podiam ser desconsideradas, pois apresentavam níveis significantes. Tendo em vista estas observações, o algoritmo foi modelado de maneira que os sinais do terminal remoto só fossem considerados no caso de faltas fase-terra.

Outra peculiaridade apresentada por essa técnica, é a necessidade de distinguir em caso de faltas aterradas, ou mais precisamente faltas fase-terra, se a mesma está alocada próxima do terminal local ou do terminal remoto, ou seja, se a falta fase-terra ocorreu na primeira ou segunda metade da linha, o que também conduz a equacionamentos diferentes, pois estas podem produzir padrões semelhantes de reflexões (tempos semelhantes). Para resolver este problema, foi necessário introduzir uma nova sub-rotina, denominada de pré-localização da falta, utilizada somente em caso de faltas fase-terra. 
Considerando o exposto acima, a parte do algoritmo de localização referente à técnica que utiliza dados de um terminal, compreende os seguintes estágios: detecção dos instantes de reflexão das ondas no terminal local e, em caso de faltas fase-terra, uma pré-localização da mesma, culminando com o cálculo da distância da falta. Estas etapas serão descritas no que segue.

\subsubsection{Determinação dos tempos de reflexão no terminal local}

Nessa técnica a detecção ou determinação dos instantes de chegada das ondas no terminal local é mais complexa, pois envolve a detecção da primeira e segunda reflexão de onda no terminal local.

No caso da detecção do instante de chegada da primeira onda ao terminal local (T1), esta sempre será proveniente do ponto de falta e será determinada de maneira análoga ao item 5.2.6.1, diferindo apenas no número de amostras consecutivas consideradas após a detecção da primeira amostra. De maneira empírica, foi considerado como ideal a utilização de mais 6 amostras consecutivas após detecção da primeira amostra, perfazendo um conjunto de sete amostras. O instante T1 estará relacionado ao maior valor deste conjunto. Na Figura 30 este tempo corresponde a $t_{a}$.

A determinação do segundo tempo (T2) referente a chegada da segunda onda no terminal local é mais complexa, pois envolve ondas provenientes do ponto de falta ou do terminal remoto, conforme o tipo de falta. Outro fator que dificulta esta detecção é a grande atenuação destas ondas durante a sua viagem pelo sistema.

O tempo T2 é determinado pela comparação do sinal de detalhe 1 do modo 1 com limiares auto-ajustáveis, conforme o sinal e o tipo de falta em específico. $\mathrm{O}$ primeiro limiar, chamado de limiar 2, é definido pelo máximo entre as amostras 4 e 5 do sinal de detalhe 1 com relação a amostra que corresponde a T1, sendo portanto o limiar 2 auto-ajustável conforme o sinal analisado. No caso de faltas fase AB-terra foram consideradas as amostras 4,5 e 6 .

Para o caso de faltas sem conexão à terra, o tempo T2 é determinado pela simples comparação do limiar 2 com as amostras do sinal detalhe 1 subseqüentes a amostra que representa T1. Caso alguma amostra supere o limiar 2, T2 será determinado analisando-se um conjunto de amostras a partir desta detecção.

Em se tratando de faltas fase-terra e fase-fase-terra, é repetido o mesmo procedimento descrito para faltas sem conexão a terra, porém se um determinado conjunto de amostras iniciais não ultrapassarem o limiar 2, novos limiares são definidos 
para estes tipos de faltas, tal procedimento busca eliminar o efeito da atenuação do sinal, mais presentes nos tipos de faltas com conexão à terra. Logo, para faltas fase-terra é estabelecido um novo limiar (limiar 3), definido pela razão entre o limiar 2 e um coeficiente de falta (cf) determinado empiricamente e ilustrado na Tabela 8. O novo limiar 3 é então comparado com as amostras do sinal de detalhe 1, caso alguma amostra exceda o seu valor, T2 é determinado analisando-se um conjunto de amostras prédefinido a partir desta detecção. As Figuras 36 e 37 ilustram a determinação de T2 referente a situações de faltas fase-terra, diferenciado-se pela necessidade ou não do limiar 3.

Em situações de faltas fase-fase-terra, a determinação do tempo T2 segue o mesmo procedimento delineado para o caso de faltas fase-terra, diferenciando-se apenas no tocante ao limiar 3, onde para o caso de faltas fase-fase-terra o limiar 3 é substituído por um limiar 4, o qual equivale ao produto do limiar 2 com relação ao coeficiente de falta (cf). Definido o limiar 4 o tempo T2 é determinado de modo análogo ao descrito para faltas fase-terra. É importante observar, que no caso de faltas fase-fase-terra o limiar 4 é função de um produto, pois com isto conseguimos eliminar da análise, as reflexões provenientes do terminal remoto, o que trouxe simplificações ao algoritmo.

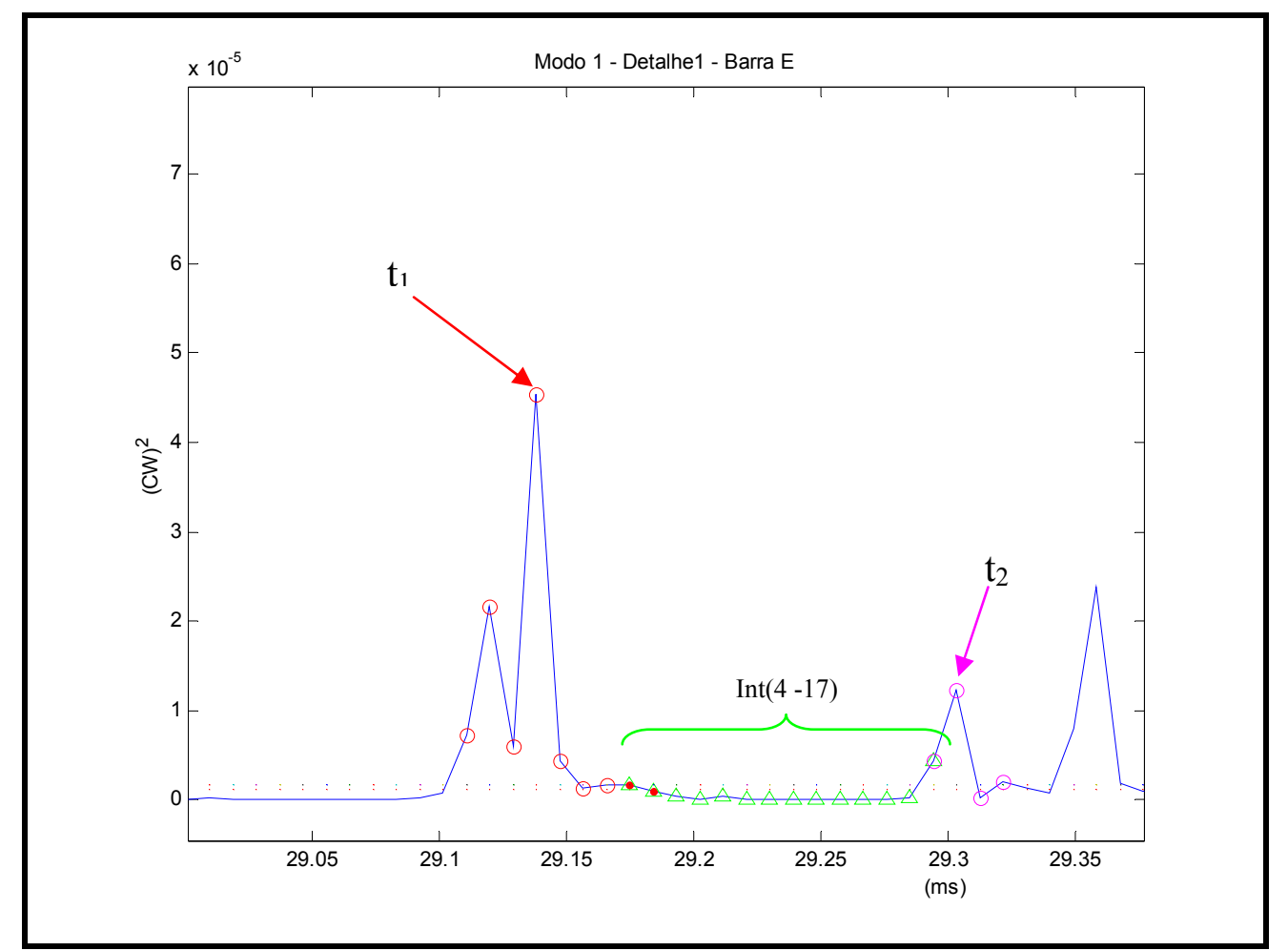

FIGURA 36 - Exemplo 1: Detecção de T2 para uma falta fase-terra sem necessidade do limiar 3 
TABELA 8-Coeficientes de falta (cf)

\begin{tabular}{cccc|ccc}
\hline & \multicolumn{3}{c|}{ Falta fase-terra } & \multicolumn{3}{c}{ Falta fase-fase } \\
\hline & AT & BT & CT & ABT & ACT & BCT \\
\hline CF & 5,2 & 1,6 & 5,2 & 1,7 & 1,5 & 4 \\
\hline
\end{tabular}

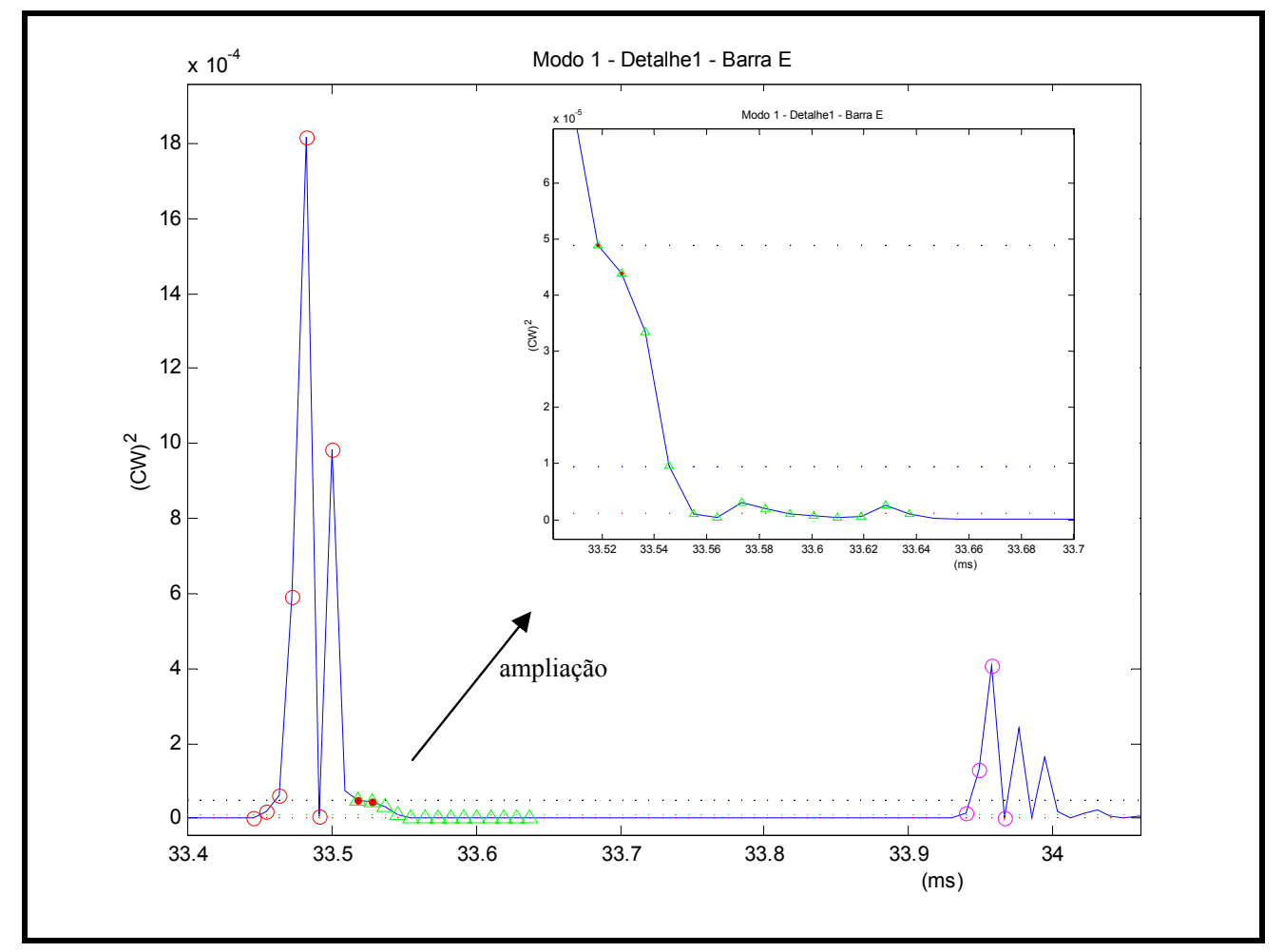

FIGURA 37 - Exemplo 2: Deteç̧ão de T2 para uma falta fase-terra com necessidade do limiar 3.

Visando uma melhor elucidação das etapas para determinação de $t_{1}$ e $t_{2}$, é apresentado, na Figura 38, o fluxograma referente essa rotina.

Voltando ao fluxograma apresentado na Figura 31, notamos que na técnica que utiliza dados de um terminal, têm-se a necessidade da determinação de um tempo $t_{3}$. Porém, este tempo só é determinado na presença de faltas fase-terra, devido a necessidade de se determinar se a falta ocorreu na primeira ou segunda metade da linha, o que conduz a equacionamentos diferentes.

A determinação do tempo $t_{3}$ é semelhante à determinação do tempo $t 1$ visto anteriormente, sendo que, neste caso, o sinal é comparado a um limiar 5. Para determinar-se $t_{3}$, ao invés de usar o sinal de detalhe 1 do modo 1 utilizamos o sinal de detalhe 1 do modo terra (D1_terra). O limiar 5 é auto-ajustável e definido de modo análogo ao limiar 1, entretanto, este é baseado na análise do sinal do modo terra. 
O sinal de detalhe 1 do modo terra é comparado com o limiar 5 (D1_terra > limiar 5), caso haja alguma variação, esta é detectada e mais cinco amostras consecutivas são consideradas. O maior valor deste conjunto de seis amostras indicará o respectivo tempo $\mathrm{T}_{3}$.

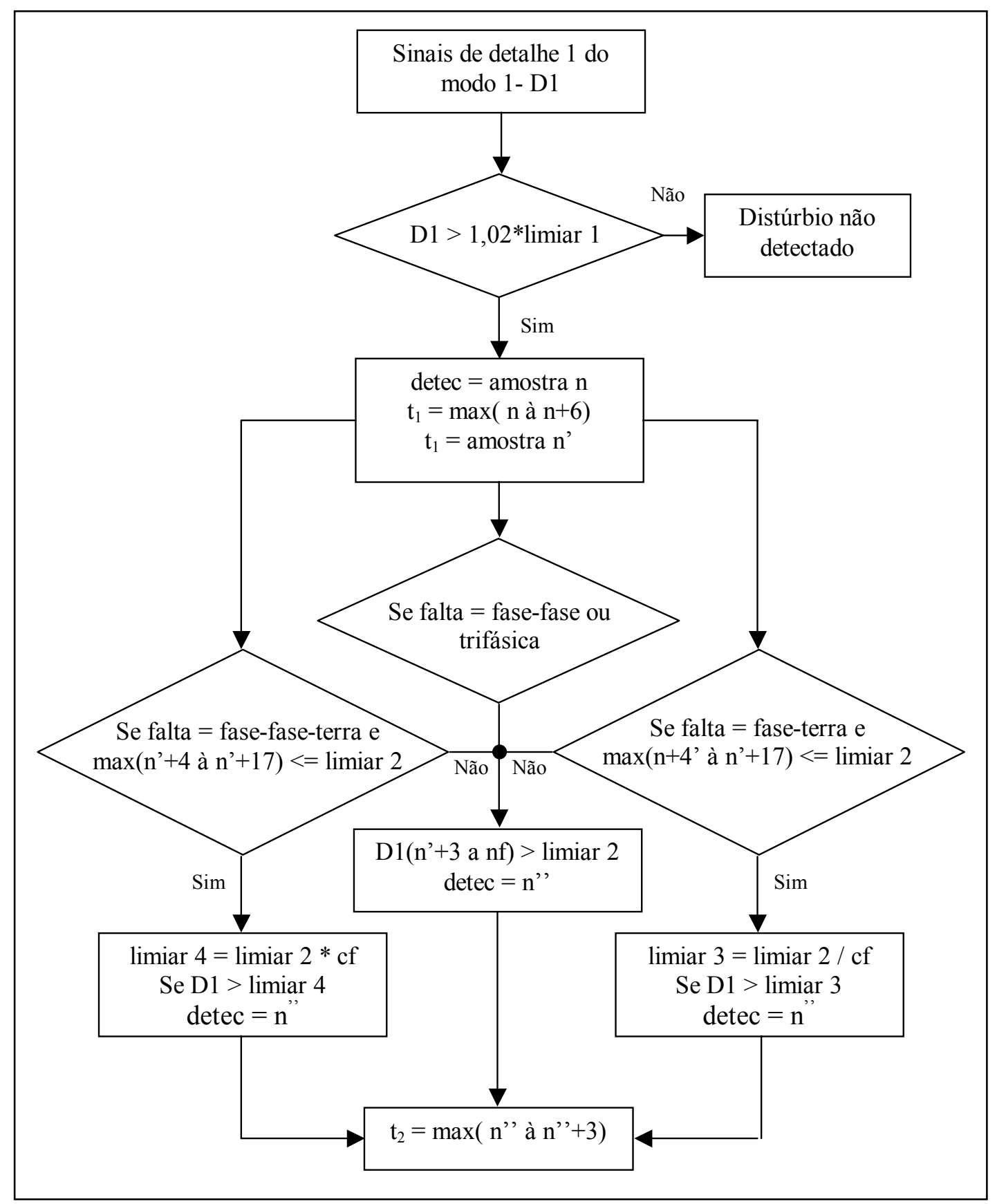

FIGURA 38 - Fluxograma referente as etapas para determinação dos tempos $t_{1}$ e $t_{2}$.

\subsubsection{Pré-Localização para faltas fase-terra}

Como já foi mencionado anteriormente, no caso de faltas fase-terra há a necessidade de pré-localizarmos a falta, ou seja, determinarmos se a mesma ocorreu na 
primeira ou segunda metade da linha. Isto em virtude da observação da segunda onda viajante no terminal local, sendo que a mesma pode ser proveniente do ponto de falta, caso esta ocorra na primeira metade da linha, ou proveniente do terminal remoto, caso a falta ocorra na segunda metade da linha.

Esse procedimento é necessário, pois neste caso, podemos ter padrões de faltas semelhantes, ou seja, podemos ter intervalos de tempos entre a primeira e a segunda onda iguais. Isto conduz a equacionamentos diferentes para o correto cálculo da distância da falta.

As Figuras 39a e 39b ilustram uma situação de falta fase-terra na segunda e primeira metade da linha, respectivamente. Notamos que se calcularmos o intervalo de tempo $\left(t_{d}=t_{2}-t_{1}\right)$ entre as duas primeiras ondas que chegam no barramento local (A), teríamos:

$$
\left.\begin{array}{l}
t_{d(a)}=2 t_{b}+t_{a}-t_{a}=2 t_{b} \\
t_{d(b)}=3 t_{a}-t_{a}=2 t_{a}
\end{array}\right\} \quad \text { mas } 2 t_{b}=2 t_{a} \text { ou } t_{b}=t_{a} \Leftrightarrow l-d
$$

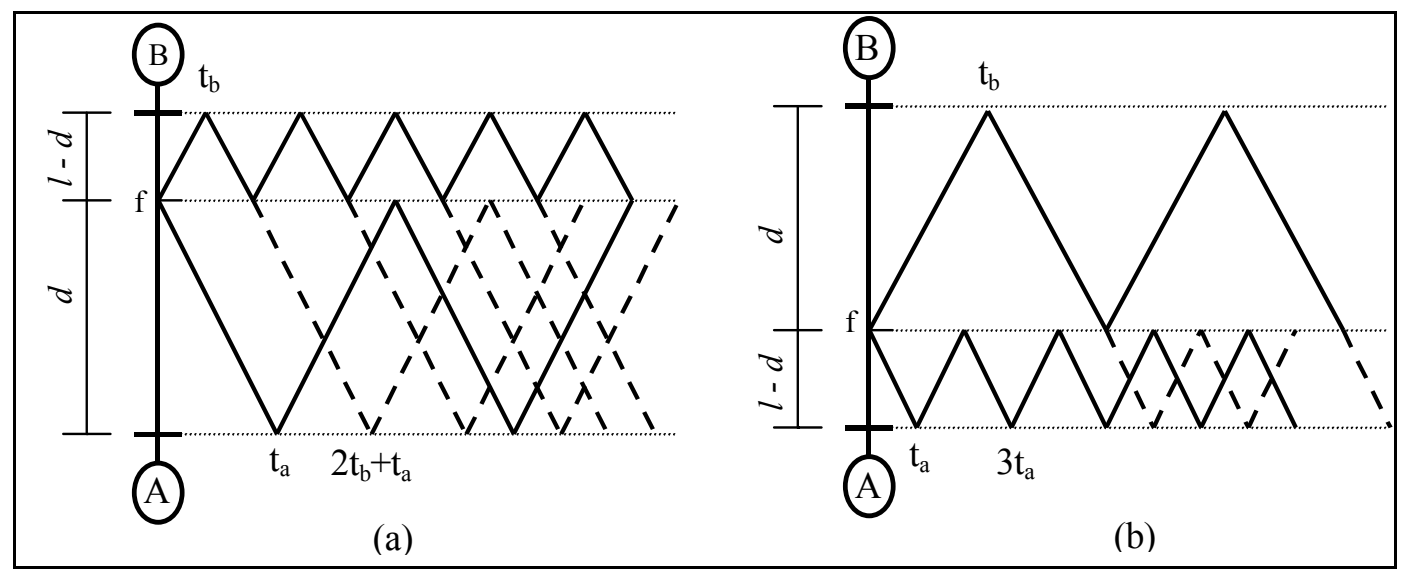

FIGURA 39 - (a) Falta fase-terra na segunda metade da linha, (b) falta fase-terra na primeira metade da linha

A pré-localização é feita baseado na comparação da diferença entre os tempos das reflexões iniciais revelados pela TW com relação ao modo terra e modo aéreo 1 (Figura 40), com a diferença entre os tempos de propagação do modo terra e aéreo $1 \mathrm{em}$ relação ao meio da linha coberta pelo localizador, como proposto por ABUR e MAGNAGO (2000)[42]. Em outras palavras, quanto maior a distância da falta, maior será a diferença entre os tempos de propagação das primeiras reflexões reveladas pela 
TW com relação a ambos os modos. Caso esse valor seja maior que a diferença dos tempos de reflexão para a metade da linha, a falta estará alocada na segunda metade, caso contrário, a falta estará alocada na primeira metade da mesma. A sub-rotina para pré-localizar faltas fase-terra pode ser formulada como segue:

$$
\begin{aligned}
& t_{m 0}=\frac{l}{2 \cdot v_{m 0}} ; \quad t_{m 1}=\frac{l}{2 \cdot v_{m 1}} \\
& t_{l / 2}=\left|t_{m 0}-t_{m 1}\right| \\
& t_{d m}=\left|t_{1}-t_{3}\right| \\
& t_{d m}>t_{l / 2} \Leftrightarrow 2^{a} \text { metade } \\
& \text { caso contrário } \Leftrightarrow \quad 1^{a} \text { metade }
\end{aligned}
$$

onde, $t_{\mathrm{m} 0}$ e $t_{\mathrm{m} 1}$ são os tempos com relação a velocidade dos modos terra e aéreo 1 que a onda leva para ir do terminal local ao meio da linha, $t_{1}$ e $t_{3}$ são os tempos relacionados aos primeiros picos dos sinais de detalhe 1 dos modos aéreo 1 (D1) e terra (D1_terra), respectivamente.

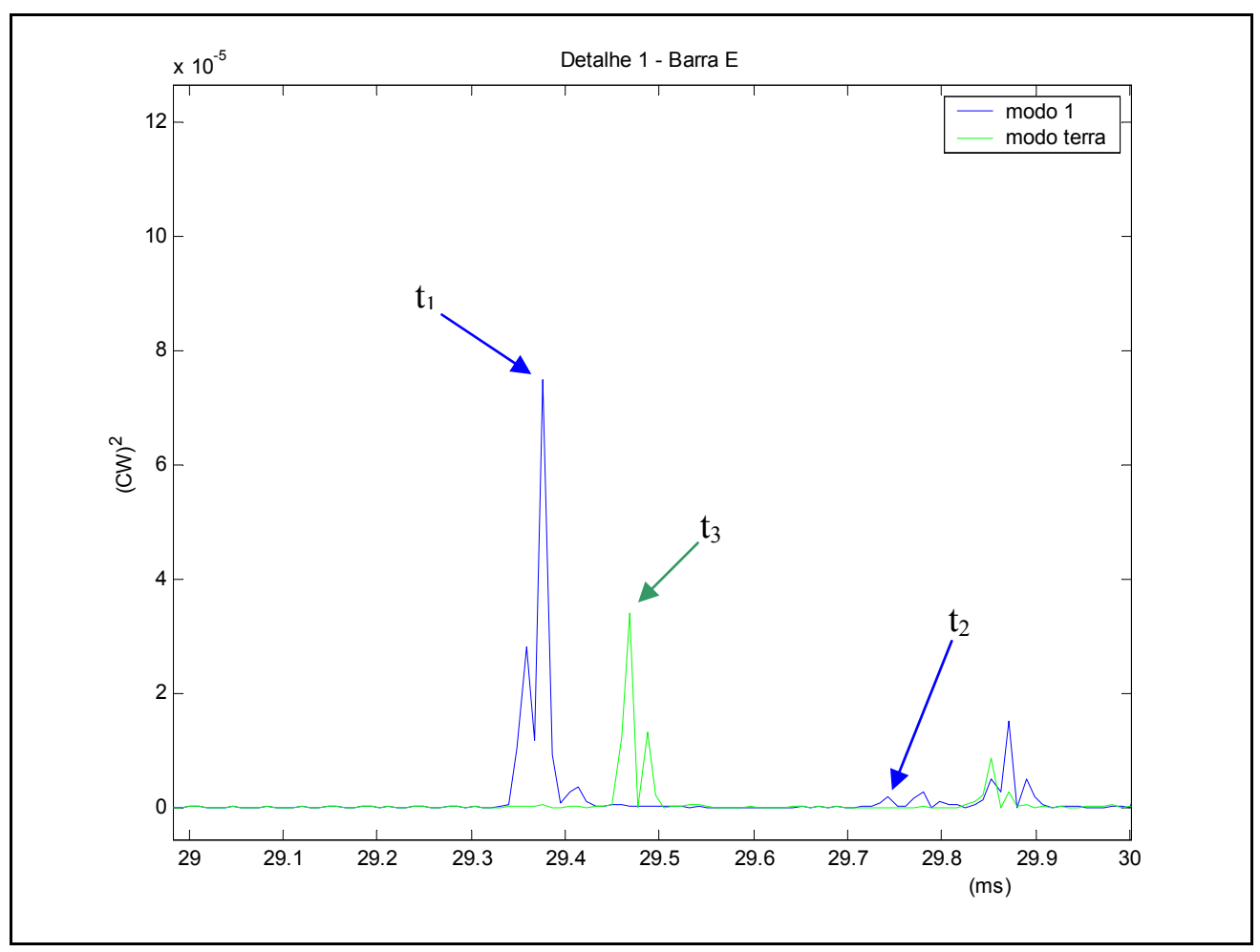

FIGURA 40 - Sinais de detalhe 1 dos modos aéreo 1 e terra para uma falta fase-terra na segunda metade da linha 
Esta técnica de pré-localização mostrou-se bastante eficaz na maioria dos testes realizados, apresentando alguns erros em casos de faltas próximas a metade da linha.

\subsubsection{Cálculo da distância para faltas fase-fase-terra, fase-fase e trifásica}

No caso de faltas fase-fase-terra, fase-fase e trifásicas, é observado que estas não geram reflexões do terminal remoto durante o transitório de falta. Assim, medindo-se o tempo entre os dois primeiros picos consecutivos dos coeficientes wavelets do detalhe 1 , referente ao modo aéreo 1 , e tomando o produto da velocidade de propagação, a distância da falta pode ser estimada. Logo, a distância da falta pode ser expressa por:

$$
d=\frac{v_{m 1} \cdot t_{d}}{2}
$$

onde $d$ é a distância da falta em $(\mathrm{km}), v_{m l}$ a velocidade de propagação do modo 1 $(\mathrm{km} / \mathrm{s})$, e $t_{d}$ a diferença entre os dois picos consecutivos dos coeficientes wavelets do detalhe 1 , referente ao modo aéreo 1 .

Para um melhor entendimento, a equação da distância e o tempo $t_{d}$ serão descritos com o auxílio da Figura 30, onde temos que:

$$
\begin{aligned}
& t_{d}=3 t_{a}-t_{a} \\
& t_{d}=2 t_{a} \\
& d=v \cdot 2 t_{a}
\end{aligned}
$$

Como $2 \mathrm{t}_{\mathrm{a}}$ representa o tempo de reflexão entre o terminal local e o ponto de falta e deste para o terminal local novamente, é necessário que se divida por 2, uma vez que queremos o tempo de reflexão entre o terminal local e o ponto de falta. Deste modo chegamos a:

$$
d=\frac{v \cdot 2 t_{a}}{2}=v \cdot t_{a}
$$

\subsubsection{Cálculo da distância para faltas fase-terra}

Conforme foi explicitado anteriormente, em caso de faltas fase-terra é necessário que seja feito uma pré-localização da falta conforme o item 5.2.7.2. Determinado em qual metade da linha ocorreu a falta, o cálculo da distância da falta pode ser feito como segue: 
- para faltas fase-terra na primeira metade da linha a distância da falta é calculada conforme a Eq.(5.8);

- para faltas fase-terra na segunda metade da linha, temos que:

$$
d=l-\frac{v_{m 1} \cdot t_{d}}{2}
$$

onde $d$ é a distância da falta em $(\mathrm{km}), l$ o comprimento da linha em questão em $(\mathrm{km})$, $v_{m l}$ a velocidade de propagação do modo $1 \mathrm{em}(\mathrm{km} / \mathrm{s})$ e $t_{d}$ a diferença entre os dois picos consecutivos dos sinais de detalhe 1 referentes ao modo aéreo 1 .

Explicado todos os passos do algoritmo de localização de faltas em linhas de transmissão, passamos agora aos testes e resultados obtidos com a aplicação do algoritmo. 


\section{LOCALIZAÇÃO DE FALTAS UTILIZANDO A TRANSFORMADA WAVELET - TESTES E RESULTADOS OBTIDOS}

O algoritmo de localização completo foi implementado através do uso do software Matlab $^{\circledR}$ e testado usando-se de dados obtidos através de simulações do software ATP/EMTP. Como descrito no Capítulo 4, foram considerados vários tipos de faltas em diferentes localizações entre os barramentos E e F, com diferentes ângulos de incidência e resistências de faltas. No decorrer dos testes também foram avaliadas as influências da taxa amostral utilizada, altas resistências de falta e o acoplamento mútuo entre as fases de um circuito de transmissão duplo.

O sistema elétrico considerado (Figura 15) apresenta para o modo aéreo 1 (modo 1) uma velocidade de propagação de $2,9316 \times 10^{5} \mathrm{~km} / \mathrm{s}$ e para o modo terra (modo 0 ) uma velocidade de propagação de $2,228 \times 10^{5} \mathrm{~km} / \mathrm{s}$, sendo o passo de amostragem usado de 8,33us (120kHz). Os sinais do modo 0 e modo 1 são decompostos em dois níveis usando como wavelet-mãe a Symlet3 (Sym3). Os sinais dos coeficientes wavelet (CW) de detalhe 1 do modo aéreo 1 (modo 1), são utilizados em ambas as técnicas de localização, enquanto os sinais dos coeficientes wavelet $(\mathrm{CW})$ de detalhe 1 do modo terra (modo 0) são utilizados apenas na técnica de localização com dados provenientes de um terminal na presença de faltas fase-terra. Cabe mencionar que para o cálculo da distância foram empregados apenas os sinais faltosos das tensões trifásicas.

Embora extensivos testes tenham sido realizados para se verificar e comprovar o desempenho do algoritmo localizador de faltas proposto, somente uma parte destes com seus respectivos comentários serão apresentados no corpo deste documento. Resultados complementares serão apresentados no Apêndice A e B.

Os resultados serão apresentados conforme a técnica de localização utilizada e serão ilustrados através de tabelas, gráficos, histogramas, etc. Cabe ainda explicar, que o 
erro percentual (relativo) apresentado é calculado em relação ao comprimento da LT em questão $(150 \mathrm{~km})$, sendo expresso pela equação:

$$
\varepsilon_{\text {rel }}(\%)=\left|\frac{d_{\text {estimado }}-d_{\text {real }}}{l_{L T}}\right| \cdot 100 \%
$$

O cálculo do erro absoluto e erro médio total são expressos conforme as equações (6.2) e (6.3), respectivamente:

$$
\begin{gathered}
\varepsilon_{\text {abs }}(\mathrm{km})=\left|d_{\text {estimado }}-d_{\text {real }}\right| \\
\varepsilon_{\text {medio }}=\frac{\sum_{1}^{N} \mathcal{E}_{\text {rel }}(\%)}{N}
\end{gathered}
$$

onde $N$ é número de situações consideradas, $d_{\text {estimado }}$ é a distância estimada pelo algoritmo, $d_{\text {real }}$ é a distância real da falta e $l_{L T}$ é o comprimento da linha entre os barras E e F.

\subsection{Resultados alcançados utilizando-se dados provenientes de dois terminais}

Assumindo o registro dos sinais de tensão em ambos os barramentos E e F com a correta sincronização por GPS, uma falta fase-terra é simulada a $110 \mathrm{~km}$ da barra E, com um ângulo de incidência de zero graus e resistência de falta de $100 \Omega$. A Figura 41 ilustra os CWs de detalhe 1 do modo 1 obtidos em ambas as barras (E e F), respectivamente. Neste exemplo, o primeiro pico dos CWs na barra E ocorreu em $t_{E}=29,413 m s$ e, na barra F em $t_{F}=29,175 m s$. Logo, $t_{d}=-0,2385 m s$. Substituindo $t_{d}$ na eq.(5.6), temos que a distância estimada é igual a 109,92 km. 


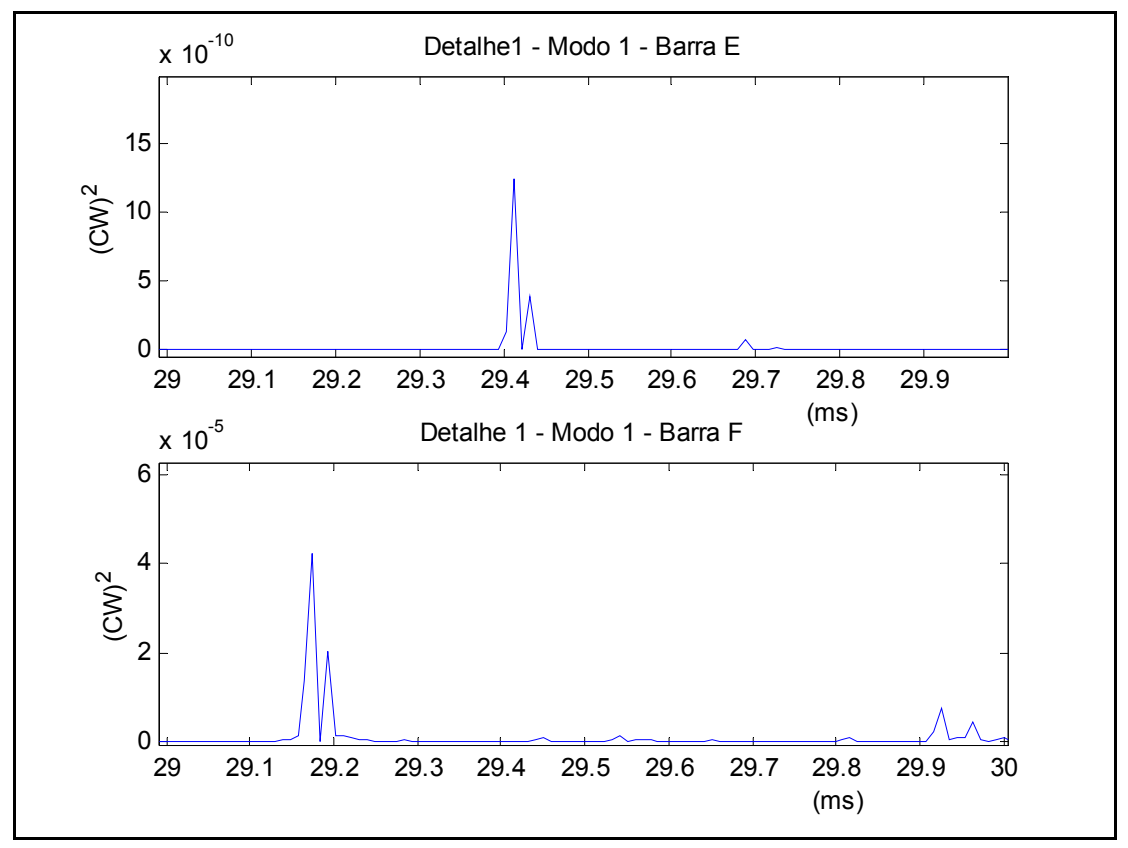

FIGURA 41 - Coeficientes wavelet para uma falta fase A-terra a $110 \mathrm{~km}$ da barra E, com resistência de falta de 100 ohms e ângulo de incidência de $0^{\circ}$.

Nas Tabelas de 9 a 12 que seguem, são apresentados os resultados alcançados pelo algoritmo de localização frente as diferentes situações de faltas simuladas. Estas tabelas apresentam os seguintes parâmetros: (i) a distância real, que representa o ponto exato da aplicação da situação de falta sobre o sistema com relação ao barramento E; (ii) o ângulo de incidência da falta, o qual indica o ângulo de inserção da mesma; (iii) a classificação do tipo de falta feita pelo algoritmo, que expressa o envolvimento das fases envolvidas no distúrbio; (iv) a distância estimada, que diz respeito a localização da falta estimada pelo algoritmo; (v) o erro absoluto calculado conforme Eq. (6.2); (vi) o erro relativo ou percentual observado, calculado conforme a eq.(6.1) e, na parte inferior (vii) o erro médio calculado conforme Eq. (6.3), para as respectivas situações de faltas. Quando a falta tem envolvimento do terra, adiciona-se às Tabelas mais um item, denominado resistência de falta, que representa o valor da resistência de falta para aquela situação.

Como ilustração, tomamos a Tabela 9, onde podemos observar que a terceira linha representa uma situação de falta fase-fase (AB), alocada a $10 \mathrm{~km}$ da barra $\mathrm{E}$ com ângulo de incidência de $0^{\circ}$. A distância estimada pelo algoritmo foi de 40,08 km, distância esta que representa um erro absoluto e percentual de 0,08 km e 0,05\%, respectivamente. 
TABELA 9 - Falta fase-fase (AB), com ângulo de incidência de falta de $0^{0}$.

\begin{tabular}{cccccc}
\hline $\begin{array}{c}\text { Distância } \\
\text { Real } \\
(\mathbf{k m})\end{array}$ & $\begin{array}{c}\text { Angulo de } \\
\text { Incidência } \\
\text { (graus) }\end{array}$ & $\begin{array}{c}\text { Tipo de } \\
\text { Falta }\end{array}$ & $\begin{array}{c}\text { Distância } \\
\text { Estimada } \\
\mathbf{( k m )}\end{array}$ & $\begin{array}{c}\text { Erro } \\
\mathbf{A b s} . \\
\mathbf{( k m )}\end{array}$ & $\begin{array}{c}\text { Erro } \\
(\mathbf{\%})\end{array}$ \\
\hline 10 & 0 & $\mathrm{AB}$ & 7,85 & 2,15 & 1,43 \\
\hline 25 & 0 & $\mathrm{AB}$ & 23,96 & 1,04 & 0,69 \\
\hline 40 & 0 & $\mathrm{AB}$ & 40,08 & 0,08 & 0,05 \\
\hline 55 & 0 & $\mathrm{AB}$ & 56,19 & 1,19 & 0,79 \\
\hline 70 & 0 & $\mathrm{AB}$ & 70,97 & 0,97 & 0,65 \\
\hline 75 & 0 & $\mathrm{AB}$ & 75 & 0 & 0,00 \\
\hline 80 & 0 & $\mathrm{AB}$ & 79,03 & 0,97 & 0,65 \\
\hline 95 & 0 & $\mathrm{AB}$ & 93,81 & 1,19 & 0,79 \\
\hline 110 & 0 & $\mathrm{AB}$ & 109,92 & 0,08 & 0,05 \\
\hline 125 & 0 & $\mathrm{AB}$ & 126,04 & 1,04 & 0,69 \\
\hline 140 & 0 & $\mathrm{AB}$ & 142,15 & 2,15 & 1,43 \\
\hline \multicolumn{7}{c}{ Erro médio (\%) } \\
\hline
\end{tabular}

TABELA 10 - Falta fase-fase (AB), com ângulo de incidência de falta de $90^{\circ}$.

\begin{tabular}{cccccc}
\hline $\begin{array}{c}\text { Distância } \\
\text { Real } \\
(\mathbf{k m})\end{array}$ & $\begin{array}{c}\text { Angulo de } \\
\text { Incidência } \\
\text { (graus) }\end{array}$ & $\begin{array}{c}\text { Tipo de } \\
\text { Falta }\end{array}$ & $\begin{array}{c}\text { Distância } \\
\text { Estimada } \\
\mathbf{( k m )}\end{array}$ & $\begin{array}{c}\text { Erro } \\
\text { Abs. } \\
\mathbf{( k m )}\end{array}$ & $\begin{array}{c}\text { Erro } \\
\mathbf{( \% )}\end{array}$ \\
\hline 10 & 90 & $\mathrm{AB}$ & 10,53 & 0,53 & 0,35 \\
\hline 25 & 90 & $\mathrm{AB}$ & 23,96 & 1,04 & 0,69 \\
\hline 40 & 90 & $\mathrm{AB}$ & 40,07 & 0,07 & 0,05 \\
\hline 55 & 90 & $\mathrm{AB}$ & 53,51 & 1,49 & 0,99 \\
\hline 70 & 90 & $\mathrm{AB}$ & 69,62 & 0,38 & 0,25 \\
\hline 75 & 90 & $\mathrm{AB}$ & 75 & 0 & 0,00 \\
\hline 80 & 90 & $\mathrm{AB}$ & 80,38 & 0,38 & 0,25 \\
\hline 95 & 90 & $\mathrm{AB}$ & 95,16 & 0,16 & 0,11 \\
\hline 110 & 90 & $\mathrm{AB}$ & 109,93 & 0,07 & 0,05 \\
\hline 125 & 90 & $\mathrm{AB}$ & 126,04 & 1,04 & 0,69 \\
\hline 140 & 90 & $\mathrm{AB}$ & 139,47 & 0,53 & 0,35 \\
\hline \multicolumn{7}{c}{ Erro médio (\%) } \\
\hline
\end{tabular}

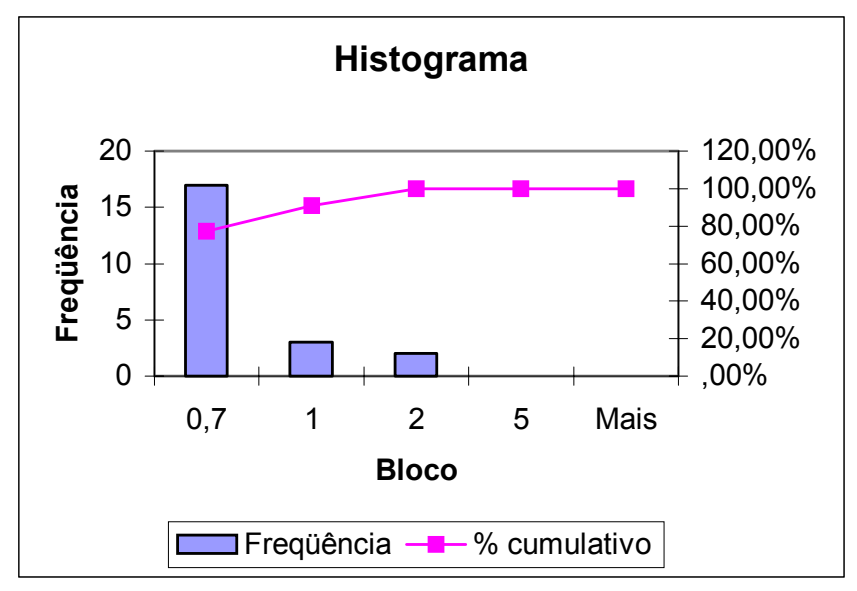

FIGURA 42 - Histograma referente as faltas (AB) com ângulo de incidência de 0 e $90^{\circ}$

TABELA 11 - Falta trifásica (ABC), com ângulo de incidência de falta de $0^{\circ}$.

\begin{tabular}{cccccc}
\hline $\begin{array}{c}\text { Distância } \\
\text { Real } \\
(\mathbf{k m})\end{array}$ & $\begin{array}{c}\text { Ângulo de } \\
\text { Incidência } \\
\text { (graus) }\end{array}$ & $\begin{array}{c}\text { Tipo de } \\
\text { Falta }\end{array}$ & $\begin{array}{c}\text { Distância } \\
\text { Estimada } \\
\mathbf{( k m )}\end{array}$ & $\begin{array}{c}\text { Erro } \\
\mathbf{A b s} . \\
\mathbf{( k m )}\end{array}$ & $\begin{array}{c}\text { Erro } \\
(\mathbf{\%})\end{array}$ \\
\hline 10 & 0 & $\mathrm{ABC}$ & 10,53 & 0,53 & 0,35 \\
\hline 25 & 0 & $\mathrm{ABC}$ & 23,96 & 1,04 & 0,69 \\
\hline 40 & 0 & $\mathrm{ABC}$ & 40,08 & 0,08 & 0,05 \\
\hline 55 & 0 & $\mathrm{ABC}$ & 53,51 & 1,49 & 0,99 \\
\hline 70 & 0 & $\mathrm{ABC}$ & 69,62 & 0,38 & 0,25 \\
\hline 75 & 0 & $\mathrm{ABC}$ & 75 & 0 & 0,00 \\
\hline 80 & 0 & $\mathrm{ABC}$ & 80,38 & 0,38 & 0,25 \\
\hline 95 & 0 & $\mathrm{ABC}$ & 93,81 & 1,19 & 0,79 \\
\hline 110 & 0 & $\mathrm{ABC}$ & 109,92 & 0,08 & 0,05 \\
\hline 125 & 0 & $\mathrm{ABC}$ & 126,04 & 1,04 & 0,69 \\
\hline 140 & 0 & $\mathrm{ABC}$ & 140,8 & 0,8 & 0,53 \\
\hline \multicolumn{7}{c}{} & Erro médio (\%) & & & $\mathbf{0 , 4 2}$ \\
\hline
\end{tabular}

TABELA 12 - Falta trifásica (ABC), com ângulo de incidência de falta de $90^{\circ}$.

\begin{tabular}{cccccc}
\hline $\begin{array}{c}\text { Distância } \\
\text { Real } \\
(\mathbf{k m})\end{array}$ & $\begin{array}{c}\text { Angulo de } \\
\text { Incidência } \\
\text { (graus) }\end{array}$ & $\begin{array}{c}\text { Tipo de } \\
\text { Falta }\end{array}$ & $\begin{array}{c}\text { Distância } \\
\text { Estimada } \\
(\mathbf{k m})\end{array}$ & $\begin{array}{c}\text { Erro } \\
\text { Abs. } \\
(\mathbf{k m})\end{array}$ & $\begin{array}{c}\text { Erro } \\
(\mathbf{\%})\end{array}$ \\
\hline 10 & 90 & $\mathrm{ABC}$ & 10,53 & 0,53 & 0,35 \\
\hline 25 & 90 & $\mathrm{ABC}$ & 25,29 & 0,29 & 0,19 \\
\hline 40 & 90 & $\mathrm{ABC}$ & 40,07 & 0,07 & 0,05 \\
\hline 55 & 90 & $\mathrm{ABC}$ & 53,51 & 1,49 & 0,99 \\
\hline 70 & 90 & $\mathrm{ABC}$ & 69,62 & 0,38 & 0,25 \\
\hline 75 & 90 & $\mathrm{ABC}$ & 75 & 0 & 0,00 \\
\hline 80 & 90 & $\mathrm{ABC}$ & 80,38 & 0,38 & 0,25 \\
\hline 95 & 90 & $\mathrm{ABC}$ & 95,16 & 0,16 & 0,11 \\
\hline 110 & 90 & $\mathrm{ABC}$ & 109,93 & 0,07 & 0,05 \\
\hline 125 & 90 & $\mathrm{ABC}$ & 124,71 & 0,29 & 0,19 \\
\hline 140 & 90 & $\mathrm{ABC}$ & 139,47 & 0,53 & 0,35 \\
\hline \multicolumn{7}{c}{ Erro médio $(\mathbf{\%})$} \\
\hline
\end{tabular}




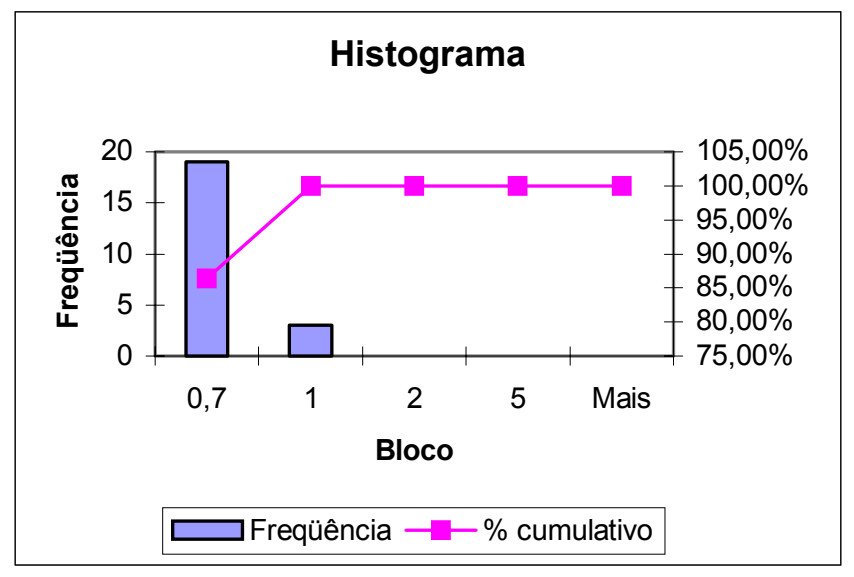

FIGURA 43 - Histograma referente as faltas (ABC) com ângulo de incidência de 0 e $90^{\circ}$

Pode-se observar pelos resultados apresentados através das Tabelas (9-12) que o algoritmo de localização com dados provenientes de dois terminais apresentou uma ótima precisão para estas situações de faltas sem envolvimento da terra. Podemos observar nos histogramas apresentados pelas Figuras (42 e 43) que aproximadamente $80 \%$ dos casos de faltas fase-fase apresentaram erros inferiores a $0,7 \%$ e que $86,4 \%$ dos casos de faltas trifásicas apresentaram resultados inferiores a 0,7\%. Para as situações de faltas fase-fase e trifásicas apresentadas, o erro máximo encontrado foi de 1,43\% e $0,99 \%$, respectivamente.

Nos casos de faltas fase-terra e fase-fase-terra a serem apresentados a seguir, o algoritmo também apresentou ótimos resultados. Nas situações de faltas fase-terra com ângulo de incidência de 0 graus, $60,6 \%$ destas apresentaram resultados inferiores a $1 \%$ (Figura 44), sendo que no pior caso o erro foi de 1,55\%. Nas faltas fase-terra com ângulo de incidência de 90 graus, 63,64\% destas situações apresentaram erros inferiores a $0,7 \%$, conforme Figura 45 . O pior erro observado neste caso de foi de $0,84 \%$.

Para os casos de faltas fase-fase-terra com ângulo de incidência de 0 graus, $84,85 \%$ destes obtiveram erros inferiores a $1 \%$, conforme Figura 46. Para o mesmo tipo de falta, porém, considerando um ângulo de incidência de 90 graus, tivemos que 100\% destes casos apresentaram um erro inferior a 1\%, conforme Figura 47. Os piores erros registrados para faltas fase-fase-terra com ângulos de incidência de 0 e 90 graus foram de $1,83 \%$ e $1,6 \%$, respectivamente.

No que segue, são apresentados novos e diferentes resultados obtidos por meio das Tabelas (13-16) e Figuras (44-47). Tais resultados referem-se a situações de faltas 
com envolvimento do terra (fase-terra e fase-fase-terra), com diferentes resistências e ângulos de incidência de falta.

TABELA 13 - Faltas fase-terra (AT), com resistências de falta de 0, 50 e $100 \Omega$ e ângulo de incidência de falta de $0^{\circ}$.

\begin{tabular}{|c|c|c|c|c|c|c|}
\hline $\begin{array}{c}\text { Distância } \\
\text { Real } \\
\text { (km) }\end{array}$ & $\begin{array}{c}\text { Resist. } \\
\text { falta } \\
(\text { ohms })\end{array}$ & $\begin{array}{c}\text { Ângulo de } \\
\text { Incidência } \\
\text { (graus) }\end{array}$ & $\begin{array}{c}\text { Tipo de } \\
\text { Falta }\end{array}$ & $\begin{array}{c}\text { Distância } \\
\text { Estimada } \\
\quad(\mathbf{k m})\end{array}$ & $\begin{array}{l}\text { Erro } \\
\text { Abs. } \\
(\mathbf{k m})\end{array}$ & $\begin{array}{r}\text { Erro } \\
(\%)\end{array}$ \\
\hline 10 & 0 & 0 & AT & 7,85 & 2,15 & 1,43 \\
\hline 10 & 50 & 0 & AT & 7,85 & 2,15 & 1,43 \\
\hline 10 & 100 & 0 & AT & 7,85 & 2,15 & 1,43 \\
\hline 25 & 0 & 0 & AT & 26,64 & 1,64 & 1,09 \\
\hline 25 & 50 & 0 & AT & 26,64 & 1,64 & 1,09 \\
\hline 25 & 100 & 0 & AT & 26,64 & 1,64 & 1,09 \\
\hline 40 & 0 & 0 & AT & 40,08 & 0,08 & 0,05 \\
\hline 40 & 50 & 0 & AT & 40,08 & 0,08 & 0,05 \\
\hline 40 & 100 & 0 & AT & 40,08 & 0,08 & 0,05 \\
\hline 55 & 0 & 0 & $\mathrm{AT}$ & 53,51 & 1,49 & 0,99 \\
\hline 55 & 50 & 0 & $\mathrm{AT}$ & 53,51 & 1,49 & 0,99 \\
\hline 55 & 100 & 0 & AT & 53,51 & 1,49 & 0,99 \\
\hline 70 & 0 & 0 & AT & 70,97 & 0,97 & 0,65 \\
\hline 70 & 50 & 0 & AT & 70,97 & 0,97 & 0,65 \\
\hline 70 & 100 & 0 & AT & 70,97 & 0,97 & 0,65 \\
\hline 75 & 0 & 0 & AT & 75 & 0 & 0,00 \\
\hline 75 & 50 & 0 & AT & 75 & 0 & 0,00 \\
\hline 75 & 100 & 0 & AT & 75 & 0 & 0,00 \\
\hline 80 & 0 & 0 & AT & 79,03 & 0,97 & 0,65 \\
\hline 80 & 50 & 0 & AT & 77,68 & 2,32 & 1,55 \\
\hline 80 & 100 & 0 & AT & 80,38 & 0,38 & 0,25 \\
\hline 95 & 0 & 0 & AT & 96,49 & 1,49 & 0,99 \\
\hline 95 & 50 & 0 & AT & 96,49 & 1,49 & 0,99 \\
\hline 95 & 100 & 0 & AT & 96,49 & 1,49 & 0,99 \\
\hline 110 & 0 & 0 & AT & 109,92 & 0,08 & 0,05 \\
\hline 110 & 50 & 0 & AT & 109,92 & 0,08 & 0,05 \\
\hline 110 & 100 & 0 & AT & 109,92 & 0,08 & 0,05 \\
\hline 125 & 0 & 0 & AT & 123,36 & 1,64 & 1,09 \\
\hline 125 & 50 & 0 & AT & 123,36 & 1,64 & 1,09 \\
\hline 125 & 100 & 0 & AT & 123,36 & 1,64 & 1,09 \\
\hline 140 & 0 & 0 & AT & 142,15 & 2,15 & 1,43 \\
\hline 140 & 50 & 0 & AT & 142,15 & 2,15 & 1,43 \\
\hline 140 & 100 & 0 & $\mathrm{AT}$ & 142,15 & 2,15 & 1,43 \\
\hline \multicolumn{6}{|c|}{ Erro médio (\%) } & $\mathbf{0 , 7 8}$ \\
\hline
\end{tabular}


TABELA 14 -Faltas fase-terra (AT), com resistências de falta de 0, 50 e $100 \Omega$ e ângulo de incidência de falta de $90^{\circ}$.

\begin{tabular}{|c|c|c|c|c|c|c|}
\hline $\begin{array}{c}\text { Distância } \\
\text { Real } \\
\text { (km) }\end{array}$ & $\begin{array}{c}\text { Resist. } \\
\text { falta } \\
\text { (ohms) }\end{array}$ & $\begin{array}{c}\text { Ângulo de } \\
\text { Incidência } \\
\text { (graus) }\end{array}$ & $\begin{array}{c}\text { Tipo de } \\
\text { Falta }\end{array}$ & $\begin{array}{c}\text { Distância } \\
\text { Estimada } \\
\quad(\mathbf{k m})\end{array}$ & $\begin{array}{l}\text { Erro } \\
\text { Abs. } \\
\text { (km) }\end{array}$ & $\begin{array}{l}\text { Erro } \\
(\%)\end{array}$ \\
\hline 10 & 0 & 90 & AT & 10,53 & 0,53 & 0,35 \\
\hline 10 & 50 & 90 & AT & 10,53 & 0,53 & 0,35 \\
\hline 10 & 100 & 90 & AT & 10,53 & 0,53 & 0,35 \\
\hline 25 & 0 & 90 & AT & 23,96 & 1,04 & 0,69 \\
\hline 25 & 50 & 90 & AT & 23,96 & 1,04 & 0,69 \\
\hline 25 & 100 & 90 & AT & 23,96 & 1,04 & 0,69 \\
\hline 40 & 0 & 90 & AT & 38,74 & 1,26 & 0,84 \\
\hline 40 & 50 & 90 & AT & 38,74 & 1,26 & 0,84 \\
\hline 40 & 100 & 90 & AT & 38,74 & 1,26 & 0,84 \\
\hline 55 & 0 & 90 & AT & 56,19 & 1,19 & 0,79 \\
\hline 55 & 50 & 90 & AT & 56,19 & 1,19 & 0,79 \\
\hline 55 & 100 & 90 & AT & 56,19 & 1,19 & 0,79 \\
\hline 70 & 0 & 90 & AT & 69,62 & 0,38 & 0,25 \\
\hline 70 & 50 & 90 & AT & 69,62 & 0,38 & 0,25 \\
\hline 70 & 100 & 90 & AT & 69,62 & 0,38 & 0,25 \\
\hline 75 & 0 & 90 & AT & 75 & 0 & 0,00 \\
\hline 75 & 50 & 90 & AT & 75 & 0 & 0,00 \\
\hline 75 & 100 & 90 & AT & 75 & 0 & 0,00 \\
\hline 80 & 0 & 90 & AT & 80,38 & 0,38 & 0,25 \\
\hline 80 & 50 & 90 & AT & 80,38 & 0,38 & 0,25 \\
\hline 80 & 100 & 90 & AT & 80,38 & 0,38 & 0,25 \\
\hline 95 & 0 & 90 & AT & 93,81 & 1,19 & 0,79 \\
\hline 95 & 50 & 90 & AT & 93,81 & 1,19 & 0,79 \\
\hline 95 & 100 & 90 & AT & 93,81 & 1,19 & 0,79 \\
\hline 110 & 0 & 90 & AT & 111,26 & 1,26 & 0,84 \\
\hline 110 & 50 & 90 & AT & 111,26 & 1,26 & 0,84 \\
\hline 110 & 100 & 90 & AT & 111,26 & 1,26 & 0,84 \\
\hline 125 & 0 & 90 & AT & 126,04 & 1,04 & 0,69 \\
\hline 125 & 50 & 90 & AT & 126,04 & 1,04 & 0,69 \\
\hline 125 & 100 & 90 & AT & 126,04 & 1,04 & 0,69 \\
\hline 140 & 0 & 90 & AT & 139,47 & 0,53 & 0,35 \\
\hline 140 & 50 & 90 & AT & 139,47 & 0,53 & 0,35 \\
\hline 140 & 100 & 90 & AT & 139,47 & 0,53 & 0,35 \\
\hline \multicolumn{6}{|c|}{ Erro médio (\%) } & $\mathbf{0 , 5 3}$ \\
\hline
\end{tabular}


TABELA 15 - Faltas fase-fase-terra (BCT), com resistências de falta de 0, 50 e $100 \Omega$ e ângulo de incidência de falta de $0^{\circ}$

\begin{tabular}{|c|c|c|c|c|c|c|}
\hline $\begin{array}{c}\text { Distância } \\
\text { Real } \\
\text { (km) }\end{array}$ & $\begin{array}{c}\text { Resist. } \\
\text { falta } \\
\text { (ohms) }\end{array}$ & $\begin{array}{c}\text { Ângulo de } \\
\text { Incidência } \\
\text { (graus) }\end{array}$ & $\begin{array}{c}\text { Tipo de } \\
\text { Falta }\end{array}$ & $\begin{array}{c}\text { Distância } \\
\text { Estimada } \\
\text { (km) }\end{array}$ & $\begin{array}{l}\text { Erro } \\
\text { Abs. } \\
(\mathrm{km})\end{array}$ & $\begin{array}{l}\text { Erro } \\
(\%)\end{array}$ \\
\hline 10 & 0 & 0 & $\mathrm{BCT}$ & 7,81 & 2,19 & 1,46 \\
\hline 10 & 50 & 0 & $\mathrm{BCT}$ & 7,81 & 2,19 & 1,46 \\
\hline 10 & 100 & 0 & BCT & 10,5 & 0,5 & 0,33 \\
\hline 25 & 0 & 0 & $\mathrm{BCT}$ & 23,93 & 1,07 & 0,71 \\
\hline 25 & 50 & 0 & $\mathrm{BCT}$ & 23,93 & 1,07 & 0,71 \\
\hline 25 & 100 & 0 & $\mathrm{BCT}$ & 23,93 & 1,07 & 0,71 \\
\hline 40 & 0 & 0 & BCT & 40,07 & 0,07 & 0,05 \\
\hline 40 & 50 & 0 & $\mathrm{BCT}$ & 40,07 & 0,07 & 0,05 \\
\hline 40 & 100 & 0 & $\mathrm{BCT}$ & 40,07 & 0,07 & 0,05 \\
\hline 55 & 0 & 0 & $\mathrm{BCT}$ & 56,18 & 1,18 & 0,79 \\
\hline 55 & 50 & 0 & $\mathrm{BCT}$ & 56,18 & 1,18 & 0,79 \\
\hline 55 & 100 & 0 & $\mathrm{BCT}$ & 56,18 & 1,18 & 0,79 \\
\hline 70 & 0 & 0 & $\mathrm{BCT}$ & 69,62 & 0,38 & 0,25 \\
\hline 70 & 50 & 0 & $\mathrm{BCT}$ & 69,62 & 0,38 & 0,25 \\
\hline 70 & 100 & 0 & $\mathrm{BCT}$ & 69,62 & 0,38 & 0,25 \\
\hline 75 & 0 & 0 & $\mathrm{BCT}$ & 75 & 0 & 0,00 \\
\hline 75 & 50 & 0 & $\mathrm{BCT}$ & 75 & 0 & 0,00 \\
\hline 75 & 100 & 0 & $\mathrm{BCT}$ & 75 & 0 & 0,00 \\
\hline 80 & 0 & 0 & $\mathrm{BCT}$ & 77,7 & 2,3 & 1,53 \\
\hline 80 & 50 & 0 & $\mathrm{BCT}$ & 80,38 & 0,38 & 0,25 \\
\hline 80 & 100 & 0 & $\mathrm{BCT}$ & 80,38 & 0,38 & 0,25 \\
\hline 95 & 0 & 0 & $\mathrm{BCT}$ & 93,82 & 1,18 & 0,79 \\
\hline 95 & 50 & 0 & $\mathrm{BCT}$ & 93,82 & 1,18 & 0,79 \\
\hline 95 & 100 & 0 & $\mathrm{BCT}$ & 93,82 & 1,18 & 0,79 \\
\hline 110 & 0 & 0 & $\mathrm{BCT}$ & 109,93 & 0,07 & 0,05 \\
\hline 110 & 50 & 0 & $\mathrm{BCT}$ & 107,25 & 2,75 & 1,83 \\
\hline 110 & 100 & 0 & $\mathrm{BCT}$ & 107,25 & 2,75 & 1,83 \\
\hline 125 & 0 & 0 & $\mathrm{BCT}$ & 126,07 & 1,07 & 0,71 \\
\hline 125 & 50 & 0 & $\mathrm{BCT}$ & 126,07 & 1,07 & 0,71 \\
\hline 125 & 100 & 0 & $\mathrm{BCT}$ & 126,07 & 1,07 & 0,71 \\
\hline 140 & 0 & 0 & $\mathrm{BCT}$ & 139,5 & 0,5 & 0,33 \\
\hline 140 & 50 & 0 & $\mathrm{BCT}$ & 139,5 & 0,5 & 0,33 \\
\hline 140 & 100 & 0 & $\mathrm{BCT}$ & 139,5 & 0,5 & 0,33 \\
\hline \multicolumn{6}{|c|}{ Erro médio (\%) } & $\mathbf{0 , 6 0}$ \\
\hline
\end{tabular}


TABELA 16 - Faltas fase-fase-terra (BCT), com resistências de falta de 0, 50 e $100 \Omega$ e ângulo de incidência de falta de $90^{\circ}$

\begin{tabular}{|c|c|c|c|c|c|c|}
\hline $\begin{array}{c}\text { Distância } \\
\text { Real } \\
\text { (km) }\end{array}$ & $\begin{array}{c}\text { Resist. } \\
\text { falta } \\
\text { (ohms) }\end{array}$ & $\begin{array}{c}\text { Ângulo de } \\
\text { Incidência } \\
\text { (graus) }\end{array}$ & $\begin{array}{c}\text { Tipo de } \\
\text { Falta }\end{array}$ & $\begin{array}{c}\text { Distância } \\
\text { Estimada } \\
\quad(\mathbf{k m})\end{array}$ & $\begin{array}{l}\text { Erro } \\
\text { Abs. } \\
\text { (km) }\end{array}$ & $\begin{array}{l}\text { Erro } \\
(\%)\end{array}$ \\
\hline 10 & 0 & 90 & $\mathrm{BCT}$ & 7,81 & 2,19 & 1,46 \\
\hline 10 & 50 & 90 & BCT & 7,81 & 2,19 & 1,46 \\
\hline 10 & 100 & 90 & BCT & 7,81 & 2,19 & 1,46 \\
\hline 25 & 0 & 90 & BCT & 23,93 & 1,07 & 0,71 \\
\hline 25 & 50 & 90 & $\mathrm{BCT}$ & 23,93 & 1,07 & 0,71 \\
\hline 25 & 100 & 90 & BCT & 23,93 & 1,07 & 0,71 \\
\hline 40 & 0 & 90 & BCT & 40,05 & 0,05 & 0,03 \\
\hline 40 & 50 & 90 & BCT & 40,05 & 0,05 & 0,03 \\
\hline 40 & 100 & 90 & BCT & 40,05 & 0,05 & 0,03 \\
\hline 55 & 0 & 90 & BCT & 56,18 & 1,18 & 0,79 \\
\hline 55 & 50 & 90 & $\mathrm{BCT}$ & 56,18 & 1,18 & 0,79 \\
\hline 55 & 100 & 90 & BCT & 56,18 & 1,18 & 0,79 \\
\hline 70 & 0 & 90 & BCT & 70,97 & 0,97 & 0,65 \\
\hline 70 & 50 & 90 & BCT & 70,97 & 0,97 & 0,65 \\
\hline 70 & 100 & 90 & BCT & 70,97 & 0,97 & 0,65 \\
\hline 75 & 0 & 90 & BCT & 75 & 0 & 0,00 \\
\hline 75 & 50 & 90 & BCT & 75 & 0 & 0,00 \\
\hline 75 & 100 & 90 & $\mathrm{BCT}$ & 75 & 0 & 0,00 \\
\hline 80 & 0 & 90 & $\mathrm{BCT}$ & 79,03 & 0,97 & 0,65 \\
\hline 80 & 50 & 90 & BCT & 79,03 & 0,97 & 0,65 \\
\hline 80 & 100 & 90 & BCT & 79,03 & 0,97 & 0,65 \\
\hline 95 & 0 & 90 & BCT & 93,82 & 1,18 & 0,79 \\
\hline 95 & 50 & 90 & BCT & 93,82 & 1,18 & 0,79 \\
\hline 95 & 100 & 90 & $\mathrm{BCT}$ & 93,82 & 1,18 & 0,79 \\
\hline 110 & 0 & 90 & BCT & 109,95 & 0,05 & 0,03 \\
\hline 110 & 50 & 90 & $\mathrm{BCT}$ & 109,95 & 0,05 & 0,03 \\
\hline 110 & 100 & 90 & $\mathrm{BCT}$ & 109,95 & 0,05 & 0,03 \\
\hline 125 & 0 & 90 & $\mathrm{BCT}$ & 127,4 & 2,4 & 1,60 \\
\hline 125 & 50 & 90 & $\mathrm{BCT}$ & 127,4 & 2,4 & 1,60 \\
\hline 125 & 100 & 90 & $\mathrm{BCT}$ & 127,4 & 2,4 & 1,60 \\
\hline 140 & 0 & 90 & $\mathrm{BCT}$ & 142,19 & 2,19 & 1,46 \\
\hline 140 & 50 & 90 & $\mathrm{BCT}$ & 142,19 & 2,19 & 1,46 \\
\hline 140 & 100 & 90 & BCT & 142,19 & 2,19 & 1,46 \\
\hline \multicolumn{6}{|c|}{ Erro médio (\%) } & $\mathbf{0 , 7 4}$ \\
\hline
\end{tabular}




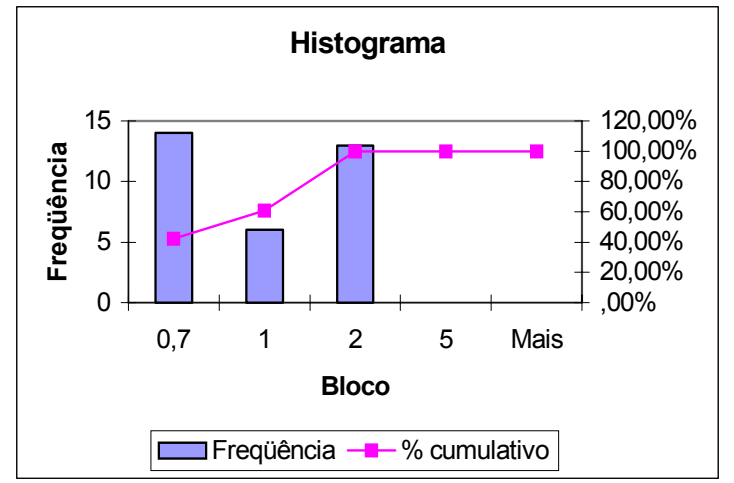

FIGURA 44 - Histograma referente as faltas (AT) com ângulo de incidência de $0^{\circ}$

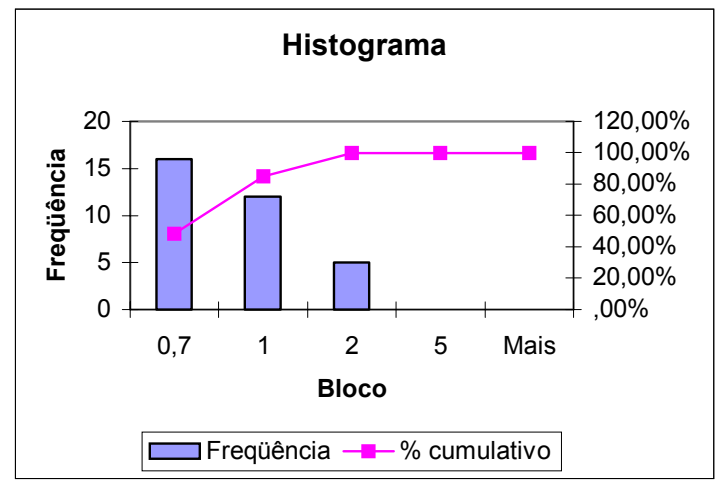

FIGURA 46 - Histograma referente as faltas (BCT) com ângulo de incidência de $0^{\circ}$

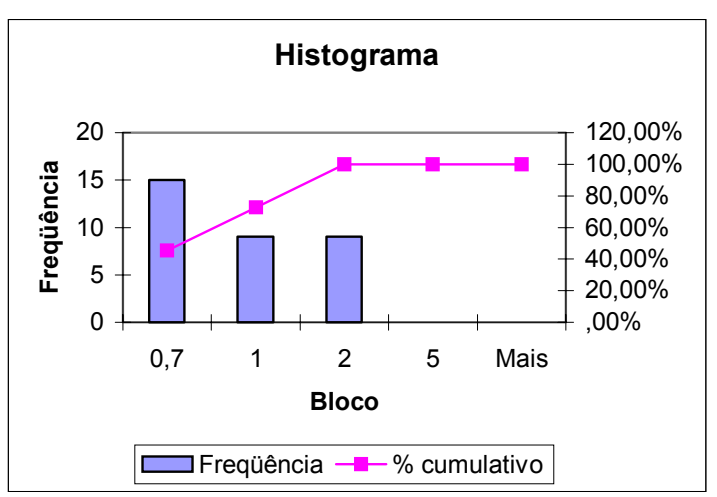

FIGURA 45 - Histograma referente as faltas (AT) com ângulo de incidência de $90^{\circ}$

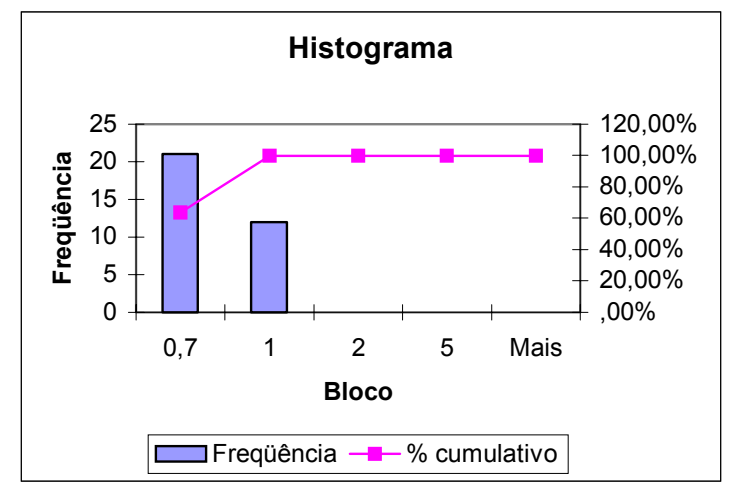

FIGURA 47 - Histograma referente as faltas (BCT) com ângulo de incidência de $90^{\circ}$

\subsubsection{Influência da variação da distância da falta}

Para análise da influência da variação da distância da falta, no desempenho do algoritmo, foram simulados diversas situações de faltas em diferentes localizações da linha de transmissão.

Observando as Figuras (48 e 49), pode-se verificar que a distância da falta não tem tanta influência na precisão desta técnica, geralmente apresentando maiores erros para faltas próximas aos terminais e excelente precisão com respeito ao meio da linha. 


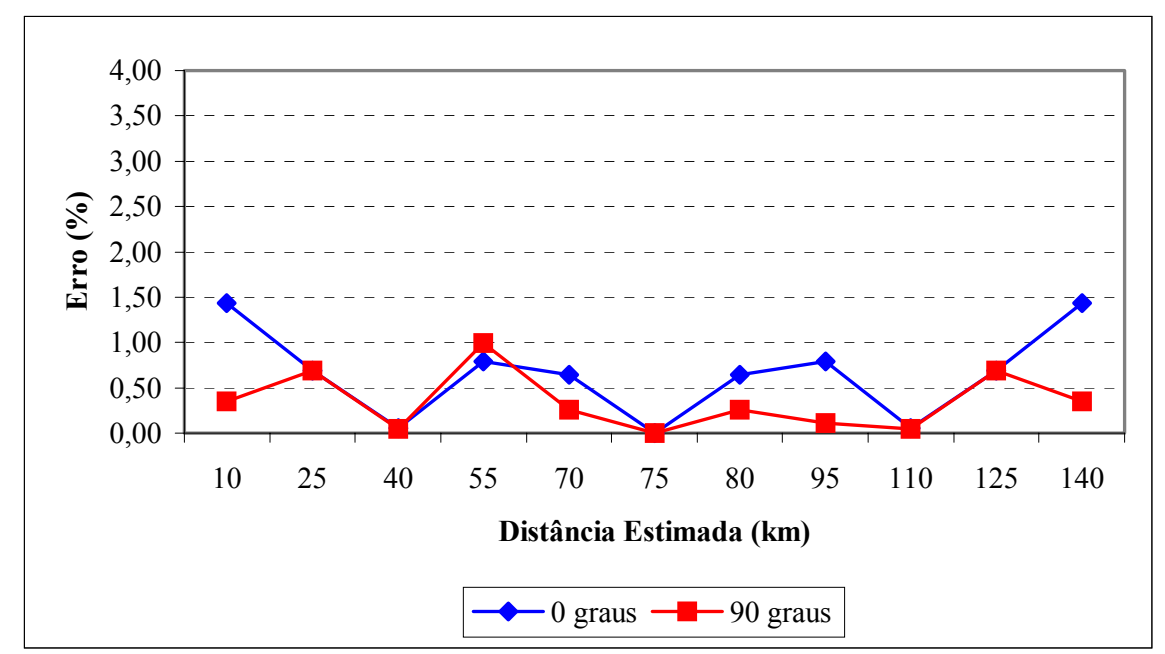

FIGURA 48 - Influência da distância para faltas fase-fase (AB)

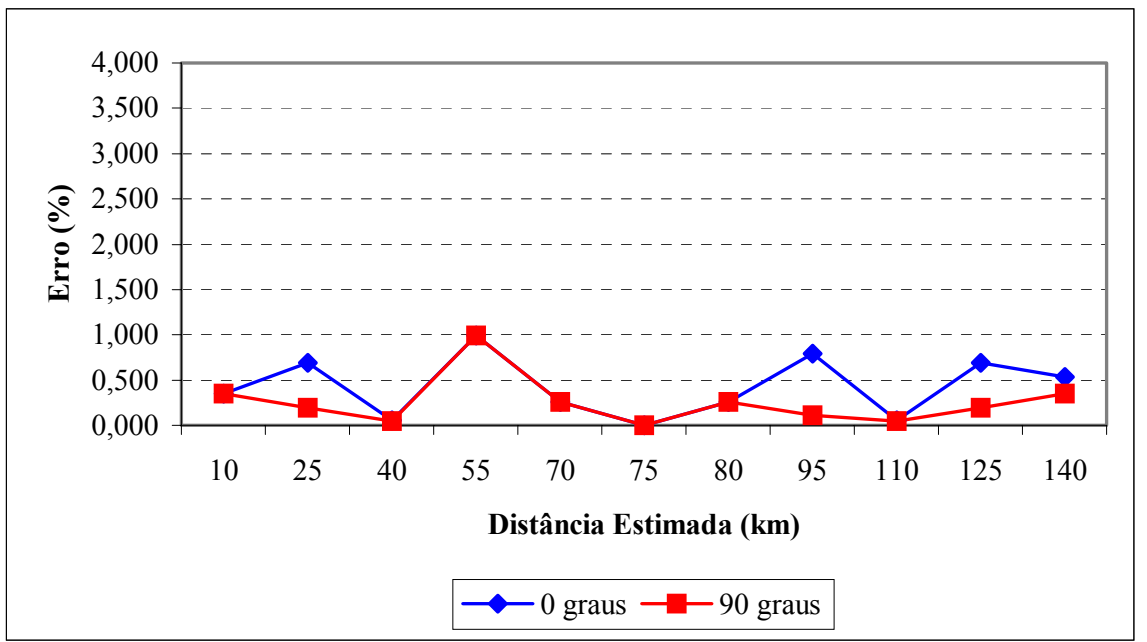

FIGURA 49 - Influência da distância para faltas trifásicas.

\subsubsection{Influência dos diferentes tipos de faltas}

É imprescindível verificarmos se os diferentes tipos de faltas (10 tipos) influenciam no desempenho do algoritmo localizador, principalmente em caso de faltas fase-terra que são predominantes nos diferentes tipos de configurações de linhas de transmissão. Essa predominância é ainda mais acentuada em linhas de alta tensão, uma vez que, os grandes espaçamentos entre os condutores dificultam o surgimento de faltas bifásicas ou trifásicas.

Uma série de testes foi realizada com o intuito de se verificar a influência do tipo da falta, servindo como exemplo todos os resultados mostrados anteriormente e 
apresentados nas Tabelas (9-16). Para melhor representar esta questão temos a Figura 50, que ilustra alguns casos de faltas fase-terra, fase-fase-terra, fase-fase e trifásicas, com ângulo de incidência de $90^{\circ}$ e resistência de falta de $0,1 \mathrm{ohm}$.

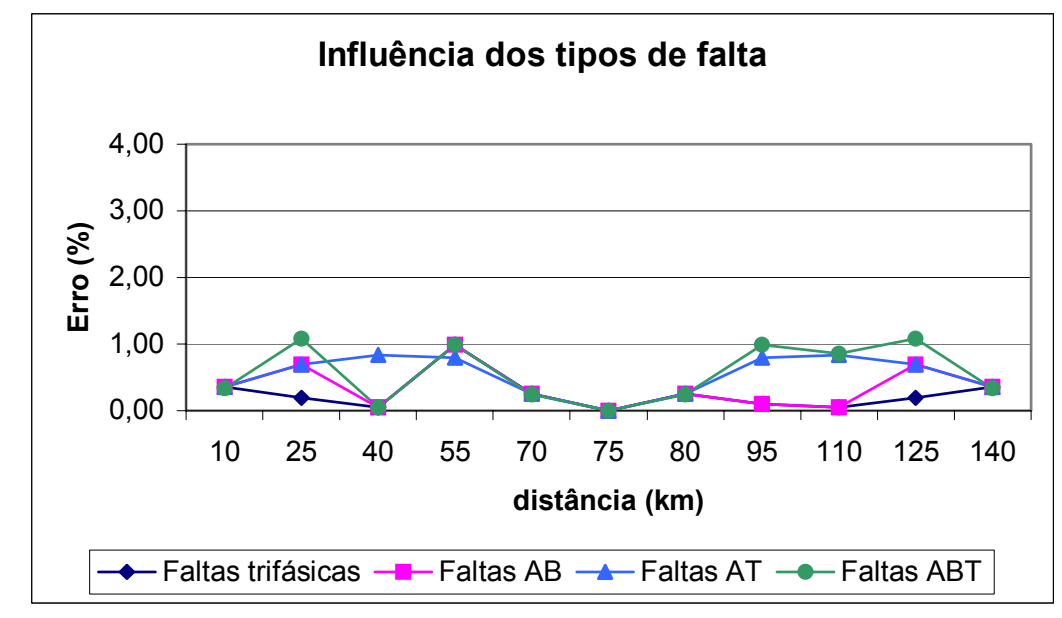

FIGURA 50 - Influência do tipo da falta na precisão do algoritmo

Pela análise da Figura 50, pode-se verificar que o erro percentual ficou dentro de $1 \%$. Somente em alguns casos o erro excedeu esta faixa, permanecendo ainda assim, inferior a $1,1 \%$. Nota-se também que o algoritmo se comportou um pouco melhor na presença de faltas sem o envolvimento da terra, destacando-se os resultados para faltas trifásicas.

De um modo geral podemos observar que os erros introduzidos pelos diferentes tipos de faltas não afetam a validade e confiabilidade da técnica de localização de faltas.

\subsubsection{Influência do ângulo de incidência da falta}

$\mathrm{Na}$ prática, as faltas podem ter origem em qualquer ponto da forma de onda da tensão, podendo isso acontecer desde um valor mínimo (forma de onda da tensão passando por zero) até um valor máximo (forma de onda passando por um máximo a $90^{\circ}$ ) na fase ou fases faltosas.

Do ponto de vista de distorções devido às ondas viajantes, o melhor caso é na presença de faltas próximas do ponto de máximo de tensão, onde a caracterização das ondas é mais marcante. No outro extremo, quando as faltas ocorrem próximas ou na tensão passando por zero, as ondas viajantes são extremamente atenuadas, devido a forma de onda não ter uma grande e repentina mudança. 
Com respeito à influência do ângulo de incidência da falta no desempenho do algoritmo e precisão da técnica, os testes demonstraram que são alcançados melhores resultados quando da inserção da falta a valores próximos do máximo da tensão, a $90^{\circ}$. Apesar de ser uma pequena melhora, tal observação pode ser comprovada através dos resultados apresentados anteriormente nas Tabelas (9-16) e Figuras (48 e 49), bem como nos demais testes realizados.

\subsubsection{Influência da resistência de falta}

Uma vez que há predominância de faltas fase-terra, é de suma importância verificar se o cálculo da localização de falta é influenciado pelas mudanças na resistência de falta. Com este intuito, foram realizados vários testes com os seguintes valores de resistência de falta: 0,1, 50, e 100 ohms. Para a grande maioria destes casos, não se notou variação na precisão do algoritmo devido à resistência de falta, conforme pode ser observado nas Figuras (51 e 52).

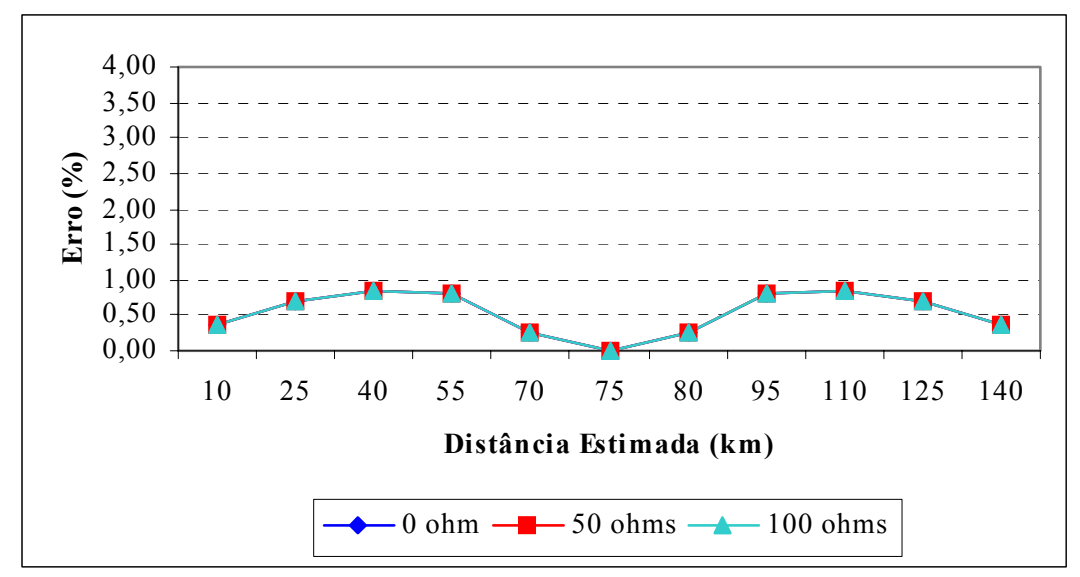

FIGURA 51 - Influência da resistência de falta em situações de faltas fase-terra (AT), com resistências de falta de 0, 50 e $100 \Omega$ e ângulo de incidência de falta de $90^{\circ}$ 


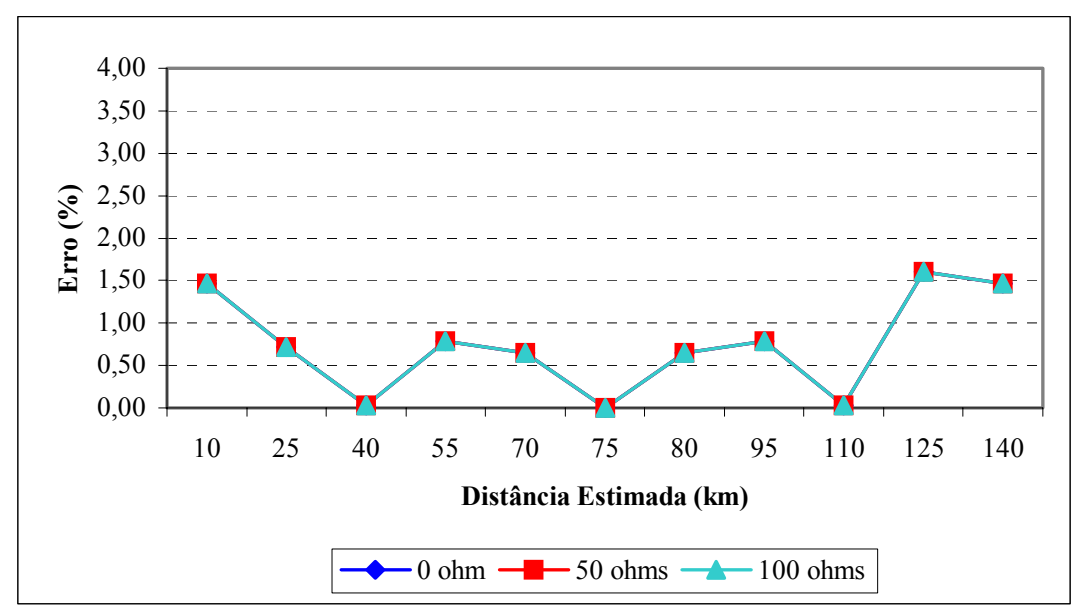

FIGURA 52 - Influência da resistência de falta em situações de faltas fase-fase-terra (BCT), com resistências de falta de 0, 50 e $100 \Omega$ e ângulo de incidência de falta de $90^{\circ}$

A fim de confirmar o desempenho do algoritmo e da técnica em questão, o mesmo também foi exposto á situações de faltas fase-terra e fase-fase-terra considerando elevadas resistências de faltas (200 e $400 \mathrm{ohms}$ ), que apesar de serem incomuns, também podem ocorrer nos sistemas.

Nestes casos o algoritmo também manteve uma ótima precisão conforme podemos verificar pela Figura 53 que apresenta alguns casos de falta AC-Terra com ângulo de incidência de $0^{\circ}$. Porém, em alguns casos de faltas fase-terra, com ângulo de incidência de falta de 0 graus e resistência de falta de 400 ohms, o algoritmo apresentou algumas localizações errôneas. Cabe ressaltar que estas circunstâncias de faltas são as piores possíveis, pois alia alta resistência a um baixo ângulo de incidência de falta, o que conduz a uma expressiva atenuação das ondas viajantes, e quase nenhuma variação da forma de onda da tensão. Esta situação pode ser ilustrada pela Figura 54, que apresenta as formas de ondas dos sinais trifásicos de tensão para uma falta AT a $80 \mathrm{~km}$ da barra E.

Sendo assim, novos testes foram realizados com os mesmos valores de resistência de falta (100, 200 e 400 ohms), mas com ângulos de incidência de faltas maiores $\left(45^{\circ}\right.$ e $\left.70^{\circ}\right)$. Como se esperava, os resultados voltaram a ser satisfatórios para todos os casos de faltas fase-terra analisados. Este resultado, assim como os demais resultados com altas resistências de falta podem ser observados no Apêndice A. 


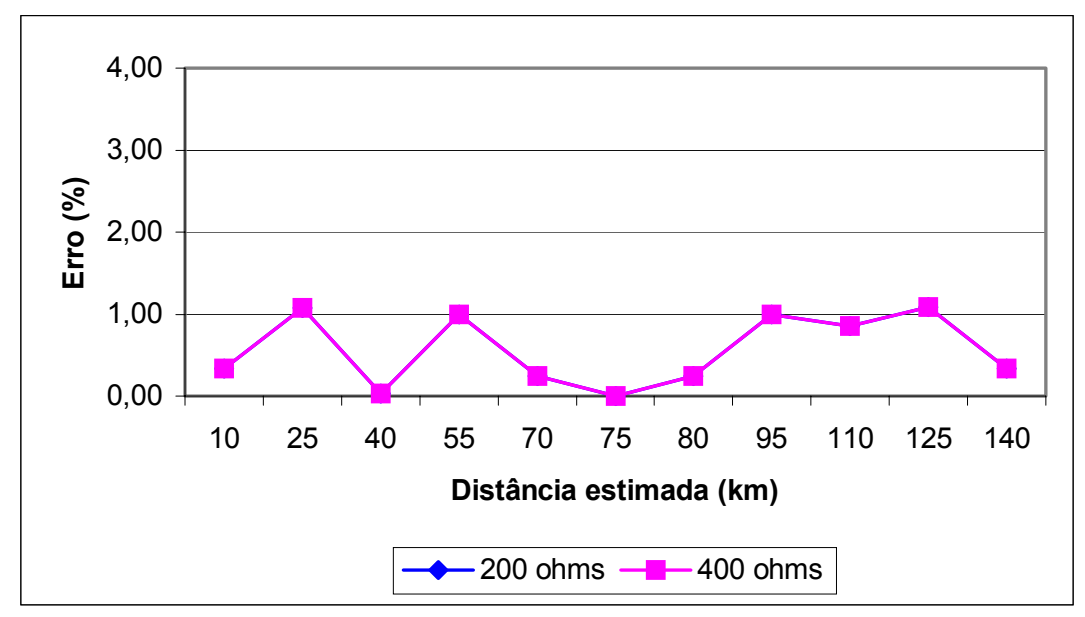

FIGURA 53 - Influência da resistência de falta em situações de faltas fase-fase-terra (ACT), ), com resistências de falta de 200 e $400 \Omega$ e ângulo de incidência de falta de $90^{\circ}$.

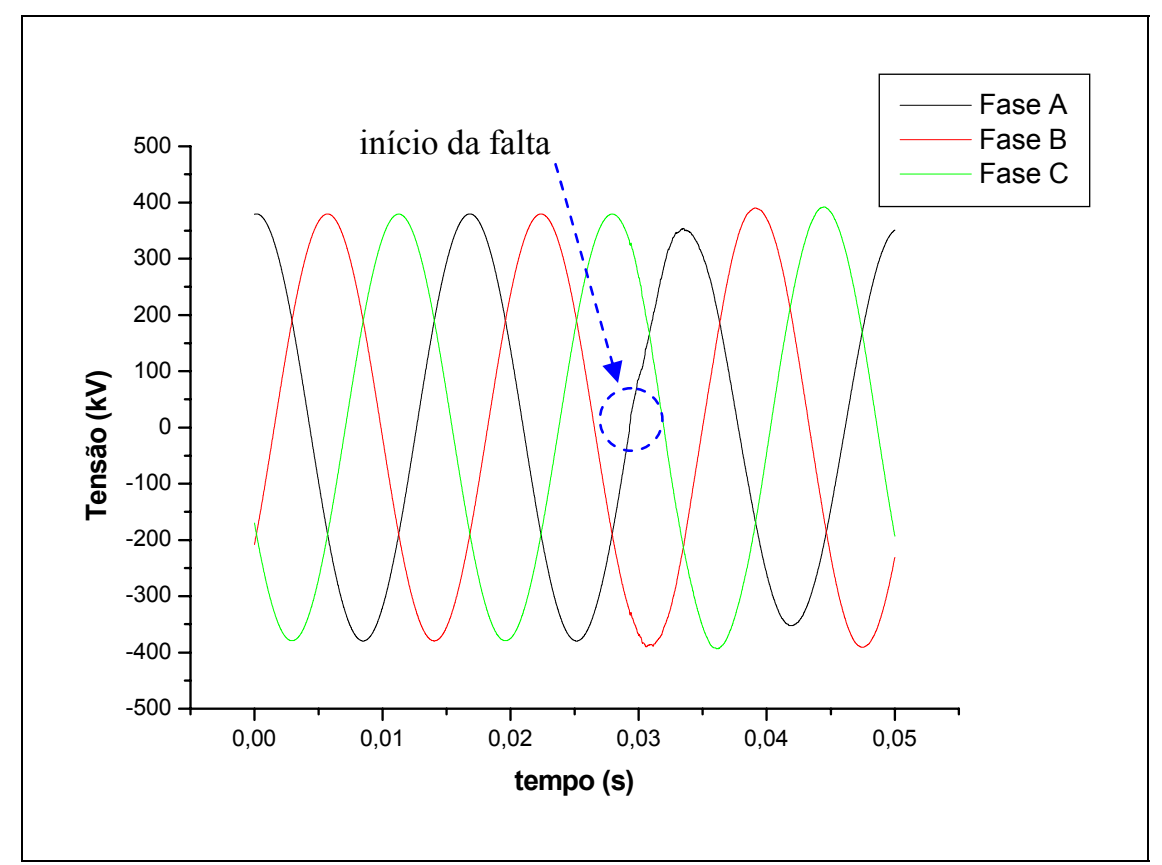

FIGURA 54 - Falta AT a $80 \mathrm{~km}$ da barra E, com ângulo de incidência de falta de $0^{0}$ e resistência de falta de $400 \Omega$

\subsubsection{Influência da taxa amostral}

A verificação da influência da taxa amostral na precisão e desempenho do algoritmo é muito importante, pois o método de localização abordado é baseado no tempo de viagem das ondas, sendo a precisão do algoritmo diretamente relacionado a freqüência de amostragem utilizada. 
A técnica que utiliza dados de dois terminais foi testada variando-se a freqüência de amostragem do sinal conforme segue: 240, 120, 60 e 15,36 kHz. Através da análise destes testes, observou-se que a precisão do algoritmo, na maioria dos testes, é proporcional a freqüência utilizada, ou seja, quanto maior a taxa amostral, maior a precisão do algoritmo. Outra observação importante é que para taxas de amostragem inferiores a $60 \mathrm{kHz}$, a precisão do algoritmo fica comprometida, embora o algoritmo ainda consiga localizar a falta.

Uma vez que esta técnica apresenta uma precisão satisfatória para os testes realizados com uma taxa amostral de 120 ou $240 \mathrm{kHz}$, não se justificaria a utilização de uma taxa amostral maior, considerando principalmente, o valor econômico a ser despendido.

As Tabelas (17 e 18) ilustram alguns testes realizados variando-se a taxa amostral empregada, para situações de faltas fase-terra e fase-fase. Os erros médios apresentados nestas Tabelas ressaltam melhor a influência da taxa amostral. Outros resultados poderão ser encontrados no Apêndice A deste trabalho.

TABELA 17 -Influência da taxa amostral em situações de falta fase-terra

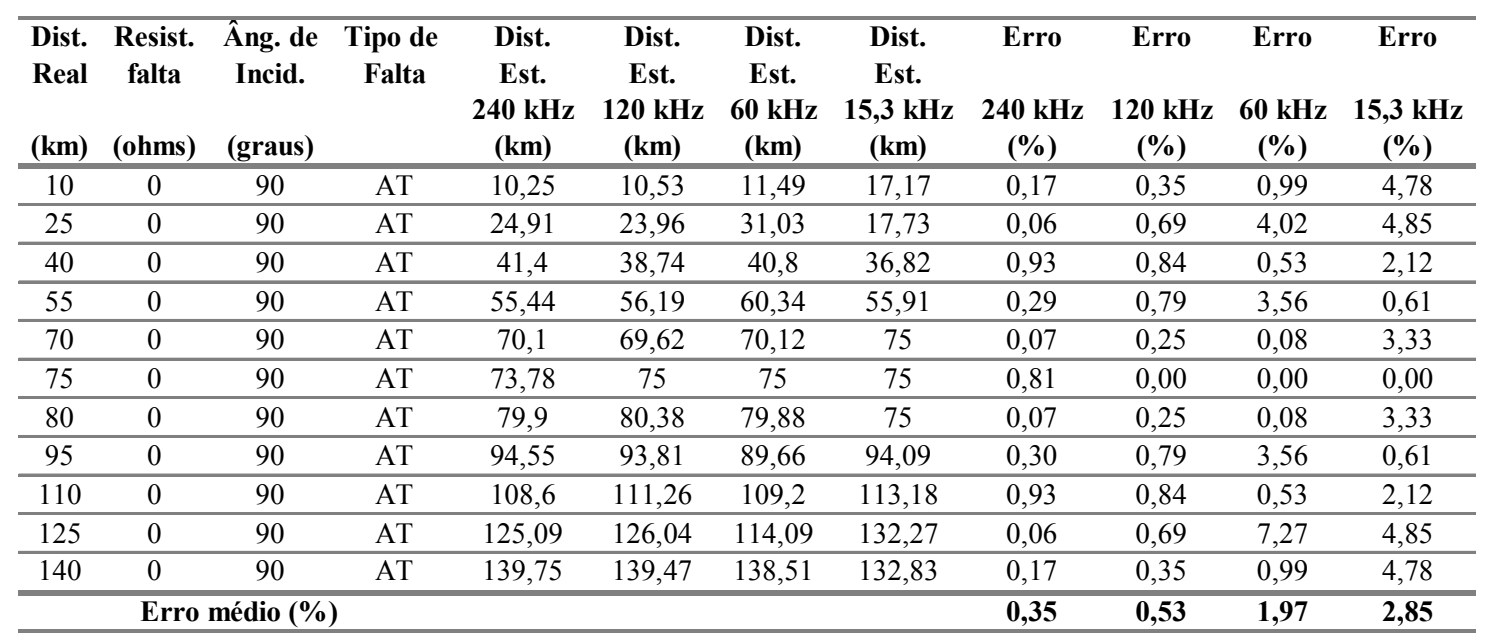


TABELA 18 -Influência da taxa amostral em situações de falta fase-fase

\begin{tabular}{|c|c|c|c|c|c|c|c|c|c|c|}
\hline $\begin{array}{c}\text { Distância } \\
\text { Real } \\
(\mathbf{k m})\end{array}$ & $\begin{array}{l}\text { Âng. de } \\
\text { Incid. } \\
\text { (graus) }\end{array}$ & $\begin{array}{c}\text { Tipo de } \\
\text { Falta }\end{array}$ & $\begin{array}{c}\text { Distância } \\
\text { Estimada } \\
240 \text { kHz } \\
(\mathbf{k m})\end{array}$ & $\begin{array}{c}\text { Distância } \\
\text { Estimada } \\
120 \text { kHz } \\
(\mathbf{k m})\end{array}$ & $\begin{array}{c}\text { Distância } \\
\text { Estimada } \\
60 \text { kHz } \\
(\mathbf{k m})\end{array}$ & $\begin{array}{c}\text { Distância } \\
\text { Estimada } \\
15,3 \text { kHz } \\
(\mathbf{k m})\end{array}$ & $\begin{array}{c}\text { Erro } \\
240 \mathrm{kHz} \\
(\%)\end{array}$ & $\begin{array}{c}\text { Erro } \\
120 \mathrm{kHz} \\
(\%)\end{array}$ & $\begin{array}{c}\text { Erro } \\
60 \mathrm{kHz} \\
(\%)\end{array}$ & $\begin{array}{c}\text { Erro } \\
15,3 \mathrm{kHz} \\
(\%)\end{array}$ \\
\hline 10 & 0 & $\mathrm{AB}$ & 10,27 & 7,85 & 11,47 & 17,16 & 0,18 & 1,43 & 0,98 & 4,77 \\
\hline 25 & 0 & $\mathrm{AB}$ & 24,93 & 23,96 & 31,03 & 36,83 & 0,05 & 0,69 & 4,02 & 7,89 \\
\hline 40 & 0 & $\mathrm{AB}$ & 41,42 & 40,08 & 40,8 & 36,83 & 0,95 & 0,05 & 0,53 & 2,11 \\
\hline 55 & 0 & $\mathrm{AB}$ & 56,68 & 56,19 & 55,45 & 55,9 & 1,12 & 0,79 & 0,30 & 0,60 \\
\hline 70 & 0 & $\mathrm{AB}$ & 70,1 & 70,97 & 70,12 & 75 & 0,07 & 0,65 & 0,08 & 3,33 \\
\hline 75 & 0 & $\mathrm{AB}$ & 75 & 75 & 75 & 75 & 0,00 & 0,00 & 0,00 & 0,00 \\
\hline 80 & 0 & $\mathrm{AB}$ & 79,9 & 79,03 & 79,88 & 75 & 0,07 & 0,65 & 0,08 & 3,33 \\
\hline 95 & 0 & $\mathrm{AB}$ & 94,55 & 93,81 & 94,55 & 94,08 & 0,30 & 0,79 & 0,30 & 0,61 \\
\hline 110 & 0 & $\mathrm{AB}$ & 108,58 & 109,92 & 109,2 & 113,17 & 0,95 & 0,05 & 0,53 & 2,11 \\
\hline 125 & 0 & $\mathrm{AB}$ & 127,07 & 126,04 & 118,98 & 113,17 & 1,38 & 0,69 & 4,01 & 7,89 \\
\hline 140 & 0 & $\mathrm{AB}$ & 139,73 & 142,15 & 138,53 & 132,84 & 0,18 & 1,43 & 0,98 & 4,77 \\
\hline \multicolumn{7}{|c|}{ Erro médio (\%) } & 0,48 & 0,66 & 1,07 & 3,40 \\
\hline
\end{tabular}

\subsubsection{Influência da perda de sincronismo dos dados}

Outro importante estudo realizado neste trabalho, diz respeito a sincronização dos dados registrados em ambos os terminais, ou melhor dizendo, o efeito de um possível mau sincronismo dos dados na precisão do algoritmo.

Como já descrito anteriormente, a técnica de sincronismo sugerida foi a utilização do GPS, por apresentar auto grau de segurança e precisão, o que justificaria o custo a ser empreendido para instalação e manutenção de tal dispositivo.

Segundo a literatura, principalmente no tocante á localização de faltas utilizando-se de GPS, o maior erro que pode ser introduzido pelo GPS na sincronização dos dados é de $1 \mu \mathrm{s}$, que corresponderia a uma imprecisão de aproximadamente $\pm 300 \mathrm{~m}$.

A fim de comprovarmos o efeito da influência de um mau sincronismo, o algoritmo foi testado utilizando-se o maior erro que o GPS poderia introduzir nas medidas, ou seja, de $1 \mu$ s em relação aos dados registrados no terminal remoto. Os resultados obtidos apresentaram um erro variando entre 140 e $150 \mathrm{~m}$. Porém, na média geral dos resultados, não houve uma significante alteração. Observa-se que o erro encontrado é aproximadamente metade do erro citado na literatura. Isto se deve a formulação característica desta técnica (Eq.(5.6)), que determina que a influência causada por um mau sincronismo dos dados seja diretamente proporcional a metade do tempo do erro total de sincronismo.

Dado a observação quanto ao efeito causado por um mau sincronismo, o algoritmo também foi testado considerando um caso mais extremo, correspondente à perda de sincronismo igual a uma amostra $(8,33 \mu \mathrm{s})$. Nestes casos o algoritmo 
apresentou um erro de $\pm 1,35 \mathrm{~km}$, o que corresponde a aproximadamente metade do erro introduzido pelo tempo de atraso total, confirmando o exposto acima.

A Figura 55 ilustra alguns casos de faltas fase-terra onde foi considerado uma perda de sincronismo correspondente a uma amostra. Outros resultados referentes a estes testes podem ser obtidos no Apêndice A.

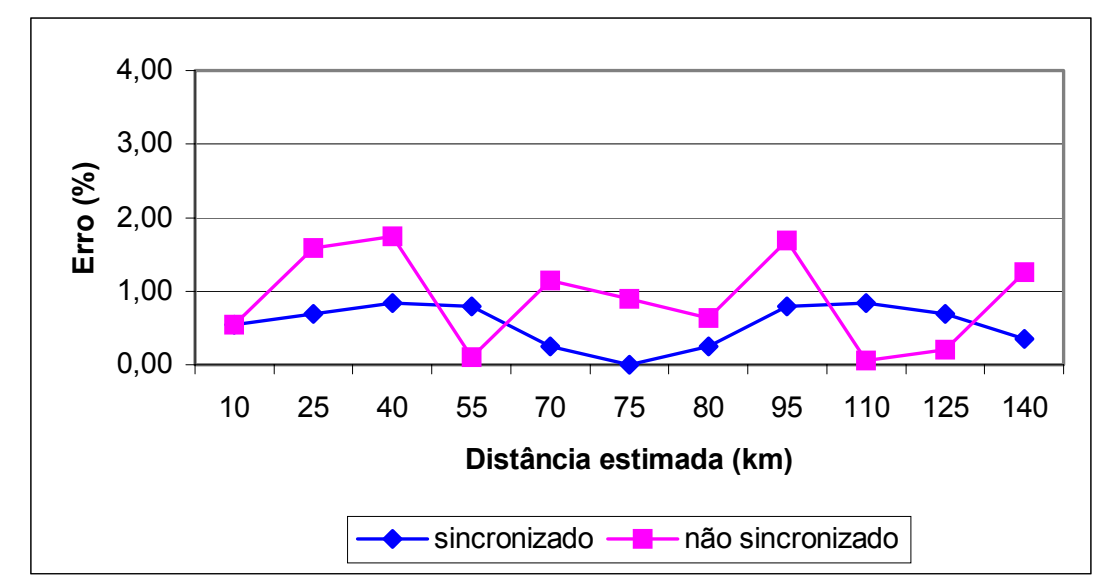

FIGURA 55 - Influência da perda de sincronismo (1 amostra) considerando situações de faltas faseterra com ângulo de incidência de $90^{\circ}$.

\subsubsection{Influência da imprecisão na determinação dos parâmetros da linha}

Tendo o conhecimento de que a obtenção de algumas variáveis, tais como os parâmetros da linha de transmissão e conseqüentemente a velocidade de propagação da onda na linha em questão, com a precisão requerida pelo método de ondas viajantes, apresenta algumas dificuldades, foram realizados alguns testes para avaliar a influência da imprecisão destas variáveis sobre o algoritmo.

Os testes foram conduzidos variando-se os parâmetros L (indutância) e C (capacitância) da linha em $+/-5 \%$, acarretando assim, imprecisões no cálculo da velocidade de propagação da onda na linha em questão.

Tais testes demonstram que há perda da precisão do algoritmo quando são utilizadas variáveis imprecisas, uma vez que estas influem diretamente no cálculo da distância e não na determinação dos tempos de reflexão das ondas, como já esperado. Contudo, o algoritmo ainda apresenta bons resultados.

Notou-se também, que o algoritmo foi significantemente afetado quando da consideração de erros tendendo a valores menores (erro de -5\%). A Figura 56 ilustra alguns exemplos de situações de faltas fase-terra com ângulo de incidência de falta de $0^{\circ}$ 
onde podemos constatar as observações descritas acima. Testes complementares podem ser encontrados no Apêndice A.

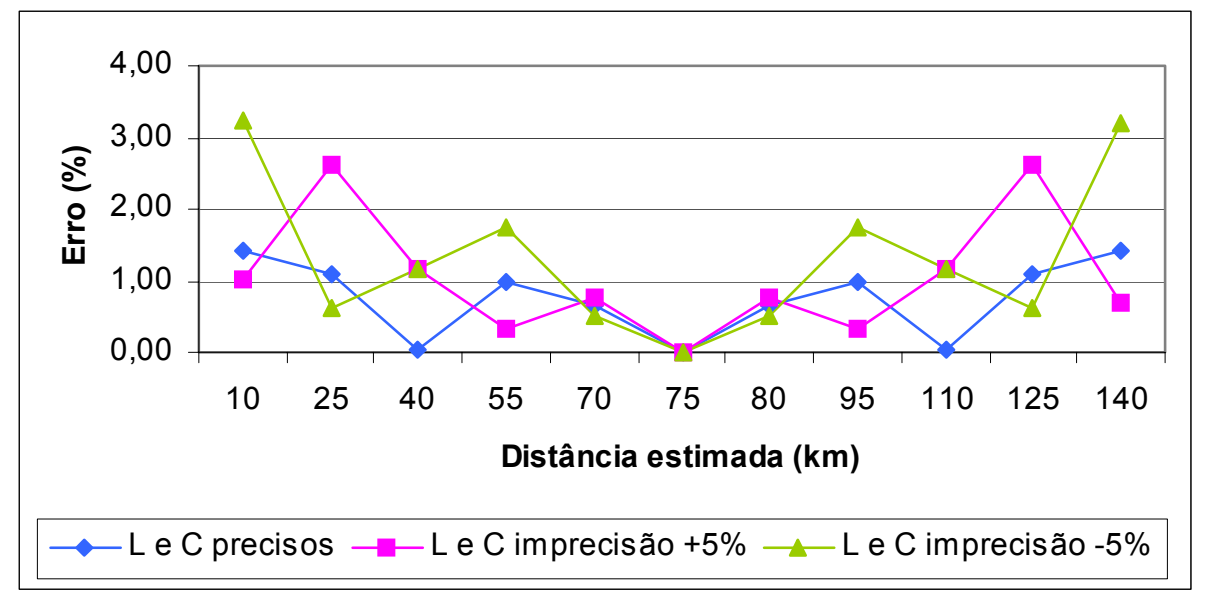

FIGURA 56 - Influência da imprecisão dos parâmetros de linha (L e C) em situações de falta fase-terra.

Tendo em vista a dificuldade em se determinar com grande precisão algumas variáveis essenciais ao algoritmo e a observância destas na precisão do algoritmo, faz-se necessário um estudo preliminar de maneira a garantir a precisão dos parâmetros envolvidos. Uma alternativa para se estimar tais variáveis seria a utilização de softwares de simulação de sistemas elétricos, tal como o ATP. Os resultados obtidos por estes meios geralmente conseguem uma boa aproximação do valor real.

\subsubsection{Comportamento do algoritmo frente ao acoplamento mútuo das fases em circuitos duplos de transmissão}

É comum encontrarmos no sistema elétrico, circuitos duplos de transmissão, por estes possibilitarem uma maior transmissão de potência a um custo menor de investimento, necessitando apenas, de uma torre para sustentação de dois circuitos.

Portanto, conforme o exposto acima, é importante verificarmos o desempenho do localizador de faltas aplicado a um sistema de transmissão duplo. Aparentemente, ao invés de um simples circuito, teríamos dois circuitos em paralelos sustentados pelas mesmas torres, mas isso não é tão simples assim, pois devemos considerar o acoplamento mútuo que existe entre as fases de ambos os circuitos, que podem vir a afetar o desempenho do localizador. 
Preocupado com o exposto acima, o algoritmo localizador foi testado, utilizando-se de dados registrados em dois terminais de um circuito duplo vertical de transmissão. Os dados trifásicos de tensão e corrente também foram obtidos através da simulação de um circuito duplo vertical em situação faltosa por meio do software ATP. Nestas simulações também foram considerados, dentre outros, os parâmetros dos cabos fase e terra e a disposição geométrica destes na torre de transmissão, buscando-se a maior fidelidade possível na representação da linha. As faltas foram aplicadas na mesma linha de $150 \mathrm{~km}$ entre as barras E e F, considerando agora um circuito duplo. Dados referentes às torres e cabos utilizados, assim como, dados sobre o circuito elétrico como um todo, podem ser encontrados no Capítulo 4.

Salienta-se que, para se aplicar o localizador de faltas sobre este tipo de sistema, algumas alterações e adequações em alguns parâmetros tais como: limiares e coeficientes de falta foram necessárias.

A Tabela 19 apresenta os resultados obtidos para casos de faltas fase-terra. Esta Tabela demonstra que o algoritmo manteve um bom desempenho, não sendo, portanto, influenciado pelo acoplamento mútuo entre os circuitos. Pela análise da Figura 57 podemos ressaltar que 97\% dos casos apresentaram erros inferiores a 1,0\%. A única alteração constatada nestes casos e em outros testes, foi a inversão de precisão com respeito ao ângulo de incidência da falta, pois nestes casos os resultados para faltas com ângulo de incidência a 0 graus foram melhores quando comparados aos resultados para faltas com ângulos de inserção de 90 graus.

Os demais resultados dos testes realizados podem ser encontrados no Apêndice B.

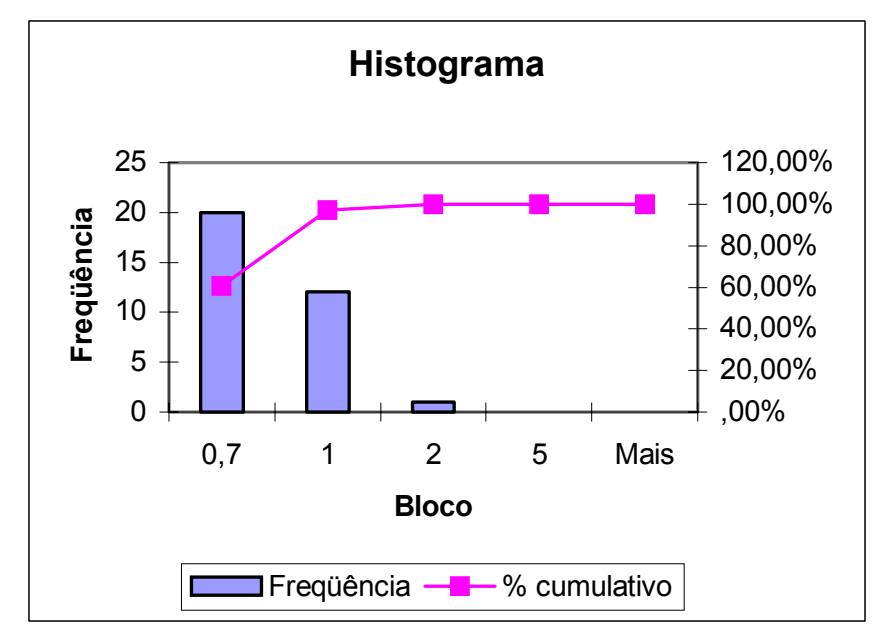

FIGURA 57 - Histograma referente aos casos de faltas fase-terra aplicadas sobre um circuito duplo 
TABELA 19 -Faltas fase-terra (AT) aplicadas no circuito duplo

\begin{tabular}{|c|c|c|c|c|c|c|}
\hline $\begin{array}{c}\text { Distância } \\
\text { Real } \\
\text { (km) }\end{array}$ & $\begin{array}{l}\text { Resist. } \\
\text { falta } \\
(\text { ohms })\end{array}$ & $\begin{array}{c}\text { Ângulo de } \\
\text { Incidência } \\
\text { (graus) }\end{array}$ & $\begin{array}{c}\text { Tipo de } \\
\text { Falta }\end{array}$ & $\begin{array}{c}\text { Distância } \\
\text { Estimada } \\
\quad(\mathbf{k m})\end{array}$ & $\begin{array}{l}\text { Erro } \\
\text { Abs. } \\
(\mathbf{k m})\end{array}$ & $\begin{array}{l}\text { Erro } \\
(\%)\end{array}$ \\
\hline 10 & 0 & 0 & AT & 8,63 & 1,37 & 0,91 \\
\hline 10 & 50 & 0 & AT & 11,29 & 1,29 & 0,86 \\
\hline 10 & 100 & 0 & AT & 11,29 & 1,29 & 0,86 \\
\hline 25 & 0 & 0 & AT & 24,56 & 0,44 & 0,29 \\
\hline 25 & 50 & 0 & AT & 24,56 & 0,44 & 0,29 \\
\hline 25 & 100 & 0 & AT & 24,56 & 0,44 & 0,29 \\
\hline 40 & 0 & 0 & AT & 40,48 & 0,48 & 0,32 \\
\hline 40 & 50 & 0 & AT & 40,48 & 0,48 & 0,32 \\
\hline 40 & 100 & 0 & AT & 40,48 & 0,48 & 0,32 \\
\hline 55 & 0 & 0 & AT & 56,41 & 1,41 & 0,94 \\
\hline 55 & 50 & 0 & AT & 56,41 & 1,41 & 0,94 \\
\hline 55 & 100 & 0 & AT & 56,41 & 1,41 & 0,94 \\
\hline 70 & 0 & 0 & AT & 69,7 & 0,3 & 0,20 \\
\hline 70 & 50 & 0 & AT & 69,7 & 0,3 & 0,20 \\
\hline 70 & 100 & 0 & AT & 69,7 & 0,3 & 0,20 \\
\hline 75 & 0 & 0 & AT & 75 & 0 & 0,00 \\
\hline 75 & 50 & 0 & $\mathrm{AT}$ & 75 & 0 & 0,00 \\
\hline 75 & 100 & 0 & AT & 75 & 0 & 0,00 \\
\hline 80 & 0 & 0 & AT & 80,3 & 0,3 & 0,20 \\
\hline 80 & 50 & 0 & AT & 80,3 & 0,3 & 0,20 \\
\hline 80 & 100 & 0 & AT & 80,3 & 0,3 & 0,20 \\
\hline 95 & 0 & 0 & $\mathrm{AT}$ & 93,58 & 1,42 & 0,95 \\
\hline 95 & 50 & 0 & AT & 93,58 & 1,42 & 0,95 \\
\hline 95 & 100 & 0 & AT & 93,58 & 1,42 & 0,95 \\
\hline 110 & 0 & 0 & AT & 109,52 & 0,48 & 0,32 \\
\hline 110 & 50 & 0 & $\mathrm{AT}$ & 109,52 & 0,48 & 0,32 \\
\hline 110 & 100 & 0 & AT & 112,17 & 2,17 & 1,45 \\
\hline 125 & 0 & 0 & $\mathrm{AT}$ & 125,44 & 0,44 & 0,29 \\
\hline 125 & 50 & 0 & $\mathrm{AT}$ & 125,44 & 0,44 & 0,29 \\
\hline 125 & 100 & 0 & $\mathrm{AT}$ & 125,44 & 0,44 & 0,29 \\
\hline 140 & 0 & 0 & AT & 141,37 & 1,37 & 0,91 \\
\hline 140 & 50 & 0 & AT & 138,71 & 1,29 & 0,86 \\
\hline 140 & 100 & 0 & AT & 141,37 & 1,37 & 0,91 \\
\hline \multicolumn{6}{|c|}{ Erro médio (\%) } & $\mathbf{0 , 5 1}$ \\
\hline
\end{tabular}




\subsubsection{Comportamento do algoritmo frente à faltas fora da zona de cobertura considerando circuitos duplos de transmissão}

No decorrer deste trabalho também foram efetuados alguns testes para verificar a sensibilidade do algoritmo quando este é submetido a situações de faltas no outro circuito de uma linha de transmissão dupla vertical. Adicionando-se a estes testes, novas situações foram aplicadas sobre o circuito onde se encontra o localizador, porém, caracterizando situações alocadas fora da zona de cobertura do localizador, a fim de se verificar o comportamento do mesmo.

Em ambas as situações verificou-se que o localizador ateve-se a ocorrência dos distúrbios fora da sua zona de cobertura, como ilustra a Figura 58, mas não os pode localizar, devido as suas características próprias de implementação e as características impostas por esse tipo de sistema.

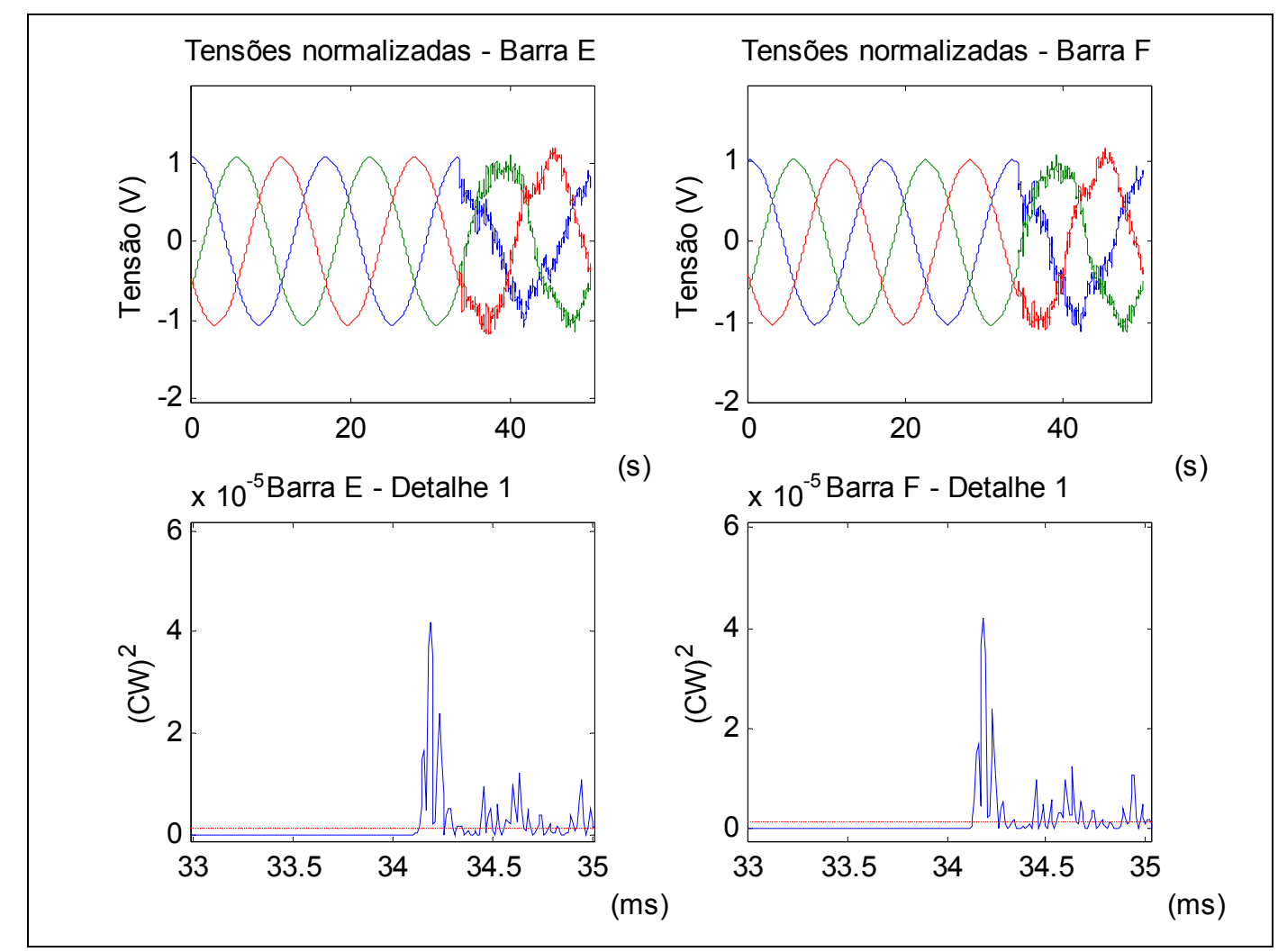

FIGURA 58 - Dados registrados na barra E e F para uma falta fase-terra (AT) aplicada no circuito 2 a $50 \mathrm{~km}$ da barra I sobre a linha $I-G$.

Cabe ressaltar que, caso haja uma falta na linha em paralelo à linha onde está o localizador, este não será responsável pela localização da falta na mesma, pois a sua 
respectiva linha permanecerá operando normalmente não sendo a localização ativada, uma vez que o localizador opera off-line.

Para resolver o problema de faltas fora da zona de proteção do localizador, propõe-se desenvolver novas rotinas capazes de fazer esta operação, podendo ser estas baseadas em conceitos de direção de corrente e intervalos de reflexão. Neste intuito alguns estudos já foram iniciados, onde rotinas que monitoram a direção da corrente e o intervalo de tempo de chegada das ondas nos terminais estão sendo testadas a fim de se detectar se a falta está fora ou dentro da área de cobertura do localizador. Os resultados obtidos até então, considerando o circuito duplo proposto, são bastante promissores, tendo em todos os casos testados até o momento 100\% de eficácia. Alguns destes resultados podem ser observados nas Tabela 20 e 21, onde podemos verificar o bom comportamento do algoritmo em detectar faltas dentro e fora da sua zona de cobertura. Pode-se observar que o algoritmo percebe o distúrbio fora da zona de proteção através da análise dos sinais de detalhe 1, mas não o localiza. A recíproca é verdadeira para o caso de faltas dentro da área de cobertura, porém nestes casos a localização da falta é efetuada com sucesso. 
TABELA 20 - Faltas fase-terra e fase-fase aplicadas no circuito 1 da linha dupla

\begin{tabular}{|c|c|c|c|c|c|c|c|}
\hline $\begin{array}{c}\text { Circuito } 1 \\
\text { Linha }\end{array}$ & $\begin{array}{c}\text { Distância } \\
\text { Real } \\
\text { (km) }\end{array}$ & $\begin{array}{c}\text { Resist. } \\
\text { falta } \\
(\text { ohms })\end{array}$ & $\begin{array}{c}\text { Ângulo de } \\
\text { Incidência } \\
\text { (graus) }\end{array}$ & $\begin{array}{c}\text { Tipo de } \\
\text { Falta }\end{array}$ & $\begin{array}{l}\text { Distância } \\
\text { Estimada } \\
\quad(\mathbf{k m})\end{array}$ & $\begin{array}{l}\text { Erro } \\
\text { Abs. } \\
(\mathbf{k m})\end{array}$ & $\begin{array}{l}\text { Erro } \\
(\%)\end{array}$ \\
\hline \multirow{9}{*}{ D-E } & 10 & 0 & 0 & AT & FAC* & - & - \\
\hline & 10 & 50 & 0 & AT & FAC & - & - \\
\hline & 10 & 100 & 0 & AT & FAC & - & - \\
\hline & 40 & 0 & 0 & AT & FAC & - & - \\
\hline & 40 & 50 & 0 & AT & FAC & - & - \\
\hline & 40 & 100 & 0 & AT & FAC & - & - \\
\hline & 60 & 0 & 0 & $\mathrm{AT}$ & FAC & - & - \\
\hline & 60 & 50 & 0 & AT & FAC & - & - \\
\hline & 60 & 100 & 0 & AT & FAC & - & - \\
\hline \multirow{9}{*}{ E-F } & 20 & 0 & 0 & $\mathrm{AB}$ & 19,25 & 0,75 & 0,50 \\
\hline & 20 & 50 & 0 & $\mathrm{AB}$ & 19,25 & 0,75 & 0,50 \\
\hline & 20 & 100 & 0 & $\mathrm{AB}$ & 19,25 & 0,75 & 0,50 \\
\hline & 80 & 0 & 0 & $\mathrm{AB}$ & 80,30 & 0,30 & 0,20 \\
\hline & 80 & 50 & 0 & $\mathrm{AB}$ & 80,30 & 0,30 & 0,20 \\
\hline & 80 & 100 & 0 & $\mathrm{AB}$ & 80,30 & 0,30 & 0,20 \\
\hline & 130 & 0 & 0 & $\mathrm{AB}$ & 130,75 & 0,75 & 0,50 \\
\hline & 130 & 50 & 0 & $\mathrm{AB}$ & 130,75 & 0,75 & 0,50 \\
\hline & 130 & 100 & 0 & $\mathrm{AB}$ & 130,75 & 0,75 & 0,50 \\
\hline \multirow{9}{*}{ F-G } & 10 & 0 & 0 & AT & FAC & - & - \\
\hline & 10 & 50 & 0 & AT & FAC & - & - \\
\hline & 10 & 100 & 0 & $\mathrm{AT}$ & FAC & - & - \\
\hline & 50 & 0 & 0 & AT & FAC & - & - \\
\hline & 50 & 50 & 0 & AT & FAC & - & - \\
\hline & 50 & 100 & 0 & AT & FAC & - & - \\
\hline & 80 & 0 & 0 & AT & FAC & - & - \\
\hline & 80 & 50 & 0 & $\mathrm{AT}$ & FAC & - & - \\
\hline & 80 & 100 & 0 & $\mathrm{AT}$ & FAC & - & - \\
\hline
\end{tabular}

*FAC = Fora da Área de Cobertura do Localizador 
TABELA 21 - Faltas fase-terra aplicadas no circuito 2 da linha dupla

\begin{tabular}{|c|c|c|c|c|c|c|c|}
\hline $\begin{array}{c}\text { Circuito } 2 \\
\text { Linha }\end{array}$ & $\begin{array}{c}\text { Distância } \\
\text { Real } \\
\text { (km) }\end{array}$ & $\begin{array}{c}\text { Resist. } \\
\text { falta } \\
(\text { ohms })\end{array}$ & $\begin{array}{c}\text { Ângulo de } \\
\text { Incidência } \\
\text { (graus) }\end{array}$ & $\begin{array}{c}\text { Tipo de } \\
\text { Falta }\end{array}$ & $\begin{array}{c}\text { Distância } \\
\text { Estimada } \\
\quad(\mathbf{k m})\end{array}$ & $\begin{array}{l}\text { Erro } \\
\text { Abs. } \\
\text { (km) }\end{array}$ & $\begin{array}{l}\text { Erro } \\
(\%)\end{array}$ \\
\hline \multirow{9}{*}{ D-H } & 10 & 0 & 0 & AT & FAC* & - & - \\
\hline & 10 & 50 & 0 & AT & FAC & - & - \\
\hline & 10 & 100 & 0 & AT & FAC & - & - \\
\hline & 40 & 0 & 0 & AT & FAC & - & - \\
\hline & 40 & 50 & 0 & AT & FAC & - & - \\
\hline & 40 & 100 & 0 & AT & FAC & - & - \\
\hline & 60 & 0 & 0 & AT & FAC & - & - \\
\hline & 60 & 50 & 0 & AT & FAC & - & - \\
\hline & 60 & 100 & 0 & AT & FAC & - & - \\
\hline \multirow{9}{*}{$\mathrm{H}-\mathrm{I}$} & 20 & 0 & 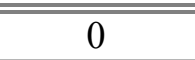 & AT & FAC & - & - \\
\hline & 20 & 50 & 0 & AT & FAC & - & - \\
\hline & 20 & 100 & 0 & AT & FAC & - & - \\
\hline & 80 & 0 & 0 & AT & FAC & - & - \\
\hline & 80 & 50 & 0 & AT & FAC & - & - \\
\hline & 80 & 100 & 0 & AT & FAC & - & - \\
\hline & 130 & 0 & 0 & AT & FAC & - & - \\
\hline & 130 & 50 & 0 & AT & FAC & - & - \\
\hline & 130 & 100 & 0 & AT & FAC & - & - \\
\hline \multirow{9}{*}{ I-G } & 10 & 0 & 0 & AT & FAC & - & - \\
\hline & 10 & 50 & 0 & AT & FAC & - & - \\
\hline & 10 & 100 & 0 & AT & FAC & - & - \\
\hline & 50 & 0 & 0 & AT & FAC & - & - \\
\hline & 50 & 50 & 0 & AT & FAC & - & - \\
\hline & 50 & 100 & 0 & AT & FAC & - & - \\
\hline & 80 & 0 & 0 & AT & FAC & - & - \\
\hline & 80 & 50 & 0 & AT & FAC & - & - \\
\hline & 80 & 100 & 0 & AT & FAC & - & - \\
\hline
\end{tabular}

*FAC = Fora da Área de Cobertura do Localizador

Outros resultados referentes a testes feitos para esta situação podem ser encontrados no apêndice B.

\subsection{Resultados alcançados utilizando-se dados provenientes de um terminal da linha}

Essa seção é dedicada à apresentação dos resultados obtidos pelo algoritmo de localização de faltas proposto, quando do emprego da técnica que utiliza dados de um terminal. 


\subsubsection{Resultados alcançados para faltas fase-fase terra, fase-fase e trifásicas}

Na técnica que utiliza dados provenientes de um terminal (terminal local), a falta é primeiramente classificada. Sendo a situação caracterizada como uma falta fase-faseterra, fase-fase ou trifásica, o tempo de reflexão $t_{d}$ entre o ponto da falta e o terminal E é obtido diretamente pela medida do intervalo de tempo entre os dois primeiros picos consecutivos dos sinais de detalhe 1 do modo 1. Resta então, o cálculo da localização da situação de falta em questão pela Eq. (5.8).

A Figura 59 mostra os sinais de detalhe 1 do modo 1 para uma falta fase-fase, simulada a $70 \mathrm{~km}$ da barra $\mathrm{E}$, com ângulo de incidência de $90^{\circ}$. Neste caso temos que $t_{d}$ é igual a 4,765e-4 seg.. Substituindo na Eq.(5.8), temos que a distância estimada da falta é igual a $d=69,85 \mathrm{~km}$.

Em busca de uma melhor visualização e análise dos resultados obtidos por esta técnica, os resultados serão apresentados por meio de tabelas, gráficos e histogramas, os quais seguem os mesmos padrões dos resultados apresentados anteriormente.

A fim de não estendermos por demais e ao mesmo tempo, não tornar cansativo a leitura e a representação dos resultados, serão apresentados apenas alguns dos resultados dentre o montante de testes realizados. Outros resultados poderão ser encontrados no Apêndice A.

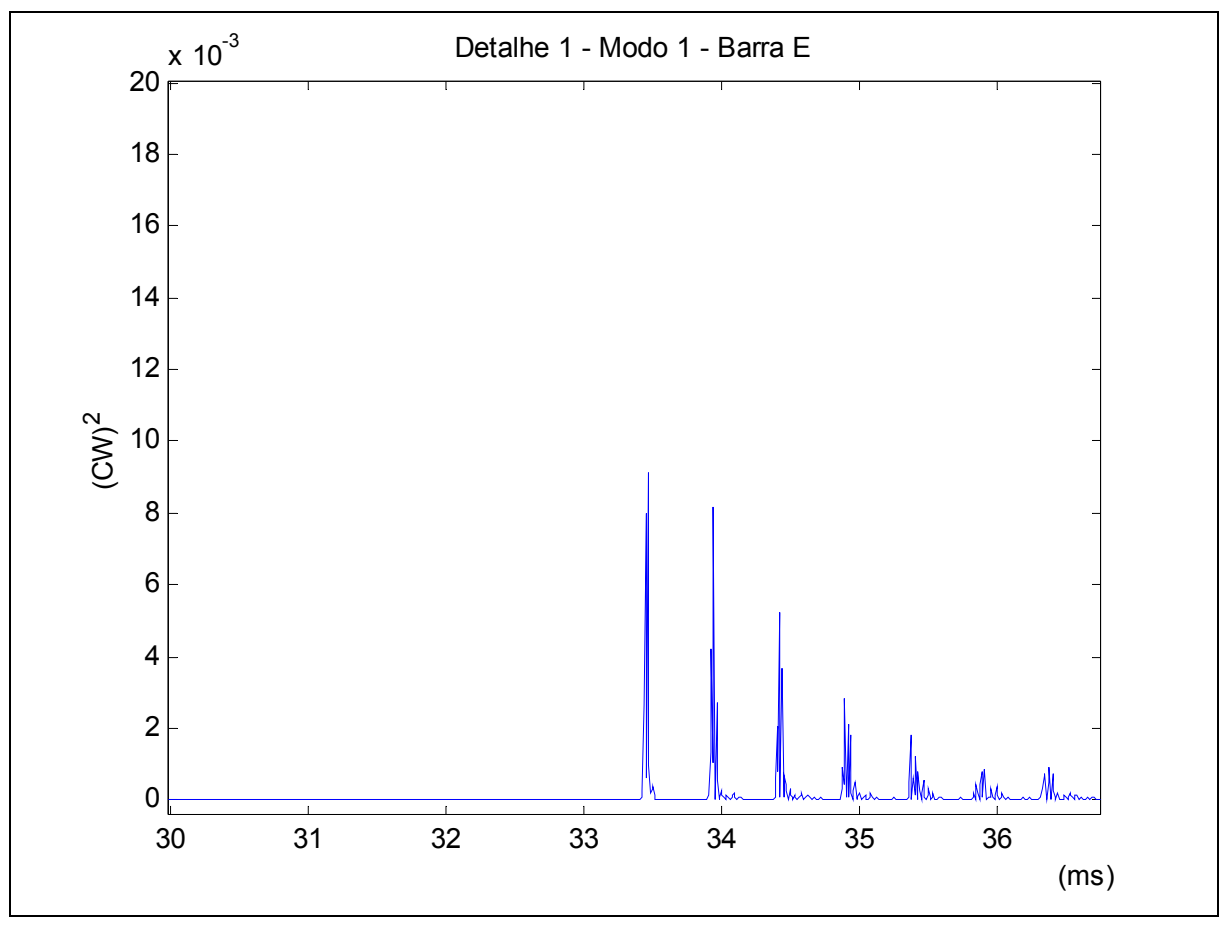

FIGURA 59 - Coeficientes wavelet para uma falta-fase fase(AB) a $70 \mathrm{~km}$ da barra E, com ângulo de incidência de $90^{\circ}$. 
TABELA 22 -Falta fase-fase (AB), com ângulo de incidência de falta de $0^{0}$

\begin{tabular}{cccccc}
\hline $\begin{array}{c}\text { Distância } \\
\text { Real } \\
(\mathbf{k m})\end{array}$ & $\begin{array}{c}\text { Angulo de } \\
\text { Incidência } \\
\text { (graus) }\end{array}$ & $\begin{array}{c}\text { Tipo de } \\
\text { Falta }\end{array}$ & $\begin{array}{c}\text { Distância } \\
\text { Estimada } \\
\mathbf{( k m )}\end{array}$ & $\begin{array}{c}\text { Erro } \\
\mathbf{A b s} . \\
(\mathbf{k m})\end{array}$ & $\begin{array}{c}\text { Erro } \\
(\mathbf{\%})\end{array}$ \\
\hline 10 & 0 & $\mathrm{AB}$ & 10,74 & 0,74 & 0,49 \\
\hline 25 & 0 & $\mathrm{AB}$ & 24,19 & 0,81 & 0,54 \\
\hline 40 & 0 & $\mathrm{AB}$ & 40,3 & 0,30 & 0,20 \\
\hline 55 & 0 & $\mathrm{AB}$ & 56,4 & 1,40 & 0,93 \\
\hline 70 & 0 & $\mathrm{AB}$ & 68,5 & 1,50 & 1,00 \\
\hline 75 & 0 & $\mathrm{AB}$ & 75,21 & 0,21 & 0,14 \\
\hline 80 & 0 & $\mathrm{AB}$ & 80,59 & 0,59 & 0,39 \\
\hline 95 & 0 & $\mathrm{AB}$ & 94,02 & 0,98 & 0,65 \\
\hline 110 & 0 & $\mathrm{AB}$ & 110,14 & 0,14 & 0,09 \\
\hline 125 & 0 & $\mathrm{AB}$ & 126,25 & 1,25 & 0,83 \\
\hline 140 & 0 & $\mathrm{AB}$ & 142,38 & 2,38 & 1,59 \\
\hline \multicolumn{7}{c}{ Erro médio $(\mathbf{\%})$} \\
\hline
\end{tabular}

TABELA 24-Faltas trifásica (ABC), com ângulo de incidência de falta de $0^{\circ}$

\begin{tabular}{cccccc}
\hline $\begin{array}{c}\text { Distância } \\
\text { Real } \\
(\mathbf{k m})\end{array}$ & $\begin{array}{c}\text { Angulo de } \\
\text { Incidência } \\
\text { (graus) }\end{array}$ & $\begin{array}{c}\text { Tipo de } \\
\text { Falta }\end{array}$ & $\begin{array}{c}\text { Distância } \\
\text { Estimada } \\
\mathbf{( k m )}\end{array}$ & $\begin{array}{c}\text { Erro } \\
\text { Abs. } \\
(\mathbf{k m})\end{array}$ & $\begin{array}{c}\text { Erro } \\
\mathbf{( \% )}\end{array}$ \\
\hline 10 & 0 & $\mathrm{ABC}$ & 8,05 & 1,95 & 1,30 \\
\hline 25 & 0 & $\mathrm{ABC}$ & 24,19 & 0,81 & 0,54 \\
\hline 40 & 0 & $\mathrm{ABC}$ & 40,3 & 0,30 & 0,20 \\
\hline 55 & 0 & $\mathrm{ABC}$ & 56,41 & 1,41 & 0,94 \\
\hline 70 & 0 & $\mathrm{ABC}$ & 69,85 & 0,15 & 0,10 \\
\hline 75 & 0 & $\mathrm{ABC}$ & 75,21 & 0,21 & 0,14 \\
\hline 80 & 0 & $\mathrm{ABC}$ & 80,59 & 0,59 & 0,39 \\
\hline 95 & 0 & $\mathrm{ABC}$ & 94,02 & 0,98 & 0,65 \\
\hline 110 & 0 & $\mathrm{ABC}$ & 110,14 & 0,14 & 0,09 \\
\hline 125 & 0 & $\mathrm{ABC}$ & 126,25 & 1,25 & 0,83 \\
\hline 140 & 0 & $\mathrm{ABC}$ & 138,35 & 1,65 & 1,10 \\
\hline \multicolumn{7}{c}{ Erro médio (\%) } \\
\hline
\end{tabular}

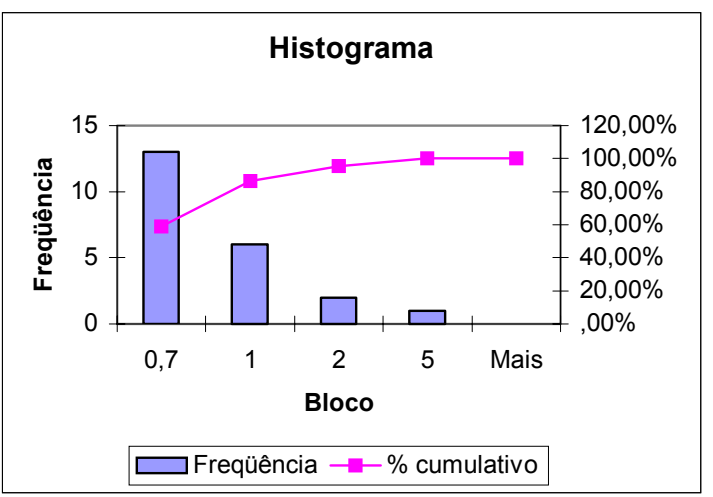

FIGURA 60 - Histograma referente as situações de faltas fase-fase ( $A B)$
TABELA 23 - Falta fase-fase (AB), com ângulo de incidência de falta de $90^{\circ}$

\begin{tabular}{cccccc}
\hline $\begin{array}{c}\text { Distância } \\
\text { Real } \\
(\mathbf{k m})\end{array}$ & $\begin{array}{c}\hat{\text { Angulo de }} \\
\text { Incidência } \\
\text { (graus) }\end{array}$ & $\begin{array}{c}\text { Tipo de } \\
\text { Falta }\end{array}$ & $\begin{array}{c}\text { Distância } \\
\text { Estimada } \\
(\mathbf{k m})\end{array}$ & $\begin{array}{c}\text { Erro } \\
\text { Abs. } \\
\mathbf{( k m )}\end{array}$ & $\begin{array}{c}\text { Erro } \\
\mathbf{( \% )}\end{array}$ \\
\hline 10 & 90 & $\mathrm{AB}$ & 10,74 & 0,74 & 0,49 \\
\hline 25 & 90 & $\mathrm{AB}$ & 24,19 & 0,81 & 0,54 \\
\hline 40 & 90 & $\mathrm{AB}$ & 40,3 & 0,30 & 0,20 \\
\hline 55 & 90 & $\mathrm{AB}$ & 53,72 & 1,28 & 0,85 \\
\hline 70 & 90 & $\mathrm{AB}$ & 69,85 & 0,15 & 0,10 \\
\hline 75 & 90 & $\mathrm{AB}$ & 75,21 & 0,21 & 0,14 \\
\hline 80 & 90 & $\mathrm{AB}$ & 85,96 & 5,96 & 3,97 \\
\hline 95 & 90 & $\mathrm{AB}$ & 96,7 & 1,70 & 1,13 \\
\hline 110 & 90 & $\mathrm{AB}$ & 108,79 & 1,21 & 0,81 \\
\hline 125 & 90 & $\mathrm{AB}$ & 123,57 & 1,43 & 0,95 \\
\hline 140 & 90 & $\mathrm{AB}$ & 139,69 & 0,31 & 0,21 \\
\hline \multicolumn{7}{c}{ Erro médio (\%) } & & & $\mathbf{0 , 8 5}$ \\
\hline
\end{tabular}

TABELA 25 -Faltas trifásicas (ABC), com ângulo de incidência de falta de $90^{\circ}$

\begin{tabular}{cccccc}
\hline $\begin{array}{c}\text { Distância } \\
\text { Real } \\
(\mathbf{k m})\end{array}$ & $\begin{array}{c}\text { Angulo de } \\
\text { Incidência } \\
\text { (graus) }\end{array}$ & $\begin{array}{c}\text { Tipo de } \\
\text { Falta }\end{array}$ & $\begin{array}{c}\text { Distância } \\
\text { Estimada } \\
\mathbf{( k m )}\end{array}$ & $\begin{array}{c}\text { Erro } \\
\text { Abs. } \\
(\mathbf{k m})\end{array}$ & Erro \\
$\mathbf{( \% )}$
\end{tabular}

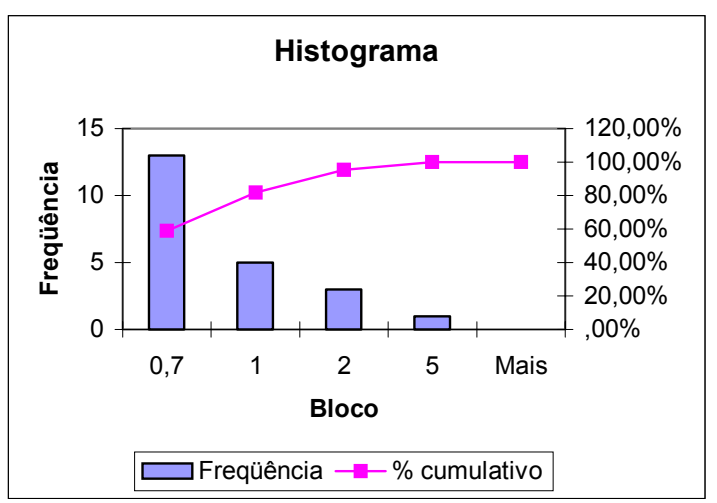

FIGURA 61 - Histograma referente as situações de faltas trifásicas $(A B C)$ 
TABELA 26 - Faltas Fase-Fase-Terra (ACT), com ângulo de incidência de falta de $0^{0}$ e resistência de falta de 0, 50 e $100 \mathrm{ohms}$

\begin{tabular}{|c|c|c|c|c|c|c|}
\hline $\begin{array}{c}\text { Distância } \\
\text { Real } \\
\text { (km) }\end{array}$ & $\begin{array}{c}\text { Resist. } \\
\text { falta } \\
\text { (ohms) }\end{array}$ & $\begin{array}{c}\text { Ângulo de } \\
\text { Incidência } \\
\text { (graus) }\end{array}$ & $\begin{array}{c}\text { Tipo de } \\
\text { Falta }\end{array}$ & $\begin{array}{c}\text { Distância } \\
\text { Estimada } \\
\quad(\mathbf{k m})\end{array}$ & $\begin{array}{l}\text { Erro } \\
\text { Abs. } \\
\text { (km) }\end{array}$ & $\begin{array}{l}\text { Erro } \\
(\%)\end{array}$ \\
\hline 10 & 0 & 0 & ACT & 9,4 & 0,60 & 0,40 \\
\hline 10 & 50 & 0 & ACT & 9,4 & 0,60 & 0,40 \\
\hline 10 & 100 & 0 & ACT & 9,4 & 0,60 & 0,40 \\
\hline 25 & 0 & 0 & ACT & 29,55 & 4,55 & 3,03 \\
\hline 25 & 50 & 0 & ACT & 29,55 & 4,55 & 3,03 \\
\hline 25 & 100 & 0 & ACT & 29,55 & 4,55 & 3,03 \\
\hline 40 & 0 & 0 & ACT & 37,61 & 2,39 & 1,59 \\
\hline 40 & 50 & 0 & ACT & 37,61 & 2,39 & 1,59 \\
\hline 40 & 100 & 0 & ACT & 37,61 & 2,39 & 1,59 \\
\hline 55 & 0 & 0 & ACT & 56,43 & 1,43 & 0,95 \\
\hline 55 & 50 & 0 & ACT & 56,43 & 1,43 & 0,95 \\
\hline 55 & 100 & 0 & ACT & 56,43 & 1,43 & 0,95 \\
\hline 70 & 0 & 0 & ACT & 69,88 & 0,12 & 0,08 \\
\hline 70 & 50 & 0 & ACT & 69,88 & 0,12 & 0,08 \\
\hline 70 & 100 & 0 & ACT & 69,88 & 0,12 & 0,08 \\
\hline 75 & 0 & 0 & ACT & 72,56 & 2,44 & 1,63 \\
\hline 75 & 50 & 0 & ACT & 72,56 & 2,44 & 1,63 \\
\hline 75 & 100 & 0 & ACT & 72,56 & 2,44 & 1,63 \\
\hline 80 & 0 & 0 & ACT & 77,94 & 2,06 & 1,37 \\
\hline 80 & 50 & 0 & ACT & 77,94 & 2,06 & 1,37 \\
\hline 80 & 100 & 0 & ACT & 77,94 & 2,06 & 1,37 \\
\hline 95 & 0 & 0 & ACT & 99,43 & 4,43 & 2,95 \\
\hline 95 & 50 & 0 & ACT & 99,43 & 4,43 & 2,95 \\
\hline 95 & 100 & 0 & ACT & 99,43 & 4,43 & 2,95 \\
\hline 110 & 0 & 0 & ACT & 110,12 & 0,12 & 0,08 \\
\hline 110 & 50 & 0 & ACT & 110,12 & 0,12 & 0,08 \\
\hline 110 & 100 & 0 & ACT & 110,12 & 0,12 & 0,08 \\
\hline 125 & 0 & 0 & ACT & 126,3 & 1,30 & 0,87 \\
\hline 125 & 50 & 0 & ACT & 126,3 & 1,30 & 0,87 \\
\hline 125 & 100 & 0 & ACT & 126,3 & 1,30 & 0,87 \\
\hline 140 & 0 & 0 & ACT & 139,74 & 0,26 & 0,17 \\
\hline 140 & 50 & 0 & ACT & 139,74 & 0,26 & 0,17 \\
\hline 140 & 100 & 0 & ACT & 139,74 & 0,26 & 0,17 \\
\hline \multicolumn{6}{|c|}{ Erro médio (\%) } & 1,19 \\
\hline
\end{tabular}




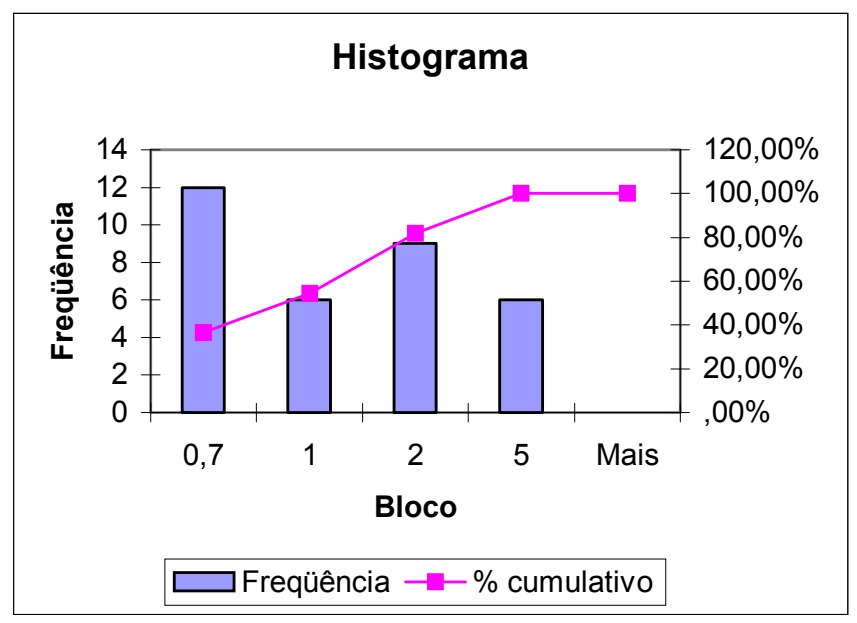

FIGURA 62 - Histograma referente as situações de falta fase-fase-terra (ACT)

Pela análise dos resultados obtidos e demonstrados nas Tabelas (22-26) e Figuras (60-62) podemos constatar que o algoritmo de localização empregando a técnica com dados registrados em um terminal apresentou uma boa precisão, sendo que, na maioria dos casos o erro percentual foi inferior a $0,7 \%$. Nota-se nas situações ilustradas que $86,36 \%$ das faltas bifásicas e $81,82 \%$ das trifásicas apresentaram erros inferiores a 1,0\%, sendo a maioria destes inferiores a 0,7\%. Os piores erros apresentados para ambos os tipos de faltas foram de 3,97\%, porém foram casos isolados. Para os casos de faltas fase-fase-terra mostrados, notamos que $81,82 \%$ destes apresentaram erros inferiores a $2,0 \%$ e o pior erro encontrado foi de $3,03 \%$.

De um modo geral, pode se observar que esta técnica é menos precisa se comparada com a técnica que utiliza dados de dois terminais, mas mesmo assim, apresenta resultados satisfatórios. Na maioria das vezes a imprecisão ou até mesmo, em alguns casos, a falha do algoritmo, justifica-se em grande parte, pela dificuldade em se detectar o segundo pico de reflexão, por ser este muito atenuado.

\subsubsection{Resultados alcançados para faltas fase-terra}

No caso de faltas fase-terra, como explicitado anteriormente, é necessário que haja uma pré-localização da falta, ou seja, determinar se a falta ocorreu na primeira ou segunda metade da LT, pois estas podem produzir padrões similares de reflexão (mesmo tempo de reflexão), o que leva a equacionamentos diferentes para se evitar localizações errôneas. Tais situações são ilustradas considerando a ocorrência de duas 
faltas, uma a $25 \mathrm{~km}$ da barra $\mathrm{E}$ (primeira metade) e outra a $125 \mathrm{~km}$ da barra $\mathrm{E}$ (segunda metade), lembrando que a linha entre as barras E e F tem um comprimento de $150 \mathrm{~km}$..

- Situação 1: falta fase A-terra à $25 \mathrm{~km}$ da barra E.

Considerando-se a falta classificada e pré-localizada na primeira metade da linha, o tempo $t_{d}$ é extraído através dos dois primeiros picos consecutivos do sinal de detalhe 1 do modo 1, conforme Figura 63. Para este exemplo, $t_{d}=1,65 e-4 \mathrm{~s}$, o qual é substituído na eq.(5.8) e, obtemos a distância da falta igual a $d=24,19 \mathrm{~km}$.

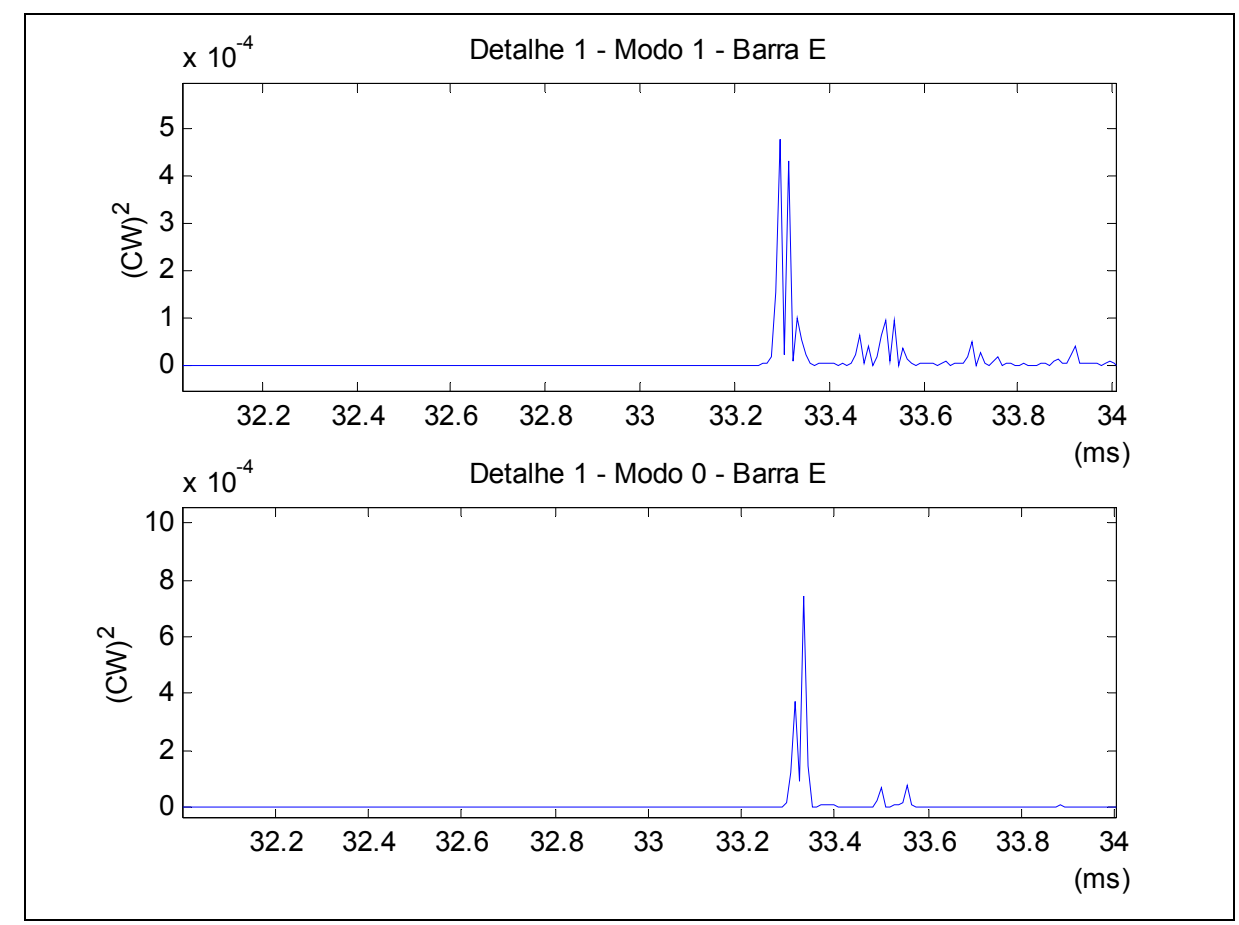

FIGURA 63 - Coeficientes wavelet para uma falta fase A-terra a $25 \mathrm{~km}$ da barra E, com resistência de falta de 0 ohms e ângulo de incidência de $90^{\circ}$.

- Situação 2: falta fase A-terra à $125 \mathrm{~km}$ da barra $\mathrm{E}$.

Análogo a situação 1 , encontramos $t_{d}=1,65 e-4 s$ através dos dois primeiros picos consecutivos do sinal de detalhe 1 do modo 1, conforme a Figura 64. Entretanto, para faltas fase-terra na segunda metade da linha, a localização da falta é estimada pela Eq. (5.9). Para este exemplo, temos que a distância da falta é igual a $d=125,81 \mathrm{~km}$. 


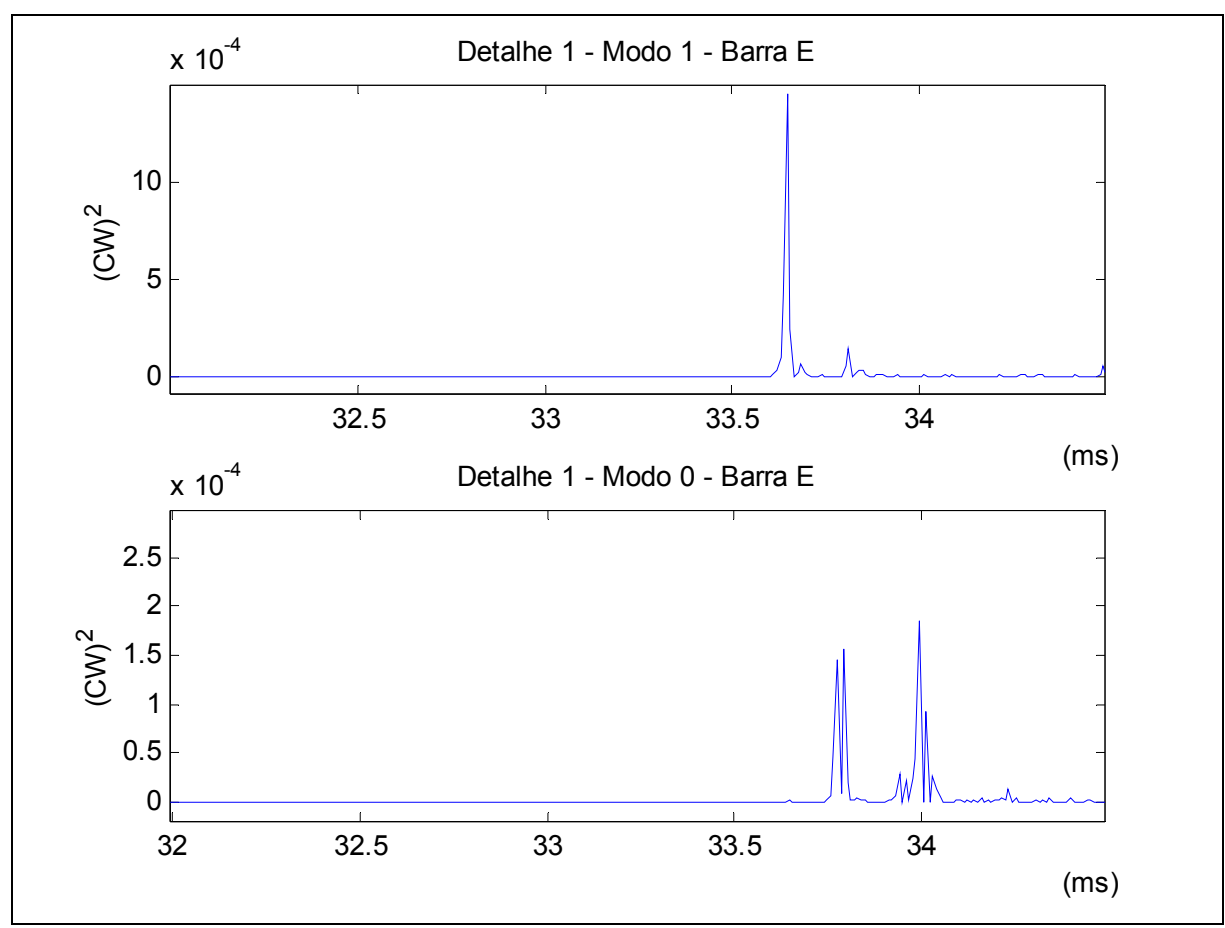

FIGURA 64 - Coeficientes wavelet para uma falta fase A-terra a $125 \mathrm{~km}$ da barra E, com resistência de falta de 0 ohms e ângulo de incidência de $90^{\circ}$.

É importante observar que, $t_{d}$ é idêntico nas duas situações 1 e 2 , o que ratifica a necessidade da pré-localização da falta para se estimar de maneira correta a localização da falta.

No que segue são demonstrados alguns resultados envolvendo faltas fase-terra, conforme Tabelas 27 e 28, considerando situações de faltas na primeira e segunda metade da linha e variações do ângulo e resistência de falta. Essas tabelas também seguem os padrões das tabelas anteriores e se distinguem pelo tipo e ângulo de incidência da falta aplicada. Resultados complementares também podem ser encontrados no Apêndice A.

Segundo os resultados apresentados nas Tabela (27-28) podemos concluir que no caso de faltas fase-terra o localizador utilizando dados de um terminal também apresentou resultados satisfatórios, embora estes tenham sido inferiores aos alcançados quando da utilização da técnica que utiliza dados de ambos os terminais. Ressalta-se que em certos casos o algoritmo veio a falhar, ou melhor dizendo, apresentou uma localização errônea, devido em grande parte a dificuldade em se detectar a segunda reflexão por ser esta muita atenuada e, em alguns casos, devido a uma pré-localização errônea da falta fase-terra. Tais falhas são destacadas na Tabela 27, sendo duas por imprecisão na detecção da segunda reflexão e uma, por erro na pré-localização da falta. 
TABELA 27 - Falta fase-terra (AT), com ângulo de incidência de falta de $0^{0}$.

\begin{tabular}{|c|c|c|c|c|c|c|c|}
\hline $\begin{array}{c}\text { Distância } \\
\text { Real } \\
\text { (km) }\end{array}$ & $\begin{array}{c}\text { Resist. } \\
\text { falta } \\
\text { (ohms) }\end{array}$ & $\begin{array}{c}\text { Ângulo de } \\
\text { Incidência } \\
\text { (graus) }\end{array}$ & $\begin{array}{c}\text { Tipo de } \\
\text { Falta }\end{array}$ & $\begin{array}{c}\text { Pré- } \\
\text { Localização } \\
\text { (1/2 - metade) }\end{array}$ & $\begin{array}{c}\text { Distância } \\
\text { Estimada } \\
\quad(\mathbf{k m})\end{array}$ & $\begin{array}{l}\text { Erro } \\
\text { Abs. } \\
\text { (km) }\end{array}$ & $\begin{array}{l}\text { Erro } \\
(\%)\end{array}$ \\
\hline 10 & 0 & 0 & AT & 1 & 8,05 & 1,95 & 1,30 \\
\hline 10 & 50 & 0 & AT & 1 & 13,43 & 3,43 & 2,29 \\
\hline 10 & 100 & 0 & AT & 1 & 8,05 & 1,95 & 1,30 \\
\hline 25 & 0 & 0 & AT & 1 & 24,19 & 0,81 & 0,54 \\
\hline 25 & 50 & 0 & AT & 1 & 24,19 & 0,81 & 0,54 \\
\hline 25 & 100 & 0 & AT & 1 & 24,19 & 0,81 & 0,54 \\
\hline 40 & 0 & 0 & AT & 1 & 40,3 & 0,3 & 0,20 \\
\hline 40 & 50 & 0 & AT & 1 & 40,3 & 0,3 & 0,20 \\
\hline 40 & 100 & 0 & AT & 1 & 8,06 & 31,9 & 21,29 \\
\hline 55 & 0 & 0 & AT & 1 & 56,41 & 1,41 & 0,94 \\
\hline 55 & 50 & 0 & AT & 1 & 56,41 & 1,41 & 0,94 \\
\hline 55 & 100 & 0 & AT & 1 & 56,41 & 1,41 & 0,94 \\
\hline 70 & 0 & 0 & AT & 1 & 68,5 & 1,5 & 1,00 \\
\hline 70 & 50 & 0 & AT & 1 & 68,5 & 1,5 & 1,00 \\
\hline 70 & 100 & 0 & AT & 1 & 28,2 & 41,8 & 27,87 \\
\hline 75 & 0 & 0 & AT & 1 & 75,21 & 0,21 & 0,14 \\
\hline 75 & 50 & 0 & AT & 1 & 75,21 & 0,21 & 0,14 \\
\hline 75 & 100 & 0 & AT & 1 & 75,21 & 0,21 & 0,14 \\
\hline 80 & 0 & 0 & AT & 2 & 80,15 & 0,15 & 0,10 \\
\hline 80 & 50 & 0 & AT & 1 & 69,85 & 10,2 & 6,77 \\
\hline 80 & 100 & 0 & AT & 2 & 80,15 & 0,15 & 0,10 \\
\hline 95 & 0 & 0 & AT & 2 & 96,28 & 1,28 & 0,85 \\
\hline 95 & 50 & 0 & AT & 2 & 96,28 & 1,28 & 0,85 \\
\hline 95 & 100 & 0 & AT & 2 & 96,28 & 1,28 & 0,85 \\
\hline 110 & 0 & 0 & AT & 2 & 109,7 & 0,3 & 0,20 \\
\hline 110 & 50 & 0 & AT & 2 & 109,7 & 0,3 & 0,20 \\
\hline 110 & 100 & 0 & AT & 2 & 109,7 & 0,3 & 0,20 \\
\hline 125 & 0 & 0 & AT & 2 & 123,13 & 1,87 & 1,25 \\
\hline 125 & 50 & 0 & AT & 2 & 123,13 & 1,87 & 1,25 \\
\hline 125 & 100 & 0 & AT & 2 & 125,83 & 0,83 & 0,55 \\
\hline 140 & 0 & 0 & AT & 2 & 139,26 & 0,74 & 0,49 \\
\hline 140 & 50 & 0 & AT & 2 & 141,94 & 1,94 & 1,29 \\
\hline 140 & 100 & 0 & $\mathrm{AT}$ & 2 & 140,59 & 0,59 & 0,39 \\
\hline \multicolumn{7}{|c|}{ Erro médio (\%) } & 2,32 \\
\hline
\end{tabular}


TABELA 28 - Faltas fase-terra (AT), com ângulo de incidência de falta de $90^{\circ}$.

\begin{tabular}{|c|c|c|c|c|c|c|c|}
\hline $\begin{array}{c}\text { Distância } \\
\text { Real } \\
\text { (km) }\end{array}$ & $\begin{array}{c}\text { Resist. } \\
\text { falta } \\
\text { (ohms) }\end{array}$ & $\begin{array}{l}\text { Ângulo de } \\
\text { Incidência } \\
\text { (graus) }\end{array}$ & $\begin{array}{c}\text { Tipo de } \\
\text { Falta }\end{array}$ & $\begin{array}{c}\text { Pré- } \\
\text { Localização } \\
\text { (1/2 - metade) }\end{array}$ & $\begin{array}{c}\text { Distância } \\
\text { Estimada } \\
\text { (km) }\end{array}$ & $\begin{array}{l}\text { Erro } \\
\text { Abs. } \\
(\mathbf{k m})\end{array}$ & $\begin{array}{l}\text { Erro } \\
(\%)\end{array}$ \\
\hline 10 & 0 & 90 & AT & 1 & 13,43 & 3,43 & 2,29 \\
\hline 10 & 50 & 90 & AT & 1 & 13,43 & 3,43 & 2,29 \\
\hline 10 & 100 & 90 & AT & 1 & 13,43 & 3,43 & 2,29 \\
\hline 25 & 0 & 90 & AT & 1 & 24,19 & 0,81 & 0,54 \\
\hline 25 & 50 & 90 & AT & 1 & 21,49 & 3,51 & 2,34 \\
\hline 25 & 100 & 90 & AT & 1 & 21,49 & 3,51 & 2,34 \\
\hline 40 & 0 & 90 & AT & 1 & 40,3 & 0,3 & 0,20 \\
\hline 40 & 50 & 90 & AT & 1 & 40,3 & 0,3 & 0,20 \\
\hline 40 & 100 & 90 & AT & 1 & 40,3 & 0,3 & 0,20 \\
\hline 55 & 0 & 90 & AT & 1 & 53,72 & 1,28 & 0,85 \\
\hline 55 & 50 & 90 & AT & 1 & 53,72 & 1,28 & 0,85 \\
\hline 55 & 100 & 90 & AT & 1 & 59,1 & 4,1 & 2,73 \\
\hline 70 & 0 & 90 & AT & 1 & 69,85 & 0,15 & 0,10 \\
\hline 70 & 50 & 90 & AT & 1 & 69,85 & 0,15 & 0,10 \\
\hline 70 & 100 & 90 & AT & 1 & 69,85 & 0,15 & 0,10 \\
\hline 75 & 0 & 90 & AT & 2 & 74,79 & 0,21 & 0,14 \\
\hline 75 & 50 & 90 & AT & 2 & 74,79 & 0,21 & 0,14 \\
\hline 75 & 100 & 90 & AT & 2 & 74,79 & 0,21 & 0,14 \\
\hline 80 & 0 & 90 & AT & 2 & 80,15 & 0,15 & 0,10 \\
\hline 80 & 50 & 90 & AT & 2 & 80,15 & 0,15 & 0,10 \\
\hline 80 & 100 & 90 & AT & 2 & 80,15 & 0,15 & 0,10 \\
\hline 95 & 0 & 90 & AT & 2 & 93,59 & 1,41 & 0,94 \\
\hline 95 & 50 & 90 & AT & 2 & 93,59 & 1,41 & 0,94 \\
\hline 95 & 100 & 90 & AT & 2 & 93,59 & 1,41 & 0,94 \\
\hline 110 & 0 & 90 & AT & 2 & 111,05 & 1,05 & 0,70 \\
\hline 110 & 50 & 90 & AT & 2 & 111,05 & 1,05 & 0,70 \\
\hline 110 & 100 & 90 & AT & 2 & 111,05 & 1,05 & 0,70 \\
\hline 125 & 0 & 90 & AT & 2 & 125,81 & 0,81 & 0,54 \\
\hline 125 & 50 & 90 & AT & 2 & 125,81 & 0,81 & 0,54 \\
\hline 125 & 100 & 90 & AT & 2 & 125,81 & 0,81 & 0,54 \\
\hline 140 & 0 & 90 & AT & 2 & 139,26 & 0,74 & 0,49 \\
\hline 140 & 50 & 90 & AT & 2 & 139,26 & 0,74 & 0,49 \\
\hline 140 & 100 & 90 & AT & 2 & 141,94 & 1,94 & 1,29 \\
\hline \multicolumn{7}{|c|}{ Erro médio (\%) } & $\mathbf{0 , 8 2}$ \\
\hline
\end{tabular}


Pelas Figuras 65 e 66 pode-se fazer uma melhor análise dos resultados apresentados nas duas tabelas anteriores, pois estas representam os histogramas referentes aqueles resultados. Podemos observar que mais de $72 \%$ dos casos de faltas fase terra com ângulo de inserção da faltas de $0^{\circ}$ apresentaram erros inferiores a 1,0\%, sendo o mesmos erros constatados para mais de $78 \%$ dos casos de falta fase-terra com ângulo de inserção de $90^{\circ}$. O pior erro relatado nestes casos, desconsiderando os erros devido as falhas, foi de $2,73 \%$

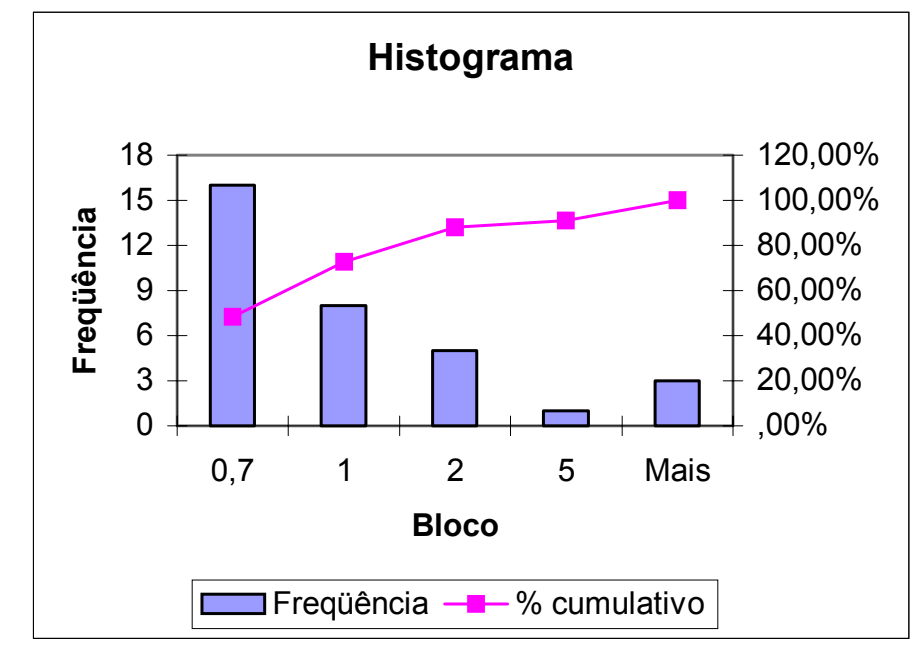

FIGURA 65 - Histograma referente as faltas fase-terra (AT), com ângulo de incidência de $00^{\circ}$

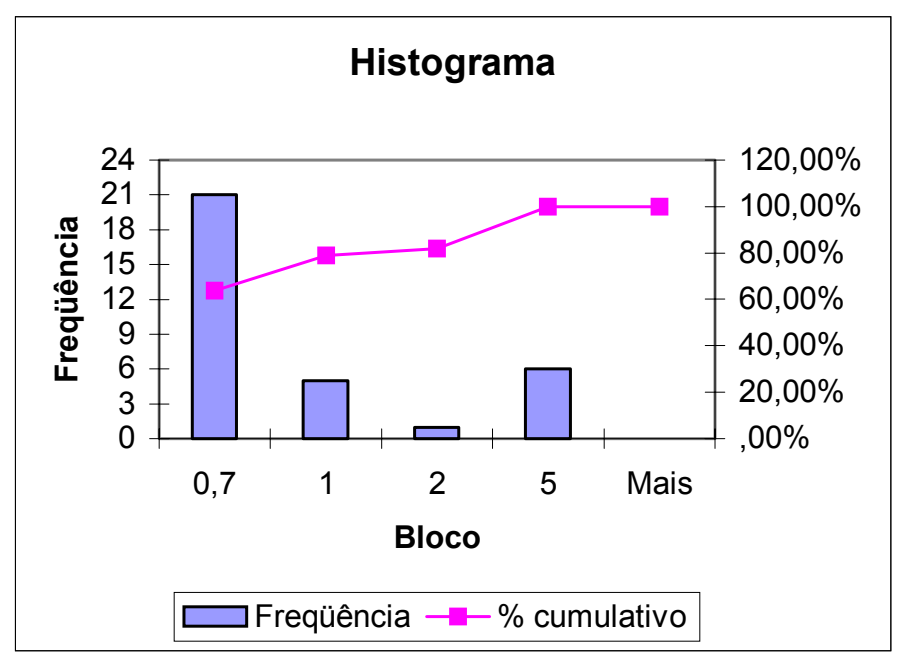

FIGURA 66 - Histograma referente as faltas fase-terra (AT), com ângulo de incidência de falta de $90^{\circ}$

De um modo geral podemos concluir que, apesar de apresentar algumas falhas, principalmente na presença de situações que envolvam a terra (fase-terra e fase-fase- 
terra), devido a motivos descritos anteriormente, o algoritmo de localização trabalhando com dados provenientes de um terminal apresentou bons resultados.

\subsubsection{Influência da variação da distância da falta}

Para análise da influência da variação da distância da falta, no desempenho do algoritmo, foram simulados diversas situações de faltas em diferentes localizações da linha de transmissão. Pode-se observar pelos testes efetuados que a distância da falta não influência significantemente na precisão desta técnica. Os maiores erros encontrados não obedeceram a padrões específicos.

\subsubsection{Influência dos diferentes tipos de faltas}

Uma série de testes foram realizados com o intuito de verificar a influência do tipo da falta no desempenho desta técnica. Para melhor delinear a influência do tipo da falta sobre o localizador tomamos por base os testes apresentados pela Figura 67, referentes a alguns casos de faltas fase-terra, fase-fase-terra, fase-fase e trifásicas, com ângulo de incidência de $0^{0}$ e resistência de falta de $0 \mathrm{ohm}$.

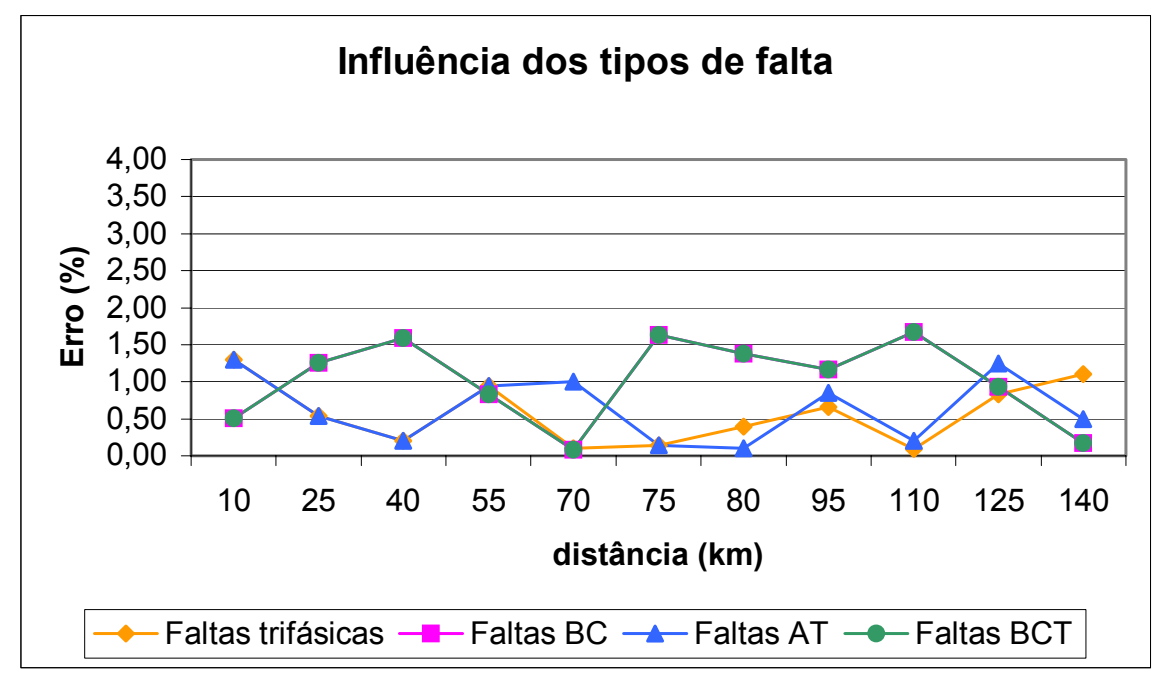

FIGURA 67 - Influência do tipo da falta na precisão da técnica de localização utilizada

Verifica-se que o erro percentual ficou em 1,5\%. Para os poucos casos que excederam este valor, o erro percentual ficou abaixo de 1,7\%. Nota-se também que nestes casos apresentados as faltas fase-fase e fase-fase-terra apresentaram uma menor 
precisão e que o algoritmo se comportou um pouco melhor na presença de faltas trifásicas.

Pelos testes realizados e resultados obtidos, observa-se que os erros introduzidos pelos diferentes tipos de faltas não afetam a validade e a confiabilidade da técnica de localização de faltas utilizada.

\subsubsection{Influência do ângulo de incidência da falta}

Com respeito à influência do ângulo de incidência da falta no desempenho do algoritmo e precisão da técnica, os testes demonstraram que são alcançados melhores resultados quando a inserção da falta ocorre a valores próximos do máximo da tensão em análise $\left(90^{\circ}\right)$. Tal observação pode ser comprovada através dos resultados apresentados graficamente pela Figuras 68 e nos demais testes realizados e descritos no Apêndice A.

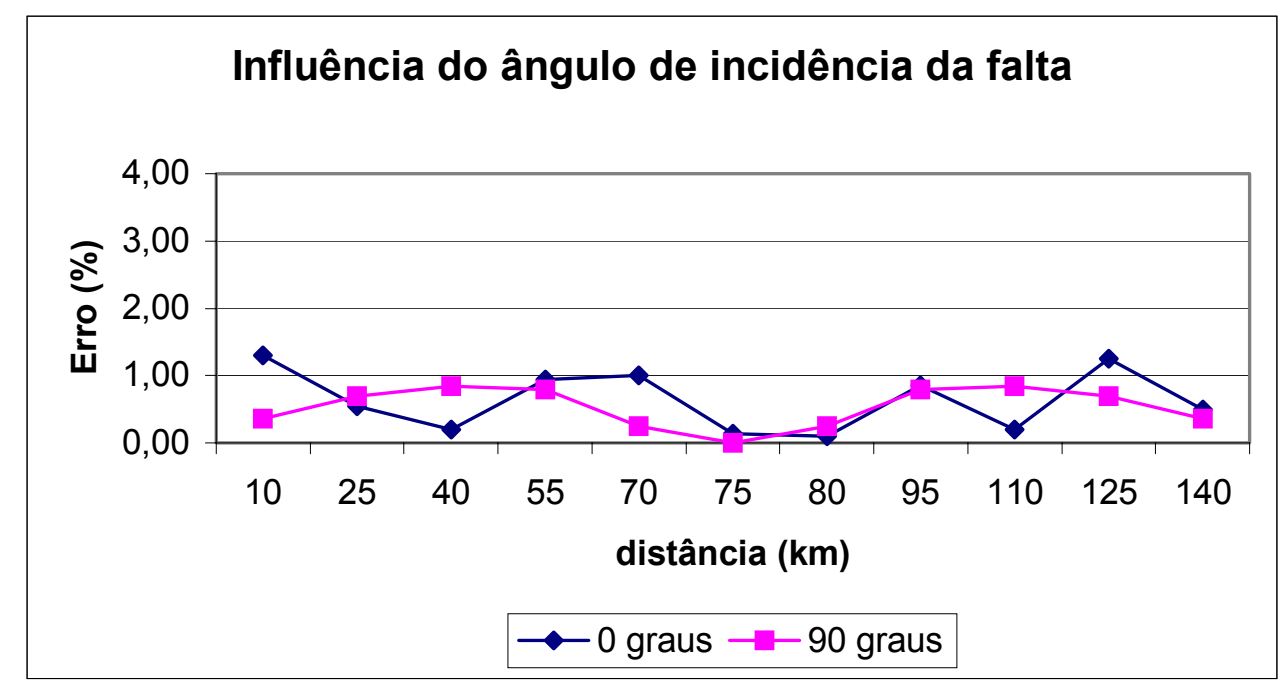

FIGURA 68 - Influência do ângulo de incidência da falta para faltas fase-terra

Fica claro, como apresentado pela Figura 68, que a técnica de localização com dados provenientes de um terminal não sofre influência devido a variação do ângulo de inserção da falta, permanecendo a maioria dos resultados dentro de uma faixa de erro de 1,5\%. Constatou-se também através de outros testes que na presença de faltas aterradas, a técnica apresenta melhores resultados em situações onde o ângulo de incidência é maior, sendo o pior caso a zero graus, tendo como agravante a resistência de falta. 
Embora o algoritmo operando nesta técnica possa apresentar erros na presença de faltas que ocorrem próximas de zero graus, esses são esporádicos e geralmente estão ligados a faltas fase-terra com alta impedância de aterramento, pois estes casos são semelhantes a uma simples variação de carga. Contudo, estes não vêm afetar a validade do algoritmo, mas sem dúvida, apontam situações que ainda merecem uma maior atenção para mitigação dos erros observados.

\subsubsection{Influência da resistência de falta}

Com o intuito de verificar a influência da resistência de falta no desempenho da técnica de localização utilizada, foram realizados vários testes com os seguintes valores de resistência de falta: 0,1, 50, 100, 200 e 400 ohms. A Figura 69 ilustra alguns casos de faltas fase-fase-terra (ACT) com ângulo de incidência de zero graus e diferentes resistências de falta.

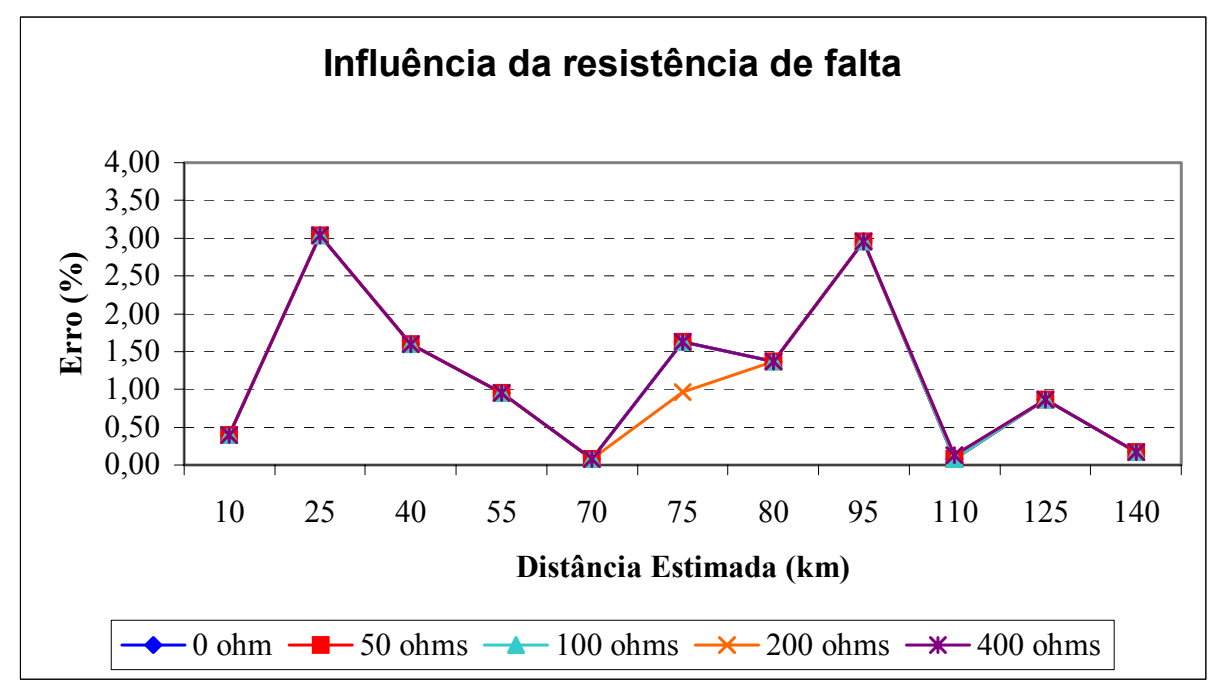

FIGURA 69 - Influência da resistência de falta para faltas fase-fase-terra (ACT)

Como pode ser observado para a grande maioria destes casos, não se notou variação na precisão do algoritmo devido à resistência de falta, mesmo em situações consideradas críticas como é o caso de faltas com ângulo de incidência de zero graus associadas a altas resistências de faltas tais como: 100, 200 e 400 ohms.

Embora a técnica utilizada tenha apresentado um desempenho satisfatório para faltas fase-fase-terra, o mesmo não ocorreu para todas as situações de faltas fase-fase, onde foi acurado alguns casos errôneos ou falhos, principalmente em se tratando de casos de faltas fase-terra com ângulos de incidência de falta próximos a zero e altas 
resistências de falta. Partindo do pressuposto que as faltas geralmente ocorrem com maior freqüência em ângulos de incidência maiores que $45^{\circ}$, o algoritmo também foi testado sobre circunstâncias onde a situação de falta incide com ângulos de 45 e 70 graus. Observou-se que para estas últimas circunstâncias, um melhor desempenho do algoritmo, mesmo em casos com altas resistências de falta. Estes resultados, assim como os demais resultados com altas resistências de faltas podem ser encontrados no Apêndice A.

\subsubsection{Influência da variação da Taxa de Amostragem do sinal}

Assim como verificado a influência da taxa da amostragem do sinal para a técnica que utiliza dados de dois terminais, também foi analisada a influência desta quando da utilização da técnica que utiliza dados registrados em apenas um terminal.

Observando-se as Tabelas 29 e 30 dadas a seguir, podemos constatar que a técnica não apresenta bons resultados para freqüências menores que $120 \mathrm{kHz}$, principalmente em caso de faltas ocorrendo a $0^{\circ}$, embora podemos constatar também que para esta mesma situação, não houve grandes melhoras quando da utilização de freqüências maiores, pelo contrário, em situações de faltas fase-terra simuladas com um freqüência de $240 \mathrm{kHz}$ e ângulo de incidência de $0^{\circ}$, a técnica apresentou resultados inferiores.

Os resultados demonstram que se faz necessário ainda um melhor aperfeiçoamento desta técnica, assim como, mais testes utilizando-se diferentes taxas de amostragem do sinal.

Não deixando de ressaltar que para a realização destes testes, houve a necessidade de ajuste em alguns dos parâmetros do algoritmo anteriormente definidos. 
TABELA 29 - Resultados obtidos para casos de faltas fase-terra com ângulo de incidência de $0^{\circ} e$ variação da freqüencia de amostragem do sinal.

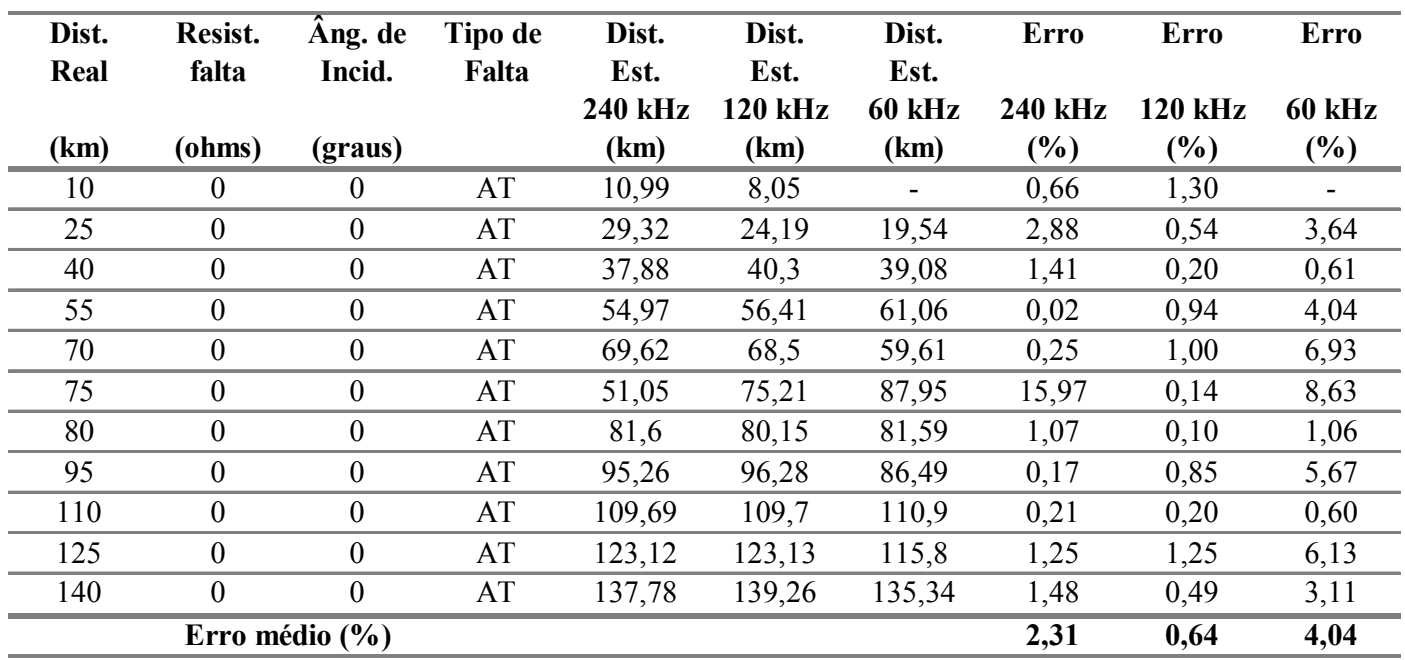

TABELA 30 - Resultados obtidos para casos de faltas fase-terra com ângulo de incidência de $90^{\circ} e$ variação da freqüencia de amostragem do sinal.

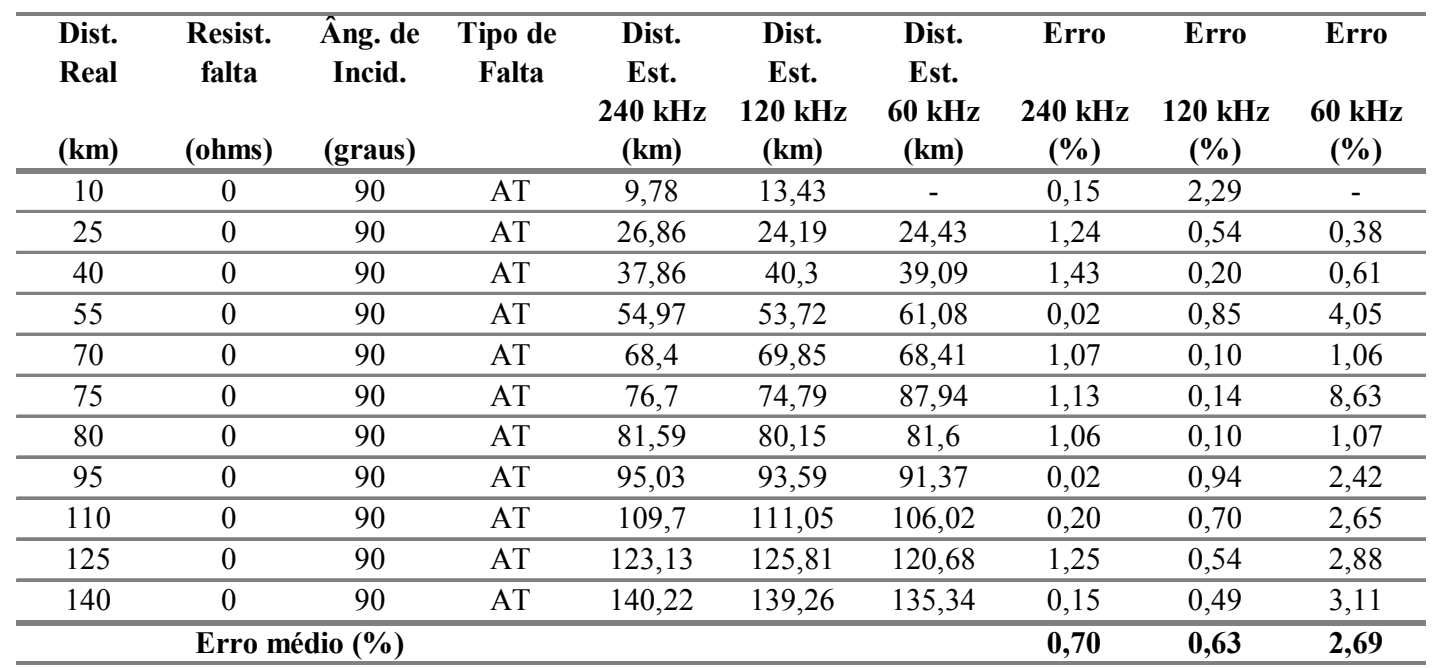

\subsubsection{Influência da imprecisão na determinação dos parâmetros da linha}

Pelos mesmos motivos delineados anteriormente na seção 6.1.7, também foram efetuados testes utilizando dados registrados localmente, a fim de se verificar a influência de parâmetros imprecisos sobre a técnica.

Em particular foram variados os parâmetros L e C da linha em questão, adicionando-se a este erros da ordem de $+/-5 \%$. Tais parâmetros foram escolhidos pois estes influenciam diretamente a obtenção da velocidade de propagação da linha, variável esta, essencial para o cálculo preciso do ponto de ocorrência da falta. 
Nesta etapa foram consideradas apenas situações de faltas fase-terra, uma vez que para este tipo de falta, a imprecisão na velocidade de propagação da onda pode acarretar erros já na pré-localização da falta, e por conseqüência, na localização precisa da mesma.

Pela análise dos resultados, observou-se que esta técnica sofre uma maior influência devido a imprecisão dos parâmetros L e C de linha e conseqüentemente da velocidade de propagação da onda na linha. A elevação do erro médio total para faltas fase-terra com ângulo de incidência de 0 e $90^{\circ}$, para uma variação de $+/-5 \%$ nos parâmetros foi aproximadamente de $2 \%$ e $1 \%$, respectivamente. Os erros referentes à pré-localização também colaboraram para essa elevação do erro médio, porém constatou-se que esses erros aconteceram próximos a metade da linha, o que é comum, e só na presença de faltas com ângulo de incidência de $0^{\circ}$.

Apesar da elevação do erro médio neste estudo, nota-se que em alguns casos a imprecisão dessas variáveis pode também ser benéfica, diminuindo o erro apresentado em casos onde tais variáveis eram precisas. Pela Figura 70, pode-se visualizar os efeitos da imprecisão das variáveis sobre o algoritmo para casos de faltas fase-terra com ângulo de incidência da falta de $0^{\circ}$. Outros resultados podem ser encontrados no Apêndice A.

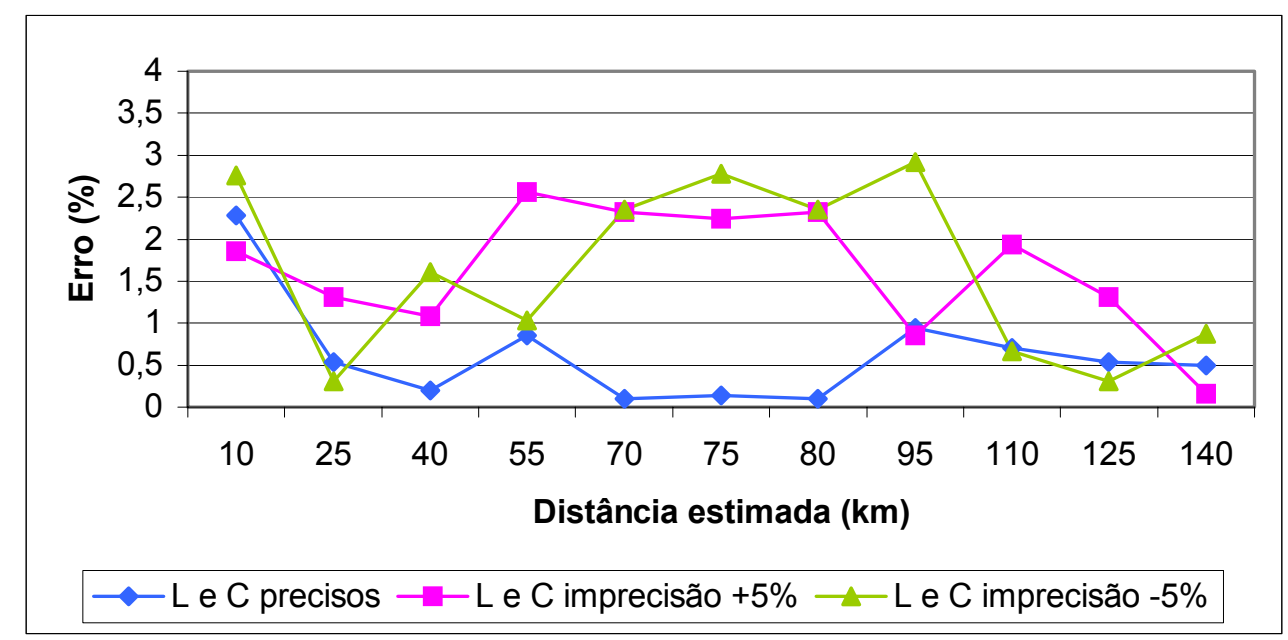

FIGURA 70 - Influência da imprecisão dos parâmetros de linha (L e C) sobre a técnica de um terminal em situações de falta fase-terra 


\subsubsection{Comportamento da técnica frente ao acoplamento mútuo entre circuitos de uma linha de transmissão dupla}

Análogo a seção 6.1.8, a técnica que utiliza dados provenientes de um terminal da linha também foi avaliada com a finalidade de se verificar o seu comportamento quando aplicada sobre uma linha de transmissão dupla vertical. O principal objetivo destes testes foi verificar a aplicabilidade dessa técnica em uma linha com circuito duplo e uma possível influência na precisão do algoritmo devido ao efeito do acoplamento mútuo entre os circuitos, imposto por este tipo de linha.

Dentre os testes realizados, alguns são ilustrados pela Tabela 31 e Figura 71, onde situações de faltas fase-fase foram consideradas. Os demais resultados dos testes realizados podem ser encontrados no Apêndice B.

Pelos resultados apresentados pela tabela e figura acima citada, pode-se verificar que a técnica que utiliza dados de um terminal não é sensivelmente influenciada pelo acoplamento mútuo entre as fases de um circuito duplo vertical. Os resultados apresentados demonstram que $100 \%$ dos casos de faltas fase-fase apresentaram erros inferiores a $1,4 \%$.

Uma comparação entre os resultados obtidos pelo localizador aplicado sobre linha simples e a linha dupla, podem ser visualizados através da Figura 72, onde podemos confirmar a pequena diferença de precisão entre tais aplicações. Nesta comparação foram consideradas situações de faltas fase-fase.

TABELA 31 - Faltas fase-fase (AB) aplicadas no circuito duplo

\begin{tabular}{|c|c|c|c|c|c|}
\hline $\begin{array}{c}\text { Distância } \\
\text { Real } \\
\text { (km) }\end{array}$ & $\begin{array}{c}\text { Ângulo de } \\
\text { Incidência } \\
\text { (graus) }\end{array}$ & $\begin{array}{c}\text { Tipo de } \\
\text { Falta }\end{array}$ & $\begin{array}{c}\text { Distância } \\
\text { Estimada } \\
\quad(\mathbf{k m})\end{array}$ & $\begin{array}{l}\text { Erro } \\
\text { Abs. } \\
(\mathbf{k m})\end{array}$ & $\begin{array}{l}\text { Erro } \\
(\%)\end{array}$ \\
\hline 10 & 0 & $\mathrm{AB}$ & 7,97 & 2,03 & 1,35 \\
\hline 25 & 0 & $\mathrm{AB}$ & 26,53 & $-1,53$ & 1,02 \\
\hline 40 & 0 & $\mathrm{AB}$ & 39,82 & 0,18 & 0,12 \\
\hline 55 & 0 & $\mathrm{AB}$ & 53,1 & 1,9 & 1,27 \\
\hline 70 & 0 & $\mathrm{AB}$ & 69,02 & 0,98 & 0,65 \\
\hline 75 & 0 & $\mathrm{AB}$ & 74,32 & 0,68 & 0,45 \\
\hline 80 & 0 & $\mathrm{AB}$ & 79,64 & 0,36 & 0,24 \\
\hline 95 & 0 & $\mathrm{AB}$ & 92,9 & 2,1 & 1,40 \\
\hline 110 & 0 & $\mathrm{AB}$ & 111,49 & $-1,49$ & 0,99 \\
\hline 125 & 0 & $\mathrm{AB}$ & 124,76 & 0,24 & 0,16 \\
\hline 140 & 0 & $\mathrm{AB}$ & 138,03 & 1,97 & 1,31 \\
\hline \multicolumn{5}{|c|}{ Erro médio (\%) } & $\mathbf{0 , 8 2}$ \\
\hline
\end{tabular}




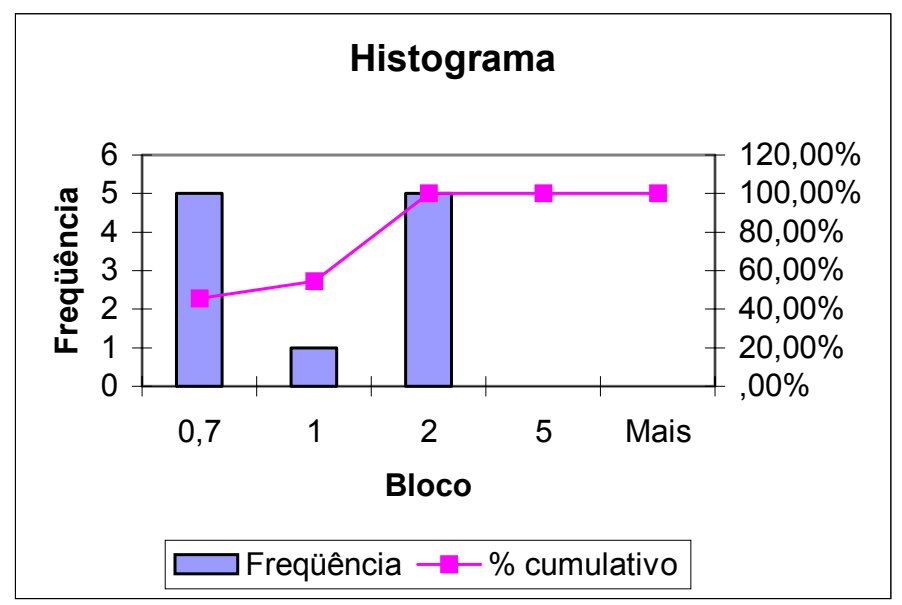

FIGURA 71 - Histograma referente as situações de falta fase-fase aplicadas ao circuito duplo

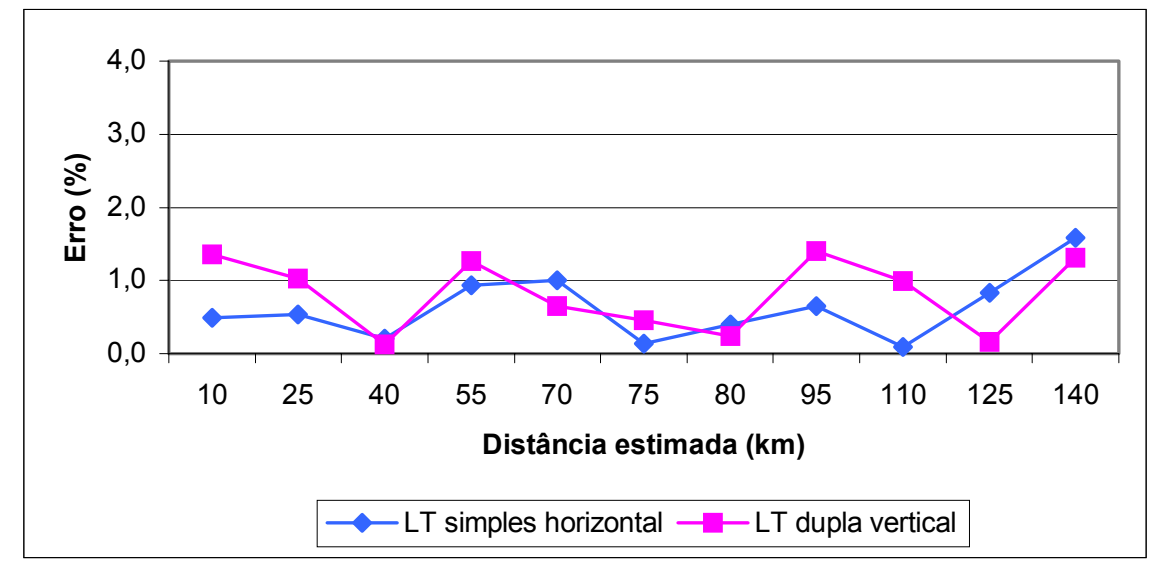

FIGURA 72 - Comparação entre a aplicação do localizador sobre diferentes configurações de linhas de transmissão

Embora a maioria dos resultados encontrados em todos os testes sejam satisfatórios, algumas localizações errôneas foram obtidas pelo algoritmo, principalmente em casos de faltas fase-terra com ângulos de incidência próximos de zero graus e se devem, em grande parte, da dificuldade em se detectar a segunda reflexão da onda na barra local. Estes resultados errôneos não afetam a validade do algoritmo, mas chamam a atenção para problemas que merecem ser mitigados.

Salienta-se que, para se aplicar o localizador de faltas sobre este tipo de sistema, algumas alterações e adequações de parâmetros foram necessárias. 


\subsubsection{Comportamento da técnica de localização frente à faltas fora da zona de cobertura considerando circuitos duplos de transmissão}

Seguindo os padrões dos testes realizados sobre a técnica que utiliza dados registrados em dois terminais, foi verificado também como se comporta a técnica que utiliza dados registrados localmente frente à faltas aplicadas fora da zona de cobertura do localizador (linha E-F), considerando a utilização do circuito duplo vertical.

São válidas para esta situação, todas a considerações feitas na seção 6.1.9, ressalvando-se apenas de uma pequena diferença na precisão de cada técnica.

Alguns resultados dos testes efetuados utilizando-se da técnica de um terminal, sobre condições de faltas fase-terra e fase-fase, fora e dentro da área cobertura do localizador, são ilustrados pelas Tabelas 32 e 33.

TABELA 32 - Faltas fase-terra e fase-fase aplicadas no circuito 1 da linha dupla

\begin{tabular}{|c|c|c|c|c|c|c|c|}
\hline $\begin{array}{c}\text { Circuito } 1 \\
\text { Linha }\end{array}$ & $\begin{array}{c}\text { Distância } \\
\text { Real } \\
\text { (km) }\end{array}$ & $\begin{array}{c}\text { Resist. } \\
\text { falta } \\
\text { (ohms) }\end{array}$ & $\begin{array}{c}\text { Ângulo de } \\
\text { Incidência } \\
\text { (graus) }\end{array}$ & $\begin{array}{c}\text { Tipo de } \\
\text { Falta }\end{array}$ & $\begin{array}{c}\text { Distância } \\
\text { Estimada } \\
\text { (km) }\end{array}$ & $\begin{array}{l}\text { Erro } \\
\text { Abs. } \\
\text { (km) }\end{array}$ & $\begin{array}{l}\text { Erro } \\
(\%)\end{array}$ \\
\hline \multirow{9}{*}{ D-E } & 10 & 0 & 0 & AT & FAC* & - & - \\
\hline & 10 & 50 & 0 & AT & FAC & - & - \\
\hline & 10 & 100 & 0 & AT & FAC & - & - \\
\hline & 40 & 0 & 0 & AT & FAC & - & - \\
\hline & 40 & 50 & 0 & $\mathrm{AT}$ & FAC & - & - \\
\hline & 40 & 100 & 0 & $\mathrm{AT}$ & FAC & - & - \\
\hline & 60 & 0 & 0 & AT & FAC & - & - \\
\hline & 60 & 50 & 0 & AT & FAC & - & - \\
\hline & 60 & 100 & 0 & AT & FAC & - & - \\
\hline \multirow{9}{*}{ E-F } & 20 & 0 & 0 & $\overline{\mathrm{AB}}$ & 18,57 & 1,43 & 0,95 \\
\hline & 20 & 50 & 0 & $\mathrm{AB}$ & 18,57 & 1,43 & 0,95 \\
\hline & 20 & 100 & 0 & $\mathrm{AB}$ & 18,57 & 1,43 & 0,95 \\
\hline & 80 & 0 & 0 & $\mathrm{AB}$ & 79,64 & 0,36 & 0,24 \\
\hline & 80 & 50 & 0 & $\mathrm{AB}$ & 79,64 & 0,36 & 0,24 \\
\hline & 80 & 100 & 0 & $\mathrm{AB}$ & 79,64 & 0,36 & 0,24 \\
\hline & 130 & 0 & 0 & $\mathrm{AB}$ & 130,07 & 0,07 & 0,05 \\
\hline & 130 & 50 & 0 & $\mathrm{AB}$ & 130,07 & 0,07 & 0,05 \\
\hline & 130 & 100 & 0 & $\mathrm{AB}$ & 130,07 & 0,07 & 0,05 \\
\hline \multirow{9}{*}{ F-G } & 10 & 0 & 0 & AT & FAC & - & - \\
\hline & 10 & 50 & 0 & $\mathrm{AT}$ & FAC & - & - \\
\hline & 10 & 100 & 0 & AT & FAC & - & - \\
\hline & 50 & 0 & 0 & AT & FAC & - & - \\
\hline & 50 & 50 & 0 & AT & FAC & - & - \\
\hline & 50 & 100 & 0 & AT & FAC & - & - \\
\hline & 80 & 0 & 0 & AT & FAC & - & - \\
\hline & 80 & 50 & 0 & AT & FAC & - & - \\
\hline & 80 & 100 & 0 & AT & FAC & - & - \\
\hline
\end{tabular}

*FAC = Fora da Área de Cobertura do Localizador 
TABELA 33 - Faltas fase-terra aplicadas no circuito 2 da linha dupla

\begin{tabular}{|c|c|c|c|c|c|c|c|}
\hline $\begin{array}{c}\text { Circuito } 2 \\
\text { Linha }\end{array}$ & $\begin{array}{c}\text { Distância } \\
\text { Real } \\
(\mathbf{k m})\end{array}$ & $\begin{array}{c}\text { Resist. } \\
\text { falta } \\
\text { (ohms) }\end{array}$ & $\begin{array}{c}\text { Ângulo de } \\
\text { Incidência } \\
\text { (graus) }\end{array}$ & $\begin{array}{c}\text { Tipo de } \\
\text { Falta }\end{array}$ & $\begin{array}{l}\text { Distância } \\
\text { Estimada } \\
(\mathbf{k m})\end{array}$ & $\begin{array}{l}\text { Erro } \\
\text { Abs. } \\
(\mathbf{k m})\end{array}$ & $\begin{array}{l}\text { Erro } \\
(\%)\end{array}$ \\
\hline \multirow{9}{*}{ D-H } & 10 & 0 & 0 & AT & FAC ${ }^{*}$ & - & - \\
\hline & 10 & 50 & 0 & $\mathrm{AT}$ & FAC & - & - \\
\hline & 10 & 100 & 0 & AT & FAC & - & - \\
\hline & 40 & 0 & 0 & AT & FAC & - & - \\
\hline & 40 & 50 & 0 & AT & FAC & - & - \\
\hline & 40 & 100 & 0 & $\mathrm{AT}$ & FAC & - & - \\
\hline & 60 & 0 & 0 & AT & FAC & - & - \\
\hline & 60 & 50 & 0 & AT & FAC & - & - \\
\hline & 60 & 100 & 0 & AT & FAC & - & - \\
\hline \multirow{9}{*}{ H-I } & 20 & 0 & 0 & $\mathrm{AT}$ & FAC & - & - \\
\hline & 20 & 50 & 0 & AT & FAC & - & - \\
\hline & 20 & 100 & 0 & $\mathrm{AT}$ & FAC & - & - \\
\hline & 80 & 0 & 0 & AT & FAC & - & - \\
\hline & 80 & 50 & 0 & AT & FAC & - & - \\
\hline & 80 & 100 & 0 & AT & FAC & - & - \\
\hline & 130 & 0 & 0 & AT & FAC & - & - \\
\hline & 130 & 50 & 0 & AT & FAC & - & - \\
\hline & 130 & 100 & 0 & AT & FAC & - & - \\
\hline \multirow{9}{*}{ I-G } & 10 & 0 & 0 & AT & FAC & - & - \\
\hline & 10 & 50 & 0 & AT & FAC & - & - \\
\hline & 10 & 100 & 0 & AT & FAC & - & - \\
\hline & 50 & 0 & 0 & $\mathrm{AT}$ & FAC & - & - \\
\hline & 50 & 50 & 0 & AT & FAC & - & - \\
\hline & 50 & 100 & 0 & AT & FAC & - & - \\
\hline & 80 & 0 & 0 & AT & FAC & - & - \\
\hline & 80 & 50 & 0 & AT & FAC & - & - \\
\hline & 80 & 100 & 0 & AT & FAC & - & - \\
\hline
\end{tabular}

É importante salientar que, embora os resultados tenham sido promissores, pelo fato das rotinas aplicadas para predizer se a falta está ou não dentro da área de cobertura do localizador serem iniciais, é necessário ainda extensivos testes e o aprimoramento de tais rotinas, a fim de garantir um alto grau de confiabilidade do algoritmo como um todo.

Alguns diferentes resultados, referentes a estes testes, podem ser encontrados no Apêndice B. 


\section{CONCLUSÕES}

Este trabalho apresenta a implementação de um algoritmo de localização de faltas fundamentado na teoria de ondas viajantes e na utilização da Transformada Wavelet (análise multiresolução wavelet). O algoritmo apresentado pode fazer uso de dados registrados em um terminal ou em dois terminais, subdividindo-se desse modo em duas técnicas, onde uma das técnicas possibilita a localização de faltas usando dados registrados em apenas um terminal da linha e, a outra técnica, realiza a determinação do local da falta utilizando dados obtidos em dois terminais da linha. A utilização de uma ou outra técnica é definida pelo usuário de acordo com as suas necessidades e disponibilidade dos dados. Ambas as técnicas foram testadas utilizando-se de diversas situações de faltas simuladas através do software ATP.

\subsection{Considerações sobre a técnica que utiliza dados somente de um terminal da linha}

O algoritmo proposto no tocante à técnica que utiliza dados provenientes de um terminal mostrou um elevado grau de desempenho acompanhado de uma precisão bastante satisfatória na maioria dos testes avaliados. É importante lembrar que esta técnica necessita da implementação obrigatória de duas sub-rotinas: uma para classificação da falta e outra para pré-localização da falta, sendo esta última necessária em situações de faltas fase-terra.

Analisando todos os resultados obtidos, utilizando-se da técnica com dados de um terminal, podemos comprovar que o algoritmo se comportou bem, apresentando uma boa precisão na maiorias dos testes. Para ilustrar a boa eficiência apresentada pela técnica, pode-se tomar como referência a Tabela 34, que traz a análise geral referente a maioria dos testes realizados. Nesta tabela não foram considerados os casos errôneos, ou falhos, apresentados pela técnica, os quais serão discutidos posteriormente. 
TABELA 34 - Resultados gerais alcançados pela técnica de um terminal

\begin{tabular}{lcc}
\hline \multicolumn{1}{c}{ Falta } & $\begin{array}{c}\text { Erro médio } \\
(\mathbf{\%})\end{array}$ & $\begin{array}{c}\text { Nível Médio de Confiança } \mathbf{( 9 5 \% )} \\
(+/-\mathbf{\%})\end{array}$ \\
\hline Fase-terra & 1,51 & 0,72 \\
\hline Fase-fase-terra & 0,99 & 0,39 \\
\hline Fase-fase & 0,94 & 0,58 \\
\hline Trifásicas & 0,71 & 0,51 \\
\hline
\end{tabular}

A Tabela 34 mostra os erros médios para as situações de faltas fase-terra (AT, BT e CT), fase-fase-terra (ABT, ACT e BCT), fase-fase (AB, AC e BC) e trifásicas $(\mathrm{ABC})$, considerando variações nos ângulos de incidência e resistências de falta.

Houve situações onde o algoritmo apresentou certa dificuldade em determinar a localização da falta com a precisão normal que vinha tendo. Contudo, estas situações foram esporádicas e observadas principalmente em casos de faltas aterradas, tendo como agravantes a associação de ângulos de incidência próximos a zero à elevadas resistências de falta. Geralmente, as imprecisões constatadas carecem da dificuldade em se determinar corretamente à chegada da segunda onda na barra local, ou então, são causadas por erros na pré-localização da falta.

A dificuldade em se determinar a chegada da segunda onda deve-se a atenuação da mesma no decorrer do seu percurso pela linha ou devido a ruídos presentes no sinal. Quanto ao erro da pré-localização da falta, este geralmente esta relacionado com uma região de incerteza que corresponde ao ponto de transição da primeira para a segunda metade da linha (região próxima ao meio da linha).

Conscientes dessas dificuldades, maiores estudos devem ser realizados a fim de mitigá-las ao máximo, visando aumentar a confiabilidade do algoritmo. Vale comentar que estas situações não são tão freqüentes e nem estão ligadas a situações comuns que possam a vir a afetar a validade da técnica.

No que diz respeito aos testes realizados considerando um circuito duplo vertical de transmissão, estes comprovam também o bom desempenho do algoritmo frente às diversas situações de faltas avaliadas. Pelos resultados observados, podemos afirmar que o acoplamento mútuo entre as fases de um circuito duplo não afeta significantemente a precisão da técnica que utiliza dados registrados em um terminal. A Tabela 35 ilustra os resultados gerais dos testes avaliados com relação ao circuito duplo vertical. Cabe salientar que estes resultados podem sofrer um acréscimo ou até mesmo um decréscimo, pois foram realizados um menor número de testes para esta situação em 
específico, uma vez que o objetivo principal deste estudo era de apenas ilustrar o comportamento do algoritmo frente ao acoplamento mútuo dos circuitos caracterizados.

TABELA 35 - Resultados gerais alcançados pela técnica de um terminal aplicada a um circuito duplo

\begin{tabular}{lcc}
\hline \multicolumn{1}{c}{ Falta } & $\begin{array}{c}\text { Erro médio } \\
(\mathbf{\%})\end{array}$ & $\begin{array}{c}\text { Nível Médio de Confiança (95\%) } \\
(+/-\%)\end{array}$ \\
\hline Fase-terra & 1,12 & 0,29 \\
\hline Fase-fase-terra & 1,11 & 0,29 \\
\hline Fase-fase & 1,11 & 0,56 \\
\hline Trifásicas & 0,98 & 0,42 \\
\hline
\end{tabular}

Quanto ao comportamento do algoritmo frente as faltas fora da zona de cobertura do localizador, os testes demonstram que o algoritmo detecta o distúrbio, mas não o localiza.

Já no que diz respeito a influência da taxa amostral, conclui-se que a técnica apresenta melhores resultados quando da utilização de taxas amostrais maiores que 60 $\mathrm{kHz}$, porém tal influência ainda precisa ser melhor estudada e o algoritmo aprimorado.

Tomando por base a maioria dos testes e resultados alcançados, pode-se assegurar que a técnica utilizada não é significantemente influenciada pelos seguintes parâmetros: distância da falta, tipo da falta, ângulo de incidência da falta e resistência de falta, salvo em alguns casos incomuns e especiais onde há combinação de pequenos ângulos de inserção (próximos a zero graus) e elevadas resistências de falta $(\geq 200$ ohms), que exigem um aprimoramento da técnica.

A técnica de localização de faltas baseado em ondas viajantes e utilização da Transformada Wavelet, de um modo geral, apresentou um desempenho satisfatório, assim como um bom grau de precisão para as diversas situações testadas. A grande vantagem desta técnica reside no fato de que todos os dados necessários para a localização da falta são obtidos localmente, o que a torna mais econômica e prática. Quanto a desvantagem, esta reside na complexidade do algoritmo como um todo e na determinação da chegada da segunda onda no terminal local. 


\subsection{Considerações sobre a técnica que utiliza dados de ambos os terminais da linha}

A técnica que utiliza dados registrados em dois terminais apresentou um ótimo desempenho e uma excelente precisão na localização de faltas em linhas de transmissão de extra alta tensão. Afirmação esta baseada nos resultados dos testes realizados. Como características específicas, esta técnica não necessita da implementação das sub-rotinas de classificação da falta (uso facultativo) e pré-localização da falta. Entretanto, requer um meio de comunicação entre os terminais e um processador, para envio dos dados e, técnicas sincronização dos mesmos. Outra vantagem constatada desta técnica esta ligada à simplicidade do algoritmo e confiabilidade da técnica.

As Tabelas 36 e 37 apresentam os resultados gerais obtidos pela técnica que utiliza dados de dois terminais, considerando para a realização dos testes um circuito simples horizontal e um circuito duplo vertical, respectivamente.

TABELA 36 - Resultados gerais alcançados pela técnica de dois terminais aplicada a um circuito simples

\begin{tabular}{lcc}
\hline \multicolumn{1}{c}{ Falta } & $\begin{array}{c}\text { Erro médio } \\
(\mathbf{\%})\end{array}$ & $\begin{array}{c}\text { Nível Médio de Confiança } \mathbf{( 9 5 \% )} \\
(+/-\mathbf{\%})\end{array}$ \\
\hline Fase-terra & 0,82 & 0,27 \\
\hline Fase-fase-terra & 0,82 & 0,23 \\
\hline Fase-fase & 0,70 & 0,37 \\
\hline Trifásicas & 0,34 & 0,20 \\
\hline
\end{tabular}

TABELA 37 - Resultados gerais alcançados pela técnica de dois terminais aplicada a um circuito duplo

\begin{tabular}{lcc}
\hline \multicolumn{1}{c}{ Falta } & $\begin{array}{c}\text { Erro médio } \\
(\mathbf{\%})\end{array}$ & $\begin{array}{c}\text { Nível Médio de Confiança } \mathbf{( 9 5 \% )} \\
(+/-\mathbf{\%})\end{array}$ \\
\hline Fase-terra & 0,65 & 0,18 \\
\hline Fase-fase-terra & 0,59 & 0,16 \\
\hline Fase-fase & 0,59 & 0,30 \\
\hline Trifásicas & 0,71 & 0,48 \\
\hline
\end{tabular}

A Tabela 36 apresenta os erros médios gerais para diversas situações de faltas fase-terra (AT, BT e CT), fase-fase-terra (ABT, ACT e BCT), fase-fase(AB, AC e BC) e trifásicas $(\mathrm{ABC})$, considerando variados ângulos de incidência e resistências de falta. Já a Tabela 37 apresenta resultados referentes a algumas situações de faltas fase-terra 
$(\mathrm{AT})$, fase-fase-terra $(\mathrm{ABT})$, fase-fase $(\mathrm{AB})$ e trifásicas $(\mathrm{ABC})$, considerando diferentes ângulos de incidência e resistências de falta.

Pelos testes constatou-se que esta técnica é muito precisa e confiável, apresentando pouquíssimas falhas, de natureza esporádica, envolvendo situações específicas de faltas fase-terra com ângulo de incidência de zero graus e resistência de falta de 400 ohms, as quais não vem afetar o desempenho da técnica. Outras situações onde a técnica pode ter sua precisão perturbada estão condicionadas ao mau sincronismo dos dados e imprecisões na entrada de dados referente a linha de transmissão.

Os resultados também confirmam que a técnica utilizada não é significantemente influenciada pelos seguintes parâmetros: distância da falta, tipo da falta, ângulo de incidência da falta, resistência de falta e pelo acoplamento mútuo entre as fases de um circuito duplo vertical.

Dos resultados observados, afirma-se que a precisão da técnica está diretamente relacionada a taxa de amostragem do sinal empregada. Através desta análise pôde-se concluir também que, a técnica tem um melhor desempenho quando se utiliza uma taxa de amostragem acima de $60 \mathrm{kHz}$.

Por último, esta técnica também é capaz de perceber e indicar a presença de distúrbios fora da sua zona de proteção, porém não os localiza.

\subsection{Considerações gerais sobre o algoritmo de localização de faltas}

A estimação da localização da falta em uma linha de transmissão é muito importante, pois permite uma rápida determinação da natureza da falta, facilitando os reparos e a posterior restauração do sistema. Esta rapidez na determinação de uma situação de falta é de vital importância para uma operação econômica e confiável do sistema de potência como um todo, principalmente nos tempos atuais, onde um alto padrão de continuidade e conformidade do fornecimento de energia estão sendo exigidos. Ambas as técnicas descritas e implementadas neste trabalho podem ser empregadas para este propósito, tendo em vista a boa precisão apresentada na totalidade das situações. No entanto, a técnica que utiliza dados de dois terminais obteve um melhor desempenho, além de ser mais confiável se comparada com a técnica que utiliza dados de um terminal. Fato este que acaba por justificar a sua preferência, caso haja a disponibilidade dos dados de ambos os terminais. 
Deve também ser enfatizado que o método aqui proposto, assim como todos os métodos baseados em componentes de alta freqüência, necessitam de uma taxa amostral bastante elevada se comparada com métodos tradicionais, baseados em componentes de freqüência fundamental, sendo esta uma das principais limitações desse método, se assim podemos dizer, visto o enorme avanço tecnológico com um todo.

Denota-se que o algoritmo proposto ainda merece alguns pequenos ajustes em seus parâmetros no sentido de se buscar o contorno dos problemas encontrados. Pode-se ainda dizer que a aplicação deste algoritmo, fundamentado na teoria de ondas viajantes e da Transformada Wavelet, é bastante propícia para o uso em sistemas de proteção, especificamente direcionados á localização de faltas.

\subsection{Continuidade da pesquisa}

Tendo em vista o aperfeiçoamento contínuo do algoritmo apresentado, principalmente no tocante a técnica que utiliza dados de um terminal, propõe-se a realização de novos testes, tais como: utilização de wavelets-mãe de outras famílias, aprimoramento da metodologia para se detectar os picos corretos de reflexão presentes nos sinais de detalhe wavelet, etc.

Outra proposta interessante, a qual faz parte de um projeto de doutorado subseqüente, é a aplicação da metodologia vista neste trabalho em um sistema de linhas com três terminais, por serem estes economicamente viáveis e de difícil proteção e localização de faltas, dispondo-se das técnicas convencionais existentes. 


\section{REFERÊNCIAS BIBLIOGRÁFICAS}

[1] COURY, D. V. (1987). Um estimador ótimo aplicado à proteção dos sistemas elétricos de potência. Dissertação (Mestrado) - Escola de Engenharia de São Carlos, Universidade de São Paulo.

[2] STEVENSON JR., W. D. (1978). Elementos de análise de sistemas de potência. Rio de Janeiro, McGraw-Hill do Brasil.

[3] GAUTIER, L. R. (1996). Localizadores digitais de faltas para linhas de transmissão de alta tensão. Dissertação (Mestrado) - - Escola de Engenharia de São Carlos, Universidade de São Paulo.

[4] COURY, D. V. (1992). A practical approach to accurate fault location on extra high voltage teed feeders. Tese (Doutorado) - Universidade de Bath.

[5] SILVEIRA, P. M.; SEARA, R.; ZURN, H. H. (2001). Localização de faltas por ondas viajantes - Uma nova abordagem baseada em decomposição wavelet. XVI Seminário Nacional de Produção e Transmissão de Energia Elétrica, Campinas, GPC/027, 7 p. out.

[6] TAKAGI, T.; YAMAKOSHI, Y.; BABA, J.; UEMURA, K.; SAKAGUCHI, T. (1981). A new algorithm of an accurate fault location for EHV/UHV transmission lines: Part I - Fourier Transformation method. IEEE Transactions on Power Apparatus and Systems, v.PAS-100, n.3, p. 1316-1322,, mar.

[7] TAKAGI, T.; YAMAKOSHI, Y.; BABA, J.; UEMURA, K.; SAKAGUCHI, T. (1982a). A new algorithm of an accurate fault location for EHV/UHV transmission lines: Part II - Laplace Transform method. IEEE Transactions on Power Apparatus and Systems, v.PAS-101, n.3, p. 564-573,, mar.

[8] TAKAGI, T.; YAMAKOSHI, Y.; YAMAURA, M.; KONDOW, R.; MATSUSHIMA, T. (1982b). Development of a new type fault locator using the 
one-terminal voltage and current data. IEEE Transactions on Power Apparatus and Systems, v.PAS-101, n.8, p. 2892-2898, aug.

[9] RICHARDS, G. G.; TAN, O. T. (1982). An accurate fault location for transmission lines. IEEE Transactions on Power Apparatus and Systems, v.PAS-101, n.4, p. 945-949, apr.

[10] ERIKSSON, L.; SAHA, M. M.; ROCKEFELLER, G. D. (1985). An accurate fault location with compensation for apparent reactance in the fault resistance resulting from remote-end infeed. IEEE Transactions on Power Apparatus and Systems, v.PAS-104, n.2, p. 424-435, feb.

[11] MORRISON, L. F.; YANG, Q. (1987). Fault location on high voltage transmission tines using solid state disturbance recorders. IEEE/CSEE Joint Conference on High Voltage Transmission in China, p. 154-160, out.

[12] RANJBAR, A. M.; SHIRANI, A. R.; FATHI, A. F. (1992). A new approach for fault location problem on power lines. IEEE Transmission on Power Delivery, v.7, n.1, p. 146-151, jan.

[13] GIRGIS, A. A.; FALLON, C. M. (1992). Fault location techniques for radial and loop transmission systems using digital fault recorded data. IEEE Transmission on Power Delivery, v.7, n.4, p. 1396-1945, out.

[14] JOHNS, A T.; MOORE, P. J.; WHITTARD, R. (1995). New technique for the accurate location of earth faults on transmission systems. IEE ProceedingGeneration, Transmission and Distribution, v.142, n.2, p. 119-127, mar.

[15] PURUSHOTHAMA, G. K.; NARENDRANATH, A U.; THUKARAM, D.; PARTHASARATHY, K. (2000). ANN applications in fault locators. ELSEVIER Electrical Power and Energy Systems, v.23, p. 491-506, jun.

[16] SAHA, M. M.; WIKSTROM, K.; IZYKOWSKI, J.; ROSOLOWSKI, E. (2001). New accurate fault location algorithm for parallel lines IEE Developments in Power System Protection, Conference Publication, n.479, p. 407-410.

[17] YIBIN, X.; WAI, D. C. T.; KEERThiPALA, W. W. L. (1997). A new technique using wavelet analysis for fault location. IEE Developments in Power System Protection, Conference Publication, n.434, p. 231-234, mar. 
[18] SOARES, L. R.; CARVALHO JR., M. A.; OliVEIRA, H. M. (2002). Localização de faltas em linhas de transmissão utilizando a representação wavelet multiresolução. XIV Congresso Brasileiro de Automática, Natal/RN, p. 2683-2688, set.

[19] SCHWEITZER, E. O.; JACHINOWSKI, J. K. (1981). A prototype microprocessor-based system for transmission line protection and monitoring. Eight Annual Western protective Relay Conference, Spokane, Washington, USA.

[20] SACHDEV, M. S.; AGGARWAL, R. (1985). Accurate faul location estimates from digital impedance relay measurements. IEE Conference Publication, n.249, p. 193-198.

[21] JEYASURYA, B.; RAHMAN, M. A. (1989). Accurate fault location of transmission lines using microprocessors. IEE Fourth International Conference, p. 13-17.

[22] JOHNS, A. T.; JAMALI, S. (1990). Accurate fault location technique for power transmission lines. IEE Proceedings, v.137, Pt. C, n.6, p. 395-402, nov.

[23] KALAM, A.; JOHNS, A. T. (1991). Accurate fault location technique for multi-terminal EHV lines. IEE International Conference on Advances in Power System Control, Operation and Management, Hong Kong, p. 420-424, nov.

[24] GIRGIS, A. A.; HART, D. G.; PETERSON, W. L. (1992). A new fault location technique for two and three terminal lines. IEEE Transactions on Power Delivery, v.7, n.1, p. 98-107, jan.

[25] AGgarwal, R. K.; COURY, D. V.; JOHNS, A. T.; KALAM, A. (1993). $A$ practical approach to accurate fault location on extra high voltage teed feeders. IEEE Transactions on Power Delivery, v.8, n.3, p. 874-883, jul.

[26] NOVOSEL, D.; HART, D. G.; UDREN, E.; SAHA, M. M. (1995). Fault location using digital relay data. IEEE Computer Applications in Power, v.8, n.3, p. 45-50, jul.

[27] ZAMORA, I.; MINAMBRES, J. F.; MAZON, A J.; ALVAREZ-ISASI, R.; LAZARO, J. (1996). Fault location on two-terminal transmission lines based 
on voltages. IEE Proceedings-Generation, Transmission and Distribution, v.143, n.1, p. 1-6, jan.

[28] GONG, Q.; CHEN, Y.;ZHANG, C.; WANG, Z. (2000). A study of the accurate fault location system for transmission line using multi-terminal signals. IEEE Power Engineering Society Winter Meeting, v.4, p. 2533-2538.

[29] SOllerO, R. B.; BIANCO, J. C. N.; ASSIS, T. M. L.; RODRIGUES, M. A. M.; MIRANDA, A. L. L.; MANTUANO FILHO, S. (2001). Localização de faltas em sistemas de transmissão a partir de sinais oscilografados em ambas as extremidades da linha. XVI Seminário Nacional de Produção e Transmissão de Energia Elétrica, Campinas/SP, GPC/025, 6 p. out.

[30] BEWLEY, L. V. (1963). Traveling waves on transmission systems. John Wiley \& Sons, New York.

[31] GAlE, P. F.; CROSSlEY, P. A.; BINGYIN, XU; YAOZHONG, GE; CORY, B. J.; BARKER, J. R.G. (1993). Fault localion based on traveling waves. Developments in Power System Protection, Fifth International Conference, p. 54-59.

[32] VITINS, M. (1978). A correlation method for transmission line protection. IEEE Transactions on Power Apparatus and Systems, v.PAS-97, n.5, p. 16071615 , sept/oct.

[33] CROSSlEY, P. A.; MCLAREN, P. G. (1983). Distance protection based on travelling waves. IEEE Transactions on Power Apparatus and Systems, v.PAS102, n.9, p. 2971-2983, sept.

[34] RAJENDRA, S.; MCLAREN, P. G. (1985). Traveling wave techniques applied to the protection of teed circuits: Principle of traveling wave techniques. IEEE Transactions on Power Apparatus and Systems, v.PAS-104, n.12, p. 3544-3550, dec.

[35] SHEHAB-ELDIN, E. H.; MCLAREN, P. G. (1988). Traveling wave distance protection - Problem areas and solutions. IEEE Transactions on Power Delivery, v.3, n.3, p. 894-902, jul. 
[36] ANCElL, G. B.; PAHALAWATHTHA, N. C. (1994). Maximum likelihood estimation of fault location on transmission lines using traveling waves. IEEE Transactions on Power Delivery, v.9, n.2, p. 680-686, apr.

[37] BO, Z. Q.; JOHNS, A. T.; AGGARWAL, R. K. (1997). A novel fault locator based on the detection of fault generated high frequency transients. IEE Developments in Power System Protection, Conference Publication, n.434, p. 197-200, mar.

[38] MAGNAGO, F. H.; ABUR, A. (1998). Fault location using wavelets. IEEE Transactions on Power Delivery, v.13, n.4, p. 1475-1480, oct.

[39] Liang, J.; Elanbovan, S.; DEVOtTA, J. B. X. (2000). Application of wavelet transform in traveling wave protection. ELSEVIER Electrical Power and Energy Systems, v.22, p. 537-542, apr.

[40] LAI, L. L.; VASEEKAR, E.; SUBASINGHE, H.; RAJKUMAR, N.; CARTER, A.; GWYN, B. J. (2000). Fault location of a teed-network with wavelet transform and neural networks. IEEE International Conference on Electric Utility Deregulation and Restructuring and Power Technologies, City University, London, p. 505-509, apr.

[41] CHEN, Z.; BO, Z. Q.; JIANG, F.; DONG, X. Z.; WELLER, G.; CHIN, N. F. (2000). Wavelet transform based accurate fault location and protection technique pro cable circuits. IEE Proceedings of the Fifth International Conference on Advances in Power System Control, Operation and Management, Hong Kong, p. 59-63, oct.

[42] ABUR, A.; MAGNAGO, F. H. (2000). Use of time delays between modal components in wavelet based fault location. ELSEVIER Electrical Power and Energy Systems, v.22, p. 397-403.

[43] SILVEIRA, P. M.; SEARA, R.; ZURN, H. H. (1999a). Fault type identification using wavelet transform. The International Conference on Intelligent Systems Application to Power Systems, p. 267-272, Rio de Janeiro, Brasil.

[44] SILVEIRA, P. M.; SEARA, R.; ZURN, H. H. (1999b). An approach using wavelet transform for fault type identification in digital relaying. IEEE Proceeding Summer Meeting, p. 937-942, Edmonton, Canadá. 
[45] IBE, A. O.; CORY, B. J. (1986). A traveling wave-based fault locator for twoand three-terminal networks. IEEE Transactions on Power Systems, v.PWRD-1, n.2, p. 283-288, apr.

[46] IBE, A. O.; CORY, B. J. (1987). Fault location algorithm for multiphase power lines. IEE Proceedings, v.134, Pt. C, n.1, p. 43-50, jan.

[47] LEE, H.; MOUSA, A. M. (1996). GPS Traveling wave fault locator systems: investigation into the anomalous measurements related to lightning strikes. IEEE Transactions on Power Systems, v.11, n.3, p.1214-1223, jul.

[48] JIAN, Q.; XIANGXUN, C.; JIANCHAO, Z. (1998). Traveling wave fault location of transmission line using wavelet transform. IEEE Proceedings International Conference on Power System Technology, v.1, p. 533-537, aug.

[49] GAlE, P. F.; TAYLOR, P. V.; NAIDOO, P.; HITCHIN, C.; CLOWES, D. (2001). Traveling wave fault locator experience on eskom's transmission network. IEE Development in Power System Protection, Conference Publication n.479, p.327-330.

[50] KIM, G.; KIM, H.; CHOI, J. (2001). Wavelet transform based power transmission line fault location using GPS for accurate time synchronization. IEEE/IECON: The $27^{\text {th }}$ Annual Conference of the IEEE Industrial Electronics Society, p. 495-499.

[51] CHANDA, D.; KISHORE, N. K.; SINHA, A. K. (2003). A wavelet multiresolution analysis for location of faults on transmission lines. Electrical Power \& Energy Systems, v.25, p.59-69.

[52] HEDMAN, D. E. (1978). Teoria das Linhas de Transmissão II. Tradução FARRET, F. A., Universidade Federal de Santa Maria, Santa Maria.

[53] GREENWOOD, A. (1971). Electrical transients in power systems. WileyInterscience, New York.

[54] NAIDU, S. R. (1985). Transitórios eletromagnéticos em sistemas de potência. Editora Grafset - Co-edição Eletrobrás/Universidade Federal do Paraíba.

[55] LIMA, P. C. Wavelets: Teoria, Algoritmos e Aplicações. Belo Horizonte: Departamento de Matemática - ICEX - UFMG, p. 2002. 
[56] GRAPS, A. (1995). An Introduction to wavelets. IEEE Computational Science and Engineering, v.2, p. 50-61, summer.

[57] SCHIMIDT, R. F. (2000). Detecção e rastreamento de faces utilizando Gabor wavelet networks. Dissertação (Mestrado), Instituto de Matemática e Estatística, Universidade de São Paulo.

[58] KIM, C. H.; AGGARWAL, R. (2000). Wavelet transforms in power systems: Part 1 General introduction to the wavelet transforms. Power Engineering Journal, v.14, n.2, p. 81-87, Apr.

[59] DAUBECHIES, I. (1996). Where Do Wavelets Come From? - A Personal Point of View. Proceedings of the IEEE, v.84, n.4, p. 510-513, Apr.

[60] MISITI, M., MISITI, Y., OPPENHEIM, G. and POGGI, J.-M. (1997). Wavelet Toolbox: User`s Guide. Natick, MA: The MathWorks, 626 p.

[61] DAUBECHIES, I. (1992). Ten lectures on wavelets. Philadelphia, Pa.: Society for Industrial and Applied Mathematics, 357 p.

[62] MEYER, Y. (1992). Wavelets and operators. Cambridge: Cambridge University Press.

[63] CHUI, C. K. (1997). Wavelets: a tool for signal analysis. Philadelphia, Pa.: Society for Industrial and Applied Mathematics.

[64] BURRUS, C. S., GOPINATH, R. A.; GUO, H. (1998). Introduction to wavelets and wavelet transforms : a primer. Upper Saddle River, NJ: Prentice Hall, 268 p.

[65] BURKE HUBBARD, B. (1998). The world according to wavelets. Wellesley, Massachusetts.: A. K. PETERS.

[66] KIM, C. H.; AGGARWAL, R. (2001). Wavelet transforms in power systems: Part 2 Examples of application to actual power system transients. Power Engineering Journal, p. 193-202, Aug.

[67] SANTOSO, S.; POWERS, E. J.; GRADY, W. M.; HOFMANN, P. (1996). Power Quality Assessment Via Wavelet Transform Analysis. IEEE Transactions on Power Delivery, v.11, n.2, p. 924-930, Apr. 
[68] ALTERNATIVE TRANSIENTS PROGRAM - Rule Book. (1987). Leuven EMTP Center (LEC).

[69] OLESKOVICZ, M. (2001). Aplicação de redes neurais artificiais na proteção de distância. Tese (Doutorado) - Escola de Engenharia de São Carlos, Universidade de São Paulo.

[70] ZHAO, W.; SONG, Y. H.; CHEN, W. R. (2001). Improved GPS traveling wave fault locator for power cables by using wavelet analysis. ELSEVIER Electrical Power and Energy Systems, v.23, p. 403-411.

[71] URUSAWA, K.; KANEMARU, K.; TOYOTA, S.; SUGIYAMA, K. (1989). New fault location system for power transmission lines using composite fiberoptic overhead ground wire $(O P G W)$. IEEE Transactions on Power Delivery, v.4, n.4, p.2005-2011, oct.

[72] CLARKE, E. (1943). Circuit analysis of A-C power systems. . John Wiley \& Sons, New York. 


\section{APÊNDICE A - Resultados dos testes sobre o circuito simples de transmissão}

Este apêndice tem por objeto ilustrar outros resultados referentes a simulações sobre o sistema simples de transmissão proposto, com o intuito de confirmar a aplicabilidade, confiabilidade e precisão do algoritmo de localização de faltas proposto.

\section{A1. Técnica que utiliza dados de dois terminais}

As Tabelas (38-51) ilustram os resultados obtidos pelo algoritmo em situações faltosas onde foram variados os seguintes parâmetros: distância, tipo, ângulo de incidência e resistência de falta;

As Tabelas (52-57) trazem resultados referentes a testes onde foram consideradas altas resistências de falta associadas a variações de distância, ângulo de incidência e tipo de falta;

Nas Tabelas (58-63) são apresentados resultados referentes a teste feitos para se verificar a influência de dados não sincronizados na precisão da técnica de localização abordada;

Resultados onde é verificada a influência da taxa amostral sobre a técnica de localização utilizada são apresentados nas Tabelas (64-69);

Nas Tabelas (70-73) que seguem são demonstrados mais resultados referentes a testes aplicados com o intuito de se verificar a influência da imprecisão na determinação dos parâmetros da linha sobre a técnica de localização em análise.

Cabe ressaltar que, os dados em destaque (..), representam casos onde o localizador apresentou uma grande imprecisão, devido a fatores descritos ao longo deste trabalho. 
TABELA 38 - Resultados para faltas fase-fase $(A C)$ com ângulo de incidência de $0^{\circ}$.

\begin{tabular}{cccccc}
\hline $\begin{array}{c}\text { Distância } \\
\text { Real } \\
(\mathbf{k m})\end{array}$ & $\begin{array}{c}\text { Anngulo de } \\
\text { Incidência } \\
\text { (graus) }\end{array}$ & $\begin{array}{c}\text { Tipo de } \\
\text { Falta }\end{array}$ & $\begin{array}{c}\text { Distância } \\
\text { Estimada } \\
(\mathbf{k m})\end{array}$ & $\begin{array}{c}\text { Erro } \\
\text { Abs. } \\
\mathbf{( k m )}\end{array}$ & $\begin{array}{c}\text { Erro } \\
\mathbf{( \% )}\end{array}$ \\
\hline 10 & 0 & $\mathrm{AC}$ & 13,19 & 3,19 & 2,13 \\
\hline 25 & 0 & $\mathrm{AC}$ & 27,2 & 2,2 & 1,47 \\
\hline 40 & 0 & $\mathrm{AC}$ & 40,07 & 0,07 & 0,05 \\
\hline 55 & 0 & $\mathrm{AC}$ & 53,5 & 1,5 & 1,00 \\
\hline 70 & 0 & $\mathrm{AC}$ & 66,94 & 3,06 & 2,04 \\
\hline 75 & 0 & $\mathrm{AC}$ & 75 & 0 & 0,00 \\
\hline 80 & 0 & $\mathrm{AC}$ & 83,06 & 3,06 & 2,04 \\
\hline 95 & 0 & $\mathrm{AC}$ & 96,5 & 1,5 & 1,00 \\
\hline 110 & 0 & $\mathrm{AC}$ & 109,93 & 0,07 & 0,05 \\
\hline 125 & 0 & $\mathrm{AC}$ & 123,37 & 1,63 & 1,09 \\
\hline 140 & 0 & $\mathrm{AC}$ & 136,81 & 3,19 & 2,13 \\
\hline \multicolumn{7}{c}{ Erro médio $\mathbf{( \% )}$} & & & $\mathbf{1 , 1 8}$ \\
\hline & & & & &
\end{tabular}

TABELA 39 - Resultados para faltas fase-fase $(A C)$ com ângulo de incidência de $90^{\circ}$.

\begin{tabular}{cccccc}
\hline $\begin{array}{c}\text { Distância } \\
\text { Real } \\
(\mathbf{k m})\end{array}$ & $\begin{array}{c}\text { Angulo de } \\
\text { Incidência } \\
\text { (graus) }\end{array}$ & $\begin{array}{c}\text { Tipo de } \\
\text { Falta }\end{array}$ & $\begin{array}{c}\text { Distância } \\
\text { Estimada } \\
\text { (km) }\end{array}$ & $\begin{array}{c}\text { Erro } \\
\text { Abs. } \\
\mathbf{( k m )}\end{array}$ & $\begin{array}{c}\text { Erro } \\
\text { (\%) }\end{array}$ \\
\hline 10 & 90 & AC & 10,5 & 0,5 & 0,33 \\
\hline 25 & 90 & AC & 26,63 & 1,63 & 1,09 \\
\hline 40 & 90 & AC & 40,05 & 0,05 & 0,03 \\
\hline 55 & 90 & AC & 53,51 & 1,49 & 0,99 \\
\hline 70 & 90 & AC & 69,64 & 0,36 & 0,24 \\
\hline 75 & 90 & AC & 75 & 0 & 0,00 \\
\hline 80 & 90 & AC & 80,37 & 0,37 & 0,25 \\
\hline 95 & 90 & AC & 96,49 & 1,49 & 0,99 \\
\hline 110 & 90 & AC & 111,28 & 1,28 & 0,85 \\
\hline 125 & 90 & AC & 123,37 & 1,63 & 1,09 \\
\hline 140 & 90 & AC & 139,5 & 0,5 & 0,33 \\
\hline \multicolumn{7}{c}{ Erro médio (\%) } & & & $\mathbf{0 , 5 6}$ \\
\hline
\end{tabular}

TABELA 42 - Resultados para faltas trifásicas $(A B C)$ com ângulo de incidência de $0^{\circ}$.

\begin{tabular}{cccccc}
\hline $\begin{array}{c}\text { Distância } \\
\text { Real } \\
(\mathbf{k m})\end{array}$ & $\begin{array}{c}\text { Angulo de } \\
\text { Incidência } \\
\text { (graus) }\end{array}$ & $\begin{array}{c}\text { Tipo de } \\
\text { Falta }\end{array}$ & $\begin{array}{c}\text { Distância } \\
\text { Estimada } \\
(\mathbf{k m})\end{array}$ & $\begin{array}{c}\text { Erro } \\
\text { Abs. } \\
(\mathbf{k m})\end{array}$ & $\begin{array}{c}\text { Erro } \\
(\mathbf{\%})\end{array}$ \\
\hline 10 & 0 & $\mathrm{ABC}$ & 10,53 & 0,53 & 0,35 \\
\hline 25 & 0 & $\mathrm{ABC}$ & 23,96 & 1,04 & 0,69 \\
\hline 40 & 0 & $\mathrm{ABC}$ & 40,08 & 0,08 & 0,05 \\
\hline 55 & 0 & $\mathrm{ABC}$ & 53,51 & 1,49 & 0,99 \\
\hline 70 & 0 & $\mathrm{ABC}$ & 69,62 & 0,38 & 0,25 \\
\hline 75 & 0 & $\mathrm{ABC}$ & 75 & 0 & 0,00 \\
\hline 80 & 0 & $\mathrm{ABC}$ & 80,38 & 0,38 & 0,25 \\
\hline 95 & 0 & $\mathrm{ABC}$ & 93,81 & 1,19 & 0,79 \\
\hline 110 & 0 & $\mathrm{ABC}$ & 109,92 & 0,08 & 0,05 \\
\hline 125 & 0 & $\mathrm{ABC}$ & 126,04 & 1,04 & 0,69 \\
\hline 140 & 0 & $\mathrm{ABC}$ & 140,8 & 0,8 & 0,53 \\
\hline \multicolumn{7}{c}{} \\
\hline \multicolumn{7}{c}{ Erro médio $\mathbf{( \% )}$} \\
\end{tabular}

TABELA 40 - Resultados para faltas fase-fase $(B C)$ com ângulo de incidência de $0^{\circ}$.

\begin{tabular}{cccccc}
\hline $\begin{array}{c}\text { Distância } \\
\text { Real } \\
(\mathbf{k m})\end{array}$ & $\begin{array}{c}\text { Angulo de } \\
\text { Incidência } \\
\text { (graus) }\end{array}$ & $\begin{array}{c}\text { Tipo de } \\
\text { Falta }\end{array}$ & $\begin{array}{c}\text { Distância } \\
\text { Estimada } \\
\mathbf{( k m )}\end{array}$ & $\begin{array}{c}\text { Erro } \\
\text { Abs. } \\
\mathbf{( k m )}\end{array}$ & $\begin{array}{c}\text { Erro } \\
\mathbf{( \% )}\end{array}$ \\
\hline 10 & 0 & $\mathrm{BC}$ & 10,5 & 0,5 & 0,33 \\
\hline 25 & 0 & $\mathrm{BC}$ & 23,93 & 1,07 & 0,71 \\
\hline 40 & 0 & $\mathrm{BC}$ & 42,75 & 2,75 & 1,83 \\
\hline 55 & 0 & $\mathrm{BC}$ & 56,18 & 1,18 & 0,79 \\
\hline 70 & 0 & $\mathrm{BC}$ & 69,62 & 0,38 & 0,25 \\
\hline 75 & 0 & $\mathrm{BC}$ & 75 & 0 & 0,00 \\
\hline 80 & 0 & $\mathrm{BC}$ & 80,38 & 0,38 & 0,25 \\
\hline 95 & 0 & $\mathrm{BC}$ & 93,82 & 1,18 & 0,79 \\
\hline 110 & 0 & $\mathrm{BC}$ & 107,25 & 2,75 & 1,83 \\
\hline 125 & 0 & $\mathrm{BC}$ & 126,07 & 1,07 & 0,71 \\
\hline 140 & 0 & $\mathrm{BC}$ & 139,5 & 0,5 & 0,33 \\
\hline \multicolumn{7}{c}{ Erro médio (\%) } & & & $\mathbf{0 , 7 1}$ \\
\hline
\end{tabular}

TABELA 41 - Resultados para faltas fase-fase(BC) com ângulo de incidência de $90^{\circ}$.

\begin{tabular}{cccccc}
\hline $\begin{array}{c}\text { Distância } \\
\text { Real } \\
(\mathbf{k m})\end{array}$ & $\begin{array}{c}\text { Angulo de } \\
\text { Incidência } \\
\text { (graus) }\end{array}$ & $\begin{array}{c}\text { Tipo de } \\
\text { Falta }\end{array}$ & $\begin{array}{c}\text { Distância } \\
\text { Estimada } \\
\text { (km) }\end{array}$ & $\begin{array}{c}\text { Erro } \\
\text { Abs. } \\
\mathbf{( k m )}\end{array}$ & $\begin{array}{c}\text { Erro } \\
\mathbf{( \% )}\end{array}$ \\
\hline 10 & 90 & $\mathrm{BC}$ & 7,81 & 2,19 & 1,46 \\
\hline 25 & 90 & $\mathrm{BC}$ & 23,93 & 1,07 & 0,71 \\
\hline 40 & 90 & $\mathrm{BC}$ & 40,05 & 0,05 & 0,03 \\
\hline 55 & 90 & $\mathrm{BC}$ & 56,18 & 1,18 & 0,79 \\
\hline 70 & 90 & $\mathrm{BC}$ & 70,97 & 0,97 & 0,65 \\
\hline 75 & 90 & $\mathrm{BC}$ & 75 & 0 & 0,00 \\
\hline 80 & 90 & $\mathrm{BC}$ & 79,03 & 0,97 & 0,65 \\
\hline 95 & 90 & $\mathrm{BC}$ & 93,82 & 1,18 & 0,79 \\
\hline 110 & 90 & $\mathrm{BC}$ & 109,95 & 0,05 & 0,03 \\
\hline 125 & 90 & $\mathrm{BC}$ & 127,4 & 2,4 & 1,60 \\
\hline 140 & 90 & $\mathrm{BC}$ & 142,19 & 2,19 & 1,46 \\
\hline \multicolumn{7}{c}{ Erro médio (\%) } & & & $\mathbf{0 , 7 4}$ \\
\hline
\end{tabular}

TABELA 43 - Resultados para faltas trifásicas $(A B C)$ com ângulo de incidência de $90^{\circ}$.

\begin{tabular}{|c|c|c|c|c|c|}
\hline $\begin{array}{c}\text { Distância } \\
\text { Real } \\
(\mathbf{k m})\end{array}$ & $\begin{array}{c}\text { Ângulo de } \\
\text { Incidência } \\
\text { (graus) }\end{array}$ & $\begin{array}{c}\text { Tipo de } \\
\text { Falta }\end{array}$ & $\begin{array}{c}\text { Distância } \\
\text { Estimada } \\
(\mathbf{k m})\end{array}$ & $\begin{array}{l}\text { Erro } \\
\text { Abs. } \\
(\mathbf{k m})\end{array}$ & $\begin{array}{l}\text { Erro } \\
(\%)\end{array}$ \\
\hline 10 & 90 & $\mathrm{ABC}$ & 10,53 & 0,53 & 0,35 \\
\hline 25 & 90 & $\mathrm{ABC}$ & 25,29 & 0,29 & 0,19 \\
\hline 40 & 90 & $\mathrm{ABC}$ & 40,07 & 0,07 & 0,05 \\
\hline 55 & 90 & $\mathrm{ABC}$ & 53,51 & 1,49 & 0,99 \\
\hline 70 & 90 & $\mathrm{ABC}$ & 69,62 & 0,38 & 0,25 \\
\hline 75 & 90 & $\mathrm{ABC}$ & 75 & 0 & 0,00 \\
\hline 80 & 90 & $\mathrm{ABC}$ & 80,38 & 0,38 & 0,25 \\
\hline 95 & 90 & $\mathrm{ABC}$ & 95,16 & 0,16 & 0,11 \\
\hline 110 & 90 & $\mathrm{ABC}$ & 109,93 & 0,07 & 0,05 \\
\hline 125 & 90 & $\mathrm{ABC}$ & 124,71 & 0,29 & 0,19 \\
\hline 140 & 90 & $\mathrm{ABC}$ & 139,47 & 0,53 & 0,35 \\
\hline \multicolumn{5}{|c|}{ Erro médio (\%) } & 0,25 \\
\hline
\end{tabular}


TABELA 44 - Resultados para faltas fase-terra(BT) com ângulo de incidência de $0^{\circ}$ e resistência de falta de 0, 50 e 100 ohms

\begin{tabular}{|c|c|c|c|c|c|c|}
\hline $\begin{array}{c}\text { Distância } \\
\text { Real } \\
\text { (km) }\end{array}$ & $\begin{array}{c}\text { Resist. } \\
\text { falta } \\
\text { (ohms) }\end{array}$ & $\begin{array}{c}\text { Ângulo de } \\
\text { Incidência } \\
\text { (graus) }\end{array}$ & $\begin{array}{c}\text { Tipo de } \\
\text { Falta }\end{array}$ & $\begin{array}{c}\text { Distância } \\
\text { Estimada } \\
\text { (km) }\end{array}$ & $\begin{array}{l}\text { Erro } \\
\text { Abs. } \\
(\mathbf{k m})\end{array}$ & $\begin{array}{r}\text { Erro } \\
(\%)\end{array}$ \\
\hline 10 & 0 & 0 & BT & 7,81 & 2,19 & 1,46 \\
\hline 10 & 50 & 0 & BT & 7,81 & 2,19 & 1,46 \\
\hline 10 & 100 & 0 & BT & 7,81 & 2,19 & 1,46 \\
\hline 25 & 0 & 0 & BT & 23,93 & 1,07 & 0,71 \\
\hline 25 & 50 & 0 & BT & 23,93 & 1,07 & 0,71 \\
\hline 25 & 100 & 0 & BT & 23,93 & 1,07 & 0,71 \\
\hline 40 & 0 & 0 & $\mathrm{BT}$ & 40,07 & 0,07 & 0,05 \\
\hline 40 & 50 & 0 & BT & 40,07 & 0,07 & 0,05 \\
\hline 40 & 100 & 0 & BT & 40,07 & 0,07 & 0,05 \\
\hline 55 & 0 & 0 & BT & 56,18 & 1,18 & 0,79 \\
\hline 55 & 50 & 0 & BT & 56,18 & 1,18 & 0,79 \\
\hline 55 & 100 & 0 & BT & 56,18 & 1,18 & 0,79 \\
\hline 70 & 0 & 0 & BT & 69,62 & 0,38 & 0,25 \\
\hline 70 & 50 & 0 & BT & 69,62 & 0,38 & 0,25 \\
\hline 70 & 100 & 0 & BT & 69,62 & 0,38 & 0,25 \\
\hline 75 & 0 & 0 & BT & 75 & 0 & 0,00 \\
\hline 75 & 50 & 0 & BT & 75 & 0 & 0,00 \\
\hline 75 & 100 & 0 & $\mathrm{BT}$ & 75 & 0 & 0,00 \\
\hline 80 & 0 & 0 & BT & 80,38 & 0,38 & 0,25 \\
\hline 80 & 50 & 0 & BT & 80,38 & 0,38 & 0,25 \\
\hline 80 & 100 & 0 & BT & 80,38 & 0,38 & 0,25 \\
\hline 95 & 0 & 0 & $\mathrm{BT}$ & 93,82 & 1,18 & 0,79 \\
\hline 95 & 50 & 0 & $\mathrm{BT}$ & 93,82 & 1,18 & 0,79 \\
\hline 95 & 100 & 0 & $\mathrm{BT}$ & 93,82 & 1,18 & 0,79 \\
\hline 110 & 0 & 0 & $\mathrm{BT}$ & 109,93 & 0,07 & 0,05 \\
\hline 110 & 50 & 0 & $\mathrm{BT}$ & 109,93 & 0,07 & 0,05 \\
\hline 110 & 100 & 0 & $\mathrm{BT}$ & 109,93 & 0,07 & 0,05 \\
\hline 125 & 0 & 0 & BT & 126,07 & 1,07 & 0,71 \\
\hline 125 & 50 & 0 & BT & 126,07 & 1,07 & 0,71 \\
\hline 125 & 100 & 0 & BT & 126,07 & 1,07 & 0,71 \\
\hline 140 & 0 & 0 & BT & 142,19 & 2,19 & 1,46 \\
\hline 140 & 50 & 0 & BT & 142,19 & 2,19 & 1,46 \\
\hline 140 & 100 & 0 & BT & 142,19 & 2,19 & 1,46 \\
\hline \multicolumn{6}{|c|}{ Erro médio (\%) } & $\mathbf{0 , 5 9}$ \\
\hline
\end{tabular}


TABELA 45 - Resultados para faltas fase-terra(BT) com ângulo de incidência de $90^{\circ}$ e resistência de falta de 0, 50 e $100 \mathrm{ohms}$

\begin{tabular}{|c|c|c|c|c|c|c|}
\hline $\begin{array}{c}\text { Distância } \\
\text { Real } \\
\text { (km) }\end{array}$ & $\begin{array}{c}\text { Resist. } \\
\text { falta } \\
\text { (ohms) }\end{array}$ & $\begin{array}{c}\text { Ângulo de } \\
\text { Incidência } \\
\text { (graus) }\end{array}$ & $\begin{array}{c}\text { Tipo de } \\
\text { Falta }\end{array}$ & $\begin{array}{c}\text { Distância } \\
\text { Estimada } \\
\text { (km) }\end{array}$ & $\begin{array}{l}\text { Erro } \\
\text { Abs. } \\
(\mathrm{km})\end{array}$ & $\begin{array}{l}\text { Erro } \\
(\%)\end{array}$ \\
\hline 10 & 0 & 90 & BT & 7,81 & 2,19 & 1,46 \\
\hline 10 & 50 & 90 & BT & 7,81 & 2,19 & 1,46 \\
\hline 10 & 100 & 90 & BT & 7,81 & 2,19 & 1,46 \\
\hline 25 & 0 & 90 & BT & 22,6 & 2,4 & 1,60 \\
\hline 25 & 50 & 90 & BT & 22,6 & 2,4 & 1,60 \\
\hline 25 & 100 & 90 & BT & 21,25 & 3,75 & 2,50 \\
\hline 40 & 0 & 90 & BT & 40,05 & 0,05 & 0,03 \\
\hline 40 & 50 & 90 & BT & 40,05 & 0,05 & 0,03 \\
\hline 40 & 100 & 90 & BT & 40,05 & 0,05 & 0,03 \\
\hline 55 & 0 & 90 & BT & 56,18 & 1,18 & 0,79 \\
\hline 55 & 50 & 90 & BT & 56,18 & 1,18 & 0,79 \\
\hline 55 & 100 & 90 & BT & 56,18 & 1,18 & 0,79 \\
\hline 70 & 0 & 90 & BT & 72,3 & 2,3 & 1,53 \\
\hline 70 & 50 & 90 & BT & 72,3 & 2,3 & 1,53 \\
\hline 70 & 100 & 90 & BT & 72,3 & 2,3 & 1,53 \\
\hline 75 & 0 & 90 & BT & 75 & 0 & 0,00 \\
\hline 75 & 50 & 90 & BT & 75 & 0 & 0,00 \\
\hline 75 & 100 & 90 & BT & 75 & 0 & 0,00 \\
\hline 80 & 0 & 90 & BT & 77,7 & 2,3 & 1,53 \\
\hline 80 & 50 & 90 & BT & 77,7 & 2,3 & 1,53 \\
\hline 80 & 100 & 90 & BT & 77,7 & 2,3 & 1,53 \\
\hline 95 & 0 & 90 & BT & 92,47 & 2,53 & 1,69 \\
\hline 95 & 50 & 90 & BT & 93,82 & 1,18 & 0,79 \\
\hline 95 & 100 & 90 & BT & 92,47 & 2,53 & 1,69 \\
\hline 110 & 0 & 90 & BT & 109,95 & 0,05 & 0,03 \\
\hline 110 & 50 & 90 & BT & 109,95 & 0,05 & 0,03 \\
\hline 110 & 100 & 90 & BT & 109,95 & 0,05 & 0,03 \\
\hline 125 & 0 & 90 & BT & 127,4 & 2,4 & 1,60 \\
\hline 125 & 50 & 90 & BT & 128,75 & 3,75 & 2,50 \\
\hline 125 & 100 & 90 & BT & 128,75 & 3,75 & 2,50 \\
\hline 140 & 0 & 90 & BT & 142,19 & 2,19 & 1,46 \\
\hline 140 & 50 & 90 & BT & 142,19 & 2,19 & 1,46 \\
\hline 140 & 100 & 90 & BT & 142,19 & 2,19 & 1,46 \\
\hline \multicolumn{6}{|c|}{ Erro médio (\%) } & 1,12 \\
\hline
\end{tabular}


TABELA 46 - Resultados para faltas fase-terra(CT) com ângulo de incidência de $0^{\circ}$ e resistência de falta de 0, 50 e $100 \mathrm{ohms}$

\begin{tabular}{|c|c|c|c|c|c|c|}
\hline $\begin{array}{c}\text { Distância } \\
\text { Real } \\
\text { (km) }\end{array}$ & $\begin{array}{c}\text { Resist. } \\
\text { falta } \\
\text { (ohms) }\end{array}$ & $\begin{array}{c}\text { Ângulo de } \\
\text { Incidência } \\
\text { (graus) }\end{array}$ & $\begin{array}{c}\text { Tipo de } \\
\text { Falta }\end{array}$ & $\begin{array}{c}\text { Distância } \\
\text { Estimada } \\
(\mathbf{k m})\end{array}$ & $\begin{array}{l}\text { Erro } \\
\text { Abs. } \\
\text { (km) }\end{array}$ & $\begin{array}{l}\text { Erro } \\
(\%)\end{array}$ \\
\hline 10 & 0 & 0 & CT & 13,19 & 3,19 & 2,13 \\
\hline 10 & 50 & 0 & CT & 13,19 & 3,19 & 2,13 \\
\hline 10 & 100 & 0 & CT & 13,19 & 3,19 & 2,13 \\
\hline 25 & 0 & 0 & CT & 26,63 & 1,63 & 1,09 \\
\hline 25 & 50 & 0 & CT & 26,63 & 1,63 & 1,09 \\
\hline 25 & 100 & 0 & $\mathrm{CT}$ & 26,63 & 1,63 & 1,09 \\
\hline 40 & 0 & 0 & CT & 40,07 & 0,07 & 0,05 \\
\hline 40 & 50 & 0 & CT & 40,07 & 0,07 & 0,05 \\
\hline 40 & 100 & 0 & CT & 40,07 & 0,07 & 0,05 \\
\hline 55 & 0 & 0 & CT & 53,51 & 1,49 & 0,99 \\
\hline 55 & 50 & 0 & CT & 53,51 & 1,49 & 0,99 \\
\hline 55 & 100 & 0 & CT & 53,51 & 1,49 & 0,99 \\
\hline 70 & 0 & 0 & CT & 66,94 & 3,06 & 2,04 \\
\hline 70 & 50 & 0 & CT & 66,94 & 3,06 & 2,04 \\
\hline 70 & 100 & 0 & CT & 66,94 & 3,06 & 2,04 \\
\hline 75 & 0 & 0 & CT & 75 & 0 & 0,00 \\
\hline 75 & 50 & 0 & CT & 75 & 0 & 0,00 \\
\hline 75 & 100 & 0 & $\mathrm{CT}$ & 75 & 0 & 0,00 \\
\hline 80 & 0 & 0 & $\mathrm{CT}$ & 83,06 & 3,06 & 2,04 \\
\hline 80 & 50 & 0 & $\mathrm{CT}$ & 83,06 & 3,06 & 2,04 \\
\hline 80 & 100 & 0 & CT & 83,06 & 3,06 & 2,04 \\
\hline 95 & 0 & 0 & $\mathrm{CT}$ & 96,49 & 1,49 & 0,99 \\
\hline 95 & 50 & 0 & CT & 96,49 & 1,49 & 0,99 \\
\hline 95 & 100 & 0 & CT & 96,49 & 1,49 & 0,99 \\
\hline 110 & 0 & 0 & CT & 109,93 & 0,07 & 0,05 \\
\hline 110 & 50 & 0 & CT & 109,93 & 0,07 & 0,05 \\
\hline 110 & 100 & 0 & CT & 109,93 & 0,07 & 0,05 \\
\hline 125 & 0 & 0 & CT & 123,37 & 1,63 & 1,09 \\
\hline 125 & 50 & 0 & $\mathrm{CT}$ & 123,37 & 1,63 & 1,09 \\
\hline 125 & 100 & 0 & CT & 123,37 & 1,63 & 1,09 \\
\hline 140 & 0 & 0 & CT & 136,81 & 3,19 & 2,13 \\
\hline 140 & 50 & 0 & CT & 136,81 & 3,19 & 2,13 \\
\hline 140 & 100 & 0 & $\mathrm{CT}$ & 136,81 & 3,19 & 2,13 \\
\hline \multicolumn{6}{|c|}{ Erro médio (\%) } & 1,14 \\
\hline
\end{tabular}


TABELA 47 - Resultados para faltas fase-terra(BT) com ângulo de incidência de $90^{\circ}$ e resistência de falta de 0, 50 e $100 \mathrm{ohms}$

\begin{tabular}{|c|c|c|c|c|c|c|}
\hline $\begin{array}{c}\text { Distância } \\
\text { Real } \\
\text { (km) }\end{array}$ & $\begin{array}{c}\text { Resist. } \\
\text { falta } \\
(\text { ohms })\end{array}$ & $\begin{array}{c}\text { Ângulo de } \\
\text { Incidência } \\
\text { (graus) }\end{array}$ & $\begin{array}{c}\text { Tipo de } \\
\text { Falta }\end{array}$ & $\begin{array}{c}\text { Distância } \\
\text { Estimada } \\
\text { (km) }\end{array}$ & $\begin{array}{l}\text { Erro } \\
\text { Abs. } \\
(\mathrm{km})\end{array}$ & $\begin{array}{l}\text { Erro } \\
(\%)\end{array}$ \\
\hline 10 & 0 & 90 & CT & 10,5 & 0,5 & 0,33 \\
\hline 10 & 50 & 90 & CT & 10,5 & 0,5 & 0,33 \\
\hline 10 & 100 & 90 & $\mathrm{CT}$ & 10,5 & 0,5 & 0,33 \\
\hline 25 & 0 & 90 & CT & 26,63 & 1,63 & 1,09 \\
\hline 25 & 50 & 90 & $\mathrm{CT}$ & 26,63 & 1,63 & 1,09 \\
\hline 25 & 100 & 90 & CT & 26,63 & 1,63 & 1,09 \\
\hline 40 & 0 & 90 & $\mathrm{CT}$ & 38,72 & 1,28 & 0,85 \\
\hline 40 & 50 & 90 & CT & 38,72 & 1,28 & 0,85 \\
\hline 40 & 100 & 90 & $\mathrm{CT}$ & 40,05 & 0,05 & 0,03 \\
\hline 55 & 0 & 90 & $\mathrm{CT}$ & 53,5 & 1,5 & 1,00 \\
\hline 55 & 50 & 90 & CT & 53,5 & 1,5 & 1,00 \\
\hline 55 & 100 & 90 & CT & 53,5 & 1,5 & 1,00 \\
\hline 70 & 0 & 90 & $\mathrm{CT}$ & 69,62 & 0,38 & 0,25 \\
\hline 70 & 50 & 90 & CT & 69,62 & 0,38 & 0,25 \\
\hline 70 & 100 & 90 & CT & 69,62 & 0,38 & 0,25 \\
\hline 75 & 0 & 90 & CT & 75 & 0 & 0,00 \\
\hline 75 & 50 & 90 & CT & 75 & 0 & 0,00 \\
\hline 75 & 100 & 90 & CT & 75 & 0 & 0,00 \\
\hline 80 & 0 & 90 & $\mathrm{CT}$ & 80,38 & 0,38 & 0,25 \\
\hline 80 & 50 & 90 & CT & 80,38 & 0,38 & 0,25 \\
\hline 80 & 100 & 90 & CT & 80,38 & 0,38 & 0,25 \\
\hline 95 & 0 & 90 & $\mathrm{CT}$ & 96,5 & 1,5 & 1,00 \\
\hline 95 & 50 & 90 & $\mathrm{CT}$ & 96,5 & 1,5 & 1,00 \\
\hline 95 & 100 & 90 & $\mathrm{CT}$ & 96,5 & 1,5 & 1,00 \\
\hline 110 & 0 & 90 & $\mathrm{CT}$ & 109,93 & 0,07 & 0,05 \\
\hline 110 & 50 & 90 & $\mathrm{CT}$ & 109,95 & 0,05 & 0,03 \\
\hline 110 & 100 & 90 & $\mathrm{CT}$ & 109,95 & 0,05 & 0,03 \\
\hline 125 & 0 & 90 & CT & 123,37 & 1,63 & 1,09 \\
\hline 125 & 50 & 90 & CT & 123,37 & 1,63 & 1,09 \\
\hline 125 & 100 & 90 & $\mathrm{CT}$ & 123,37 & 1,63 & 1,09 \\
\hline 140 & 0 & 90 & CT & 139,5 & 0,5 & 0,33 \\
\hline 140 & 50 & 90 & $\mathrm{CT}$ & 139,5 & 0,5 & 0,33 \\
\hline 140 & 100 & 90 & CT & 139,5 & 0,5 & 0,33 \\
\hline \multicolumn{6}{|c|}{ Erro médio (\%) } & $\mathbf{0 , 5 4}$ \\
\hline
\end{tabular}


TABELA 48 - Resultados para faltas fase-fase-terra(ABT) com ângulo de incidência de $0^{\circ}$ e resistência de falta de 0, 50 e $100 \mathrm{ohms}$

\begin{tabular}{|c|c|c|c|c|c|c|}
\hline $\begin{array}{c}\text { Distância } \\
\text { Real } \\
\text { (km) }\end{array}$ & $\begin{array}{c}\text { Resist. } \\
\text { falta } \\
(\text { ohms })\end{array}$ & $\begin{array}{c}\text { Ângulo de } \\
\text { Incidência } \\
\text { (graus) }\end{array}$ & $\begin{array}{c}\text { Tipo de } \\
\text { Falta }\end{array}$ & $\begin{array}{c}\text { Distância } \\
\text { Estimada } \\
\text { (km) }\end{array}$ & $\begin{array}{l}\text { Erro } \\
\text { Abs. } \\
(\mathrm{km})\end{array}$ & $\begin{array}{l}\text { Erro } \\
(\%)\end{array}$ \\
\hline 10 & 0 & 0 & ABT & 13,19 & 3,19 & 2,13 \\
\hline 10 & 50 & 0 & ABT & 13,19 & 3,19 & 2,13 \\
\hline 10 & 100 & 0 & ABT & 13,19 & 3,19 & 2,13 \\
\hline 25 & 0 & 0 & ABT & 26,63 & 1,63 & 1,09 \\
\hline 25 & 50 & 0 & ABT & 26,63 & 1,63 & 1,09 \\
\hline 25 & 100 & 0 & ABT & 26,63 & 1,63 & 1,09 \\
\hline 40 & 0 & 0 & ABT & 40,07 & 0,07 & 0,05 \\
\hline 40 & 50 & 0 & ABT & 40,07 & 0,07 & 0,05 \\
\hline 40 & 100 & 0 & ABT & 40,07 & 0,07 & 0,05 \\
\hline 55 & 0 & 0 & ABT & 53,5 & 1,5 & 1,00 \\
\hline 55 & 50 & 0 & ABT & 53,5 & 1,5 & 1,00 \\
\hline 55 & 100 & 0 & ABT & 53,5 & 1,5 & 1,00 \\
\hline 70 & 0 & 0 & ABT & 66,94 & 3,06 & 2,04 \\
\hline 70 & 50 & 0 & ABT & 66,94 & 3,06 & 2,04 \\
\hline 70 & 100 & 0 & ABT & 66,94 & 3,06 & 2,04 \\
\hline 75 & 0 & 0 & ABT & 75 & 0 & 0,00 \\
\hline 75 & 50 & 0 & ABT & 75 & 0 & 0,00 \\
\hline 75 & 100 & 0 & ABT & 75 & 0 & 0,00 \\
\hline 80 & 0 & 0 & ABT & 83,06 & 3,06 & 2,04 \\
\hline 80 & 50 & 0 & ABT & 83,06 & 3,06 & 2,04 \\
\hline 80 & 100 & 0 & ABT & 83,06 & 3,06 & 2,04 \\
\hline 95 & 0 & 0 & ABT & 96,5 & 1,5 & 1,00 \\
\hline 95 & 50 & 0 & ABT & 96,5 & 1,5 & 1,00 \\
\hline 95 & 100 & 0 & ABT & 96,5 & 1,5 & 1,00 \\
\hline 110 & 0 & 0 & ABT & 112,61 & 2,61 & 1,74 \\
\hline 110 & 50 & 0 & ABT & 109,93 & 0,07 & 0,05 \\
\hline 110 & 100 & 0 & ABT & 109,93 & 0,07 & 0,05 \\
\hline 125 & 0 & 0 & ABT & 123,37 & 1,63 & 1,09 \\
\hline 125 & 50 & 0 & ABT & 123,37 & 1,63 & 1,09 \\
\hline 125 & 100 & 0 & ABT & 123,37 & 1,63 & 1,09 \\
\hline 140 & 0 & 0 & ABT & 136,81 & 3,19 & 2,13 \\
\hline 140 & 50 & 0 & ABT & 136,81 & 3,19 & 2,13 \\
\hline 140 & 100 & 0 & ABT & 136,81 & 3,19 & 2,13 \\
\hline \multicolumn{6}{|c|}{ Erro médio (\%) } & 1,20 \\
\hline
\end{tabular}


TABELA 49 - Resultados para faltas fase-fase-terra(ABT) com ângulo de incidência de $90^{\circ}$ e resistência de falta de 0, 50 e $100 \mathrm{ohms}$

\begin{tabular}{|c|c|c|c|c|c|c|}
\hline $\begin{array}{c}\text { Distância } \\
\text { Real } \\
\text { (km) }\end{array}$ & $\begin{array}{c}\text { Resist. } \\
\text { falta } \\
\text { (ohms) }\end{array}$ & $\begin{array}{c}\text { Ângulo de } \\
\text { Incidência } \\
\text { (graus) }\end{array}$ & $\begin{array}{c}\text { Tipo de } \\
\text { Falta }\end{array}$ & $\begin{array}{c}\text { Distância } \\
\text { Estimada } \\
(\mathbf{k m})\end{array}$ & $\begin{array}{l}\text { Erro } \\
\text { Abs. } \\
\text { (km) }\end{array}$ & $\begin{array}{l}\text { Erro } \\
(\%)\end{array}$ \\
\hline 10 & 0 & 90 & ABT & 10,5 & 0,5 & 0,33 \\
\hline 10 & 50 & 90 & ABT & 10,5 & 0,5 & 0,33 \\
\hline 10 & 100 & 90 & ABT & 10,5 & 0,5 & 0,33 \\
\hline 25 & 0 & 90 & ABT & 26,63 & 1,63 & 1,09 \\
\hline 25 & 50 & 90 & ABT & 26,63 & 1,63 & 1,09 \\
\hline 25 & 100 & 90 & ABT & 26,63 & 1,63 & 1,09 \\
\hline 40 & 0 & 90 & ABT & 40,07 & 0,07 & 0,05 \\
\hline 40 & 50 & 90 & ABT & 40,07 & 0,07 & 0,05 \\
\hline 40 & 100 & 90 & ABT & 40,07 & 0,07 & 0,05 \\
\hline 55 & 0 & 90 & ABT & 53,51 & 1,49 & 0,99 \\
\hline 55 & 50 & 90 & ABT & 53,51 & 1,49 & 0,99 \\
\hline 55 & 100 & 90 & ABT & 53,51 & 1,49 & 0,99 \\
\hline 70 & 0 & 90 & ABT & 69,64 & 0,36 & 0,24 \\
\hline 70 & 50 & 90 & ABT & 69,64 & 0,36 & 0,24 \\
\hline 70 & 100 & 90 & ABT & 69,64 & 0,36 & 0,24 \\
\hline 75 & 0 & 90 & ABT & 75 & 0 & 0,00 \\
\hline 75 & 50 & 90 & ABT & 75 & 0 & 0,00 \\
\hline 75 & 100 & 90 & ABT & 75 & 0 & 0,00 \\
\hline 80 & 0 & 90 & ABT & 80,36 & 0,36 & 0,24 \\
\hline 80 & 50 & 90 & ABT & 80,36 & 0,36 & 0,24 \\
\hline 80 & 100 & 90 & ABT & 80,36 & 0,36 & 0,24 \\
\hline 95 & 0 & 90 & ABT & 96,49 & 1,49 & 0,99 \\
\hline 95 & 50 & 90 & ABT & 96,49 & 1,49 & 0,99 \\
\hline 95 & 100 & 90 & ABT & 96,49 & 1,49 & 0,99 \\
\hline 110 & 0 & 90 & $\mathrm{ABT}$ & 111,28 & 1,28 & 0,85 \\
\hline 110 & 50 & 90 & ABT & 111,28 & 1,28 & 0,85 \\
\hline 110 & 100 & 90 & ABT & 111,28 & 1,28 & 0,85 \\
\hline 125 & 0 & 90 & ABT & 123,37 & 1,63 & 1,09 \\
\hline 125 & 50 & 90 & ABT & 123,37 & 1,63 & 1,09 \\
\hline 125 & 100 & 90 & ABT & 123,37 & 1,63 & 1,09 \\
\hline 140 & 0 & 90 & ABT & 139,5 & 0,5 & 0,33 \\
\hline 140 & 50 & 90 & ABT & 139,5 & 0,5 & 0,33 \\
\hline 140 & 100 & 90 & ABT & 139,5 & 0,5 & 0,33 \\
\hline \multicolumn{6}{|c|}{ Erro médio (\%) } & $\mathbf{0 , 5 6}$ \\
\hline
\end{tabular}


TABELA 50 - Resultados para faltas fase-fase-terra (ACT) com ângulo de incidência de $0^{\circ}$ e resistência de falta de 0, 50 e 100 ohms

\begin{tabular}{|c|c|c|c|c|c|c|}
\hline $\begin{array}{c}\text { Distância } \\
\text { Real } \\
\text { (km) }\end{array}$ & $\begin{array}{c}\text { Resist. } \\
\text { falta } \\
(\text { ohms })\end{array}$ & $\begin{array}{c}\text { Ângulo de } \\
\text { Incidência } \\
\text { (graus) }\end{array}$ & $\begin{array}{c}\text { Tipo de } \\
\text { Falta }\end{array}$ & $\begin{array}{c}\text { Distância } \\
\text { Estimada } \\
\text { (km) }\end{array}$ & $\begin{array}{l}\text { Erro } \\
\text { Abs. } \\
(\mathrm{km})\end{array}$ & $\begin{array}{l}\text { Erro } \\
(\%)\end{array}$ \\
\hline 10 & 0 & 0 & ACT & 13,19 & 3,19 & 2,13 \\
\hline 10 & 50 & 0 & ACT & 13,19 & 3,19 & 2,13 \\
\hline 10 & 100 & 0 & ACT & 13,19 & 3,19 & 2,13 \\
\hline 25 & 0 & 0 & ACT & 26,63 & 1,63 & 1,09 \\
\hline 25 & 50 & 0 & ACT & 26,63 & 1,63 & 1,09 \\
\hline 25 & 100 & 0 & ACT & 26,63 & 1,63 & 1,09 \\
\hline 40 & 0 & 0 & ACT & 40,07 & 0,07 & 0,05 \\
\hline 40 & 50 & 0 & $\mathrm{ACT}$ & 40,07 & 0,07 & 0,05 \\
\hline 40 & 100 & 0 & ACT & 40,07 & 0,07 & 0,05 \\
\hline 55 & 0 & 0 & ACT & 53,5 & 1,5 & 1,00 \\
\hline 55 & 50 & 0 & ACT & 53,5 & 1,5 & 1,00 \\
\hline 55 & 100 & 0 & ACT & 53,5 & 1,5 & 1,00 \\
\hline 70 & 0 & 0 & ACT & 66,94 & 3,06 & 2,04 \\
\hline 70 & 50 & 0 & ACT & 66,94 & 3,06 & 2,04 \\
\hline 70 & 100 & 0 & ACT & 66,94 & 3,06 & 2,04 \\
\hline 75 & 0 & 0 & ACT & 75 & 0 & 0,00 \\
\hline 75 & 50 & 0 & ACT & 75 & 0 & 0,00 \\
\hline 75 & 100 & 0 & ACT & 75 & 0 & 0,00 \\
\hline 80 & 0 & 0 & ACT & 83,06 & 3,06 & 2,04 \\
\hline 80 & 50 & 0 & ACT & 83,06 & 3,06 & 2,04 \\
\hline 80 & 100 & 0 & ACT & 83,06 & 3,06 & 2,04 \\
\hline 95 & 0 & 0 & ACT & 96,5 & 1,5 & 1,00 \\
\hline 95 & 50 & 0 & ACT & 96,5 & 1,5 & 1,00 \\
\hline 95 & 100 & 0 & ACT & 96,5 & 1,5 & 1,00 \\
\hline 110 & 0 & 0 & ACT & 109,93 & 0,07 & 0,05 \\
\hline 110 & 50 & 0 & ACT & 109,93 & 0,07 & 0,05 \\
\hline 110 & 100 & 0 & ACT & 109,93 & 0,07 & 0,05 \\
\hline 125 & 0 & 0 & ACT & 123,37 & 1,63 & 1,09 \\
\hline 125 & 50 & 0 & ACT & 123,37 & 1,63 & 1,09 \\
\hline 125 & 100 & 0 & ACT & 123,37 & 1,63 & 1,09 \\
\hline 140 & 0 & 0 & ACT & 136,81 & 3,19 & 2,13 \\
\hline 140 & 50 & 0 & ACT & 136,81 & 3,19 & 2,13 \\
\hline 140 & 100 & 0 & $\mathrm{ACT}$ & 136,81 & 3,19 & 2,13 \\
\hline \multicolumn{6}{|c|}{ Erro médio (\%) } & 1,15 \\
\hline
\end{tabular}


TABELA 51 - Resultados para faltas fase-fase-terra(ACT) com ângulo de incidência de $90^{\circ}$ e resistência de falta de 0, 50 e $100 \mathrm{ohms}$

\begin{tabular}{|c|c|c|c|c|c|c|}
\hline $\begin{array}{c}\text { Distância } \\
\text { Real } \\
\text { (km) }\end{array}$ & $\begin{array}{c}\text { Resist. } \\
\text { falta } \\
\text { (ohms) }\end{array}$ & $\begin{array}{c}\text { Ângulo de } \\
\text { Incidência } \\
\text { (graus) }\end{array}$ & $\begin{array}{c}\text { Tipo de } \\
\text { Falta }\end{array}$ & $\begin{array}{c}\text { Distância } \\
\text { Estimada } \\
\text { (km) }\end{array}$ & $\begin{array}{l}\text { Erro } \\
\text { Abs. } \\
\text { (km) }\end{array}$ & $\begin{array}{l}\text { Erro } \\
(\%)\end{array}$ \\
\hline 10 & 0 & 90 & ACT & 10,5 & 0,5 & 0,33 \\
\hline 10 & 50 & 90 & ACT & 10,5 & 0,5 & 0,33 \\
\hline 10 & 100 & 90 & ACT & 10,5 & 0,5 & 0,33 \\
\hline 25 & 0 & 90 & ACT & 26,63 & 1,63 & 1,09 \\
\hline 25 & 50 & 90 & ACT & 26,63 & 1,63 & 1,09 \\
\hline 25 & 100 & 90 & ACT & 26,63 & 1,63 & 1,09 \\
\hline 40 & 0 & 90 & ACT & 40,07 & 0,07 & 0,05 \\
\hline 40 & 50 & 90 & ACT & 40,07 & 0,07 & 0,05 \\
\hline 40 & 100 & 90 & ACT & 40,07 & 0,07 & 0,05 \\
\hline 55 & 0 & 90 & ACT & 53,51 & 1,49 & 0,99 \\
\hline 55 & 50 & 90 & ACT & 53,51 & 1,49 & 0,99 \\
\hline 55 & 100 & 90 & ACT & 53,51 & 1,49 & 0,99 \\
\hline 70 & 0 & 90 & ACT & 69,64 & 0,36 & 0,24 \\
\hline 70 & 50 & 90 & ACT & 69,64 & 0,36 & 0,24 \\
\hline 70 & 100 & 90 & ACT & 69,64 & 0,36 & 0,24 \\
\hline 75 & 0 & 90 & ACT & 75 & 0 & 0,00 \\
\hline 75 & 50 & 90 & ACT & 75 & 0 & 0,00 \\
\hline 75 & 100 & 90 & ACT & 75 & 0 & 0,00 \\
\hline 80 & 0 & 90 & ACT & 80,36 & 0,36 & 0,24 \\
\hline 80 & 50 & 90 & ACT & 80,36 & 0,36 & 0,24 \\
\hline 80 & 100 & 90 & ACT & 80,36 & 0,36 & 0,24 \\
\hline 95 & 0 & 90 & ACT & 96,49 & 1,49 & 0,99 \\
\hline 95 & 50 & 90 & ACT & 96,49 & 1,49 & 0,99 \\
\hline 95 & 100 & 90 & ACT & 96,49 & 1,49 & 0,99 \\
\hline 110 & 0 & 90 & ACT & 111,28 & 1,28 & 0,85 \\
\hline 110 & 50 & 90 & ACT & 111,28 & 1,28 & 0,85 \\
\hline 110 & 100 & 90 & $\mathrm{ACT}$ & 111,28 & 1,28 & 0,85 \\
\hline 125 & 0 & 90 & ACT & 123,37 & 1,63 & 1,09 \\
\hline 125 & 50 & 90 & ACT & 123,37 & 1,63 & 1,09 \\
\hline 125 & 100 & 90 & ACT & 123,37 & 1,63 & 1,09 \\
\hline 140 & 0 & 90 & ACT & 139,5 & 0,5 & 0,33 \\
\hline 140 & 50 & 90 & ACT & 139,5 & 0,5 & 0,33 \\
\hline 140 & 100 & 90 & ACT & 139,5 & 0,5 & 0,33 \\
\hline \multicolumn{6}{|c|}{ Erro médio (\%) } & 0,56 \\
\hline
\end{tabular}


TABELA 52 - Resultados para faltas fase-terra(AT) com ângulo de incidência de $45^{\circ}$ e resistência de falta de 100, 200 e $400 \mathrm{ohms}$

\begin{tabular}{|c|c|c|c|c|c|c|}
\hline $\begin{array}{c}\text { Distância } \\
\text { Real } \\
(\mathbf{k m})\end{array}$ & $\begin{array}{l}\text { Resist. } \\
\text { falta } \\
\text { (ohms) }\end{array}$ & $\begin{array}{c}\text { Ângulo de } \\
\text { Incidência } \\
\text { (graus) }\end{array}$ & $\begin{array}{c}\text { Tipo de } \\
\text { Falta }\end{array}$ & $\begin{array}{c}\text { Distância } \\
\text { Estimada } \\
(\mathbf{k m})\end{array}$ & $\begin{array}{l}\text { Erro } \\
\text { Abs. } \\
\text { (km) }\end{array}$ & Erro \\
\hline 10 & 100 & 45 & AT & 7,82 & 2,18 & 1,45 \\
\hline 10 & 200 & 45 & $\mathrm{AT}$ & 10,5 & 0,5 & 0,33 \\
\hline 10 & 400 & 45 & AT & 10,5 & 0,5 & 0,33 \\
\hline 25 & 100 & 45 & AT & 22,6 & 2,4 & 1,60 \\
\hline 25 & 200 & 45 & AT & 22,6 & 2,4 & 1,60 \\
\hline 25 & 400 & 45 & AT & 22,6 & 2,4 & 1,60 \\
\hline 40 & 100 & 45 & AT & 40,07 & 0,07 & 0,05 \\
\hline 40 & 200 & 45 & AT & 40,07 & 0,07 & 0,05 \\
\hline 40 & 400 & 45 & AT & 40,07 & 0,07 & 0,05 \\
\hline 55 & 100 & 45 & AT & 56,19 & 1,19 & 0,79 \\
\hline 55 & 200 & 45 & AT & 56,19 & 1,19 & 0,79 \\
\hline 55 & 400 & 45 & AT & 56,19 & 1,19 & 0,79 \\
\hline 70 & 100 & 45 & AT & 72,31 & 2,31 & 1,54 \\
\hline 70 & 200 & 45 & AT & 69,64 & 0,36 & 0,24 \\
\hline 70 & 400 & 45 & AT & 69,64 & 0,36 & 0,24 \\
\hline 75 & 100 & 45 & AT & 75 & 0 & 0,00 \\
\hline 75 & 200 & 45 & AT & 75 & 0 & 0,00 \\
\hline 75 & 400 & 45 & $\mathrm{AT}$ & 75 & 0 & 0,00 \\
\hline 80 & 100 & 45 & AT & 77,68 & 2,32 & 1,55 \\
\hline 80 & 200 & 45 & AT & 80,36 & 0,36 & 0,24 \\
\hline 80 & 400 & 45 & $\mathrm{AT}$ & 80,36 & 0,36 & 0,24 \\
\hline 95 & 100 & 45 & AT & 93,8 & 1,2 & 0,80 \\
\hline 95 & 200 & 45 & AT & 93,8 & 1,2 & 0,80 \\
\hline 95 & 400 & 45 & AT & 93,8 & 1,2 & 0,80 \\
\hline 110 & 100 & 45 & $\mathrm{AT}$ & 109,93 & 0,07 & 0,05 \\
\hline 110 & 200 & 45 & AT & 109,93 & 0,07 & 0,05 \\
\hline 110 & 400 & 45 & AT & 109,93 & 0,07 & 0,05 \\
\hline 125 & 100 & 45 & AT & 127,4 & 2,4 & 1,60 \\
\hline 125 & 200 & 45 & AT & 127,4 & 2,4 & 1,60 \\
\hline 125 & 400 & 45 & AT & 127,4 & 2,4 & 1,60 \\
\hline 140 & 100 & 45 & AT & 142,17 & 2,17 & 1,45 \\
\hline 140 & 200 & 45 & AT & 139,5 & 0,5 & 0,33 \\
\hline 140 & 400 & 45 & AT & 139,5 & 0,5 & 0,33 \\
\hline \multicolumn{6}{|c|}{ Erro médio (\%) } & 0,70 \\
\hline
\end{tabular}


TABELA 53 - Resultados para faltas fase-terra(AT) com ângulo de incidência de $70^{\circ}$ e resistência de falta de 100, 200 e 400 ohms

\begin{tabular}{|c|c|c|c|c|c|c|}
\hline $\begin{array}{c}\text { Distância } \\
\text { Real } \\
\text { (km) }\end{array}$ & $\begin{array}{c}\text { Resist. } \\
\text { falta } \\
\text { (ohms) }\end{array}$ & $\begin{array}{c}\text { Ângulo de } \\
\text { Incidência } \\
\text { (graus) }\end{array}$ & $\begin{array}{c}\text { Tipo de } \\
\text { Falta }\end{array}$ & $\begin{array}{c}\text { Distância } \\
\text { Estimada } \\
\text { (km) }\end{array}$ & $\begin{array}{l}\text { Erro } \\
\text { Abs. } \\
(\mathbf{k m})\end{array}$ & $\begin{array}{l}\text { Erro } \\
(\%)\end{array}$ \\
\hline 10 & 100 & 70 & AT & 7,82 & 2,18 & 1,45 \\
\hline 10 & 200 & 70 & AT & 7,82 & 2,18 & 1,45 \\
\hline 10 & 400 & 70 & AT & 10,5 & 0,5 & 0,33 \\
\hline 25 & 100 & 70 & AT & 22,6 & 2,4 & 1,60 \\
\hline 25 & 200 & 70 & AT & 22,6 & 2,4 & 1,60 \\
\hline 25 & 400 & 70 & AT & 22,6 & 2,4 & 1,60 \\
\hline 40 & 100 & 70 & AT & 40,07 & 0,07 & 0,05 \\
\hline 40 & 200 & 70 & AT & 40,07 & 0,07 & 0,05 \\
\hline 40 & 400 & 70 & AT & 40,07 & 0,07 & 0,05 \\
\hline 55 & 100 & 70 & AT & 56,19 & 1,19 & 0,79 \\
\hline 55 & 200 & 70 & AT & 56,19 & 1,19 & 0,79 \\
\hline 55 & 400 & 70 & AT & 56,19 & 1,19 & 0,79 \\
\hline 70 & 100 & 70 & AT & 72,31 & 2,31 & 1,54 \\
\hline 70 & 200 & 70 & AT & 72,31 & 2,31 & 1,54 \\
\hline 70 & 400 & 70 & AT & 69,64 & 0,36 & 0,24 \\
\hline 75 & 100 & 70 & AT & 72,31 & 2,69 & 1,79 \\
\hline 75 & 200 & 70 & AT & 75 & 0 & 0,00 \\
\hline 75 & 400 & 70 & AT & 75 & 0 & 0,00 \\
\hline 80 & 100 & 70 & AT & 77,68 & 2,32 & 1,55 \\
\hline 80 & 200 & 70 & AT & 77,68 & 2,32 & 1,55 \\
\hline 80 & 400 & 70 & AT & 80,36 & 0,36 & 0,24 \\
\hline 95 & 100 & 70 & AT & 93,8 & 1,2 & 0,80 \\
\hline 95 & 200 & 70 & AT & 93,8 & 1,2 & 0,80 \\
\hline 95 & 400 & 70 & AT & 93,8 & 1,2 & 0,80 \\
\hline 110 & 100 & 70 & AT & 109,93 & 0,07 & 0,05 \\
\hline 110 & 200 & 70 & AT & 109,93 & 0,07 & 0,05 \\
\hline 110 & 400 & 70 & AT & 109,93 & 0,07 & 0,05 \\
\hline 125 & 100 & 70 & AT & 127,4 & 2,4 & 1,60 \\
\hline 125 & 200 & 70 & AT & 127,4 & 2,4 & 1,60 \\
\hline 125 & 400 & 70 & AT & 127,4 & 2,4 & 1,60 \\
\hline 140 & 100 & 70 & AT & 142,17 & 2,17 & 1,45 \\
\hline 140 & 200 & 70 & AT & 142,17 & 2,17 & 1,45 \\
\hline 140 & 400 & 70 & AT & 139,5 & 0,5 & 0,33 \\
\hline \multicolumn{6}{|c|}{ Erro médio (\%) } & 0,90 \\
\hline
\end{tabular}


TABELA 54 - Resultados para faltas fase-terra(AT) com ângulo de incidência de $0^{\circ}$ e resistência de falta de 200 e 400 ohms

\begin{tabular}{ccccccc}
\hline $\begin{array}{c}\text { Distância } \\
\text { Real } \\
(\mathbf{k m})\end{array}$ & $\begin{array}{c}\text { Resist. } \\
\text { falta } \\
(\mathbf{o h m s})\end{array}$ & $\begin{array}{c}\text { Ângulo de } \\
\text { Incidência } \\
\text { (graus) }\end{array}$ & $\begin{array}{c}\text { Tipo de } \\
\text { Falta }\end{array}$ & $\begin{array}{c}\text { Distância } \\
\text { Estimada } \\
\mathbf{( k m )}\end{array}$ & $\begin{array}{c}\text { Erro } \\
\text { Abs. } \\
\mathbf{( k m )}\end{array}$ & $\begin{array}{c}\text { Erro } \\
\mathbf{( \% )}\end{array}$ \\
\hline 10 & 200 & 0 & AT & 13,18 & 3,18 & 2,12 \\
\hline 10 & 400 & 0 & AT & 160,98 & 150,98 & 100,65 \\
\hline 25 & 200 & 0 & AT & 26,62 & 1,62 & 1,08 \\
\hline 25 & 400 & 0 & AT & 26,62 & 1,62 & 1,08 \\
\hline 40 & 200 & 0 & AT & 40,07 & 0,07 & 0,05 \\
\hline 40 & 400 & 0 & AT & 40,07 & 0,07 & 0,05 \\
\hline 55 & 200 & 0 & AT & 53,5 & 1,5 & 1,00 \\
\hline 55 & 400 & 0 & AT & 53,5 & 1,5 & 1,00 \\
\hline 70 & 200 & 0 & AT & 66,94 & 3,06 & 2,04 \\
\hline 70 & 400 & 0 & AT & 80,87 & 10,87 & 7,25 \\
\hline 75 & 200 & 0 & AT & 75 & 0 & 0,00 \\
\hline 75 & 400 & 0 & AT & 75 & 0 & 0,00 \\
\hline 80 & 200 & 0 & AT & 83,06 & 3,06 & 2,04 \\
\hline 80 & 400 & 0 & AT & 230,87 & 150,87 & 100,58 \\
\hline 95 & 200 & 0 & AT & 96,5 & 1,5 & 1,00 \\
\hline 95 & 400 & 0 & AT & 96,5 & 1,5 & 1,00 \\
\hline 110 & 200 & 0 & AT & 109,93 & 0,07 & 0,05 \\
\hline 110 & 400 & 0 & AT & 109,93 & 0,07 & 0,05 \\
\hline 125 & 200 & 0 & AT & 123,37 & 1,63 & 1,09 \\
\hline 125 & 400 & 0 & AT & 123,37 & 1,63 & 1,09 \\
\hline 140 & 200 & 0 & AT & 136,81 & 3,19 & 2,13 \\
\hline 140 & 400 & 0 & AT & 10,98 & 129,02 & 86,01 \\
\hline & & Erro médio (\%) & & & & $\mathbf{1 4 , 1 5}$ \\
\hline & & & & & & \\
\hline
\end{tabular}


TABELA 55 - Resultados para faltas fase-terra(AT) com ângulo de incidência de $90^{\circ}$ e resistência de falta de 200 e 400 ohms

\begin{tabular}{ccccccc}
\hline $\begin{array}{c}\text { Distância } \\
\text { Real } \\
(\mathbf{k m})\end{array}$ & $\begin{array}{c}\text { Resist. } \\
\text { falta } \\
(\mathbf{o h m s})\end{array}$ & $\begin{array}{c}\text { Angulo de } \\
\text { Incidência } \\
\text { (graus) }\end{array}$ & $\begin{array}{c}\text { Tipo de } \\
\text { Falta }\end{array}$ & $\begin{array}{c}\text { Distância } \\
\text { Estimada } \\
\mathbf{( k m )}\end{array}$ & $\begin{array}{c}\text { Erro } \\
\text { Abs. } \\
\mathbf{( k m )}\end{array}$ & $\begin{array}{c}\text { Erro) } \\
\mathbf{( \% )}\end{array}$ \\
\hline 10 & 200 & 90 & AT & 10,5 & 0,5 & 0,33 \\
\hline 10 & 400 & 90 & AT & 13,18 & 3,18 & 2,12 \\
\hline 25 & 200 & 90 & AT & 26,62 & 1,62 & 1,08 \\
\hline 25 & 400 & 90 & AT & 23,95 & 1,05 & 0,70 \\
\hline 40 & 200 & 90 & AT & 40,07 & 0,07 & 0,05 \\
\hline 40 & 400 & 90 & AT & 40,07 & 0,07 & 0,05 \\
\hline 55 & 200 & 90 & AT & 53,5 & 1,5 & 1,00 \\
\hline 55 & 400 & 90 & AT & 53,5 & 1,5 & 1,00 \\
\hline 70 & 200 & 90 & AT & 69,64 & 0,36 & 0,24 \\
\hline 70 & 400 & 90 & AT & 69,64 & 0,36 & 0,24 \\
\hline 75 & 200 & 90 & AT & 75 & 0 & 0,00 \\
\hline 75 & 400 & 90 & AT & 75 & 0 & 0,00 \\
\hline 80 & 200 & 90 & AT & 80,36 & 0,36 & 0,24 \\
\hline 80 & 400 & 90 & AT & 80,36 & 0,36 & 0,24 \\
\hline 95 & 200 & 90 & AT & 96,49 & 1,49 & 0,99 \\
\hline 95 & 400 & 90 & AT & 96,49 & 1,49 & 0,99 \\
\hline 110 & 200 & 90 & AT & 109,93 & 0,07 & 0,05 \\
\hline 110 & 400 & 90 & AT & 109,93 & 0,07 & 0,05 \\
\hline 125 & 200 & 90 & AT & 123,37 & 1,63 & 1,09 \\
\hline 125 & 400 & 90 & AT & 123,37 & 1,63 & 1,09 \\
\hline 140 & 200 & 90 & AT & 139,5 & 0,5 & 0,33 \\
\hline 140 & 400 & 90 & AT & 136,81 & 3,19 & 2,13 \\
\hline & & Erro médio (\%) & & & & $\mathbf{0 , 6 4}$ \\
\hline & & & & & &
\end{tabular}


TABELA 56 - Resultados para faltas fase-fase-terra(ACT) com ângulo de incidência de $0^{\circ}$ e resistência de falta de 200 e $400 \mathrm{ohms}$

\begin{tabular}{ccccccc}
\hline $\begin{array}{c}\text { Distância } \\
\text { Real } \\
(\mathbf{k m})\end{array}$ & $\begin{array}{c}\text { Resist. } \\
\text { falta } \\
(\mathbf{o h m s})\end{array}$ & $\begin{array}{c}\text { Angulo de } \\
\text { Incidência } \\
\text { (graus) }\end{array}$ & $\begin{array}{c}\text { Tipo de } \\
\text { Falta }\end{array}$ & $\begin{array}{c}\text { Distância } \\
\text { Estimada } \\
\mathbf{( k m )}\end{array}$ & $\begin{array}{c}\text { Erro } \\
\text { Abs. } \\
\mathbf{( k m )}\end{array}$ & $\begin{array}{c}\text { Erro } \\
\mathbf{( \% )}\end{array}$ \\
\hline 10 & 200 & 0 & ACT & 13,18 & 3,18 & 2,12 \\
\hline 10 & 400 & 0 & ACT & 13,18 & 3,18 & 2,12 \\
\hline 25 & 200 & 0 & ACT & 26,62 & 1,62 & 1,08 \\
\hline 25 & 400 & 0 & ACT & 26,62 & 1,62 & 1,08 \\
\hline 40 & 200 & 0 & ACT & 40,07 & 0,07 & 0,05 \\
\hline 40 & 400 & 0 & ACT & 40,07 & 0,07 & 0,05 \\
\hline 55 & 200 & 0 & ACT & 53,5 & 1,5 & 1,00 \\
\hline 55 & 400 & 0 & ACT & 53,5 & 1,5 & 1,00 \\
\hline 70 & 200 & 0 & ACT & 66,94 & 3,06 & 2,04 \\
\hline 70 & 400 & 0 & ACT & 66,94 & 3,06 & 2,04 \\
\hline 75 & 200 & 0 & ACT & 75 & 0 & 0,00 \\
\hline 75 & 400 & 0 & ACT & 75 & 0 & 0,00 \\
\hline 80 & 200 & 0 & ACT & 83,06 & 3,06 & 2,04 \\
\hline 80 & 400 & 0 & ACT & 83,06 & 3,06 & 2,04 \\
\hline 95 & 200 & 0 & ACT & 96,5 & 1,5 & 1,00 \\
\hline 95 & 400 & 0 & ACT & 96,5 & 1,5 & 1,00 \\
\hline 110 & 200 & 0 & ACT & 109,93 & 0,07 & 0,05 \\
\hline 110 & 400 & 0 & ACT & 109,93 & 0,07 & 0,05 \\
\hline 125 & 200 & 0 & ACT & 123,37 & 1,63 & 1,09 \\
\hline 125 & 400 & 0 & ACT & 123,37 & 1,63 & 1,09 \\
\hline 140 & 200 & 0 & ACT & 136,81 & 3,19 & 2,13 \\
\hline 140 & 400 & 0 & ACT & 136,81 & 3,19 & 2,13 \\
\hline & & Erro médio (\%) & & & $\mathbf{1 , 1 4}$ \\
\hline & & & & & & \\
\hline
\end{tabular}


TABELA 57 - Resultados para faltas fase-fase-terra(ACT) com ângulo de incidência de $90^{\circ}$ e resistência de falta de 200 e $400 \mathrm{ohms}$

\begin{tabular}{ccccccc}
\hline $\begin{array}{c}\text { Distância } \\
\text { Real } \\
(\mathbf{k m})\end{array}$ & $\begin{array}{c}\text { Resist. } \\
\text { falta } \\
(\mathbf{o h m s})\end{array}$ & $\begin{array}{c}\text { Angulo de } \\
\text { Incidência } \\
\text { (graus) }\end{array}$ & $\begin{array}{c}\text { Tipo de } \\
\text { Falta }\end{array}$ & $\begin{array}{c}\text { Distância } \\
\text { Estimada } \\
\mathbf{( k m )}\end{array}$ & $\begin{array}{c}\text { Erro } \\
\text { Abs. } \\
(\mathbf{k m})\end{array}$ & $\begin{array}{c}\text { Erro } \\
(\mathbf{\%})\end{array}$ \\
\hline 10 & 200 & 90 & ACT & 10,5 & 0,5 & 0,33 \\
\hline 10 & 400 & 90 & ACT & 10,5 & 0,5 & 0,33 \\
\hline 25 & 200 & 90 & ACT & 26,62 & 1,62 & 1,08 \\
\hline 25 & 400 & 90 & ACT & 26,62 & 1,62 & 1,08 \\
\hline 40 & 200 & 90 & ACT & 40,05 & 0,05 & 0,03 \\
\hline 40 & 400 & 90 & ACT & 40,05 & 0,05 & 0,03 \\
\hline 55 & 200 & 90 & ACT & 53,51 & 1,49 & 0,99 \\
\hline 55 & 400 & 90 & ACT & 53,51 & 1,49 & 0,99 \\
\hline 70 & 200 & 90 & ACT & 69,64 & 0,36 & 0,24 \\
\hline 70 & 400 & 90 & ACT & 69,64 & 0,36 & 0,24 \\
\hline 75 & 200 & 90 & ACT & 75 & 0 & 0,00 \\
\hline 75 & 400 & 90 & ACT & 75 & 0 & 0,00 \\
\hline 80 & 200 & 90 & ACT & 80,36 & 0,36 & 0,24 \\
\hline 80 & 400 & 90 & ACT & 80,36 & 0,36 & 0,24 \\
\hline 95 & 200 & 90 & ACT & 96,49 & 1,49 & 0,99 \\
\hline 95 & 400 & 90 & ACT & 96,49 & 1,49 & 0,99 \\
\hline 110 & 200 & 90 & ACT & 111,28 & 1,28 & 0,85 \\
\hline 110 & 400 & 90 & ACT & 111,28 & 1,28 & 0,85 \\
\hline 125 & 200 & 90 & ACT & 123,37 & 1,63 & 1,09 \\
\hline 125 & 400 & 90 & ACT & 123,37 & 1,63 & 1,09 \\
\hline 140 & 200 & 90 & ACT & 139,5 & 0,5 & 0,33 \\
\hline 140 & 400 & 90 & ACT & 139,5 & 0,5 & 0,33 \\
\hline & & Erro médio (\%) & & & $\mathbf{0 , 5 6}$ \\
\hline & & & & & &
\end{tabular}


TABELA 58 - Resultados da perda de sincronismo (1 $\mu$ s) para faltas AT com ângulo de incidência de $0^{o}$.

\begin{tabular}{|c|c|c|c|c|c|c|c|c|}
\hline $\begin{array}{c}\text { Distância } \\
\text { Real } \\
(\mathbf{k m})\end{array}$ & $\begin{array}{c}\text { Resist. } \\
\text { falta } \\
(\text { ohms })\end{array}$ & $\begin{array}{l}\text { Ângulo de } \\
\text { Incidência } \\
\text { (graus) }\end{array}$ & $\begin{array}{c}\text { Tipo de } \\
\text { Falta }\end{array}$ & $\begin{array}{c}\text { Dist. } \\
\text { sincron. } \\
(\mathrm{km})\end{array}$ & $\begin{array}{c}\text { Dist. } \\
\text { ñ sincron. } \\
(\mathbf{k m})\end{array}$ & $\begin{array}{c}\text { Erro } \\
\text { sincr }-\tilde{\mathbf{n}} \text { sincr } \\
(+/-\mathbf{k m})\end{array}$ & $\begin{array}{c}\text { Erro } \\
\text { sincron } \\
(\%)\end{array}$ & $\begin{array}{c}\text { Erro } \\
\text { ñ. sincron } \\
(\%)\end{array}$ \\
\hline 10 & 0 & 0 & AT & 7,85 & 7,7 & 0,15 & 1,53 & 1,53 \\
\hline 10 & 50 & 0 & AT & 7,85 & 7,7 & 0,15 & 1,43 & 1,53 \\
\hline 10 & 100 & 0 & AT & 7,85 & 7,7 & 0,15 & 1,43 & 1,53 \\
\hline 25 & 0 & 0 & AT & 26,64 & 26,5 & 0,14 & 1,09 & 1,00 \\
\hline 25 & 50 & 0 & AT & 26,64 & 26,5 & 0,14 & 1,09 & 1,00 \\
\hline 25 & 100 & 0 & AT & 26,64 & 26,5 & 0,14 & 1,09 & 1,00 \\
\hline 40 & 0 & 0 & AT & 40,08 & 39,94 & 0,14 & 0,05 & 0,04 \\
\hline 40 & 50 & 0 & AT & 40,08 & 39,94 & 0,14 & 0,05 & 0,04 \\
\hline 40 & 100 & 0 & AT & 40,08 & 39,94 & 0,14 & 0,05 & 0,04 \\
\hline 55 & 0 & 0 & AT & 53,51 & 53,36 & 0,15 & 0,99 & 1,09 \\
\hline 55 & 50 & 0 & AT & 53,51 & 53,36 & 0,15 & 0,99 & 1,09 \\
\hline 55 & 100 & 0 & $\mathrm{AT}$ & 53,51 & 53,36 & 0,15 & 0,99 & 1,09 \\
\hline 70 & 0 & 0 & AT & 70,97 & 70,82 & 0,15 & 0,65 & 0,55 \\
\hline 70 & 50 & 0 & AT & 70,97 & 70,82 & 0,15 & 0,65 & 0,55 \\
\hline 70 & 100 & 0 & AT & 70,97 & 70,82 & 0,15 & 0,65 & 0,55 \\
\hline 75 & 0 & 0 & AT & 75 & 74,85 & 0,15 & 0,00 & 0,10 \\
\hline 75 & 50 & 0 & AT & 75 & 74,85 & 0,15 & 0,00 & 0,10 \\
\hline 75 & 100 & 0 & $\mathrm{AT}$ & 75 & 74,85 & 0,15 & 0,00 & 0,10 \\
\hline 80 & 0 & 0 & AT & 79,03 & 78,88 & 0,15 & 0,65 & 0,75 \\
\hline 80 & 50 & 0 & $\mathrm{AT}$ & 77,68 & 77,54 & 0,14 & 1,55 & 1,64 \\
\hline 80 & 100 & 0 & AT & 80,38 & 80,23 & 0,15 & 0,25 & 0,15 \\
\hline 95 & 0 & 0 & AT & 96,49 & 96,34 & 0,15 & 0,99 & 0,89 \\
\hline 95 & 50 & 0 & AT & 96,49 & 96,34 & 0,15 & 0,99 & 0,89 \\
\hline 95 & 100 & 0 & AT & 96,49 & 96,34 & 0,15 & 0,99 & 0,89 \\
\hline 110 & 0 & 0 & AT & 109,92 & 109,77 & 0,15 & 0,05 & 0,15 \\
\hline 110 & 50 & 0 & AT & 109,92 & 109,77 & 0,15 & 0,05 & 0,15 \\
\hline 110 & 100 & 0 & $\mathrm{AT}$ & 109,92 & 109,77 & 0,15 & 0,05 & 0,15 \\
\hline 125 & 0 & 0 & $\mathrm{AT}$ & 123,36 & 123,21 & 0,15 & 1,09 & 1,19 \\
\hline 125 & 50 & 0 & AT & 123,36 & 123,21 & 0,15 & 1,09 & 1,19 \\
\hline 125 & 100 & 0 & AT & 123,36 & 123,21 & 0,15 & 1,09 & 1,19 \\
\hline 140 & 0 & 0 & AT & 142,15 & 142 & 0,15 & 1,43 & 1,33 \\
\hline 140 & 50 & 0 & AT & 142,15 & 142 & 0,15 & 1,43 & 1,33 \\
\hline 140 & 100 & 0 & AT & 142,15 & 142 & 0,15 & 1,43 & 1,33 \\
\hline \multicolumn{7}{|c|}{ Erro médio (\%) } & $\mathbf{0 , 7 9}$ & $\mathbf{0 , 7 9}$ \\
\hline
\end{tabular}


TABELA 59 - Resultados da perda de sincronismo (1 $\mu$ s) para faltas AT com ângulo de incidência de $90^{\circ}$.

\begin{tabular}{|c|c|c|c|c|c|c|c|c|}
\hline $\begin{array}{c}\text { Distância } \\
\text { Real } \\
\text { (km) }\end{array}$ & $\begin{array}{c}\text { Resist. } \\
\text { falta } \\
\text { (ohms) }\end{array}$ & $\begin{array}{c}\text { Ângulo de } \\
\text { Incidência } \\
\text { (graus) }\end{array}$ & $\begin{array}{c}\text { Tipo de } \\
\text { Falta }\end{array}$ & $\begin{array}{c}\text { Dist. } \\
\text { sincron. } \\
\text { (km) }\end{array}$ & $\begin{array}{c}\text { Dist. } \\
\text { ñ sincron. } \\
(\mathbf{k m})\end{array}$ & $\begin{array}{c}\text { Erro } \\
\text { sincr }-\tilde{\mathbf{n}} \text { sincr } \\
(+/-\mathbf{k m})\end{array}$ & $\begin{array}{c}\text { Erro } \\
\text { sincron } \\
(\%)\end{array}$ & $\begin{array}{c}\text { Erro } \\
\text { ñ. sincron } \\
(\%)\end{array}$ \\
\hline 10 & 0 & 90 & AT & 10,53 & 10,39 & 0,14 & 0,26 & 0,26 \\
\hline 10 & 50 & 90 & AT & 10,53 & 10,39 & 0,14 & 0,35 & 0,26 \\
\hline 10 & 100 & 90 & $\mathrm{AT}$ & 10,53 & 10,39 & 0,14 & 0,35 & 0,26 \\
\hline 25 & 0 & 90 & $\mathrm{AT}$ & 23,96 & 23,81 & 0,15 & 0,69 & 0,79 \\
\hline 25 & 50 & 90 & AT & 23,96 & 23,81 & 0,15 & 0,69 & 0,79 \\
\hline 25 & 100 & 90 & $\mathrm{AT}$ & 23,96 & 23,81 & 0,15 & 0,69 & 0,79 \\
\hline 40 & 0 & 90 & $\mathrm{AT}$ & 38,74 & 38,59 & 0,15 & 0,84 & 0,94 \\
\hline 40 & 50 & 90 & $\mathrm{AT}$ & 38,74 & 38,59 & 0,15 & 0,84 & 0,94 \\
\hline 40 & 100 & 90 & AT & 38,74 & 38,59 & 0,15 & 0,84 & 0,94 \\
\hline 55 & 0 & 90 & $\mathrm{AT}$ & 56,19 & 56,04 & 0,15 & 0,79 & 0,69 \\
\hline 55 & 50 & 90 & $\mathrm{AT}$ & 56,19 & 56,04 & 0,15 & 0,79 & 0,69 \\
\hline 55 & 100 & 90 & $\mathrm{AT}$ & 56,19 & 56,04 & 0,15 & 0,79 & 0,69 \\
\hline 70 & 0 & 90 & $\mathrm{AT}$ & 69,62 & 69,47 & 0,15 & 0,25 & 0,35 \\
\hline 70 & 50 & 90 & $\mathrm{AT}$ & 69,62 & 69,47 & 0,15 & 0,25 & 0,35 \\
\hline 70 & 100 & 90 & $\mathrm{AT}$ & 69,62 & 69,47 & 0,15 & 0,25 & 0,35 \\
\hline 75 & 0 & 90 & $\mathrm{AT}$ & 75 & 74,85 & 0,15 & 0,00 & 0,10 \\
\hline 75 & 50 & 90 & $\mathrm{AT}$ & 75 & 74,85 & 0,15 & 0,00 & 0,10 \\
\hline 75 & 100 & 90 & $\mathrm{AT}$ & 75 & 74,85 & 0,15 & 0,00 & 0,10 \\
\hline 80 & 0 & 90 & $\mathrm{AT}$ & 80,38 & 80,23 & 0,15 & 0,25 & 0,15 \\
\hline 80 & 50 & 90 & $\mathrm{AT}$ & 80,38 & 80,23 & 0,15 & 0,25 & 0,15 \\
\hline 80 & 100 & 90 & $\mathrm{AT}$ & 80,38 & 80,23 & 0,15 & 0,25 & 0,15 \\
\hline 95 & 0 & 90 & $\mathrm{AT}$ & 93,81 & 93,66 & 0,15 & 0,79 & 0,89 \\
\hline 95 & 50 & 90 & $\mathrm{AT}$ & 93,81 & 93,66 & 0,15 & 0,79 & 0,89 \\
\hline 95 & 100 & 90 & $\mathrm{AT}$ & 93,81 & 93,66 & 0,15 & 0,79 & 0,89 \\
\hline 110 & 0 & 90 & $\mathrm{AT}$ & 111,26 & 111,12 & 0,14 & 0,84 & 0,75 \\
\hline 110 & 50 & 90 & $\mathrm{AT}$ & 111,26 & 111,12 & 0,14 & 0,84 & 0,75 \\
\hline 110 & 100 & 90 & $\mathrm{AT}$ & 111,26 & 111,12 & 0,14 & 0,84 & 0,75 \\
\hline 125 & 0 & 90 & $\mathrm{AT}$ & 126,04 & 125,89 & 0,15 & 0,69 & 0,59 \\
\hline 125 & 50 & 90 & $\mathrm{AT}$ & 126,04 & 125,89 & 0,15 & 0,69 & 0,59 \\
\hline 125 & 100 & 90 & $\mathrm{AT}$ & 126,04 & 125,89 & 0,15 & 0,69 & 0,59 \\
\hline 140 & 0 & 90 & $\mathrm{AT}$ & 139,47 & 139,32 & 0,15 & 0,35 & 0,45 \\
\hline 140 & 50 & 90 & $\mathrm{AT}$ & 139,47 & 139,32 & 0,15 & 0,35 & 0,45 \\
\hline 140 & 100 & 90 & $\mathrm{AT}$ & 139,47 & 139,32 & 0,15 & 0,35 & 0,45 \\
\hline \multicolumn{7}{|c|}{ Erro médio (\%) } & $\mathbf{0 , 5 3}$ & $\mathbf{0 , 5 4}$ \\
\hline
\end{tabular}


TABELA 60 - Resultados da perda de sincronismo (1 amostra) para faltas AT com ângulo de incidência de $0^{\circ}$.

\begin{tabular}{|c|c|c|c|c|c|c|c|c|}
\hline $\begin{array}{c}\text { Distância } \\
\text { Real } \\
(\mathbf{k m})\end{array}$ & $\begin{array}{c}\text { Resist. } \\
\text { falta } \\
(\text { ohms })\end{array}$ & $\begin{array}{c}\text { Ângulo de } \\
\text { Incidência } \\
\text { (graus) }\end{array}$ & $\begin{array}{c}\text { Tipo de } \\
\text { Falta }\end{array}$ & $\begin{array}{c}\text { Dist. } \\
\text { sincron. } \\
\text { (km) }\end{array}$ & $\begin{array}{c}\text { Dist. } \\
\text { ñ sincron. } \\
(\mathbf{k m})\end{array}$ & $\begin{array}{c}\text { Erro } \\
\text { sincr }-\tilde{\mathbf{n}} \text { sincr } \\
(+/-\mathbf{k m})\end{array}$ & $\begin{array}{c}\text { Erro } \\
\text { sincron } \\
(\%)\end{array}$ & $\begin{array}{c}\text { Erro } \\
\text { ñ. sincron } \\
(\%)\end{array}$ \\
\hline 10 & 0 & 0 & AT & 7,85 & 6,51 & 1,34 & 2,33 & 2,33 \\
\hline 10 & 50 & 0 & AT & 7,85 & 6,51 & 1,34 & 1,43 & 2,33 \\
\hline 10 & 100 & 0 & AT & 7,85 & 6,51 & 1,34 & 1,43 & 2,33 \\
\hline 25 & 0 & 0 & AT & 26,64 & 25,3 & 1,34 & 1,09 & 0,20 \\
\hline 25 & 50 & 0 & $\mathrm{AT}$ & 26,64 & 25,3 & 1,34 & 1,09 & 0,20 \\
\hline 25 & 100 & 0 & AT & 26,64 & 25,3 & 1,34 & 1,09 & 0,20 \\
\hline 40 & 0 & 0 & AT & 40,08 & 38,74 & 1,34 & 0,05 & 0,84 \\
\hline 40 & 50 & 0 & AT & 40,08 & 38,74 & 1,34 & 0,05 & 0,84 \\
\hline 40 & 100 & 0 & AT & 40,08 & 38,74 & 1,34 & 0,05 & 0,84 \\
\hline 55 & 0 & 0 & AT & 53,51 & 52,17 & 1,34 & 0,99 & 1,89 \\
\hline 55 & 50 & 0 & AT & 53,51 & 52,17 & 1,34 & 0,99 & 1,89 \\
\hline 55 & 100 & 0 & $\mathrm{AT}$ & 53,51 & 52,17 & 1,34 & 0,99 & 1,89 \\
\hline 70 & 0 & 0 & $\mathrm{AT}$ & 70,97 & 69,63 & 1,34 & 0,65 & 0,25 \\
\hline 70 & 50 & 0 & AT & 70,97 & 69,63 & 1,34 & 0,65 & 0,25 \\
\hline 70 & 100 & 0 & AT & 70,97 & 69,63 & 1,34 & 0,65 & 0,25 \\
\hline 75 & 0 & 0 & $\mathrm{AT}$ & 75 & 73,66 & 1,34 & 0,00 & 0,89 \\
\hline 75 & 50 & 0 & AT & 75 & 73,66 & 1,34 & 0,00 & 0,89 \\
\hline 75 & 100 & 0 & AT & 75 & 73,66 & 1,34 & 0,00 & 0,89 \\
\hline 80 & 0 & 0 & $\mathrm{AT}$ & 79,03 & 77,69 & 1,34 & 0,65 & 1,54 \\
\hline 80 & 50 & 0 & $\mathrm{AT}$ & 77,68 & 76,34 & 1,34 & 1,55 & 2,44 \\
\hline 80 & 100 & 0 & AT & 80,38 & 79,04 & 1,34 & 0,25 & 0,64 \\
\hline 95 & 0 & 0 & AT & 96,49 & 95,15 & 1,34 & 0,99 & 0,10 \\
\hline 95 & 50 & 0 & AT & 96,49 & 95,15 & 1,34 & 0,99 & 0,10 \\
\hline 95 & 100 & 0 & AT & 96,49 & 95,15 & 1,34 & 0,99 & 0,10 \\
\hline 110 & 0 & 0 & $\mathrm{AT}$ & 109,92 & 108,57 & 1,35 & 0,05 & 0,95 \\
\hline 110 & 50 & 0 & AT & 109,92 & 108,57 & 1,35 & 0,05 & 0,95 \\
\hline 110 & 100 & 0 & AT & 109,92 & 108,57 & 1,35 & 0,05 & 0,95 \\
\hline 125 & 0 & 0 & $\mathrm{AT}$ & 123,36 & 122,01 & 1,35 & 1,09 & 1,99 \\
\hline 125 & 50 & 0 & $\mathrm{AT}$ & 123,36 & 122,01 & 1,35 & 1,09 & 1,99 \\
\hline 125 & 100 & 0 & AT & 123,36 & 122,01 & 1,35 & 1,09 & 1,99 \\
\hline 140 & 0 & 0 & AT & 142,15 & 140,81 & 1,34 & 1,43 & 0,54 \\
\hline 140 & 50 & 0 & AT & 142,15 & 140,81 & 1,34 & 1,43 & 0,54 \\
\hline 140 & 100 & 0 & AT & 142,15 & 140,81 & 1,34 & 1,43 & 0,54 \\
\hline \multicolumn{7}{|c|}{ Erro médio (\%) } & $\mathbf{0 , 8 1}$ & 1,05 \\
\hline
\end{tabular}


TABELA 61 - Resultados da perda de sincronismo (1 amostra) para faltas AT com ângulo de incidência de $90^{\circ}$.

\begin{tabular}{|c|c|c|c|c|c|c|c|c|}
\hline $\begin{array}{c}\text { Distância } \\
\text { Real } \\
\text { (km) }\end{array}$ & $\begin{array}{l}\text { Resist. } \\
\text { falta } \\
(\text { ohms })\end{array}$ & $\begin{array}{c}\text { Ângulo de } \\
\text { Incidência } \\
\text { (graus) }\end{array}$ & $\begin{array}{c}\text { Tipo de } \\
\text { Falta }\end{array}$ & $\begin{array}{c}\text { Dist. } \\
\text { sincron. } \\
\text { (km) }\end{array}$ & $\begin{array}{c}\text { Dist. } \\
\text { ñ sincron. } \\
(\mathbf{k m})\end{array}$ & $\begin{array}{c}\text { Erro } \\
\text { sincr - ̃̃ sincr } \\
(+/-\mathbf{k m})\end{array}$ & $\begin{array}{c}\text { Erro } \\
\text { sincron } \\
(\%)\end{array}$ & $\begin{array}{c}\text { Erro } \\
\text { ñ. sincron } \\
(\%)\end{array}$ \\
\hline 10 & 0 & 90 & $\mathrm{AT}$ & 10,53 & 9,19 & 1,34 & 0,54 & 0,54 \\
\hline 10 & 50 & 90 & AT & 10,53 & 9,19 & 1,34 & 0,35 & 0,54 \\
\hline 10 & 100 & 90 & AT & 10,53 & 9,19 & 1,34 & 0,35 & 0,54 \\
\hline 25 & 0 & 90 & AT & 23,96 & 22,62 & 1,34 & 0,69 & 1,59 \\
\hline 25 & 50 & 90 & AT & 23,96 & 22,62 & 1,34 & 0,69 & 1,59 \\
\hline 25 & 100 & 90 & AT & 23,96 & 22,62 & 1,34 & 0,69 & 1,59 \\
\hline 40 & 0 & 90 & AT & 38,74 & 37,39 & 1,35 & 0,84 & 1,74 \\
\hline 40 & 50 & 90 & AT & 38,74 & 37,39 & 1,35 & 0,84 & 1,74 \\
\hline 40 & 100 & 90 & AT & 38,74 & 37,39 & 1,35 & 0,84 & 1,74 \\
\hline 55 & 0 & 90 & AT & 56,19 & 54,85 & 1,34 & 0,79 & 0,10 \\
\hline 55 & 50 & 90 & $\mathrm{AT}$ & 56,19 & 54,85 & 1,34 & 0,79 & 0,10 \\
\hline 55 & 100 & 90 & AT & 56,19 & 54,85 & 1,34 & 0,79 & 0,10 \\
\hline 70 & 0 & 90 & $\mathrm{AT}$ & 69,62 & 68,28 & 1,34 & 0,25 & 1,15 \\
\hline 70 & 50 & 90 & $\mathrm{AT}$ & 69,62 & 68,28 & 1,34 & 0,25 & 1,15 \\
\hline 70 & 100 & 90 & $\mathrm{AT}$ & 69,62 & 68,28 & 1,34 & 0,25 & 1,15 \\
\hline 75 & 0 & 90 & $\mathrm{AT}$ & 75 & 73,66 & 1,34 & 0,00 & 0,89 \\
\hline 75 & 50 & 90 & $\mathrm{AT}$ & 75 & 73,66 & 1,34 & 0,00 & 0,89 \\
\hline 75 & 100 & 90 & AT & 75 & 73,66 & 1,34 & 0,00 & 0,89 \\
\hline 80 & 0 & 90 & $\mathrm{AT}$ & 80,38 & 79,04 & 1,34 & 0,25 & 0,64 \\
\hline 80 & 50 & 90 & $\mathrm{AT}$ & 80,38 & 79,04 & 1,34 & 0,25 & 0,64 \\
\hline 80 & 100 & 90 & $\mathrm{AT}$ & 80,38 & 79,04 & 1,34 & 0,25 & 0,64 \\
\hline 95 & 0 & 90 & $\mathrm{AT}$ & 93,81 & 92,46 & 1,35 & 0,79 & 1,69 \\
\hline 95 & 50 & 90 & $\mathrm{AT}$ & 93,81 & 92,46 & 1,35 & 0,79 & 1,69 \\
\hline 95 & 100 & 90 & AT & 93,81 & 92,46 & 1,35 & 0,79 & 1,69 \\
\hline 110 & 0 & 90 & $\mathrm{AT}$ & 111,26 & 109,92 & 1,34 & 0,84 & 0,05 \\
\hline 110 & 50 & 90 & $\mathrm{AT}$ & 111,26 & 109,92 & 1,34 & 0,84 & 0,05 \\
\hline 110 & 100 & 90 & AT & 111,26 & 109,92 & 1,34 & 0,84 & 0,05 \\
\hline 125 & 0 & 90 & $\mathrm{AT}$ & 126,04 & 124,7 & 1,34 & 0,69 & 0,20 \\
\hline 125 & 50 & 90 & $\mathrm{AT}$ & 126,04 & 124,7 & 1,34 & 0,69 & 0,20 \\
\hline 125 & 100 & 90 & $\mathrm{AT}$ & 126,04 & 124,7 & 1,34 & 0,69 & 0,20 \\
\hline 140 & 0 & 90 & $\mathrm{AT}$ & 139,47 & 138,12 & 1,35 & 0,35 & 1,25 \\
\hline 140 & 50 & 90 & $\mathrm{AT}$ & 139,47 & 138,12 & 1,35 & 0,35 & 1,25 \\
\hline 140 & 100 & 90 & AT & 139,47 & 138,12 & 1,35 & 0,35 & 1,25 \\
\hline \multicolumn{7}{|c|}{ Erro médio (\%) } & 0,54 & 0,90 \\
\hline
\end{tabular}


TABELA 62 - Resultados da perda de sincronismo (1 $\mu$ s) para faltas AB com ângulo de incidência de $0^{\circ} e$ $90^{\circ}$.

\begin{tabular}{|c|c|c|c|c|c|c|c|}
\hline $\begin{array}{c}\text { Distância } \\
\text { Real } \\
\text { (km) }\end{array}$ & $\begin{array}{c}\text { Ângulo de } \\
\text { Incidência } \\
\text { (graus) }\end{array}$ & $\begin{array}{l}\text { Tipo de } \\
\text { Falta }\end{array}$ & $\begin{array}{c}\text { Dist. } \\
\text { sincron. } \\
\text { (km) }\end{array}$ & $\begin{array}{c}\text { Dist. } \\
\text { ñ sincron. } \\
(\mathbf{k m})\end{array}$ & $\begin{array}{c}\text { Erro } \\
\text { sincr }-\tilde{\mathbf{n}} \text { sincr } \\
(+/-\mathbf{k m})\end{array}$ & $\begin{array}{c}\text { Erro } \\
\text { sincron } \\
(\%)\end{array}$ & $\begin{array}{c}\text { Erro } \\
\text { ñ. sincron } \\
(\%)\end{array}$ \\
\hline 10 & 0 & $\mathrm{AB}$ & 7,85 & 7,7 & 0,15 & 1,43 & 1,53 \\
\hline 25 & 0 & $\mathrm{AB}$ & 23,96 & 23,81 & 0,15 & 0,69 & 0,79 \\
\hline 40 & 0 & $\mathrm{AB}$ & 40,08 & 39,94 & 0,14 & 0,05 & 0,04 \\
\hline 55 & 0 & $\mathrm{AB}$ & 56,19 & 56,05 & 0,14 & 0,79 & 0,70 \\
\hline 70 & 0 & $\mathrm{AB}$ & 70,97 & 70,82 & 0,15 & 0,65 & 0,55 \\
\hline 75 & 0 & $\mathrm{AB}$ & 75 & 74,85 & 0,15 & 0,00 & 0,10 \\
\hline 80 & 0 & $\mathrm{AB}$ & 79,03 & 78,88 & 0,15 & 0,65 & 0,75 \\
\hline 95 & 0 & $\mathrm{AB}$ & 93,81 & 93,66 & 0,15 & 0,79 & 0,89 \\
\hline 110 & 0 & $\mathrm{AB}$ & 109,92 & 109,77 & 0,15 & 0,05 & 0,15 \\
\hline 125 & 0 & $\mathrm{AB}$ & 126,04 & 125,89 & 0,15 & 0,69 & 0,59 \\
\hline 140 & 0 & $\mathrm{AB}$ & 142,15 & 142 & 0,15 & 1,43 & 1,33 \\
\hline \multicolumn{6}{|c|}{ Erro médio (\%) } & 0,66 & $\mathbf{0 , 6 8}$ \\
\hline 10 & 90 & $\mathrm{AB}$ & 10,53 & 10,39 & 0,14 & 0,35 & 0,26 \\
\hline 25 & 90 & $\mathrm{AB}$ & 23,96 & 23,81 & 0,15 & 0,69 & 0,79 \\
\hline 40 & 90 & $\mathrm{AB}$ & 40,07 & 39,92 & 0,15 & 0,05 & 0,05 \\
\hline 55 & 90 & $\mathrm{AB}$ & 53,51 & 53,36 & 0,15 & 0,99 & 1,09 \\
\hline 70 & 90 & $\mathrm{AB}$ & 69,62 & 69,47 & 0,15 & 0,25 & 0,35 \\
\hline 75 & 90 & $\mathrm{AB}$ & 75 & 74,85 & 0,15 & 0,00 & 0,10 \\
\hline 80 & 90 & $\mathrm{AB}$ & 80,38 & 80,23 & 0,15 & 0,25 & 0,15 \\
\hline 95 & 90 & $\mathrm{AB}$ & 95,16 & 95 & 0,16 & 0,11 & 0,00 \\
\hline 110 & 90 & $\mathrm{AB}$ & 109,93 & 109,78 & 0,15 & 0,05 & 0,15 \\
\hline 125 & 90 & $\mathrm{AB}$ & 126,04 & 125,89 & 0,15 & 0,69 & 0,59 \\
\hline 140 & 90 & $\mathrm{AB}$ & 139,47 & 139,32 & 0,15 & 0,35 & 0,45 \\
\hline \multicolumn{6}{|c|}{ Erro médio (\%) } & $\mathbf{0 , 3 4}$ & $\mathbf{0 , 3 6}$ \\
\hline
\end{tabular}

TABELA 63 - Resultados da perda de sincronismo (1 amostra) para faltas AB com ângulo de incidência de $0^{\circ}$ e $90^{\circ}$.

\begin{tabular}{|c|c|c|c|c|c|c|c|}
\hline $\begin{array}{c}\text { Distância } \\
\text { Real } \\
(\mathbf{k m})\end{array}$ & $\begin{array}{c}\text { Ângulo de } \\
\text { Incidência } \\
\text { (graus) }\end{array}$ & $\begin{array}{c}\text { Tipo de } \\
\text { Falta }\end{array}$ & $\begin{array}{c}\text { Dist. } \\
\text { sincron. } \\
(\mathbf{k m})\end{array}$ & $\begin{array}{c}\text { Dist. } \\
\text { ñ sincron. } \\
(\mathbf{k m})\end{array}$ & $\begin{array}{c}\text { Erro } \\
\text { sincr }-\tilde{\mathbf{n}} \text { sincr } \\
(+/-\mathbf{k m})\end{array}$ & $\begin{array}{c}\text { Erro } \\
\text { sincron } \\
(\%)\end{array}$ & $\begin{array}{c}\text { Erro } \\
\text { ñ. sincron } \\
(\%)\end{array}$ \\
\hline 10 & 0 & $\mathrm{AB}$ & 7,85 & 6,51 & 1,34 & 1,43 & 2,33 \\
\hline 25 & 0 & $\mathrm{AB}$ & 23,96 & 22,62 & 1,34 & 0,69 & 1,59 \\
\hline 40 & 0 & $\mathrm{AB}$ & 40,08 & 38,74 & 1,34 & 0,05 & 0,84 \\
\hline 55 & 0 & $\mathrm{AB}$ & 56,19 & 54,85 & 1,34 & 0,79 & 0,10 \\
\hline 70 & 0 & $\mathrm{AB}$ & 70,97 & 69,63 & 1,34 & 0,65 & 0,25 \\
\hline 75 & 0 & $\mathrm{AB}$ & 75 & 73,66 & 1,34 & 0,00 & 0,89 \\
\hline 80 & 0 & $\mathrm{AB}$ & 79,03 & 77,69 & 1,34 & 0,65 & 1,54 \\
\hline 95 & 0 & $\mathrm{AB}$ & 93,81 & 92,46 & 1,35 & 0,79 & 1,69 \\
\hline 110 & 0 & $\mathrm{AB}$ & 109,92 & 108,57 & 1,35 & 0,05 & 0,95 \\
\hline 125 & 0 & AB & 126,04 & 124,7 & 1,34 & 0,69 & 0,20 \\
\hline 140 & 0 & $\mathrm{AB}$ & 142,15 & 140,81 & 1,34 & 1,43 & 0,54 \\
\hline \multicolumn{5}{|c|}{ Erro médio (\%) } & & 0,66 & 0,99 \\
\hline 10 & 90 & $\mathrm{AB}$ & 10,53 & 9,19 & 1,34 & 0,35 & 0,54 \\
\hline 25 & 90 & $\mathrm{AB}$ & 23,96 & 22,62 & 1,34 & 0,69 & 1,59 \\
\hline 40 & 90 & $\mathrm{AB}$ & 40,07 & 38,73 & 1,34 & 0,05 & 0,85 \\
\hline 55 & 90 & $\mathrm{AB}$ & 53,51 & 52,17 & 1,34 & 0,99 & 1,89 \\
\hline 70 & 90 & $\mathrm{AB}$ & 69,62 & 68,28 & 1,34 & 0,25 & 1,15 \\
\hline 75 & 90 & $\mathrm{AB}$ & 75 & 73,66 & 1,34 & 0,00 & 0,89 \\
\hline 80 & 90 & $\mathrm{AB}$ & 80,38 & 79,04 & 1,34 & 0,25 & 0,64 \\
\hline 95 & 90 & $\mathrm{AB}$ & 95,16 & 93,81 & 1,35 & 0,11 & 0,79 \\
\hline 110 & 90 & $\mathrm{AB}$ & 109,93 & 108,59 & 1,34 & 0,05 & 0,94 \\
\hline 125 & 90 & $\mathrm{AB}$ & 126,04 & 124,7 & 1,34 & 0,69 & 0,20 \\
\hline 140 & 90 & $\mathrm{AB}$ & 139,47 & 138,12 & 1,35 & 0,35 & 1,25 \\
\hline \multicolumn{6}{|c|}{ Erro médio (\%) } & 0,34 & $\mathbf{0 , 9 8}$ \\
\hline
\end{tabular}


TABELA 64 - Efeito da taxa de amostragem para faltas fase-terra (AT) com ângulo de incidência de $0^{\circ} e$ resistência de falta de 0, 50 e 100 ohms

\begin{tabular}{|c|c|c|c|c|c|c|c|c|c|c|c|}
\hline $\begin{array}{l}\text { Dist. } \\
\text { Real } \\
(\mathbf{k m})\end{array}$ & $\begin{array}{c}\text { Resist. } \\
\text { falta } \\
\text { (ohms) }\end{array}$ & $\begin{array}{l}\text { Âng. de } \\
\text { Incid. } \\
\text { (graus) }\end{array}$ & $\begin{array}{c}\text { Tipo de } \\
\text { Falta }\end{array}$ & $\begin{array}{l}\text { Dist. } \\
\text { Est. } \\
240 \text { kHz } \\
\text { (km) }\end{array}$ & Erro & $\begin{array}{l}\text { Dist. } \\
\text { Est. } \\
120 \mathrm{kHz} \\
(\mathbf{k m})\end{array}$ & Erro & $\begin{array}{l}\text { Dist. } \\
\text { Est. } \\
60 \mathrm{kHz} \\
(\mathbf{k m})\end{array}$ & $\begin{array}{l}\text { Erro } \\
(\%)\end{array}$ & $\begin{array}{c}\text { Dist. } \\
\text { Est. } \\
\text { 15,36 kHz } \\
\text { (km) }\end{array}$ & Erro \\
\hline 10 & 0 & 0 & AT & 10,27 & 0,18 & 7,85 & 1,43 & 11,47 & 0,98 & 17,16 & 4,77 \\
\hline 10 & 50 & 0 & AT & 7,82 & 1,45 & 7,85 & 1,43 & 11,47 & 0,98 & 17,16 & 4,77 \\
\hline 10 & 100 & 0 & AT & $*$ & & 7,85 & 1,43 & 11,47 & 0,98 & 17,16 & 4,77 \\
\hline 25 & 0 & 0 & AT & 26,13 & 0,75 & 26,64 & 1,09 & 31,03 & 4,02 & 17,16 & 5,23 \\
\hline 25 & 50 & 0 & AT & $*$ & & 26,64 & 1,09 & 31,03 & 4,02 & 17,16 & 5,23 \\
\hline 25 & 100 & 0 & AT & 26,15 & 0,77 & 26,64 & 1,09 & 31,03 & 4,02 & 17,16 & 5,23 \\
\hline 40 & 0 & 0 & AT & 42,02 & 1,35 & 40,08 & 0,05 & 40,8 & 0,53 & 36,83 & 2,11 \\
\hline 40 & 50 & 0 & AT & 40,79 & 0,53 & 40,08 & 0,05 & 40,8 & 0,53 & 36,83 & 2,11 \\
\hline 40 & 100 & 0 & AT & 42,02 & 1,35 & 40,08 & 0,05 & 40,8 & 0,53 & 36,83 & 2,11 \\
\hline 55 & 0 & 0 & AT & 55,45 & 0,30 & 53,51 & 0,99 & 60,34 & 3,56 & 55,91 & 0,61 \\
\hline 55 & 50 & 0 & AT & 55,45 & 0,30 & 53,51 & 0,99 & 60,34 & 3,56 & 55,91 & 0,61 \\
\hline 55 & 100 & 0 & AT & 56,68 & 1,12 & 53,51 & 0,99 & 60,34 & 3,56 & 55,91 & 0,61 \\
\hline 70 & 0 & 0 & AT & 71,34 & 0,89 & 70,97 & 0,65 & 70,12 & 0,08 & 75 & 3,33 \\
\hline 70 & 50 & 0 & AT & 70,1 & 0,07 & 70,97 & 0,65 & 70,12 & 0,08 & 75 & 3,33 \\
\hline 70 & 100 & 0 & AT & 70,1 & 0,07 & 70,97 & 0,65 & 70,12 & 0,08 & 75 & 3,33 \\
\hline 75 & 0 & 0 & AT & 75 & 0,00 & 75 & 0,00 & 75 & 0,00 & 75 & 0,00 \\
\hline 75 & 50 & 0 & AT & 75 & 0,00 & 75 & 0,00 & 75 & 0,00 & 75 & 0,00 \\
\hline 75 & 100 & 0 & AT & 75 & 0,00 & 75 & 0,00 & 75 & 0,00 & 75 & 0,00 \\
\hline 80 & 0 & 0 & AT & 79,9 & 0,07 & 79,03 & 0,65 & 79,88 & 0,08 & 75 & 3,33 \\
\hline 80 & 50 & 0 & AT & 79,9 & 0,07 & 77,68 & 1,55 & 79,88 & 0,08 & 75 & 3,33 \\
\hline 80 & 100 & 0 & AT & 79,9 & 0,07 & 80,38 & 0,25 & 79,88 & 0,08 & 75 & 3,33 \\
\hline 95 & 0 & 0 & AT & 94,55 & 0,30 & 96,49 & 0,99 & 89,66 & 3,56 & 94,09 & 0,61 \\
\hline 95 & 50 & 0 & AT & 93,32 & 1,12 & 96,49 & 0,99 & 89,66 & 3,56 & 94,09 & 0,61 \\
\hline 95 & 100 & 0 & AT & 93,32 & 1,12 & 96,49 & 0,99 & 89,66 & 3,56 & 94,09 & 0,61 \\
\hline 110 & 0 & 0 & AT & 107,98 & 1,35 & 109,92 & 0,05 & 109,2 & 0,53 & 113,17 & 2,11 \\
\hline 110 & 50 & 0 & AT & 109,21 & 0,53 & 109,92 & 0,05 & 109,2 & 0,53 & 113,17 & 2,11 \\
\hline 110 & 100 & 0 & AT & 109,21 & 0,53 & 109,92 & 0,05 & 109,2 & 0,53 & 113,17 & 2,11 \\
\hline 125 & 0 & 0 & AT & 125,07 & 0,05 & 123,36 & 1,09 & 118,98 & 4,01 & 132,26 & 4,84 \\
\hline 125 & 50 & 0 & AT & 125,07 & 0,05 & 123,36 & 1,09 & 118,98 & 4,01 & 132,26 & 4,84 \\
\hline 125 & 100 & 0 & AT & $*$ & & 123,36 & 1,09 & 118,98 & 4,01 & 132,26 & 4,84 \\
\hline 140 & 0 & 0 & AT & 142,18 & 1,45 & 142,15 & 1,43 & 138,53 & 0,98 & 132,84 & 4,77 \\
\hline 140 & 50 & 0 & AT & 142,18 & 1,45 & 142,15 & 1,43 & 138,53 & 0,98 & 132,84 & 4,77 \\
\hline 140 & 100 & 0 & AT & 139,73 & 0,18 & 142,15 & 1,43 & 138,53 & 0,98 & 132,84 & 4,77 \\
\hline \multicolumn{5}{|c|}{ Erro médio (\%) } & $\mathbf{0 , 5 8}$ & & 0,78 & & 1,67 & & 2,88 \\
\hline
\end{tabular}


TABELA 65 - Efeito da taxa de amostragem para faltas fase-fase-terra (ABT) com ângulo de incidência de $0^{\circ}$ e resistência de falta de 0 , 50 e $100 \mathrm{ohms}$

\begin{tabular}{|c|c|c|c|c|c|c|c|c|c|c|c|}
\hline $\begin{array}{l}\text { Dist. } \\
\text { Real } \\
(\mathbf{k m})\end{array}$ & $\begin{array}{l}\text { Resist. } \\
\text { falta } \\
\text { (ohms) }\end{array}$ & $\begin{array}{l}\text { Âng. de } \\
\text { Incid. } \\
\text { (graus) }\end{array}$ & $\begin{array}{c}\text { Tipo de } \\
\text { Falta }\end{array}$ & $\begin{array}{c}\text { Dist. } \\
\text { Est. } \\
240 \mathrm{kHz} \\
\text { (km) }\end{array}$ & $\begin{array}{l}\text { Erro } \\
(\%)\end{array}$ & $\begin{array}{c}\text { Dist. } \\
\text { Est. } \\
120 \mathrm{kHz} \\
(\mathrm{km})\end{array}$ & Erro & $\begin{array}{c}\text { Dist. } \\
\text { Est. } \\
60 \mathrm{kHz} \\
(\mathbf{k m})\end{array}$ & Erro & $\begin{array}{c}\text { Dist. } \\
\text { Est. } \\
\text { 15,36 kHz } \\
\text { (km) }\end{array}$ & Erro \\
\hline 10 & 0 & 0 & ABT & 10,27 & 0,18 & 13,19 & 2,13 & 11,47 & 0,98 & 17,16 & 4,77 \\
\hline 10 & 50 & 0 & ABT & 10,27 & 0,18 & 13,19 & 2,13 & 11,47 & 0,98 & 17,16 & 4,77 \\
\hline 10 & 100 & 0 & ABT & 10,27 & 0,18 & 13,19 & 2,13 & 11,47 & 0,98 & 17,16 & 4,77 \\
\hline 25 & 0 & 0 & ABT & 24,93 & 0,05 & 26,63 & 1,09 & 31,03 & 4,02 & 17,16 & 5,23 \\
\hline 25 & 50 & 0 & ABT & 24,93 & 0,05 & 26,63 & 1,09 & 31,03 & 4,02 & 17,16 & 5,23 \\
\hline 25 & 100 & 0 & ABT & 24,93 & 0,05 & 26,63 & 1,09 & 31,03 & 4,02 & 17,16 & 5,23 \\
\hline 40 & 0 & 0 & $\mathrm{ABT}$ & 41,42 & 0,95 & 40,07 & 0,05 & 40,8 & 0,53 & 36,83 & 2,11 \\
\hline 40 & 50 & 0 & $\mathrm{ABT}$ & 41,42 & 0,95 & 40,07 & 0,05 & 40,8 & 0,53 & 36,83 & 2,11 \\
\hline 40 & 100 & 0 & $\mathrm{ABT}$ & 41,42 & 0,95 & 40,07 & 0,05 & 40,8 & 0,53 & 36,83 & 2,11 \\
\hline 55 & 0 & 0 & $\mathrm{ABT}$ & 55,45 & 0,30 & 53,5 & 1,00 & 55,45 & 0,30 & 55,91 & 0,61 \\
\hline 55 & 50 & 0 & $\mathrm{ABT}$ & 56,68 & 1,12 & 53,5 & 1,00 & 55,45 & 0,30 & 55,91 & 0,61 \\
\hline 55 & 100 & 0 & $\mathrm{ABT}$ & 56,68 & 1,12 & 53,5 & 1,00 & 60,34 & 3,56 & 55,91 & 0,61 \\
\hline 70 & 0 & 0 & $\mathrm{ABT}$ & 70,1 & 0,07 & 66,94 & 2,04 & 70,12 & 0,08 & 75 & 3,33 \\
\hline 70 & 50 & 0 & $\mathrm{ABT}$ & 70,1 & 0,07 & 66,94 & 2,04 & 70,12 & 0,08 & 75 & 3,33 \\
\hline 70 & 100 & 0 & $\mathrm{ABT}$ & 70,1 & 0,07 & 66,94 & 2,04 & 70,12 & 0,08 & 75 & 3,33 \\
\hline 75 & 0 & 0 & ABT & 75 & 0,00 & 75 & 0,00 & 75 & 0,00 & 75 & 0,00 \\
\hline 75 & 50 & 0 & $\mathrm{ABT}$ & 75 & 0,00 & 75 & 0,00 & 75 & 0,00 & 75 & 0,00 \\
\hline 75 & 100 & 0 & $\mathrm{ABT}$ & 75 & 0,00 & 75 & 0,00 & 75 & 0,00 & 75 & 0,00 \\
\hline 80 & 0 & 0 & $\mathrm{ABT}$ & 79,9 & 0,07 & 83,06 & 2,04 & 79,88 & 0,08 & 75 & 3,33 \\
\hline 80 & 50 & 0 & $\mathrm{ABT}$ & 79,9 & 0,07 & 83,06 & 2,04 & 79,88 & 0,08 & 75 & 3,33 \\
\hline 80 & 100 & 0 & $\mathrm{ABT}$ & 79,9 & 0,07 & 83,06 & 2,04 & 79,88 & 0,08 & 75 & 3,33 \\
\hline 95 & 0 & 0 & ABT & 94,55 & 0,30 & 96,5 & 1,00 & 94,55 & 0,30 & 94,09 & 0,61 \\
\hline 95 & 50 & 0 & ABT & 93,32 & 1,12 & 96,5 & 1,00 & 94,55 & 0,30 & 94,09 & 0,61 \\
\hline 95 & 100 & 0 & ABT & 93,32 & 1,12 & 96,5 & 1,00 & 94,55 & 0,30 & 94,09 & 0,61 \\
\hline 110 & 0 & 0 & ABT & 107,98 & 1,35 & 112,61 & 1,74 & 109,2 & 0,53 & 113,17 & 2,11 \\
\hline 110 & 50 & 0 & ABT & 108,58 & 0,95 & 109,93 & 0,05 & 109,2 & 0,53 & 113,17 & 2,11 \\
\hline 110 & 100 & 0 & ABT & 108,58 & 0,95 & 109,93 & 0,05 & 109,2 & 0,53 & 113,17 & 2,11 \\
\hline 125 & 0 & 0 & ABT & 125,07 & 0,05 & 123,37 & 1,09 & 118,98 & 4,01 & 132,26 & 4,84 \\
\hline 125 & 50 & 0 & ABT & 125,07 & 0,05 & 123,37 & 1,09 & 118,98 & 4,01 & 132,26 & 4,84 \\
\hline 125 & 100 & 0 & ABT & 125,07 & 0,05 & 123,37 & 1,09 & 118,98 & 4,01 & 132,26 & 4,84 \\
\hline 140 & 0 & 0 & ABT & 139,73 & 0,18 & 136,81 & 2,13 & 138,53 & 0,98 & 132,84 & 4,77 \\
\hline 140 & 50 & 0 & ABT & 139,73 & 0,18 & 136,81 & 2,13 & 138,53 & 0,98 & 132,84 & 4,77 \\
\hline 140 & 100 & 0 & $\mathrm{ABT}$ & 139,73 & 0,18 & 136,81 & 2,13 & 138,53 & 0,98 & 132,84 & 4,77 \\
\hline \multicolumn{5}{|c|}{ Erro médio (\%) } & 0,39 & & 1,20 & & 1,17 & & 2,88 \\
\hline
\end{tabular}


TABELA 66 - Efeito da taxa de amostragem para faltas fase-terra (ABT) com ângulo de incidência de $90^{\circ}$ e resistência de falta de 0,50 e $100 \mathrm{ohms}$

\begin{tabular}{|c|c|c|c|c|c|c|c|c|c|c|c|}
\hline $\begin{array}{l}\text { Dist. } \\
\text { Real }\end{array}$ & $\begin{array}{l}\text { Resist. } \\
\text { falta } \\
\text { (ohms) }\end{array}$ & $\begin{array}{l}\text { Âng. de } \\
\text { Incid. } \\
\text { (graus) }\end{array}$ & $\begin{array}{c}\text { Tipo de } \\
\text { Falta }\end{array}$ & $\begin{array}{l}\text { Dist. } \\
\text { Est. } \\
240 \mathrm{kHz} \\
(\mathbf{k m})\end{array}$ & Erro & $\begin{array}{c}\text { Dist. } \\
\text { Est. } \\
120 \text { kHz } \\
(\mathbf{k m})\end{array}$ & Erro & $\begin{array}{c}\text { Dist. } \\
\text { Est. } \\
60 \mathrm{kHz} \\
(\mathbf{k m})\end{array}$ & Erro & $\begin{array}{c}\text { Dist. } \\
\text { Est. } \\
\text { 15,36 kHz } \\
\text { (km) }\end{array}$ & Erro \\
\hline 10 & 0 & 90 & ABT & 10,25 & 0,17 & 10,5 & 0,33 & 11,47 & 0,98 & 17,16 & 4,77 \\
\hline 10 & 50 & 90 & $\mathrm{ABT}$ & 10,25 & 0,17 & 10,5 & 0,33 & 11,47 & 0,98 & 17,16 & 4,77 \\
\hline 10 & 100 & 90 & $\mathrm{ABT}$ & 10,25 & 0,17 & 10,5 & 0,33 & 11,47 & 0,98 & 17,16 & 4,77 \\
\hline 25 & 0 & 90 & $\mathrm{ABT}$ & 24,91 & 0,06 & 26,63 & 1,09 & 31,03 & 4,02 & 17,16 & 5,23 \\
\hline 25 & 50 & 90 & $\mathrm{ABT}$ & 24,91 & 0,06 & 26,63 & 1,09 & 31,03 & 4,02 & 17,16 & 5,23 \\
\hline 25 & 100 & 90 & $\mathrm{ABT}$ & 24,91 & 0,06 & 26,63 & 1,09 & 31,03 & 4,02 & 17,16 & 5,23 \\
\hline 40 & 0 & 90 & $\mathrm{ABT}$ & 39,57 & 0,29 & 40,07 & 0,05 & 40,79 & 0,53 & 36,83 & 2,11 \\
\hline 40 & 50 & 90 & $\mathrm{ABT}$ & 39,57 & 0,29 & 40,07 & 0,05 & 40,79 & 0,53 & 36,83 & 2,11 \\
\hline 40 & 100 & 90 & $\mathrm{ABT}$ & 39,57 & 0,29 & 40,07 & 0,05 & 40,79 & 0,53 & 36,83 & 2,11 \\
\hline 55 & 0 & 90 & $\mathrm{ABT}$ & 55,45 & 0,30 & 53,51 & 0,99 & 60,34 & 3,56 & 55,91 & 0,61 \\
\hline 55 & 50 & 90 & $\mathrm{ABT}$ & 55,45 & 0,30 & 53,51 & 0,99 & 60,34 & 3,56 & 55,91 & 0,61 \\
\hline 55 & 100 & 90 & $\mathrm{ABT}$ & 55,45 & 0,30 & 53,51 & 0,99 & 60,34 & 3,56 & 55,91 & 0,61 \\
\hline 70 & 0 & 90 & $\mathrm{ABT}$ & 70,1 & 0,07 & 69,64 & 0,24 & 70,1 & 0,07 & 75 & 3,33 \\
\hline 70 & 50 & 90 & $\mathrm{ABT}$ & 70,1 & 0,07 & 69,64 & 0,24 & 70,1 & 0,07 & 75 & 3,33 \\
\hline 70 & 100 & 90 & $\mathrm{ABT}$ & 70,1 & 0,07 & 69,64 & 0,24 & 70,1 & 0,07 & 75 & 3,33 \\
\hline 75 & 0 & 90 & $\mathrm{ABT}$ & 75 & 0,00 & 75 & 0,00 & 75 & 0,00 & 75 & 0,00 \\
\hline 75 & 50 & 90 & $\mathrm{ABT}$ & 75 & 0,00 & 75 & 0,00 & 75 & 0,00 & 75 & 0,00 \\
\hline 75 & 100 & 90 & $\mathrm{ABT}$ & 75 & 0,00 & 75 & 0,00 & 75 & 0,00 & 75 & 0,00 \\
\hline 80 & 0 & 90 & $\mathrm{ABT}$ & 79,9 & 0,07 & 80,36 & 0,24 & 79,9 & 0,07 & 75 & 3,33 \\
\hline 80 & 50 & 90 & ABT & 79,9 & 0,07 & 80,36 & 0,24 & 79,9 & 0,07 & 75 & 3,33 \\
\hline 80 & 100 & 90 & $\mathrm{ABT}$ & 79,9 & 0,07 & 80,36 & 0,24 & 79,9 & 0,07 & 75 & 3,33 \\
\hline 95 & 0 & 90 & $\mathrm{ABT}$ & 94,55 & 0,30 & 96,49 & 0,99 & 89,66 & 3,56 & 94,09 & 0,61 \\
\hline 95 & 50 & 90 & ABT & 94,55 & 0,30 & 96,49 & 0,99 & 89,66 & 3,56 & 94,09 & 0,61 \\
\hline 95 & 100 & 90 & ABT & 94,55 & 0,30 & 96,49 & 0,99 & 89,66 & 3,56 & 94,09 & 0,61 \\
\hline 110 & 0 & 90 & ABT & 108,6 & 0,93 & 111,28 & 0,85 & 109,2 & 0,53 & 113,17 & 2,11 \\
\hline 110 & 50 & 90 & ABT & 108,6 & 0,93 & 111,28 & 0,85 & 109,2 & 0,53 & 113,17 & 2,11 \\
\hline 110 & 100 & 90 & ABT & 108,6 & 0,93 & 111,28 & 0,85 & 109,2 & 0,53 & 113,17 & 2,11 \\
\hline 125 & 0 & 90 & ABT & 125,09 & 0,06 & 123,37 & 1,09 & 118,98 & 4,01 & 132,26 & 4,84 \\
\hline 125 & 50 & 90 & ABT & 125,09 & 0,06 & 123,37 & 1,09 & 118,98 & 4,01 & 132,26 & 4,84 \\
\hline 125 & 100 & 90 & $\mathrm{ABT}$ & 125,09 & 0,06 & 123,37 & 1,09 & 118,98 & 4,01 & 132,26 & 4,84 \\
\hline 140 & 0 & 90 & ABT & 139,75 & 0,17 & 139,5 & 0,33 & 138,53 & 0,98 & 132,84 & 4,77 \\
\hline 140 & 50 & 90 & ABT & 139,75 & 0,17 & 139,5 & 0,33 & 138,53 & 0,98 & 132,84 & 4,77 \\
\hline 140 & 100 & 90 & $\mathrm{ABT}$ & 139,75 & 0,17 & 139,5 & 0,33 & 138,53 & 0,98 & 132,84 & 4,77 \\
\hline \multicolumn{5}{|c|}{ Erro médio (\%) } & 0,22 & & 0,56 & & 1,66 & & 2,88 \\
\hline
\end{tabular}


TABELA 67 - Efeito da taxa de amostragem para faltas fase-fase (AB) com ângulo de incidência de $90^{\circ}$.

\begin{tabular}{|c|c|c|c|c|c|c|c|c|c|c|}
\hline $\begin{array}{c}\text { Distância } \\
\text { Real } \\
\text { (km) }\end{array}$ & $\begin{array}{l}\text { Âng. de } \\
\text { Incid. } \\
\text { (graus) }\end{array}$ & $\begin{array}{c}\text { Tipo de } \\
\text { Falta }\end{array}$ & $\begin{array}{c}\text { Distância } \\
\text { Estimada } \\
240 \text { kHz } \\
(\mathrm{km})\end{array}$ & $\begin{array}{c}\text { Distância } \\
\text { Estimada } \\
120 \text { kHz } \\
(\mathrm{km})\end{array}$ & $\begin{array}{c}\text { Distância } \\
\text { Estimada } \\
60 \text { kHz } \\
\text { (km) }\end{array}$ & $\begin{array}{c}\text { Distância } \\
\text { Estimada } \\
15,3 \mathrm{kHz} \\
(\mathrm{km})\end{array}$ & $\begin{array}{c}240 \mathrm{kHz} \\
(\%)\end{array}$ & $\begin{array}{c}\text { Erro } \\
120 \mathrm{kHz} \\
(\%)\end{array}$ & $\begin{array}{c}\text { Erro } \\
60 \mathrm{kHz} \\
(\%)\end{array}$ & $\begin{array}{c}\text { Erro } \\
\text { 15,3 kHz } \\
(\%)\end{array}$ \\
\hline 10 & 90 & $\mathrm{AB}$ & 10,25 & 10,53 & 11,47 & 17,16 & 0,17 & 0,35 & 0,98 & 4,77 \\
\hline 25 & 90 & $\mathrm{AB}$ & 24,91 & 23,96 & 31,03 & 36,81 & 0,06 & 0,69 & 4,02 & 7,87 \\
\hline 40 & 90 & $\mathrm{AB}$ & 39,57 & 40,07 & 40,79 & 36,81 & 0,29 & 0,05 & 0,53 & 2,13 \\
\hline 55 & 90 & $\mathrm{AB}$ & 55,45 & 53,51 & 60,34 & 46,37 & 0,30 & 0,99 & 3,56 & 5,75 \\
\hline 70 & 90 & $\mathrm{AB}$ & 70,1 & 69,62 & 70,1 & 75 & 0,07 & 0,25 & 0,07 & 3,33 \\
\hline 75 & 90 & $\mathrm{AB}$ & 75 & 75 & 75 & 75 & 0,00 & 0,00 & 0,00 & 0,00 \\
\hline 80 & 90 & $\mathrm{AB}$ & 79,9 & 80,38 & 79,9 & 75 & 0,07 & 0,25 & 0,07 & 3,33 \\
\hline 95 & 90 & $\mathrm{AB}$ & 94,55 & 95,16 & 89,66 & 103,63 & 0,30 & 0,11 & 3,56 & 5,75 \\
\hline 110 & 90 & $\mathrm{AB}$ & 108,6 & 109,93 & 109,21 & 113,18 & 0,93 & 0,05 & 0,53 & 2,12 \\
\hline 125 & 90 & $\mathrm{AB}$ & 125,09 & 126,04 & 118,97 & 113,18 & 0,06 & 0,69 & 4,02 & 7,88 \\
\hline 140 & 90 & $\mathrm{AB}$ & 139,75 & 139,47 & 138,53 & 132,84 & 0,17 & 0,35 & 0,98 & 4,77 \\
\hline \multicolumn{3}{|c|}{ Erro médio (\%) } & & & & & 0,22 & $\mathbf{0 , 3 4}$ & 1,66 & 4,34 \\
\hline
\end{tabular}

TABELA 68 - Efeito da taxa de amostragem para faltas trifásicas (ABC) com ângulo de incidência de $0^{\circ}$.

\begin{tabular}{|c|c|c|c|c|c|c|c|c|c|c|}
\hline $\begin{array}{c}\text { Distância } \\
\text { Real } \\
\text { (km) }\end{array}$ & $\begin{array}{l}\text { Âng. de } \\
\text { Incid. } \\
\text { (graus) }\end{array}$ & $\begin{array}{c}\text { Tipo de } \\
\text { Falta }\end{array}$ & $\begin{array}{c}\text { Distância } \\
\text { Estimada } \\
240 \text { kHz } \\
(\mathrm{km})\end{array}$ & $\begin{array}{c}\text { Distância } \\
\text { Estimada } \\
120 \text { kHz } \\
(\mathrm{km})\end{array}$ & $\begin{array}{c}\text { Distância } \\
\text { Estimada } \\
60 \mathrm{kHz} \\
(\mathrm{km})\end{array}$ & $\begin{array}{c}\text { Distância } \\
\text { Estimada } \\
15,3 \mathrm{kHz} \\
(\mathrm{km})\end{array}$ & $\begin{array}{c}240 \mathrm{kHz} \\
(\%)\end{array}$ & $\begin{array}{c}120 \mathrm{kHz} \\
(\%)\end{array}$ & $\begin{array}{c}60 \mathrm{kHz} \\
(\%)\end{array}$ & $\begin{array}{c}\text { Erro } \\
15,3 \mathrm{kHz} \\
(\%)\end{array}$ \\
\hline 10 & 0 & $\mathrm{ABC}$ & 10,27 & 10,53 & 11,47 & 17,17 & 0,18 & 0,35 & 0,98 & 4,78 \\
\hline 25 & 0 & $\mathrm{ABC}$ & 24,93 & 23,96 & 31,03 & 36,83 & 0,05 & 0,69 & 4,02 & 7,89 \\
\hline 40 & 0 & $\mathrm{ABC}$ & 40,79 & 40,08 & 40,8 & 27,28 & 0,53 & 0,05 & 0,53 & 8,48 \\
\hline 55 & 0 & $\mathrm{ABC}$ & 55,45 & 53,51 & 60,34 & 55,9 & 0,30 & 0,99 & 3,56 & 0,60 \\
\hline 70 & 0 & $\mathrm{ABC}$ & 70,1 & 69,62 & 70,12 & 84,54 & 0,07 & 0,25 & 0,08 & 9,69 \\
\hline 75 & 0 & $\mathrm{ABC}$ & 75 & 75 & 75 & 75 & 0,00 & 0,00 & 0,00 & 0,00 \\
\hline 80 & 0 & $\mathrm{ABC}$ & 79,9 & 80,38 & 79,88 & 65,45 & 0,07 & 0,25 & 0,08 & 9,70 \\
\hline 95 & 0 & $\mathrm{ABC}$ & 93,32 & 93,81 & 89,66 & 94,08 & 1,12 & 0,79 & 3,56 & 0,61 \\
\hline 110 & 0 & $\mathrm{ABC}$ & 109,81 & 109,92 & 109,2 & 122,7 & 0,13 & 0,05 & 0,53 & 8,47 \\
\hline 125 & 0 & $\mathrm{ABC}$ & 125,07 & 126,04 & 118,98 & 113,17 & 0,05 & 0,69 & 4,01 & 7,89 \\
\hline 140 & 0 & $\mathrm{ABC}$ & 139,73 & 140,8 & 138,53 & 132,82 & 0,18 & 0,53 & 0,98 & 4,79 \\
\hline \multicolumn{3}{|c|}{ Erro médio (\%) } & & & & & 0,24 & 0,42 & 1,67 & 5,72 \\
\hline
\end{tabular}

TABELA 69 - Efeito da taxa de amostragem para faltas trifásicas (ABC) com ângulo de incidência de $90^{\circ}$.

\begin{tabular}{|c|c|c|c|c|c|c|c|c|c|c|}
\hline $\begin{array}{c}\text { Distância } \\
\text { Real } \\
\text { (km) }\end{array}$ & $\begin{array}{l}\text { Âng. de } \\
\text { Incid. } \\
\text { (graus) }\end{array}$ & $\begin{array}{c}\text { Tipo de } \\
\text { Falta }\end{array}$ & $\begin{array}{c}\text { Distância } \\
\text { Estimada } \\
240 \text { kHz } \\
(\mathrm{km})\end{array}$ & $\begin{array}{c}\text { Distância } \\
\text { Estimada } \\
120 \text { kHz } \\
(\mathrm{km})\end{array}$ & $\begin{array}{c}\text { Distância } \\
\text { Estimada } \\
60 \text { kHz } \\
(\mathrm{km})\end{array}$ & $\begin{array}{c}\text { Distância } \\
\text { Estimada } \\
15,3 \mathrm{kHz} \\
(\mathrm{km})\end{array}$ & $\begin{array}{c}240 \mathrm{kHz} \\
(\%)\end{array}$ & $\begin{array}{c}120 \mathrm{kHz} \\
(\%)\end{array}$ & $\begin{array}{c}60 \mathrm{kHz} \\
(\%)\end{array}$ & $\begin{array}{c}\text { Erro } \\
\begin{array}{c}15,3 \mathrm{kHz} \\
(\%)\end{array}\end{array}$ \\
\hline 10 & 90 & $\mathrm{ABC}$ & 10,25 & 10,53 & 11,47 & 17,16 & 0,17 & 0,35 & 0,98 & 4,77 \\
\hline 25 & 90 & $\mathrm{ABC}$ & 24,91 & 25,29 & 31,03 & 36,81 & 0,06 & 0,19 & 4,02 & 7,87 \\
\hline 40 & 90 & $\mathrm{ABC}$ & 39,57 & 40,07 & 40,79 & 36,81 & 0,29 & 0,05 & 0,53 & 2,13 \\
\hline 55 & 90 & $\mathrm{ABC}$ & 55,45 & 53,51 & 60,34 & 55,9 & 0,30 & 0,99 & 3,56 & 0,60 \\
\hline 70 & 90 & $\mathrm{ABC}$ & 70,1 & 69,62 & 70,1 & 75 & 0,07 & 0,25 & 0,07 & 3,33 \\
\hline 75 & 90 & $\mathrm{ABC}$ & 75 & 75 & 75 & 75 & 0,00 & 0,00 & 0,00 & 0,00 \\
\hline 80 & 90 & $\mathrm{ABC}$ & 79,9 & 80,38 & 79,9 & 75 & 0,07 & 0,25 & 0,07 & 3,33 \\
\hline 95 & 90 & $\mathrm{ABC}$ & 94,55 & 95,16 & 94,54 & 103,64 & 0,30 & 0,11 & 0,31 & 5,76 \\
\hline 110 & 90 & $\mathrm{ABC}$ & 110,43 & 109,93 & 109,21 & 113,18 & 0,29 & 0,05 & 0,53 & 2,12 \\
\hline 125 & 90 & $\mathrm{ABC}$ & 125,09 & 124,71 & 118,97 & 113,18 & 0,06 & 0,19 & 4,02 & 7,88 \\
\hline 140 & 90 & $\mathrm{ABC}$ & 139,75 & 139,47 & 138,53 & 132,84 & 0,17 & 0,35 & 0,98 & 4,77 \\
\hline \multicolumn{3}{|c|}{ Erro médio (\%) } & & & & & 0,16 & 0,25 & 1,37 & 3,87 \\
\hline
\end{tabular}


TABELA 70 - Efeito da imprecisão de $+5 \%$ nos parâmetros L e C da linha de transmissão considerando faltas fase-terra com ângulo de incidência da falta de $0^{\circ}$.

\begin{tabular}{|c|c|c|c|c|c|c|}
\hline $\begin{array}{c}\text { Distância } \\
\text { Real } \\
\text { (km) }\end{array}$ & $\begin{array}{l}\text { Resist. } \\
\text { falta } \\
\text { (ohms) }\end{array}$ & $\begin{array}{l}\text { Ângulo de } \\
\text { Incidência } \\
\text { (graus) }\end{array}$ & $\begin{array}{c}\text { Tipo de } \\
\text { Falta }\end{array}$ & $\begin{array}{c}\text { Distância } \\
\text { Estimada } \\
(\mathbf{k m})\end{array}$ & $\begin{array}{l}\text { Erro } \\
\text { Abs. } \\
\text { (km) }\end{array}$ & $\begin{array}{l}\text { Erro } \\
\text { (\%) }\end{array}$ \\
\hline 10 & 0 & 0 & AT & 8,49 & 1,51 & 1,00 \\
\hline 10 & 50 & 0 & AT & 11,05 & 1,05 & 0,70 \\
\hline 10 & 100 & 0 & AT & 11,05 & 1,05 & 0,70 \\
\hline 25 & 0 & 0 & AT & 28,95 & 3,95 & 2,63 \\
\hline 25 & 50 & 0 & AT & 28,95 & 3,95 & 2,63 \\
\hline 25 & 100 & 0 & AT & 28,95 & 3,95 & 2,63 \\
\hline 40 & 0 & 0 & AT & 41,75 & 1,75 & 1,16 \\
\hline 40 & 50 & 0 & AT & 41,75 & 1,75 & 1,16 \\
\hline 40 & 100 & 0 & AT & 41,75 & 1,75 & 1,16 \\
\hline 55 & 0 & 0 & AT & 54,53 & 0,47 & 0,31 \\
\hline 55 & 50 & 0 & AT & 54,53 & 0,47 & 0,31 \\
\hline 55 & 100 & 0 & AT & 54,53 & 0,47 & 0,31 \\
\hline 70 & 0 & 0 & AT & 71,16 & 1,16 & 0,77 \\
\hline 70 & 50 & 0 & AT & 71,16 & 1,16 & 0,77 \\
\hline 70 & 100 & 0 & AT & 71,16 & 1,16 & 0,77 \\
\hline 75 & 0 & 0 & AT & 75,00 & 0,00 & 0,00 \\
\hline 75 & 50 & 0 & AT & 75,00 & 0,00 & 0,00 \\
\hline 75 & 100 & 0 & AT & 75,00 & 0,00 & 0,00 \\
\hline 80 & 0 & 0 & AT & 78,84 & 1,16 & 0,77 \\
\hline 80 & 50 & 0 & AT & 77,55 & 2,45 & 1,63 \\
\hline 80 & 100 & 0 & AT & 80,12 & 0,12 & 0,08 \\
\hline 95 & 0 & 0 & AT & 95,47 & 0,47 & 0,31 \\
\hline 95 & 50 & 0 & AT & 95,47 & 0,47 & 0,31 \\
\hline 95 & 100 & 0 & AT & 95,47 & 0,47 & 0,31 \\
\hline 110 & 0 & 0 & AT & 108,25 & 1,75 & 1,16 \\
\hline 110 & 50 & 0 & AT & 108,25 & 1,75 & 1,16 \\
\hline 110 & 100 & 0 & AT & 108,25 & 1,75 & 1,16 \\
\hline 125 & 0 & 0 & AT & 121,05 & 3,95 & 2,63 \\
\hline 125 & 50 & 0 & AT & 121,05 & 3,95 & 2,63 \\
\hline 125 & 100 & 0 & AT & 121,05 & 3,95 & 2,63 \\
\hline 140 & 0 & 0 & AT & 138,95 & 1,05 & 0,70 \\
\hline 140 & 50 & 0 & AT & 138,95 & 1,05 & 0,70 \\
\hline 140 & 100 & 0 & AT & 138,95 & 1,05 & 0,70 \\
\hline \multicolumn{6}{|c|}{ Erro médio (\%) } & 1,03 \\
\hline
\end{tabular}


TABELA 71 - Efeito da imprecisão de $+5 \%$ nos parâmetros L e C da linha de transmissão considerando faltas fase-terra com ângulo de incidência da falta de $90^{\circ}$.

\begin{tabular}{|c|c|c|c|c|c|c|}
\hline $\begin{array}{c}\text { Distância } \\
\text { Real } \\
\text { (km) }\end{array}$ & $\begin{array}{c}\text { Resist. } \\
\text { falta } \\
\text { (ohms) }\end{array}$ & $\begin{array}{c}\text { Ângulo de } \\
\text { Incidência } \\
\text { (graus) }\end{array}$ & $\begin{array}{c}\text { Tipo de } \\
\text { Falta }\end{array}$ & $\begin{array}{c}\text { Distância } \\
\text { Estimada } \\
\quad(\mathbf{k m})\end{array}$ & $\begin{array}{l}\text { Erro } \\
\text { Abs. } \\
\text { (km) }\end{array}$ & $\begin{array}{l}\text { Erro } \\
(\%)\end{array}$ \\
\hline 10 & 0 & 90 & AT & 13,60 & 3,60 & 2,40 \\
\hline 10 & 50 & 90 & AT & 13,60 & 3,60 & 2,40 \\
\hline 10 & 100 & 90 & AT & 13,60 & 3,60 & 2,40 \\
\hline 25 & 0 & 90 & AT & 26,39 & 1,39 & 0,93 \\
\hline 25 & 50 & 90 & AT & 26,39 & 1,39 & 0,93 \\
\hline 25 & 100 & 90 & AT & 26,39 & 1,39 & 0,93 \\
\hline 40 & 0 & 90 & AT & 40,46 & 0,46 & 0,31 \\
\hline 40 & 50 & 90 & AT & 40,46 & 0,46 & 0,31 \\
\hline 40 & 100 & 90 & AT & 40,46 & 0,46 & 0,31 \\
\hline 55 & 0 & 90 & AT & 57,09 & 2,09 & 1,39 \\
\hline 55 & 50 & 90 & AT & 57,09 & 2,09 & 1,39 \\
\hline 55 & 100 & 90 & AT & 57,09 & 2,09 & 1,39 \\
\hline 70 & 0 & 90 & AT & 69,88 & 0,12 & 0,08 \\
\hline 70 & 50 & 90 & AT & 69,88 & 0,12 & 0,08 \\
\hline 70 & 100 & 90 & AT & 69,88 & 0,12 & 0,08 \\
\hline 75 & 0 & 90 & AT & 75,00 & 0,00 & 0,00 \\
\hline 75 & 50 & 90 & AT & 75,00 & 0,00 & 0,00 \\
\hline 75 & 100 & 90 & AT & 75,00 & 0,00 & 0,00 \\
\hline 80 & 0 & 90 & AT & 80,12 & 0,12 & 0,08 \\
\hline 80 & 50 & 90 & AT & 80,12 & 0,12 & 0,08 \\
\hline 80 & 100 & 90 & AT & 80,12 & 0,12 & 0,08 \\
\hline 95 & 0 & 90 & AT & 92,91 & 2,09 & 1,39 \\
\hline 95 & 50 & 90 & AT & 92,91 & 2,09 & 1,39 \\
\hline 95 & 100 & 90 & AT & 92,91 & 2,09 & 1,39 \\
\hline 110 & 0 & 90 & AT & 109,54 & 0,46 & 0,31 \\
\hline 110 & 50 & 90 & AT & 109,54 & 0,46 & 0,31 \\
\hline 110 & 100 & 90 & AT & 109,54 & 0,46 & 0,31 \\
\hline 125 & 0 & 90 & AT & 123,61 & 1,39 & 0,93 \\
\hline 125 & 50 & 90 & AT & 123,61 & 1,39 & 0,93 \\
\hline 125 & 100 & 90 & AT & 123,61 & 1,39 & 0,93 \\
\hline 140 & 0 & 90 & AT & 136,40 & 3,60 & 2,40 \\
\hline 140 & 50 & 90 & AT & 136,40 & 3,60 & 2,40 \\
\hline 140 & 100 & 90 & AT & 136,40 & 3,60 & 2,40 \\
\hline \multicolumn{6}{|c|}{ Erro médio (\%) } & $\mathbf{0 , 9 3}$ \\
\hline
\end{tabular}


TABELA 72 - Efeito da imprecisão de -5\% nos parâmetros L e C da linha de transmissão considerando faltas fase-terra com ângulo de incidência da falta de $0^{\circ}$.

\begin{tabular}{|c|c|c|c|c|c|c|}
\hline $\begin{array}{c}\text { Distância } \\
\text { Real } \\
\text { (km) }\end{array}$ & $\begin{array}{c}\text { Resist. } \\
\text { falta } \\
\text { (ohms) }\end{array}$ & $\begin{array}{c}\text { Ângulo de } \\
\text { Incidência } \\
\text { (graus) }\end{array}$ & $\begin{array}{c}\text { Tipo de } \\
\text { Falta }\end{array}$ & $\begin{array}{c}\text { Distância } \\
\text { Estimada } \\
(\mathbf{k m})\end{array}$ & $\begin{array}{l}\text { Erro } \\
\text { Abs. } \\
(\mathbf{k m})\end{array}$ & $\begin{array}{l}\text { Erro } \\
\text { (\%) }\end{array}$ \\
\hline 10 & 0 & 0 & AT & 5,15 & 4,85 & 3,23 \\
\hline 10 & 50 & 0 & AT & 5,15 & 4,85 & 3,23 \\
\hline 10 & 100 & 0 & AT & 5,15 & 4,85 & 3,23 \\
\hline 25 & 0 & 0 & AT & 24,10 & 0,90 & 0,60 \\
\hline 25 & 50 & 0 & AT & 24,10 & 0,90 & 0,60 \\
\hline 25 & 100 & 0 & AT & 24,10 & 0,90 & 0,60 \\
\hline 40 & 0 & 0 & AT & 38,25 & 1,75 & 1,17 \\
\hline 40 & 50 & 0 & AT & 38,25 & 1,75 & 1,17 \\
\hline 40 & 100 & 0 & AT & 38,25 & 1,75 & 1,17 \\
\hline 55 & 0 & 0 & AT & 52,38 & 2,62 & 1,75 \\
\hline 55 & 50 & 0 & AT & 52,38 & 2,62 & 1,75 \\
\hline 55 & 100 & 0 & AT & 52,38 & 2,62 & 1,75 \\
\hline 70 & 0 & 0 & AT & 70,76 & 0,76 & 0,50 \\
\hline 70 & 50 & 0 & AT & 70,76 & 0,76 & 0,50 \\
\hline 70 & 100 & 0 & AT & 70,76 & 0,76 & 0,50 \\
\hline 75 & 0 & 0 & AT & 75,00 & 0,00 & 0,00 \\
\hline 75 & 50 & 0 & AT & 75,00 & 0,00 & 0,00 \\
\hline 75 & 100 & 0 & AT & 75,00 & 0,00 & 0,00 \\
\hline 80 & 0 & 0 & AT & 79,24 & 0,76 & 0,50 \\
\hline 80 & 50 & 0 & AT & 77,82 & 2,18 & 1,45 \\
\hline 80 & 100 & 0 & AT & 80,66 & 0,66 & 0,44 \\
\hline 95 & 0 & 0 & AT & 97,62 & 2,62 & 1,75 \\
\hline 95 & 50 & 0 & AT & 97,62 & 2,62 & 1,75 \\
\hline 95 & 100 & 0 & AT & 97,62 & 2,62 & 1,75 \\
\hline 110 & 0 & 0 & AT & 111,75 & 1,75 & 1,17 \\
\hline 110 & 50 & 0 & AT & 111,75 & 1,75 & 1,17 \\
\hline 110 & 100 & 0 & AT & 111,75 & 1,75 & 1,17 \\
\hline 125 & 0 & 0 & AT & 125,90 & 0,90 & 0,60 \\
\hline 125 & 50 & 0 & AT & 125,90 & 0,90 & 0,60 \\
\hline 125 & 100 & 0 & AT & 125,90 & 0,90 & 0,60 \\
\hline 140 & 0 & 0 & AT & 144,80 & 4,80 & 3,20 \\
\hline 140 & 50 & 0 & AT & 144,80 & 4,80 & 3,20 \\
\hline 140 & 100 & 0 & AT & 144,80 & 4,80 & 3,20 \\
\hline \multicolumn{6}{|c|}{ Erro médio (\%) } & 1,34 \\
\hline
\end{tabular}


TABELA 73 - Efeito da imprecisão de -5\% nos parâmetros L e C da linha de transmissão considerando faltas fase-terra com ângulo de incidência da falta de $90^{\circ}$.

\begin{tabular}{|c|c|c|c|c|c|c|}
\hline $\begin{array}{c}\text { Distância } \\
\text { Real } \\
\text { (km) }\end{array}$ & $\begin{array}{c}\text { Resist. } \\
\text { falta } \\
\text { (ohms) }\end{array}$ & $\begin{array}{c}\text { Ângulo de } \\
\text { Incidência } \\
\text { (graus) }\end{array}$ & $\begin{array}{c}\text { Tipo de } \\
\text { Falta }\end{array}$ & $\begin{array}{c}\text { Distância } \\
\text { Estimada } \\
(\mathbf{k m})\end{array}$ & $\begin{array}{l}\text { Erro } \\
\text { Abs. } \\
\text { (km) }\end{array}$ & $\begin{array}{r}\text { Erro } \\
(\%) \\
\end{array}$ \\
\hline 10 & 0 & 90 & AT & 7,14 & 2,86 & 1,91 \\
\hline 10 & 50 & 90 & AT & 7,14 & 2,86 & 1,91 \\
\hline 10 & 100 & 90 & AT & 7,14 & 2,86 & 1,91 \\
\hline 25 & 0 & 90 & AT & 21,27 & 3,73 & 2,48 \\
\hline 25 & 50 & 90 & AT & 21,27 & 3,73 & 2,48 \\
\hline 25 & 100 & 90 & AT & 21,27 & 3,73 & 2,48 \\
\hline 40 & 0 & 90 & AT & 36,83 & 3,17 & 2,12 \\
\hline 40 & 50 & 90 & AT & 36,83 & 3,17 & 2,12 \\
\hline 40 & 100 & 90 & AT & 36,83 & 3,17 & 2,12 \\
\hline 55 & 0 & 90 & AT & 55,20 & 0,20 & 0,14 \\
\hline 55 & 50 & 90 & AT & 55,20 & 0,20 & 0,14 \\
\hline 55 & 100 & 90 & AT & 55,20 & 0,20 & 0,14 \\
\hline 70 & 0 & 90 & AT & 69,34 & 0,66 & 0,44 \\
\hline 70 & 50 & 90 & AT & 69,34 & 0,66 & 0,44 \\
\hline 70 & 100 & 90 & AT & 69,34 & 0,66 & 0,44 \\
\hline 75 & 0 & 90 & AT & 75,00 & 0,00 & 0,00 \\
\hline 75 & 50 & 90 & AT & 75,00 & 0,00 & 0,00 \\
\hline 75 & 100 & 90 & AT & 75,00 & 0,00 & 0,00 \\
\hline 80 & 0 & 90 & AT & 80,66 & 0,66 & 0,44 \\
\hline 80 & 50 & 90 & AT & 80,66 & 0,66 & 0,44 \\
\hline 80 & 100 & 90 & AT & 80,66 & 0,66 & 0,44 \\
\hline 95 & 0 & 90 & AT & 94,80 & 0,20 & 0,14 \\
\hline 95 & 50 & 90 & AT & 94,80 & 0,20 & 0,14 \\
\hline 95 & 100 & 90 & AT & 94,80 & 0,20 & 0,14 \\
\hline 110 & 0 & 90 & AT & 113,17 & 3,17 & 2,12 \\
\hline 110 & 50 & 90 & AT & 113,17 & 3,17 & 2,12 \\
\hline 110 & 100 & 90 & AT & 113,17 & 3,17 & 2,12 \\
\hline 125 & 0 & 90 & AT & 128,73 & 3,73 & 2,48 \\
\hline 125 & 50 & 90 & AT & 128,73 & 3,73 & 2,48 \\
\hline 125 & 100 & 90 & AT & 128,73 & 3,73 & 2,48 \\
\hline 140 & 0 & 90 & AT & 142,86 & 2,86 & 1,91 \\
\hline 140 & 50 & 90 & AT & 142,86 & 2,86 & 1,91 \\
\hline 140 & 100 & 90 & AT & 142,86 & 2,86 & 1,91 \\
\hline \multicolumn{6}{|c|}{ Erro médio (\%) } & 1,29 \\
\hline
\end{tabular}




\section{A2. Técnica que utiliza dados de um terminal}

As Tabelas (74-85) ilustram os resultados obtidos pelo algoritmo em situações faltosas onde foram variados os seguintes parâmetros: distância, tipo, ângulo de incidência e resistência de falta;

As Tabelas (86-93) trazem resultados referentes a testes onde foram consideradas altas resistências de falta associadas a variações de distância, ângulo de incidência e tipo de falta;

Resultados onde é verificada a influência da taxa amostral sobre a técnica de localização utilizada são apresentados nas Tabelas (94-95);

Nas Tabelas (96-99) que seguem são demonstrados mais resultados referentes a testes aplicados com o intuito de se verificar a influência da imprecisão na determinação dos parâmetros da linha sobre a técnica de localização em análise. 
TABELA 74 - Resultados para faltas fase-terra (BT) com ângulo de incidência de $0^{\circ}$ e resistência de falta de 0,50 e 100 ohms.

\begin{tabular}{|c|c|c|c|c|c|c|c|}
\hline $\begin{array}{c}\text { Distância } \\
\text { Real } \\
\text { (km) }\end{array}$ & $\begin{array}{c}\text { Resist. } \\
\text { falta } \\
\text { (ohms) }\end{array}$ & $\begin{array}{c}\text { Ângulo de } \\
\text { Incidência } \\
\text { (graus) }\end{array}$ & $\begin{array}{c}\text { Tipo de } \\
\text { Falta }\end{array}$ & $\begin{array}{c}\text { Pré- } \\
\text { Localização } \\
(1 / 2 \text { - seção) }\end{array}$ & $\begin{array}{c}\text { Distância } \\
\text { Estimada } \\
\text { (km) }\end{array}$ & $\begin{array}{l}\text { Erro } \\
\text { Abs. } \\
\text { (km) }\end{array}$ & $\begin{array}{l}\text { Erro } \\
(\%)\end{array}$ \\
\hline 10 & 0 & 0 & BT & 1 & 10,74 & 0,74 & 0,49 \\
\hline 10 & 50 & 0 & BT & 1 & 16,12 & 6,12 & 4,08 \\
\hline 10 & 100 & 0 & BT & 1 & 21,49 & 11,5 & 7,66 \\
\hline 25 & 0 & 0 & BT & 1 & 26,88 & 1,88 & 1,25 \\
\hline 25 & 50 & 0 & BT & 1 & 30,91 & 5,91 & 3,94 \\
\hline 25 & 100 & 0 & BT & 1 & 26,88 & 1,88 & 1,25 \\
\hline 40 & 0 & 0 & BT & 1 & 37,61 & 2,39 & 1,59 \\
\hline 40 & 50 & 0 & BT & 1 & 51,05 & 11,1 & 7,37 \\
\hline 40 & 100 & 0 & BT & 2 & 136,55 & 96,6 & 64,37 \\
\hline 55 & 0 & 0 & $\mathrm{BT}$ & 1 & 53,75 & 1,25 & 0,83 \\
\hline 55 & 50 & 0 & $\mathrm{BT}$ & 1 & 53,75 & 1,25 & 0,83 \\
\hline 55 & 100 & 0 & $\mathrm{BT}$ & 1 & 52,4 & 2,6 & 1,73 \\
\hline 70 & 0 & 0 & $\mathrm{BT}$ & 1 & 69,88 & 0,12 & 0,08 \\
\hline 70 & 50 & 0 & $\mathrm{BT}$ & 1 & 10,76 & 59,2 & 39,49 \\
\hline 70 & 100 & 0 & $\mathrm{BT}$ & 1 & 69,88 & 0,12 & 0,08 \\
\hline 75 & 0 & 0 & $\mathrm{BT}$ & 2 & 136,57 & 61,6 & 41,05 \\
\hline 75 & 50 & 0 & BT & 2 & 77,44 & 2,44 & 1,63 \\
\hline 75 & 100 & 0 & BT & 2 & 74,76 & 0,24 & 0,16 \\
\hline 80 & 0 & 0 & $\mathrm{BT}$ & 1 & 69,88 & 10,1 & 6,75 \\
\hline 80 & 50 & 0 & BT & 2 & 77,44 & 2,56 & 1,71 \\
\hline 80 & 100 & 0 & $\mathrm{BT}$ & 2 & 80,14 & 0,14 & 0,09 \\
\hline 95 & 0 & 0 & BT & 2 & 93,57 & 1,43 & 0,95 \\
\hline 95 & 50 & 0 & BT & 2 & 94,91 & 0,09 & 0,06 \\
\hline 95 & 100 & 0 & BT & 2 & 93,57 & 1,43 & 0,95 \\
\hline 110 & 0 & 0 & BT & 2 & 112,37 & 2,37 & 1,58 \\
\hline 110 & 50 & 0 & $\mathrm{BT}$ & 2 & 112,37 & 2,37 & 1,58 \\
\hline 110 & 100 & 0 & $\mathrm{BT}$ & 2 & 112,37 & 2,37 & 1,58 \\
\hline 125 & 0 & 0 & $\mathrm{BT}$ & 2 & 120,45 & 4,55 & 3,03 \\
\hline 125 & 50 & 0 & $\mathrm{BT}$ & 2 & 120,45 & 4,55 & 3,03 \\
\hline 125 & 100 & 0 & $\mathrm{BT}$ & 2 & 120,45 & 4,55 & 3,03 \\
\hline 140 & 0 & 0 & BT & 2 & 136,57 & 3,43 & 2,29 \\
\hline 140 & 50 & 0 & $\mathrm{BT}$ & 2 & 136,57 & 3,43 & 2,29 \\
\hline 140 & 100 & 0 & BT & 2 & 136,57 & 3,43 & 2,29 \\
\hline \multicolumn{7}{|c|}{ Erro médio (\%) } & 6,34 \\
\hline
\end{tabular}


TABELA 75 - Resultados para faltas fase-terra (BT) com ângulo de incidência de $90^{\circ}$ e resistência de falta de 0, 50 e $100 \mathrm{ohms}$.

\begin{tabular}{|c|c|c|c|c|c|c|c|}
\hline $\begin{array}{c}\text { Distância } \\
\text { Real } \\
\text { (km) }\end{array}$ & $\begin{array}{c}\text { Resist. } \\
\text { falta } \\
\text { (ohms) }\end{array}$ & $\begin{array}{c}\text { Ângulo de } \\
\text { Incidência } \\
\text { (graus) }\end{array}$ & $\begin{array}{c}\text { Tipo de } \\
\text { Falta }\end{array}$ & $\begin{array}{c}\text { Pré- } \\
\text { Localização } \\
(1 / 2 \text { - seção) }\end{array}$ & $\begin{array}{c}\text { Distância } \\
\text { Estimada } \\
\text { (km) }\end{array}$ & $\begin{array}{l}\text { Erro } \\
\text { Abs. } \\
\text { (km) }\end{array}$ & $\begin{array}{l}\text { Erro } \\
(\%)\end{array}$ \\
\hline 10 & 0 & 90 & BT & 1 & 13,43 & 3,43 & 2,29 \\
\hline 10 & 50 & 90 & BT & 1 & 13,43 & 3,43 & 2,29 \\
\hline 10 & 100 & 90 & BT & 1 & 139,74 & 130 & 86,49 \\
\hline 25 & 0 & 90 & BT & 1 & 26,88 & 1,88 & 1,25 \\
\hline 25 & 50 & 90 & BT & 1 & 26,88 & 1,88 & 1,25 \\
\hline 25 & 100 & 90 & BT & 1 & 26,88 & 1,88 & 1,25 \\
\hline 40 & 0 & 90 & BT & 1 & 53,75 & 13,8 & 9,17 \\
\hline 40 & 50 & 90 & BT & 1 & 53,75 & 13,8 & 9,17 \\
\hline 40 & 100 & 90 & BT & 1 & 53,75 & 13,8 & 9,17 \\
\hline 55 & 0 & 90 & $\mathrm{BT}$ & 1 & 53,75 & 1,25 & 0,83 \\
\hline 55 & 50 & 90 & $\mathrm{BT}$ & 1 & 53,75 & 1,25 & 0,83 \\
\hline 55 & 100 & 90 & $\mathrm{BT}$ & 1 & 53,75 & 1,25 & 0,83 \\
\hline 70 & 0 & 90 & BT & 1 & 69,88 & 0,12 & 0,08 \\
\hline 70 & 50 & 90 & $\mathrm{BT}$ & 1 & 69,88 & 0,12 & 0,08 \\
\hline 70 & 100 & 90 & $\mathrm{BT}$ & 1 & 69,88 & 0,12 & 0,08 \\
\hline 75 & 0 & 90 & BT & 2 & 53,26 & 21,7 & 14,49 \\
\hline 75 & 50 & 90 & BT & 2 & 74,76 & 0,24 & 0,16 \\
\hline 75 & 100 & 90 & BT & 2 & 74,76 & 0,24 & 0,16 \\
\hline 80 & 0 & 90 & $\mathrm{BT}$ & 1 & 69,88 & 10,1 & 6,75 \\
\hline 80 & 50 & 90 & BT & 1 & 69,88 & 10,1 & 6,75 \\
\hline 80 & 100 & 90 & BT & 1 & 69,88 & 10,1 & 6,75 \\
\hline 95 & 0 & 90 & BT & 2 & 93,57 & 1,43 & 0,95 \\
\hline 95 & 50 & 90 & BT & 2 & 93,57 & 1,43 & 0,95 \\
\hline 95 & 100 & 90 & BT & 2 & 93,57 & 1,43 & 0,95 \\
\hline 110 & 0 & 90 & BT & 2 & 109,69 & 0,31 & 0,21 \\
\hline 110 & 50 & 90 & $\mathrm{BT}$ & 2 & 109,69 & 0,31 & 0,21 \\
\hline 110 & 100 & 90 & $\mathrm{BT}$ & 2 & 109,69 & 0,31 & 0,21 \\
\hline 125 & 0 & 90 & $\mathrm{BT}$ & 2 & 128,49 & 3,49 & 2,33 \\
\hline 125 & 50 & 90 & BT & 2 & 128,49 & 3,49 & 2,33 \\
\hline 125 & 100 & 90 & BT & 2 & 128,49 & 3,49 & 2,33 \\
\hline 140 & 0 & 90 & BT & 2 & 136,57 & 3,43 & 2,29 \\
\hline 140 & 50 & 90 & BT & 2 & 136,57 & 3,43 & 2,29 \\
\hline 140 & 100 & 90 & BT & 2 & 136,57 & 3,43 & 2,29 \\
\hline \multicolumn{7}{|c|}{ Erro médio (\%) } & 5,38 \\
\hline
\end{tabular}


TABELA 76 - Resultados para faltas fase-terra (CT) com ângulo de incidência de $0^{\circ}$ e resistência de falta de 0,50 e 100 ohms.

\begin{tabular}{|c|c|c|c|c|c|c|c|}
\hline $\begin{array}{c}\text { Distância } \\
\text { Real } \\
\text { (km) }\end{array}$ & $\begin{array}{c}\text { Resist. } \\
\text { falta } \\
\text { (ohms) }\end{array}$ & $\begin{array}{c}\text { Ângulo de } \\
\text { Incidência } \\
\text { (graus) }\end{array}$ & $\begin{array}{c}\text { Tipo de } \\
\text { Falta }\end{array}$ & $\begin{array}{c}\text { Pré- } \\
\text { Localização } \\
(1 / 2 \text { - seção) }\end{array}$ & $\begin{array}{c}\text { Distância } \\
\text { Estimada } \\
\text { (km) }\end{array}$ & $\begin{array}{l}\text { Erro } \\
\text { Abs. } \\
\text { (km) }\end{array}$ & $\begin{array}{l}\text { Erro } \\
(\%)\end{array}$ \\
\hline 10 & 0 & 0 & CT & 1 & 8,06 & 1,94 & 1,29 \\
\hline 10 & 50 & 0 & CT & 1 & 13,44 & 3,44 & 2,29 \\
\hline 10 & 100 & 0 & CT & 1 & 8,06 & 1,94 & 1,29 \\
\hline 25 & 0 & 0 & CT & 1 & 29,56 & 4,56 & 3,04 \\
\hline 25 & 50 & 0 & CT & 1 & 32,25 & 7,25 & 4,83 \\
\hline 25 & 100 & 0 & CT & 1 & 37,63 & 12,6 & 8,42 \\
\hline 40 & 0 & 0 & CT & 1 & 37,63 & 2,37 & 1,58 \\
\hline 40 & 50 & 0 & CT & 1 & 37,63 & 2,37 & 1,58 \\
\hline 40 & 100 & 0 & CT & 2 & 109,69 & 69,7 & 46,46 \\
\hline 55 & 0 & 0 & $\mathrm{CT}$ & 1 & 56,43 & 1,43 & 0,95 \\
\hline 55 & 50 & 0 & $\mathrm{CT}$ & 1 & 56,43 & 1,43 & 0,95 \\
\hline 55 & 100 & 0 & $\mathrm{CT}$ & 1 & 56,43 & 1,43 & 0,95 \\
\hline 70 & 0 & 0 & $\mathrm{CT}$ & 1 & 69,86 & 0,14 & 0,09 \\
\hline 70 & 50 & 0 & CT & 1 & 79,27 & 9,27 & 6,18 \\
\hline 70 & 100 & 0 & $\mathrm{CT}$ & 1 & 80,62 & 10,6 & 7,08 \\
\hline 75 & 0 & 0 & CT & 1 & 96,74 & 21,7 & 14,49 \\
\hline 75 & 50 & 0 & CT & 1 & 72,56 & 2,44 & 1,63 \\
\hline 75 & 100 & 0 & CT & 1 & 75,24 & 0,24 & 0,16 \\
\hline 80 & 0 & 0 & $\mathrm{CT}$ & 1 & 67,18 & 12,8 & 8,55 \\
\hline 80 & 50 & 0 & CT & 1 & 77,92 & 2,08 & 1,39 \\
\hline 80 & 100 & 0 & $\mathrm{CT}$ & 1 & 67,18 & 12,8 & 8,55 \\
\hline 95 & 0 & 0 & CT & 2 & 96,25 & 1,25 & 0,83 \\
\hline 95 & 50 & 0 & CT & 2 & 96,25 & 1,25 & 0,83 \\
\hline 95 & 100 & 0 & CT & 2 & 96,25 & 1,25 & 0,83 \\
\hline 110 & 0 & 0 & CT & 2 & 112,37 & 2,37 & 1,58 \\
\hline 110 & 50 & 0 & CT & 2 & 112,37 & 2,37 & 1,58 \\
\hline 110 & 100 & 0 & $\mathrm{CT}$ & 2 & 109,69 & 0,31 & 0,21 \\
\hline 125 & 0 & 0 & $\mathrm{CT}$ & 2 & 123,13 & 1,87 & 1,25 \\
\hline 125 & 50 & 0 & $\mathrm{CT}$ & 2 & 123,13 & 1,87 & 1,25 \\
\hline 125 & 100 & 0 & $\mathrm{CT}$ & 2 & 123,13 & 1,87 & 1,25 \\
\hline 140 & 0 & 0 & $\mathrm{CT}$ & 2 & 139,26 & 0,74 & 0,49 \\
\hline 140 & 50 & 0 & $\mathrm{CT}$ & 2 & 139,26 & 0,74 & 0,49 \\
\hline 140 & 100 & 0 & CT & 2 & 139,26 & 0,74 & 0,49 \\
\hline \multicolumn{7}{|c|}{ Erro médio (\%) } & 4,03 \\
\hline
\end{tabular}


TABELA 77 - Resultados para faltas fase-terra (BT) com ângulo de incidência de $90^{\circ}$ e resistência de falta de 0, 50 e $100 \mathrm{ohms}$.

\begin{tabular}{|c|c|c|c|c|c|c|c|}
\hline $\begin{array}{c}\text { Distância } \\
\text { Real } \\
\text { (km) }\end{array}$ & $\begin{array}{c}\text { Resist. } \\
\text { falta } \\
\text { (ohms) }\end{array}$ & $\begin{array}{c}\text { Ângulo de } \\
\text { Incidência } \\
\text { (graus) }\end{array}$ & $\begin{array}{c}\text { Tipo de } \\
\text { Falta }\end{array}$ & $\begin{array}{c}\text { Pré- } \\
\text { Localização } \\
(1 / 2 \text { - seção) }\end{array}$ & $\begin{array}{c}\text { Distância } \\
\text { Estimada } \\
\text { (km) }\end{array}$ & $\begin{array}{l}\text { Erro } \\
\text { Abs. } \\
\text { (km) }\end{array}$ & $\begin{array}{l}\text { Erro } \\
(\%)\end{array}$ \\
\hline 10 & 0 & 90 & BT & 1 & 8,06 & 1,94 & 1,29 \\
\hline 10 & 50 & 90 & BT & 1 & 8,06 & 1,94 & 1,29 \\
\hline 10 & 100 & 90 & BT & 1 & 8,06 & 1,94 & 1,29 \\
\hline 25 & 0 & 90 & BT & 1 & 37,63 & 12,6 & 8,42 \\
\hline 25 & 50 & 90 & BT & 1 & 123,63 & 98,6 & 65,75 \\
\hline 25 & 100 & 90 & BT & 1 & 123,63 & 98,6 & 65,75 \\
\hline 40 & 0 & 90 & BT & 1 & 40,31 & 0,31 & 0,21 \\
\hline 40 & 50 & 90 & BT & 1 & 40,31 & 0,31 & 0,21 \\
\hline 40 & 100 & 90 & BT & 1 & 40,31 & 0,31 & 0,21 \\
\hline 55 & 0 & 90 & $\mathrm{BT}$ & 1 & 56,43 & 1,43 & 0,95 \\
\hline 55 & 50 & 90 & $\mathrm{BT}$ & 1 & 56,43 & 1,43 & 0,95 \\
\hline 55 & 100 & 90 & $\mathrm{BT}$ & 1 & 53,75 & 1,25 & 0,83 \\
\hline 70 & 0 & 90 & $\mathrm{BT}$ & 1 & 69,88 & 0,12 & 0,08 \\
\hline 70 & 50 & 90 & $\mathrm{BT}$ & 1 & 69,88 & 0,12 & 0,08 \\
\hline 70 & 100 & 90 & $\mathrm{BT}$ & 1 & 69,88 & 0,12 & 0,08 \\
\hline 75 & 0 & 90 & $\mathrm{BT}$ & 2 & 50,56 & 24,4 & 16,29 \\
\hline 75 & 50 & 90 & BT & 2 & 50,56 & 24,4 & 16,29 \\
\hline 75 & 100 & 90 & BT & 2 & 50,56 & 24,4 & 16,29 \\
\hline 80 & 0 & 90 & $\mathrm{BT}$ & 2 & 74,76 & 5,24 & 3,49 \\
\hline 80 & 50 & 90 & BT & 2 & 74,76 & 5,24 & 3,49 \\
\hline 80 & 100 & 90 & $\mathrm{BT}$ & 2 & 74,76 & 5,24 & 3,49 \\
\hline 95 & 0 & 90 & BT & 2 & 96,26 & 1,26 & 0,84 \\
\hline 95 & 50 & 90 & BT & 2 & 96,26 & 1,26 & 0,84 \\
\hline 95 & 100 & 90 & BT & 2 & 96,26 & 1,26 & 0,84 \\
\hline 110 & 0 & 90 & BT & 2 & 109,69 & 0,31 & 0,21 \\
\hline 110 & 50 & 90 & $\mathrm{BT}$ & 2 & 109,69 & 0,31 & 0,21 \\
\hline 110 & 100 & 90 & $\mathrm{BT}$ & 2 & 109,69 & 0,31 & 0,21 \\
\hline 125 & 0 & 90 & $\mathrm{BT}$ & 2 & 125,81 & 0,81 & 0,54 \\
\hline 125 & 50 & 90 & $\mathrm{BT}$ & 2 & 125,81 & 0,81 & 0,54 \\
\hline 125 & 100 & 90 & $\mathrm{BT}$ & 2 & 125,81 & 0,81 & 0,54 \\
\hline 140 & 0 & 90 & BT & 2 & 139,24 & 0,76 & 0,51 \\
\hline 140 & 50 & 90 & $\mathrm{BT}$ & 2 & 139,24 & 0,76 & 0,51 \\
\hline 140 & 100 & 90 & BT & 2 & 139,24 & 0,76 & 0,51 \\
\hline \multicolumn{7}{|c|}{ Erro médio (\%) } & 6,46 \\
\hline
\end{tabular}


TABELA 78 - Resultados para faltas fase-terra (AT) com ângulo de incidência de $90^{\circ}$ e resistência de falta de 200 e 400 ohms.

\begin{tabular}{|c|c|c|c|c|c|c|c|}
\hline $\begin{array}{c}\text { Distância } \\
\text { Real } \\
\text { (km) }\end{array}$ & $\begin{array}{l}\text { Resist. } \\
\text { falta } \\
\text { (ohms) }\end{array}$ & $\begin{array}{c}\text { Ângulo de } \\
\text { Incidência } \\
\text { (graus) }\end{array}$ & $\begin{array}{c}\text { Tipo de } \\
\text { Falta }\end{array}$ & $\begin{array}{c}\text { Pré- } \\
\text { Localização } \\
\text { (1/2 - metade) }\end{array}$ & $\begin{array}{l}\text { Distância } \\
\text { Estimada } \\
(\mathbf{k m})\end{array}$ & $\begin{array}{l}\text { Erro } \\
\text { Abs. } \\
\text { (km) }\end{array}$ & $\begin{array}{l}\text { Erro } \\
(\%)\end{array}$ \\
\hline 10 & 200 & 90 & AT & 1 & 16,12 & 6,12 & 4,08 \\
\hline 10 & 400 & 90 & AT & 1 & 8,06 & 1,94 & 1,29 \\
\hline 25 & 200 & 90 & AT & 1 & 37,62 & 12,62 & 8,41 \\
\hline 25 & 400 & 90 & AT & 1 & 123,61 & 98,61 & 65,74 \\
\hline 40 & 200 & 90 & AT & 1 & 40,31 & 0,31 & 0,21 \\
\hline 40 & 400 & 90 & AT & 1 & 40,31 & 0,31 & 0,21 \\
\hline 55 & 200 & 90 & AT & 1 & 53,75 & 1,25 & 0,83 \\
\hline 55 & 400 & 90 & AT & 1 & 56,43 & 1,43 & 0,95 \\
\hline 70 & 200 & 90 & AT & 1 & 69,86 & 0,14 & 0,09 \\
\hline 70 & 400 & 90 & AT & 1 & 80,62 & 10,62 & 7,08 \\
\hline 75 & 200 & 90 & AT & 2 & 70,72 & 4,28 & 2,85 \\
\hline 75 & 400 & 90 & AT & 2 & 70,72 & 4,28 & 2,85 \\
\hline 80 & 200 & 90 & AT & 2 & 80,12 & 0,12 & 0,08 \\
\hline 80 & 400 & 90 & AT & 2 & 80,12 & 0,12 & 0,08 \\
\hline 95 & 200 & 90 & AT & 2 & 96,24 & 1,24 & 0,83 \\
\hline 95 & 400 & 90 & AT & 2 & 96,24 & 1,24 & 0,83 \\
\hline 110 & 200 & 90 & AT & 2 & 112,37 & 2,37 & 1,58 \\
\hline 110 & 400 & 90 & AT & 2 & 112,37 & 2,37 & 1,58 \\
\hline 125 & 200 & 90 & AT & 2 & 125,81 & 0,81 & 0,54 \\
\hline 125 & 400 & 90 & AT & 2 & 128,81 & 3,81 & 2,54 \\
\hline 140 & 200 & 90 & AT & 2 & 133,88 & 6,12 & 4,08 \\
\hline 140 & 400 & 90 & AT & 2 & 133,88 & 6,12 & 4,08 \\
\hline \multicolumn{7}{|c|}{ Erro médio (\%) } & 5,04 \\
\hline
\end{tabular}


TABELA 79 - Resultados para faltas fase-fase-terra (ABT) com ângulo de incidência de $0^{\circ}$ e resistência de falta de 0, 50 e $100 \mathrm{ohms}$.

\begin{tabular}{|c|c|c|c|c|c|c|}
\hline $\begin{array}{c}\text { Distância } \\
\text { Real } \\
\text { (km) }\end{array}$ & $\begin{array}{c}\text { Resist. } \\
\text { falta } \\
\text { (ohms) }\end{array}$ & $\begin{array}{c}\text { Ângulo de } \\
\text { Incidência } \\
\text { (graus) }\end{array}$ & $\begin{array}{c}\text { Tipo de } \\
\text { Falta }\end{array}$ & $\begin{array}{l}\text { Distância } \\
\text { Estimada } \\
\quad(\mathbf{k m})\end{array}$ & $\begin{array}{l}\text { Erro } \\
\text { Abs. } \\
(\mathbf{k m})\end{array}$ & $\begin{array}{r}\text { Erro } \\
(\%)\end{array}$ \\
\hline 10 & 0 & 0 & ABT & 10,74 & 0,74 & 0,49 \\
\hline 10 & 50 & 0 & ABT & 10,74 & 0,74 & 0,49 \\
\hline 10 & 100 & 0 & ABT & 10,74 & 0,74 & 0,49 \\
\hline 25 & 0 & 0 & ABT & 24,19 & 0,81 & 0,54 \\
\hline 25 & 50 & 0 & ABT & 24,19 & 0,81 & 0,54 \\
\hline 25 & 100 & 0 & ABT & 24,19 & 0,81 & 0,54 \\
\hline 40 & 0 & 0 & ABT & 40,3 & 0,30 & 0,20 \\
\hline 40 & 50 & 0 & ABT & 40,3 & 0,30 & 0,20 \\
\hline 40 & 100 & 0 & ABT & 40,3 & 0,30 & 0,20 \\
\hline 55 & 0 & 0 & ABT & 56,41 & 1,41 & 0,94 \\
\hline 55 & 50 & 0 & $\mathrm{ABT}$ & 56,41 & 1,41 & 0,94 \\
\hline 55 & 100 & 0 & ABT & 56,41 & 1,41 & 0,94 \\
\hline 70 & 0 & 0 & ABT & 67,15 & 2,85 & 1,90 \\
\hline 70 & 50 & 0 & ABT & 67,15 & 2,85 & 1,90 \\
\hline 70 & 100 & 0 & ABT & 67,15 & 2,85 & 1,90 \\
\hline 75 & 0 & 0 & ABT & 75,21 & 0,21 & 0,14 \\
\hline 75 & 50 & 0 & ABT & 75,21 & 0,21 & 0,14 \\
\hline 75 & 100 & 0 & ABT & 75,21 & 0,21 & 0,14 \\
\hline 80 & 0 & 0 & ABT & 69,85 & 10,15 & 6,77 \\
\hline 80 & 50 & 0 & ABT & 80,59 & 0,59 & 0,39 \\
\hline 80 & 100 & 0 & ABT & 80,59 & 0,59 & 0,39 \\
\hline 95 & 0 & 0 & ABT & 94,02 & 0,98 & 0,65 \\
\hline 95 & 50 & 0 & ABT & 94,02 & 0,98 & 0,65 \\
\hline 95 & 100 & 0 & $\mathrm{ABT}$ & 94,02 & 0,98 & 0,65 \\
\hline 110 & 0 & 0 & $\mathrm{ABT}$ & 40,3 & 69,70 & 46,47 \\
\hline 110 & 50 & 0 & $\mathrm{ABT}$ & 110,14 & 0,14 & 0,09 \\
\hline 110 & 100 & 0 & ABT & 110,14 & 0,14 & 0,09 \\
\hline 125 & 0 & 0 & $\mathrm{ABT}$ & 126,25 & 1,25 & 0,83 \\
\hline 125 & 50 & 0 & ABT & 13,43 & 111,57 & 74,38 \\
\hline 125 & 100 & 0 & ABT & 126,25 & 1,25 & 0,83 \\
\hline 140 & 0 & 0 & ABT & 24,17 & 115,83 & 77,22 \\
\hline 140 & 50 & 0 & ABT & 142,38 & 2,38 & 1,59 \\
\hline 140 & 100 & 0 & ABT & 142,38 & 2,38 & 1,59 \\
\hline \multicolumn{6}{|c|}{ Erro médio (\%) } & 6,83 \\
\hline
\end{tabular}


TABELA 80 - Resultados para faltas fase-fase-terra (ABT) com ângulo de incidência de $90^{\circ}$ e resistência de falta de 0, 50 e $100 \mathrm{ohms}$.

\begin{tabular}{|c|c|c|c|c|c|c|}
\hline $\begin{array}{c}\text { Distância } \\
\text { Real } \\
\text { (km) }\end{array}$ & $\begin{array}{l}\text { Resist. } \\
\text { falta } \\
\text { (ohms) }\end{array}$ & $\begin{array}{c}\text { Ângulo de } \\
\text { Incidência } \\
\text { (graus) }\end{array}$ & $\begin{array}{c}\text { Tipo de } \\
\text { Falta }\end{array}$ & $\begin{array}{c}\text { Distância } \\
\text { Estimada } \\
\text { (km) }\end{array}$ & $\begin{array}{l}\text { Erro } \\
\text { Abs. } \\
\text { (km) }\end{array}$ & $\begin{array}{l}\text { Erro } \\
(\%)\end{array}$ \\
\hline 10 & 0 & 90 & $\mathrm{ABT}$ & 10,74 & 0,74 & 0,49 \\
\hline 10 & 50 & 90 & ABT & 10,74 & 0,74 & 0,49 \\
\hline 10 & 100 & 90 & ABT & 10,74 & 0,74 & 0,49 \\
\hline 25 & 0 & 90 & ABT & 24,19 & 0,81 & 0,54 \\
\hline 25 & 50 & 90 & $\mathrm{ABT}$ & 24,19 & 0,81 & 0,54 \\
\hline 25 & 100 & 90 & ABT & 24,19 & 0,81 & 0,54 \\
\hline 40 & 0 & 90 & ABT & 40,3 & 0,30 & 0,20 \\
\hline 40 & 50 & 90 & ABT & 40,3 & 0,30 & 0,20 \\
\hline 40 & 100 & 90 & ABT & 40,3 & 0,30 & 0,20 \\
\hline 55 & 0 & 90 & ABT & 53,72 & 1,28 & 0,85 \\
\hline 55 & 50 & 90 & ABT & 53,72 & 1,28 & 0,85 \\
\hline 55 & 100 & 90 & ABT & 53,72 & 1,28 & 0,85 \\
\hline 70 & 0 & 90 & ABT & 69,85 & 0,15 & 0,10 \\
\hline 70 & 50 & 90 & ABT & 69,85 & 0,15 & 0,10 \\
\hline 70 & 100 & 90 & ABT & 69,85 & 0,15 & 0,10 \\
\hline 75 & 0 & 90 & ABT & 75,21 & 0,21 & 0,14 \\
\hline 75 & 50 & 90 & ABT & 75,21 & 0,21 & 0,14 \\
\hline 75 & 100 & 90 & ABT & 75,21 & 0,21 & 0,14 \\
\hline 80 & 0 & 90 & ABT & 85,96 & 5,96 & 3,97 \\
\hline 80 & 50 & 90 & ABT & 85,96 & 5,96 & 3,97 \\
\hline 80 & 100 & 90 & ABT & 85,96 & 5,96 & 3,97 \\
\hline 95 & 0 & 90 & ABT & 96,7 & 1,70 & 1,13 \\
\hline 95 & 50 & 90 & ABT & 96,7 & 1,70 & 1,13 \\
\hline 95 & 100 & 90 & ABT & 96,7 & 1,70 & 1,13 \\
\hline 110 & 0 & 90 & ABT & 108,79 & 1,21 & 0,81 \\
\hline 110 & 50 & 90 & ABT & 108,79 & 1,21 & 0,81 \\
\hline 110 & 100 & 90 & ABT & 108,79 & 1,21 & 0,81 \\
\hline 125 & 0 & 90 & ABT & 123,57 & 1,43 & 0,95 \\
\hline 125 & 50 & 90 & ABT & 123,57 & 1,43 & 0,95 \\
\hline 125 & 100 & 90 & ABT & 123,57 & 1,43 & 0,95 \\
\hline 140 & 0 & 90 & $\mathrm{ABT}$ & 139,69 & 0,31 & 0,21 \\
\hline 140 & 50 & 90 & ABT & 139,69 & 0,31 & 0,21 \\
\hline 140 & 100 & 90 & ABT & 139,69 & 0,31 & 0,21 \\
\hline \multicolumn{6}{|c|}{ Erro médio (\%) } & $\mathbf{0 , 8 5}$ \\
\hline
\end{tabular}


TABELA 81 - Resultados para faltas fase-fase-terra (ACT) com ângulo de incidência de $90^{\circ}$ e resistência de falta de 0, 50 e $100 \mathrm{ohms}$.

\begin{tabular}{|c|c|c|c|c|c|c|}
\hline $\begin{array}{c}\text { Distância } \\
\text { Real } \\
\text { (km) }\end{array}$ & $\begin{array}{c}\text { Resist. } \\
\text { falta } \\
(\text { ohms })\end{array}$ & $\begin{array}{c}\text { Ângulo de } \\
\text { Incidência } \\
\text { (graus) }\end{array}$ & $\begin{array}{c}\text { Tipo de } \\
\text { Falta }\end{array}$ & $\begin{array}{c}\text { Distância } \\
\text { Estimada } \\
\text { (km) }\end{array}$ & $\begin{array}{l}\text { Erro } \\
\text { Abs. } \\
\text { (km) }\end{array}$ & $\begin{array}{l}\text { Erro } \\
(\%)\end{array}$ \\
\hline 10 & 0 & 90 & $\mathrm{ACT}$ & 8,06 & 1,94 & 1,29 \\
\hline 10 & 50 & 90 & ACT & 8,06 & 1,94 & 1,29 \\
\hline 10 & 100 & 90 & ACT & 8,06 & 1,94 & 1,29 \\
\hline 25 & 0 & 90 & ACT & 24,12 & 0,88 & 0,59 \\
\hline 25 & 50 & 90 & ACT & 24,12 & 0,88 & 0,59 \\
\hline 25 & 100 & 90 & ACT & 24,12 & 0,88 & 0,59 \\
\hline 40 & 0 & 90 & ACT & 40,31 & 0,31 & 0,21 \\
\hline 40 & 50 & 90 & ACT & 40,31 & 0,31 & 0,21 \\
\hline 40 & 100 & 90 & ACT & 40,31 & 0,31 & 0,21 \\
\hline 55 & 0 & 90 & ACT & 56,43 & 1,43 & 0,95 \\
\hline 55 & 50 & 90 & ACT & 56,43 & 1,43 & 0,95 \\
\hline 55 & 100 & 90 & ACT & 56,43 & 1,43 & 0,95 \\
\hline 70 & 0 & 90 & ACT & 69,86 & 0,14 & 0,09 \\
\hline 70 & 50 & 90 & ACT & 69,86 & 0,14 & 0,09 \\
\hline 70 & 100 & 90 & ACT & 69,86 & 0,14 & 0,09 \\
\hline 75 & 0 & 90 & ACT & 80,62 & 5,62 & 3,75 \\
\hline 75 & 50 & 90 & ACT & 80,62 & 5,62 & 3,75 \\
\hline 75 & 100 & 90 & ACT & 80,62 & 5,62 & 3,75 \\
\hline 80 & 0 & 90 & $\mathrm{ACT}$ & 80,62 & 0,62 & 0,41 \\
\hline 80 & 50 & 90 & ACT & 80,62 & 0,62 & 0,41 \\
\hline 80 & 100 & 90 & ACT & 80,62 & 0,62 & 0,41 \\
\hline 95 & 0 & 90 & ACT & 94,06 & 0,94 & 0,63 \\
\hline 95 & 50 & 90 & ACT & 94,06 & 0,94 & 0,63 \\
\hline 95 & 100 & 90 & ACT & 94,06 & 0,94 & 0,63 \\
\hline 110 & 0 & 90 & ACT & 110,19 & 0,19 & 0,13 \\
\hline 110 & 50 & 90 & $\mathrm{ACT}$ & 110,19 & 0,19 & 0,13 \\
\hline 110 & 100 & 90 & $\mathrm{ACT}$ & 110,19 & 0,19 & 0,13 \\
\hline 125 & 0 & 90 & ACT & 123,63 & 1,37 & 0,91 \\
\hline 125 & 50 & 90 & $\mathrm{ACT}$ & 123,63 & 1,37 & 0,91 \\
\hline 125 & 100 & 90 & $\mathrm{ACT}$ & 123,63 & 1,37 & 0,91 \\
\hline 140 & 0 & 90 & ACT & 139,74 & 0,26 & 0,17 \\
\hline 140 & 50 & 90 & ACT & 139,74 & 0,26 & 0,17 \\
\hline 140 & 100 & 90 & $\mathrm{ACT}$ & 139,74 & 0,26 & 0,17 \\
\hline \multicolumn{6}{|c|}{ Erro médio (\%) } & $\mathbf{0 , 8 3}$ \\
\hline
\end{tabular}


TABELA 82 - Resultados para faltas fase-fase-terra (BCT) com ângulo de incidência de $0^{\circ}$ e resistência de falta de 0, 50 e $100 \mathrm{ohms}$.

\begin{tabular}{ccccccc}
\hline $\begin{array}{c}\text { Distância } \\
\text { Real } \\
\mathbf{( k m )}\end{array}$ & $\begin{array}{c}\text { Resist. } \\
\text { falta } \\
\text { (ohms) }\end{array}$ & $\begin{array}{c}\text { Angulo de } \\
\text { Incidência } \\
\text { (graus) }\end{array}$ & $\begin{array}{c}\text { Tipo de } \\
\text { Falta }\end{array}$ & $\begin{array}{c}\text { Distância } \\
\text { Estimada }\end{array}$ & $\begin{array}{c}\text { Erro } \\
\text { Abs. }\end{array}$ & Erro \\
(km) & $\mathbf{( \% )}$ \\
\hline 10 & 0 & 0 & BCT & 10,76 & 0,76 & 0,51 \\
\hline 10 & 50 & 0 & BCT & 10,76 & 0,76 & 0,51 \\
\hline 10 & 100 & 0 & BCT & 10,76 & 0,76 & 0,51 \\
\hline 25 & 0 & 0 & BCT & 26,88 & 1,88 & 1,25 \\
\hline 25 & 50 & 0 & BCT & 26,88 & 1,88 & 1,25 \\
\hline 25 & 100 & 0 & BCT & 26,88 & 1,88 & 1,25 \\
\hline 40 & 0 & 0 & BCT & 37,61 & 2,39 & 1,59 \\
\hline 40 & 50 & 0 & BCT & 37,61 & 2,39 & 1,59 \\
\hline 40 & 100 & 0 & BCT & 37,61 & 2,39 & 1,59 \\
\hline 55 & 0 & 0 & BCT & 53,75 & 1,25 & 0,83 \\
\hline 55 & 50 & 0 & BCT & 53,75 & 1,25 & 0,83 \\
\hline 55 & 100 & 0 & BCT & 53,75 & 1,25 & 0,83 \\
\hline 70 & 0 & 0 & BCT & 69,88 & 0,12 & 0,08 \\
\hline 70 & 50 & 0 & BCT & 69,88 & 0,12 & 0,08 \\
\hline 70 & 100 & 0 & BCT & 69,88 & 0,12 & 0,08 \\
\hline 75 & 0 & 0 & BCT & 72,56 & 2,44 & 1,63 \\
\hline 75 & 50 & 0 & BCT & 72,56 & 2,44 & 1,63 \\
\hline 75 & 100 & 0 & BCT & 72,56 & 2,44 & 1,63 \\
\hline 80 & 0 & 0 & BCT & 77,94 & 2,06 & 1,37 \\
\hline 80 & 50 & 0 & BCT & 77,94 & 2,06 & 1,37 \\
\hline 80 & 100 & 0 & BCT & 77,94 & 2,06 & 1,37 \\
\hline 95 & 0 & 0 & BCT & 96,74 & 1,74 & 1,16 \\
\hline 95 & 50 & 0 & BCT & 96,74 & 1,74 & 1,16 \\
\hline 95 & 100 & 0 & BCT & 96,74 & 1,74 & 1,16 \\
\hline 110 & 0 & 0 & BCT & 107,49 & 2,51 & 1,67 \\
\hline 110 & 50 & 0 & BCT & 107,49 & 2,51 & 1,67 \\
\hline 110 & 100 & 0 & BCT & 107,49 & 2,51 & 1,67 \\
\hline 125 & 0 & 0 & BCT & 123,61 & 1,39 & 0,93 \\
\hline 125 & 50 & 0 & BCT & 123,61 & 1,39 & 0,93 \\
\hline 125 & 100 & 0 & BCT & 123,61 & 1,39 & 0,93 \\
\hline 140 & 0 & 0 & BCT & 139,74 & 0,26 & 0,17 \\
\hline 140 & 50 & 0 & BCT & 139,74 & 0,26 & 0,17 \\
\hline 140 & 100 & 0 & BCT & 139,74 & 0,26 & 0,17 \\
\hline & & Erro médio (\%) & & & & $\mathbf{1 , 0 2}$ \\
\hline & & & & & & \\
\hline & 0 & 0 & & & &
\end{tabular}


TABELA 83 - Resultados para faltas fase-fase-terra (BCT) com ângulo de incidência de $90^{\circ}$ e resistência de falta de 0 , 50 e 100 ohms.

\begin{tabular}{ccccccc}
\hline $\begin{array}{c}\text { Distância } \\
\text { Real } \\
\text { (km) }\end{array}$ & $\begin{array}{c}\text { Resist. } \\
\text { falta } \\
\text { (ohms) }\end{array}$ & $\begin{array}{c}\text { Angulo de } \\
\text { Incidência } \\
\text { (graus) }\end{array}$ & $\begin{array}{c}\text { Tipo de } \\
\text { Falta }\end{array}$ & $\begin{array}{c}\text { Distância } \\
\text { Estimada } \\
\text { (km) }\end{array}$ & $\begin{array}{c}\text { Erro } \\
\text { Abs. } \\
\text { (km) }\end{array}$ & Erro \\
\hline 10 & 0 & 90 & BCT & 8,06 & 1,94 & 1,29 \\
\hline 10 & 50 & 90 & BCT & 8,09 & 1,91 & 1,27 \\
\hline 10 & 100 & 90 & BCT & 8,06 & 1,94 & 1,29 \\
\hline 25 & 0 & 90 & BCT & 26,88 & 1,88 & 1,25 \\
\hline 25 & 50 & 90 & BCT & 26,88 & 1,88 & 1,25 \\
\hline 25 & 100 & 90 & BCT & 26,88 & 1,88 & 1,25 \\
\hline 40 & 0 & 90 & BCT & 40,31 & 0,31 & 0,21 \\
\hline 40 & 50 & 90 & BCT & 40,31 & 0,31 & 0,21 \\
\hline 40 & 100 & 90 & BCT & 40,31 & 0,31 & 0,21 \\
\hline 55 & 0 & 90 & BCT & 53,75 & 1,25 & 0,83 \\
\hline 55 & 50 & 90 & BCT & 53,75 & 1,25 & 0,83 \\
\hline 55 & 100 & 90 & BCT & 53,75 & 1,25 & 0,83 \\
\hline 70 & 0 & 90 & BCT & 69,88 & 0,12 & 0,08 \\
\hline 70 & 50 & 90 & BCT & 69,88 & 0,12 & 0,08 \\
\hline 70 & 100 & 90 & BCT & 69,88 & 0,12 & 0,08 \\
\hline 75 & 0 & 90 & BCT & 75,24 & 0,24 & 0,16 \\
\hline 75 & 50 & 90 & BCT & 75,24 & 0,24 & 0,16 \\
\hline 75 & 100 & 90 & BCT & 75,24 & 0,24 & 0,16 \\
\hline 80 & 0 & 90 & BCT & 77,94 & 2,06 & 1,37 \\
\hline 80 & 50 & 90 & BCT & 77,94 & 2,06 & 1,37 \\
\hline 80 & 100 & 90 & BCT & 77,94 & 2,06 & 1,37 \\
\hline 95 & 0 & 90 & BCT & 96,74 & 1,74 & 1,16 \\
\hline 95 & 50 & 90 & BCT & 96,74 & 1,74 & 1,16 \\
\hline 95 & 100 & 90 & BCT & 96,74 & 1,74 & 1,16 \\
\hline 110 & 0 & 90 & BCT & 115,55 & 5,55 & 3,70 \\
\hline 110 & 50 & 90 & BCT & 115,55 & 5,55 & 3,70 \\
\hline 110 & 100 & 90 & BCT & 115,55 & 5,55 & 3,70 \\
\hline 125 & 0 & 90 & BCT & 120,93 & 4,07 & 2,71 \\
\hline 125 & 50 & 90 & BCT & 120,93 & 4,07 & 2,71 \\
\hline 125 & 100 & 90 & BCT & 120,93 & 4,07 & 2,71 \\
\hline 140 & 0 & 90 & BCT & 139,74 & 0,26 & 0,17 \\
\hline 140 & 50 & 90 & BCT & 139,74 & 0,26 & 0,17 \\
\hline 140 & 100 & 90 & BCT & 139,74 & 0,26 & 0,17 \\
\hline & & Erro médio (\%) & & & & $\mathbf{1 , 1 8}$ \\
\hline & & & & & & \\
\hline & & & & & &
\end{tabular}


TABELA 84 - Resultados para faltas fase-fase (AC) com ângulo de incidência de $0^{\circ}$.

\begin{tabular}{cccccc}
\hline $\begin{array}{c}\text { Distância } \\
\text { Real } \\
(\mathbf{k m})\end{array}$ & $\begin{array}{c}\text { Âng. de } \\
\text { Incid. } \\
\text { (graus) }\end{array}$ & $\begin{array}{c}\text { Tipo de } \\
\text { Falta }\end{array}$ & $\begin{array}{c}\text { Distância } \\
\text { Estimada } \\
\text { (km) }\end{array}$ & $\begin{array}{c}\text { Erro } \\
\text { Abs. } \\
\text { (km) }\end{array}$ & $\begin{array}{c}\text { Erro } \\
(\mathbf{\%})\end{array}$ \\
\hline 10 & 0 & $\mathrm{AC}$ & 9,4 & 0,60 & 0,40 \\
\hline 25 & 0 & $\mathrm{AC}$ & 29,55 & 4,55 & 3,03 \\
\hline 40 & 0 & $\mathrm{AC}$ & 37,61 & 2,39 & 1,59 \\
\hline 55 & 0 & $\mathrm{AC}$ & 56,43 & 1,43 & 0,95 \\
\hline 70 & 0 & $\mathrm{AC}$ & 69,88 & 0,12 & 0,08 \\
\hline 75 & 0 & $\mathrm{AC}$ & 72,56 & 2,44 & 1,63 \\
\hline 80 & 0 & $\mathrm{AC}$ & 77,94 & 2,06 & 1,37 \\
\hline 95 & 0 & $\mathrm{AC}$ & 99,43 & 4,43 & 2,95 \\
\hline 110 & 0 & $\mathrm{AC}$ & 110,19 & 0,19 & 0,13 \\
\hline 125 & 0 & $\mathrm{AC}$ & 126,3 & 1,30 & 0,87 \\
\hline 140 & 0 & $\mathrm{AC}$ & 139,74 & 0,26 & 0,17 \\
\hline \multicolumn{7}{c}{ Erro médio (\%) } & & & $\mathbf{1 , 2 0}$ \\
\hline
\end{tabular}

TABELA 86 - Resultados para faltas fase-fase (BC) com ângulo de incidência de $0^{\circ}$.

\begin{tabular}{|c|c|c|c|c|c|}
\hline $\begin{array}{c}\text { Distância } \\
\text { Real } \\
\text { (km) }\end{array}$ & $\begin{array}{l}\text { Âng. de } \\
\text { Incid. } \\
\text { (graus) }\end{array}$ & $\begin{array}{c}\text { Tipo de } \\
\text { Falta }\end{array}$ & $\begin{array}{c}\text { Distância } \\
\text { Estimada } \\
(\mathbf{k m})\end{array}$ & $\begin{array}{l}\text { Erro } \\
\text { Abs. } \\
\text { (km) }\end{array}$ & $\begin{array}{c}\text { Erro } \\
(\%)\end{array}$ \\
\hline 10 & 0 & $\mathrm{BC}$ & 10,76 & 0,76 & 0,51 \\
\hline 25 & 0 & $\mathrm{BC}$ & 26,88 & 1,88 & 1,25 \\
\hline 40 & 0 & $\mathrm{BC}$ & 37,61 & 2,39 & 1,59 \\
\hline 55 & 0 & $\mathrm{BC}$ & 53,75 & 1,25 & 0,83 \\
\hline 70 & 0 & $\mathrm{BC}$ & 69,88 & 0,12 & 0,08 \\
\hline 75 & 0 & $\mathrm{BC}$ & 72,56 & 2,44 & 1,63 \\
\hline 80 & 0 & $\mathrm{BC}$ & 77,94 & 2,06 & 1,37 \\
\hline 95 & 0 & $\mathrm{BC}$ & 96,74 & 1,74 & 1,16 \\
\hline 110 & 0 & $\mathrm{BC}$ & 107,49 & 2,51 & 1,67 \\
\hline 125 & 0 & $\mathrm{BC}$ & 123,61 & 1,39 & 0,93 \\
\hline 140 & 0 & $\mathrm{BC}$ & 139,74 & 0,26 & 0,17 \\
\hline
\end{tabular}

TABELA 85 - Resultados para faltas fase-fase (AC) com ângulo de incidência de $90^{\circ}$.

\begin{tabular}{cccccc}
\hline $\begin{array}{c}\text { Distância } \\
\text { Real } \\
(\mathbf{k m})\end{array}$ & $\begin{array}{c}\text { Âng. de } \\
\text { Incid. } \\
\text { (graus) }\end{array}$ & $\begin{array}{c}\text { Tipo de } \\
\text { Falta }\end{array}$ & $\begin{array}{c}\text { Distância } \\
\text { Estimada } \\
\text { (km) }\end{array}$ & $\begin{array}{c}\text { Erro } \\
\text { Abs. } \\
(\mathbf{k m})\end{array}$ & $\begin{array}{c}\text { Erro } \\
(\mathbf{\%})\end{array}$ \\
\hline 10 & 90 & $\mathrm{AC}$ & 8,06 & 1,94 & 1,29 \\
\hline 25 & 90 & $\mathrm{AC}$ & 24,19 & 0,81 & 0,54 \\
\hline 40 & 90 & $\mathrm{AC}$ & 40,31 & 0,31 & 0,21 \\
\hline 55 & 90 & $\mathrm{AC}$ & 56,43 & 1,43 & 0,95 \\
\hline 70 & 90 & $\mathrm{AC}$ & 69,86 & 0,14 & 0,09 \\
\hline 75 & 90 & $\mathrm{AC}$ & 80,62 & 5,62 & 3,75 \\
\hline 80 & 90 & $\mathrm{AC}$ & 80,62 & 0,62 & 0,41 \\
\hline 95 & 90 & $\mathrm{AC}$ & 94,06 & 0,94 & 0,63 \\
\hline 110 & 90 & $\mathrm{AC}$ & 110,19 & 0,19 & 0,13 \\
\hline 125 & 90 & $\mathrm{AC}$ & 123,63 & 1,37 & 0,91 \\
\hline 140 & 90 & $\mathrm{AC}$ & 139,74 & 0,26 & 0,17 \\
\hline \multicolumn{7}{c}{ Erro médio (\%) } & & & $\mathbf{0 , 8 3}$ \\
\hline \multicolumn{7}{c}{}
\end{tabular}

TABELA 87 - Resultados para faltas fase-fase (BC) com ângulo de incidência de $90^{\circ}$.

\begin{tabular}{cccccc}
\hline $\begin{array}{c}\text { Distância } \\
\text { Real } \\
(\mathbf{k m})\end{array}$ & $\begin{array}{c}\text { Âng. de } \\
\text { Incid. } \\
\text { (graus) }\end{array}$ & $\begin{array}{c}\text { Tipo de } \\
\text { Falta }\end{array}$ & $\begin{array}{c}\text { Distância } \\
\text { Estimada } \\
\text { (km) }\end{array}$ & $\begin{array}{c}\text { Erro } \\
\text { Abs. } \\
\text { (km) }\end{array}$ & $\begin{array}{c}\text { Erro } \\
(\mathbf{\%})\end{array}$ \\
\hline 10 & 90 & BC & 8,06 & 1,94 & 1,29 \\
\hline 25 & 90 & BC & 26,88 & 1,88 & 1,25 \\
\hline 40 & 90 & BC & 40,31 & 0,31 & 0,21 \\
\hline 55 & 90 & BC & 53,75 & 1,25 & 0,83 \\
\hline 70 & 90 & BC & 69,88 & 0,12 & 0,08 \\
\hline 75 & 90 & BC & 75,24 & 0,24 & 0,16 \\
\hline 80 & 90 & BC & 77,94 & 2,06 & 1,37 \\
\hline 95 & 90 & BC & 96,74 & 1,74 & 1,16 \\
\hline 110 & 90 & BC & 115,55 & 5,55 & 3,70 \\
\hline 125 & 90 & BC & 120,93 & 4,07 & 2,71 \\
\hline 140 & 90 & BC & 139,74 & 0,26 & 0,17 \\
\hline \multicolumn{7}{c}{ Erro médio (\%) } & & & $\mathbf{1 , 1 8}$ \\
\hline
\end{tabular}


TABELA 88 - Resultados para faltas fase-fase (AB) com ângulo de incidência de $45^{\circ}$.

\begin{tabular}{cccccc}
\hline $\begin{array}{c}\text { Distância } \\
\text { Real } \\
(\mathbf{k m})\end{array}$ & $\begin{array}{c}\text { Âng. de } \\
\text { Incid. } \\
\text { (graus) }\end{array}$ & $\begin{array}{c}\text { Tipo de } \\
\text { Falta }\end{array}$ & $\begin{array}{c}\text { Distância } \\
\text { Estimada } \\
\text { (km) }\end{array}$ & $\begin{array}{c}\text { Erro } \\
\text { Abs. } \\
\mathbf{( k m )}\end{array}$ & $\begin{array}{c}\text { Erro } \\
\text { (\%) }\end{array}$ \\
\hline 10 & 45 & $\mathrm{AB}$ & 8,06 & 1,94 & 1,29 \\
\hline 25 & 45 & $\mathrm{AB}$ & 26,87 & 1,87 & 1,25 \\
\hline 40 & 45 & $\mathrm{AB}$ & 40,31 & 0,31 & 0,21 \\
\hline 55 & 45 & $\mathrm{AB}$ & 53,74 & 1,26 & 0,84 \\
\hline 70 & 45 & $\mathrm{AB}$ & 69,86 & 0,14 & 0,09 \\
\hline 75 & 45 & $\mathrm{AB}$ & 75,24 & 0,24 & 0,16 \\
\hline 80 & 45 & $\mathrm{AB}$ & 77,94 & 2,06 & 1,37 \\
\hline 95 & 45 & $\mathrm{AB}$ & 96,74 & 1,74 & 1,16 \\
\hline 110 & 45 & $\mathrm{AB}$ & 115,5 & 5,50 & 3,67 \\
\hline 125 & 45 & $\mathrm{AB}$ & 120,93 & 4,07 & 2,71 \\
\hline 140 & 45 & $\mathrm{AB}$ & 139,73 & 0,27 & 0,18 \\
\hline \multicolumn{7}{c}{ Erro médio (\%) } & & & $\mathbf{1 , 1 8}$ \\
\hline
\end{tabular}

TABELA 89 - Resultados para faltas fase-fase (AB) com ângulo de incidência de $70^{\circ}$.

\begin{tabular}{cccccc}
\hline $\begin{array}{c}\text { Distância } \\
\text { Real } \\
(\mathbf{k m})\end{array}$ & $\begin{array}{c}\text { Âng. de } \\
\text { Incid. } \\
\text { (graus) }\end{array}$ & $\begin{array}{c}\text { Tipo de } \\
\text { Falta }\end{array}$ & $\begin{array}{c}\text { Distância } \\
\text { Estimada } \\
\mathbf{( k m )}\end{array}$ & $\begin{array}{c}\text { Erro } \\
\text { Abs. } \\
\mathbf{( k m )}\end{array}$ & $\begin{array}{c}\text { Erro } \\
\mathbf{( \% )}\end{array}$ \\
\hline 10 & 70 & $\mathrm{AB}$ & 10,74 & 0,74 & 0,49 \\
\hline 25 & 70 & $\mathrm{AB}$ & 24,19 & 0,81 & 0,54 \\
\hline 40 & 70 & $\mathrm{AB}$ & 40,3 & 0,30 & 0,20 \\
\hline 55 & 70 & $\mathrm{AB}$ & 56,4 & 1,40 & 0,93 \\
\hline 70 & 70 & $\mathrm{AB}$ & 68,5 & 1,50 & 1,00 \\
\hline 75 & 70 & $\mathrm{AB}$ & 75,21 & 0,21 & 0,14 \\
\hline 80 & 70 & $\mathrm{AB}$ & 80,59 & 0,59 & 0,39 \\
\hline 95 & 70 & $\mathrm{AB}$ & 94,02 & 0,98 & 0,65 \\
\hline 110 & 70 & $\mathrm{AB}$ & 110,14 & 0,14 & 0,09 \\
\hline 125 & 70 & $\mathrm{AB}$ & 126,25 & 1,25 & 0,83 \\
\hline 140 & 70 & $\mathrm{AB}$ & 142,38 & 2,38 & 1,59 \\
\hline \multicolumn{7}{c}{ Erro médio (\%) } & & & $\mathbf{0 , 6 2}$ \\
\hline
\end{tabular}

TABELA 90 - Resultados para faltas fase-fase-terra (ACT) com ângulo de incidência de $0^{\circ}$ e resistência de falta de 200 e $400 \mathrm{ohms}$.

\begin{tabular}{ccccccc}
\hline $\begin{array}{c}\text { Distância } \\
\text { Real } \\
(\mathbf{k m})\end{array}$ & $\begin{array}{c}\text { Resist. } \\
\text { falta } \\
(\mathbf{o h m s})\end{array}$ & $\begin{array}{c}\text { Angulo de } \\
\text { Incidência } \\
\text { (graus) }\end{array}$ & $\begin{array}{c}\text { Tipo de } \\
\text { Falta }\end{array}$ & $\begin{array}{c}\text { Distância } \\
\text { Estimada } \\
\mathbf{( k m )}\end{array}$ & $\begin{array}{c}\text { Erro } \\
\text { Abs. } \\
\mathbf{( k m )}\end{array}$ & Erro \\
\hline 10 & 200 & 0 & ACT & 9,4 & 0,6 & 0,40 \\
\hline 10 & 400 & 0 & ACT & 9,4 & 0,6 & 0,40 \\
\hline 25 & 200 & 0 & ACT & 29,55 & 4,55 & 3,03 \\
\hline 25 & 400 & 0 & ACT & 29,55 & 4,55 & 3,03 \\
\hline 40 & 200 & 0 & ACT & 37,61 & 2,39 & 1,59 \\
\hline 40 & 400 & 0 & ACT & 37,61 & 2,39 & 1,59 \\
\hline 55 & 200 & 0 & ACT & 56,43 & 1,43 & 0,95 \\
\hline 55 & 400 & 0 & ACT & 56,43 & 1,43 & 0,95 \\
\hline 70 & 200 & 0 & ACT & 69,88 & 0,12 & 0,08 \\
\hline 70 & 400 & 0 & ACT & 69,88 & 0,12 & 0,08 \\
\hline 75 & 200 & 0 & ACT & 73,56 & 1,44 & 0,96 \\
\hline 75 & 400 & 0 & ACT & 72,56 & 2,44 & 1,63 \\
\hline 80 & 200 & 0 & ACT & 77,94 & 2,06 & 1,37 \\
\hline 80 & 400 & 0 & ACT & 77,94 & 2,06 & 1,37 \\
\hline 95 & 200 & 0 & ACT & 99,43 & 4,43 & 2,95 \\
\hline 95 & 400 & 0 & ACT & 99,43 & 4,43 & 2,95 \\
\hline 110 & 200 & 0 & ACT & 110,19 & 0,19 & 0,13 \\
\hline 110 & 400 & 0 & ACT & 110,19 & 0,19 & 0,13 \\
\hline 125 & 200 & 0 & ACT & 126,3 & 1,3 & 0,87 \\
\hline 125 & 400 & 0 & ACT & 126,3 & 1,3 & 0,87 \\
\hline 140 & 200 & 0 & ACT & 139,74 & 0,26 & 0,17 \\
\hline 140 & 400 & 0 & ACT & 139,74 & 0,26 & 0,17 \\
\hline & & Erro médio (\%) & & & $\mathbf{1 , 1 7}$ \\
\hline
\end{tabular}


TABELA 91 - Resultados para faltas fase-fase-terra (ACT) com ângulo de incidência de $90^{\circ}$ e resistência de falta de 200 e $400 \mathrm{ohms}$.

\begin{tabular}{ccccccc}
\hline $\begin{array}{c}\text { Distância } \\
\text { Real } \\
(\mathbf{k m})\end{array}$ & $\begin{array}{c}\text { Resist. } \\
\text { falta } \\
\text { (ohms) }\end{array}$ & $\begin{array}{c}\text { Angulo de } \\
\text { Incidência } \\
\text { (graus) }\end{array}$ & $\begin{array}{c}\text { Tipo de } \\
\text { Falta }\end{array}$ & $\begin{array}{c}\text { Distância } \\
\text { Estimada } \\
\mathbf{( k m )}\end{array}$ & $\begin{array}{c}\text { Erro } \\
\text { Abs. } \\
\mathbf{( k m )}\end{array}$ & $\begin{array}{c}\text { Erro } \\
\text { Relativo } \\
(\mathbf{\%})\end{array}$ \\
\hline 10 & 200 & 90 & ACT & 8,06 & 1,94 & 1,29 \\
\hline 10 & 400 & 90 & ACT & 8,06 & 1,94 & 1,29 \\
\hline 25 & 200 & 90 & ACT & 24,19 & 0,81 & 0,54 \\
\hline 25 & 400 & 90 & ACT & 24,19 & 0,81 & 0,54 \\
\hline 40 & 200 & 90 & ACT & 40,31 & 0,31 & 0,21 \\
\hline 40 & 400 & 90 & ACT & 40,31 & 0,31 & 0,21 \\
\hline 55 & 200 & 90 & ACT & 8,06 & 46,94 & 31,29 \\
\hline 55 & 400 & 90 & ACT & 8,06 & 46,94 & 31,29 \\
\hline 70 & 200 & 90 & ACT & 69,86 & 0,14 & 0,09 \\
\hline 70 & 400 & 90 & ACT & 69,86 & 0,14 & 0,09 \\
\hline 75 & 200 & 90 & ACT & 80,62 & 5,62 & 3,75 \\
\hline 75 & 400 & 90 & ACT & 80,62 & 5,62 & 3,75 \\
\hline 80 & 200 & 90 & ACT & 80,62 & 0,62 & 0,41 \\
\hline 80 & 400 & 90 & ACT & 80,62 & 0,62 & 0,41 \\
\hline 95 & 200 & 90 & ACT & 94,06 & 0,94 & 0,63 \\
\hline 95 & 400 & 90 & ACT & 94,06 & 0,94 & 0,63 \\
\hline 110 & 200 & 90 & ACT & 110,18 & 0,18 & 0,12 \\
\hline 110 & 400 & 90 & ACT & 110,18 & 0,18 & 0,12 \\
\hline 125 & 200 & 90 & ACT & 123,63 & 1,37 & 0,91 \\
\hline 125 & 400 & 90 & ACT & 123,63 & 1,37 & 0,91 \\
\hline 140 & 200 & 90 & ACT & 139,74 & 0,26 & 0,17 \\
\hline 140 & 400 & 90 & ACT & 139,74 & 0,26 & 0,17 \\
\hline & & Erro médio (\%) & & & $\mathbf{3 , 5 8}$ \\
\hline & & & & & & \\
\hline
\end{tabular}


TABELA 92 - Resultados para faltas fase-terra (AT) com ângulo de incidência de $45^{\circ}$ e resistência de falta de 100, 200 e $400 \mathrm{ohms}$.

\begin{tabular}{|c|c|c|c|c|c|c|c|}
\hline $\begin{array}{c}\text { Distância } \\
\text { Real } \\
(\mathbf{k m})\end{array}$ & $\begin{array}{c}\text { Resist. } \\
\text { falta } \\
(\text { ohms })\end{array}$ & $\begin{array}{c}\text { Ângulo de } \\
\text { Incidência } \\
\text { (graus) }\end{array}$ & $\begin{array}{l}\text { Tipo de } \\
\text { Falta }\end{array}$ & $\begin{array}{c}\text { Pré- } \\
\text { Localização } \\
\text { (1/2 - seção) }\end{array}$ & $\begin{array}{c}\text { Distância } \\
\text { Estimada } \\
\quad(\mathbf{k m})\end{array}$ & $\begin{array}{l}\text { Erro } \\
\text { Abs. } \\
(\mathbf{k m})\end{array}$ & $\begin{array}{l}\text { Erro } \\
(\%)\end{array}$ \\
\hline 10 & 100 & 45 & AT & 1 & 8,06 & 1,94 & 1,29 \\
\hline 10 & 200 & 45 & $\mathrm{AT}$ & 1 & 8,06 & 1,94 & 1,29 \\
\hline 10 & 400 & 45 & AT & 1 & 13,44 & 3,44 & 2,29 \\
\hline 25 & 100 & 45 & AT & 1 & 26,87 & 1,87 & 1,25 \\
\hline 25 & 200 & 45 & $\mathrm{AT}$ & 1 & 26,87 & 1,87 & 1,25 \\
\hline 25 & 400 & 45 & $\mathrm{AT}$ & 1 & 26,87 & 1,87 & 1,25 \\
\hline 40 & 100 & 45 & AT & 1 & 40,31 & 0,31 & 0,21 \\
\hline 40 & 200 & 45 & $\mathrm{AT}$ & 1 & 40,31 & 0,31 & 0,21 \\
\hline 40 & 400 & 45 & AT & 1 & 53,74 & 13,7 & 9,16 \\
\hline 55 & 100 & 45 & AT & 1 & 53,74 & 1,26 & 0,84 \\
\hline 55 & 200 & 45 & AT & 1 & 53,74 & 1,26 & 0,84 \\
\hline 55 & 400 & 45 & AT & 1 & 53,74 & 1,26 & 0,84 \\
\hline 70 & 100 & 45 & AT & 1 & 69,86 & 0,14 & 0,09 \\
\hline 70 & 200 & 45 & $\mathrm{AT}$ & 1 & 69,86 & 0,14 & 0,09 \\
\hline 70 & 400 & 45 & $\mathrm{AT}$ & 1 & 69,86 & 0,14 & 0,09 \\
\hline 75 & 100 & 45 & AT & 2 & 74,76 & 0,24 & 0,16 \\
\hline 75 & 200 & 45 & AT & 2 & 74,76 & 0,24 & 0,16 \\
\hline 75 & 400 & 45 & AT & 2 & 74,76 & 0,24 & 0,16 \\
\hline 80 & 100 & 45 & AT & 1 & 10,75 & 69,3 & 46,17 \\
\hline 80 & 200 & 45 & $\mathrm{AT}$ & 1 & 69,88 & 10,1 & 6,75 \\
\hline 80 & 400 & 45 & AT & 1 & 10,75 & 69,3 & 46,17 \\
\hline 95 & 100 & 45 & $\mathrm{AT}$ & 2 & 93,57 & 1,43 & 0,95 \\
\hline 95 & 200 & 45 & AT & 2 & 93,57 & 1,43 & 0,95 \\
\hline 95 & 400 & 45 & AT & 2 & 93,57 & 1,43 & 0,95 \\
\hline 110 & 100 & 45 & AT & 2 & 109,69 & 0,31 & 0,21 \\
\hline 110 & 200 & 45 & AT & 2 & 109,69 & 0,31 & 0,21 \\
\hline 110 & 400 & 45 & AT & 2 & 109,69 & 0,31 & 0,21 \\
\hline 125 & 100 & 45 & AT & 2 & 127,16 & 2,16 & 1,44 \\
\hline 125 & 200 & 45 & AT & 2 & 127,16 & 2,16 & 1,44 \\
\hline 125 & 400 & 45 & $\mathrm{AT}$ & 2 & 127,16 & 2,16 & 1,44 \\
\hline 140 & 100 & 45 & $\mathrm{AT}$ & 2 & 139,26 & 0,74 & 0,49 \\
\hline 140 & 200 & 45 & AT & 2 & 139,26 & 0,74 & 0,49 \\
\hline 140 & 400 & 45 & AT & 2 & 139,26 & 0,74 & 0,49 \\
\hline \multicolumn{7}{|c|}{ Erro médio (\%) } & 3,93 \\
\hline
\end{tabular}


TABELA 93 - Resultados para faltas fase-terra (AT) com ângulo de incidência de $70^{\circ}$ e resistência de falta de 100, 200 e $400 \mathrm{ohms}$.

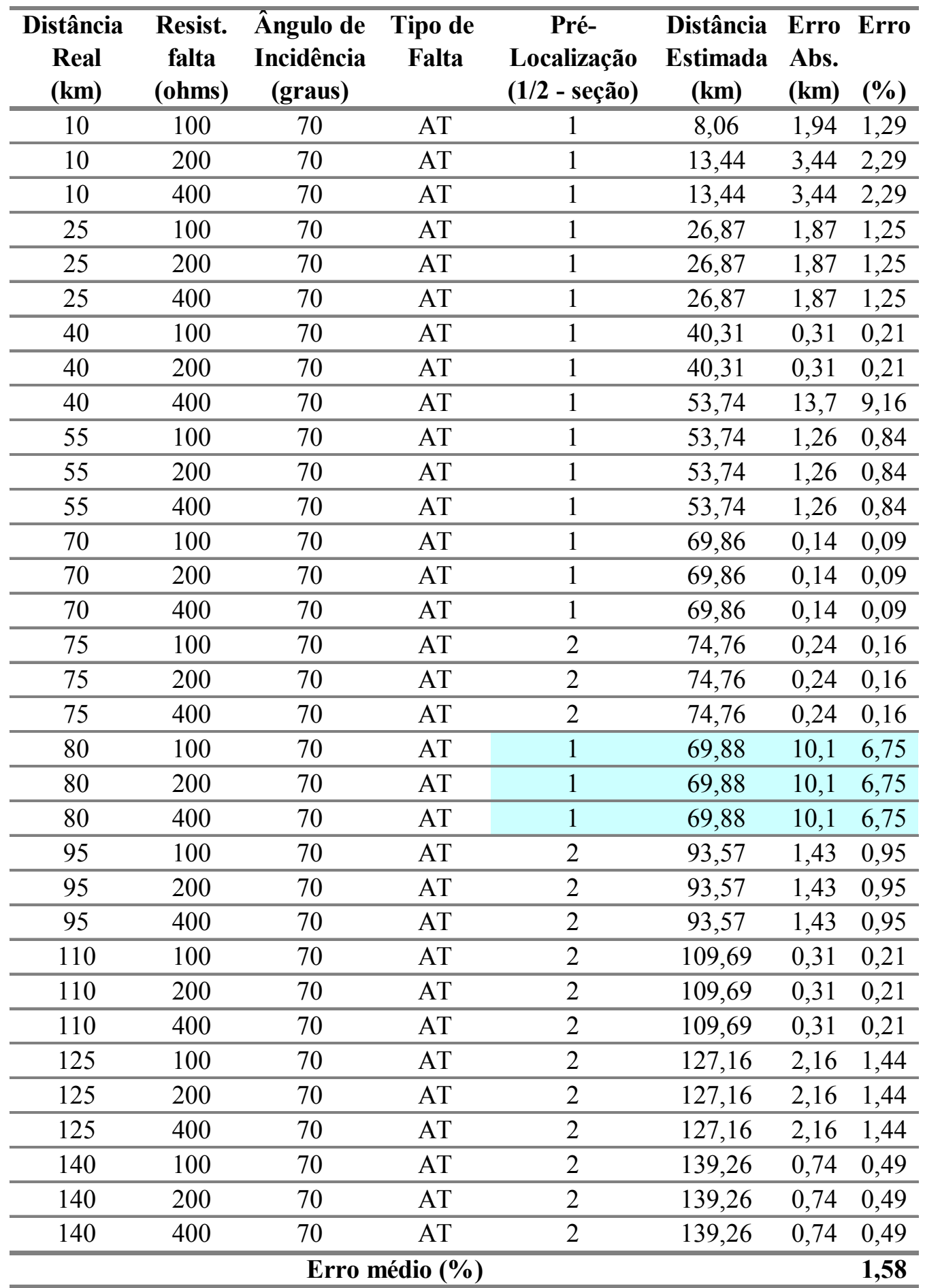


TABELA 94 - Efeito da variação da taxa amostral dos dados considerando casos de faltas fase-terra com ângulo de incidência da falta de $0^{\circ}$.

\begin{tabular}{|c|c|c|c|c|c|c|c|c|c|}
\hline $\begin{array}{l}\text { Dist. } \\
\text { Real }\end{array}$ & $\begin{array}{l}\text { Resist. } \\
\text { falta } \\
\text { (ohms) }\end{array}$ & $\begin{array}{l}\text { Âng. de } \\
\text { Incid. } \\
\text { (graus) }\end{array}$ & $\begin{array}{c}\text { Tipo de } \\
\text { Falta }\end{array}$ & $\begin{array}{c}\text { Dist. } \\
\text { Est. } \\
240 \text { kHz } \\
(\mathbf{k m})\end{array}$ & $\begin{array}{c}\text { Dist. } \\
\text { Est. } \\
120 \mathrm{kHz} \\
(\mathbf{k m})\end{array}$ & $\begin{array}{c}\text { Dist. } \\
\text { Est. } \\
60 \mathrm{kHz} \\
(\mathrm{km})\end{array}$ & $\begin{array}{c}\text { Erro } \\
240 \mathrm{kHz} \\
(\%)\end{array}$ & $\begin{array}{c}\text { Erro } \\
120 \mathrm{kHz} \\
(\%)\end{array}$ & $\begin{array}{c}\text { Erro } \\
60 \mathrm{kHz} \\
(\%)\end{array}$ \\
\hline 10 & 0 & 0 & AT & 10,99 & 8,05 & - & 0,66 & 1,30 & - \\
\hline 25 & 0 & 0 & AT & 29,32 & 24,19 & 19,54 & 2,88 & 0,54 & 3,64 \\
\hline 40 & 0 & 0 & AT & 37,88 & 40,3 & 39,08 & 1,41 & 0,20 & 0,61 \\
\hline 55 & 0 & 0 & AT & 54,97 & 56,41 & 61,06 & 0,02 & 0,94 & 4,04 \\
\hline 70 & 0 & 0 & AT & 69,62 & 68,5 & 59,61 & 0,25 & 1,00 & 6,93 \\
\hline 75 & 0 & 0 & AT & 51,05 & 75,21 & 87,95 & 15,97 & 0,14 & 8,63 \\
\hline 80 & 0 & 0 & AT & 81,6 & 80,15 & 81,59 & 1,07 & 0,10 & 1,06 \\
\hline 95 & 0 & 0 & AT & 95,26 & 96,28 & 86,49 & 0,17 & 0,85 & 5,67 \\
\hline 110 & 0 & 0 & AT & 109,69 & 109,7 & 110,9 & 0,21 & 0,20 & 0,60 \\
\hline 125 & 0 & 0 & AT & 123,12 & 123,13 & 115,8 & 1,25 & 1,25 & 6,13 \\
\hline 140 & 0 & 0 & AT & 137,78 & 139,26 & 135,34 & 1,48 & 0,49 & 3,11 \\
\hline \multicolumn{4}{|c|}{ Erro médio (\%) } & & & & 2,31 & 0,64 & 4,04 \\
\hline
\end{tabular}

TABELA 95 - Efeito da variação da taxa amostral dos dados considerando casos de faltas fase-terra com ângulo de incidência da falta de $90^{\circ}$.

\begin{tabular}{|c|c|c|c|c|c|c|c|c|c|}
\hline $\begin{array}{l}\text { Dist. } \\
\text { Real } \\
(\mathbf{k m})\end{array}$ & $\begin{array}{l}\text { Resist. } \\
\text { falta } \\
\text { (ohms) }\end{array}$ & $\begin{array}{l}\text { Âng. de } \\
\text { Incid. } \\
\text { (graus) }\end{array}$ & $\begin{array}{c}\text { Tipo de } \\
\text { Falta }\end{array}$ & $\begin{array}{l}\text { Dist. } \\
\text { Est. } \\
240 \text { kHz } \\
\text { (km) }\end{array}$ & $\begin{array}{c}\text { Dist. } \\
\text { Est. } \\
120 \mathrm{kHz} \\
(\mathrm{km})\end{array}$ & $\begin{array}{l}\text { Dist. } \\
\text { Est. } \\
60 \mathrm{kHz} \\
(\mathbf{k m})\end{array}$ & $\begin{array}{c}\text { Erro } \\
240 \mathrm{kHz} \\
(\%)\end{array}$ & $\begin{array}{c}\text { Erro } \\
120 \mathrm{kHz} \\
(\%)\end{array}$ & $\begin{array}{c}\text { Erro } \\
60 \mathrm{kHz} \\
(\%)\end{array}$ \\
\hline 10 & 0 & 90 & AT & 9,78 & 13,43 & - & 0,15 & 2,29 & - \\
\hline 25 & 0 & 90 & AT & 26,86 & 24,19 & 24,43 & 1,24 & 0,54 & 0,38 \\
\hline 40 & 0 & 90 & AT & 37,86 & 40,3 & 39,09 & 1,43 & 0,20 & 0,61 \\
\hline 55 & 0 & 90 & AT & 54,97 & 53,72 & 61,08 & 0,02 & 0,85 & 4,05 \\
\hline 70 & 0 & 90 & AT & 68,4 & 69,85 & 68,41 & 1,07 & 0,10 & 1,06 \\
\hline 75 & 0 & 90 & AT & 76,7 & 74,79 & 87,94 & 1,13 & 0,14 & 8,63 \\
\hline 80 & 0 & 90 & AT & 81,59 & 80,15 & 81,6 & 1,06 & 0,10 & 1,07 \\
\hline 95 & 0 & 90 & AT & 95,03 & 93,59 & 91,37 & 0,02 & 0,94 & 2,42 \\
\hline 110 & 0 & 90 & AT & 109,7 & 111,05 & 106,02 & 0,20 & 0,70 & 2,65 \\
\hline 125 & 0 & 90 & AT & 123,13 & 125,81 & 120,68 & 1,25 & 0,54 & 2,88 \\
\hline 140 & 0 & 90 & AT & 140,22 & 139,26 & 135,34 & 0,15 & 0,49 & 3,11 \\
\hline \multicolumn{4}{|c|}{ Erro médio (\%) } & & & & $\mathbf{0 , 7 0}$ & 0,63 & 2,69 \\
\hline
\end{tabular}


TABELA 96 - Efeito da imprecisão de $+5 \%$ nos parâmetros L e C da linha de transmissão considerando faltas fase-terra com ângulo de incidência da falta de $0^{\circ}$.

\begin{tabular}{|c|c|c|c|c|c|c|c|}
\hline $\begin{array}{c}\text { Distância } \\
\text { Real } \\
(\mathbf{k m})\end{array}$ & $\begin{array}{c}\text { Resist. } \\
\text { falta } \\
\text { (ohms) }\end{array}$ & $\begin{array}{l}\text { Ângulo de } \\
\text { Incidência } \\
\text { (graus) }\end{array}$ & $\begin{array}{c}\text { Tipo de } \\
\text { Falta }\end{array}$ & $\begin{array}{c}\text { Pré- } \\
\text { Localização } \\
\text { (1/2 - metade) }\end{array}$ & $\begin{array}{c}\text { Distância } \\
\text { Estimada } \\
\text { (km) }\end{array}$ & $\begin{array}{l}\text { Erro } \\
\text { Abs. } \\
(\mathbf{k m}) \\
\end{array}$ & $\begin{array}{l}\text { Erro } \\
(\%) \\
\end{array}$ \\
\hline 10 & 0 & 0 & AT & 1 & 11,50 & 1,50 & 1,00 \\
\hline 10 & 50 & 0 & AT & 1 & 12,79 & 2,79 & 1,86 \\
\hline 10 & 100 & 0 & AT & 1 & 11,50 & 1,50 & 1,00 \\
\hline 25 & 0 & 0 & AT & 1 & 23,03 & 1,97 & 1,31 \\
\hline 25 & 50 & 0 & AT & 1 & 23,03 & 1,97 & 1,31 \\
\hline 25 & 100 & 0 & AT & 1 & 23,03 & 1,97 & 1,31 \\
\hline 40 & 0 & 0 & AT & 1 & 38,38 & 1,62 & 1,08 \\
\hline 40 & 50 & 0 & AT & 1 & 38,38 & 1,62 & 1,08 \\
\hline 40 & 100 & 0 & AT & 1 & 7,68 & 32,32 & 21,55 \\
\hline 55 & 0 & 0 & AT & 1 & 53,72 & 1,28 & 0,85 \\
\hline 55 & 50 & 0 & AT & 1 & 53,72 & 1,28 & 0,85 \\
\hline 55 & 100 & 0 & AT & 1 & 12,79 & 42,21 & 28,14 \\
\hline 70 & 0 & 0 & AT & 1 & 65,24 & 4,76 & 3,18 \\
\hline 70 & 50 & 0 & AT & 1 & 65,24 & 4,76 & 3,18 \\
\hline 70 & 100 & 0 & AT & 1 & 19,20 & 50,80 & 33,87 \\
\hline 75 & 0 & 0 & AT & 1 & 71,63 & 3,37 & 2,25 \\
\hline 75 & 50 & 0 & AT & 1 & 71,63 & 3,37 & 2,25 \\
\hline 75 & 100 & 0 & AT & 1 & 71,63 & 3,37 & 2,25 \\
\hline 80 & 0 & 0 & AT & 2 & 83,48 & 3,48 & 2,32 \\
\hline 80 & 50 & 0 & AT & 1 & 66,52 & 13,48 & 8,99 \\
\hline 80 & 100 & 0 & AT & 2 & 83,48 & 3,48 & 2,32 \\
\hline 95 & 0 & 0 & AT & 2 & 98,84 & 3,84 & 2,56 \\
\hline 95 & 50 & 0 & AT & 2 & 98,84 & 3,84 & 2,56 \\
\hline 95 & 100 & 0 & AT & 2 & 98,84 & 3,84 & 2,56 \\
\hline 110 & 0 & 0 & AT & 2 & 111,62 & 1,62 & 1,08 \\
\hline 110 & 50 & 0 & AT & 2 & 111,62 & 1,62 & 1,08 \\
\hline 110 & 100 & 0 & AT & 2 & 111,62 & 1,62 & 1,08 \\
\hline 125 & 0 & 0 & AT & 2 & 126,98 & 1,98 & 1,32 \\
\hline 125 & 50 & 0 & AT & 2 & 124,41 & 0,59 & 0,39 \\
\hline 125 & 100 & 0 & AT & 2 & 126,98 & 1,98 & 1,32 \\
\hline 140 & 0 & 0 & AT & 2 & 139,77 & 0,23 & 0,16 \\
\hline 140 & 50 & 0 & AT & 2 & 142,32 & 2,32 & 1,55 \\
\hline 140 & 100 & 0 & AT & 2 & 133,37 & 6,63 & 4,42 \\
\hline \multicolumn{7}{|c|}{ Erro médio (\%) } & 4,30 \\
\hline
\end{tabular}


TABELA 97 - Efeito da imprecisão de $+5 \%$ nos parâmetros $L$ e C da linha de transmissão considerando faltas fase-terra com ângulo de incidência da falta de $90^{\circ}$.

\begin{tabular}{|c|c|c|c|c|c|c|c|}
\hline $\begin{array}{c}\text { Distância } \\
\text { Real } \\
(\mathbf{k m})\end{array}$ & $\begin{array}{c}\text { Resist. } \\
\text { falta } \\
(\text { ohms })\end{array}$ & $\begin{array}{c}\text { Ângulo de } \\
\text { Incidência } \\
\text { (graus) }\end{array}$ & $\begin{array}{c}\text { Tipo de } \\
\text { Falta }\end{array}$ & $\begin{array}{c}\text { Pré- } \\
\text { Localização } \\
\text { (1/2 - metade) }\end{array}$ & $\begin{array}{c}\text { Distância } \\
\text { Estimada } \\
(\mathbf{k m})\end{array}$ & $\begin{array}{l}\text { Erro } \\
\text { Abs. } \\
(\mathbf{k m})\end{array}$ & $\begin{array}{l}\text { Erro } \\
(\%) \\
\end{array}$ \\
\hline 10 & 0 & 90 & AT & 1 & 12,79 & 2,79 & 1,86 \\
\hline 10 & 50 & 90 & AT & 1 & 12,79 & 2,79 & 1,86 \\
\hline 10 & 100 & 90 & AT & 1 & 12,79 & 2,79 & 1,86 \\
\hline 25 & 0 & 90 & AT & 1 & 23,03 & 1,97 & 1,31 \\
\hline 25 & 50 & 90 & AT & 1 & 20,47 & 4,53 & 3,02 \\
\hline 25 & 100 & 90 & AT & 1 & 20,47 & 4,53 & 3,02 \\
\hline 40 & 0 & 90 & $\mathrm{AT}$ & 1 & 38,38 & 1,62 & 1,08 \\
\hline 40 & 50 & 90 & $\mathrm{AT}$ & 1 & 38,38 & 1,62 & 1,08 \\
\hline 40 & 100 & 90 & $\mathrm{AT}$ & 1 & 38,38 & 1,62 & 1,08 \\
\hline 55 & 0 & 90 & $\mathrm{AT}$ & 1 & 51,16 & 3,84 & 2,56 \\
\hline 55 & 50 & 90 & $\mathrm{AT}$ & 1 & 51,16 & 3,84 & 2,56 \\
\hline 55 & 100 & 90 & AT & 1 & 56,29 & 1,29 & 0,86 \\
\hline 70 & 0 & 90 & AT & 1 & 66,52 & 3,48 & 2,32 \\
\hline 70 & 50 & 90 & $\mathrm{AT}$ & 1 & 66,52 & 3,48 & 2,32 \\
\hline 70 & 100 & 90 & AT & 1 & 66,52 & 3,48 & 2,32 \\
\hline 75 & 0 & 90 & AT & 2 & 78,37 & 3,37 & 2,25 \\
\hline 75 & 50 & 90 & $\mathrm{AT}$ & 2 & 78,37 & 3,37 & 2,25 \\
\hline 75 & 100 & 90 & $\mathrm{AT}$ & 2 & 78,37 & 3,37 & 2,25 \\
\hline 80 & 0 & 90 & $\mathrm{AT}$ & 2 & 83,48 & 3,48 & 2,32 \\
\hline 80 & 50 & 90 & AT & 2 & 83,48 & 3,48 & 2,32 \\
\hline 80 & 100 & 90 & AT & 2 & 83,48 & 3,48 & 2,32 \\
\hline 95 & 0 & 90 & $\mathrm{AT}$ & 2 & 96,28 & 1,28 & 0,85 \\
\hline 95 & 50 & 90 & AT & 2 & 96,28 & 1,28 & 0,85 \\
\hline 95 & 100 & 90 & $\mathrm{AT}$ & 2 & 96,28 & 1,28 & 0,85 \\
\hline 110 & 0 & 90 & $\mathrm{AT}$ & 2 & 112,91 & 2,91 & 1,94 \\
\hline 110 & 50 & 90 & $\mathrm{AT}$ & 2 & 112,91 & 2,91 & 1,94 \\
\hline 110 & 100 & 90 & $\mathrm{AT}$ & 2 & 112,91 & 2,91 & 1,94 \\
\hline 125 & 0 & 90 & AT & 2 & 126,97 & 1,97 & 1,31 \\
\hline 125 & 50 & 90 & AT & 2 & 126,97 & 1,97 & 1,31 \\
\hline 125 & 100 & 90 & $\mathrm{AT}$ & 2 & 126,97 & 1,97 & 1,31 \\
\hline 140 & 0 & 90 & AT & 2 & 139,77 & 0,23 & 0,16 \\
\hline 140 & 50 & 90 & AT & 2 & 139,77 & 0,23 & 0,16 \\
\hline 140 & 100 & 90 & AT & 2 & 142,32 & 2,32 & 1,55 \\
\hline \multicolumn{7}{|c|}{ Erro médio (\%) } & 1,73 \\
\hline
\end{tabular}


TABELA 98 - Efeito da imprecisão de -5\% nos parâmetros L e C da linha de transmissão considerando faltas fase-terra com ângulo de incidência da falta de $0^{\circ}$.

\begin{tabular}{|c|c|c|c|c|c|c|c|}
\hline $\begin{array}{c}\text { Distância } \\
\text { Real } \\
(\mathbf{k m})\end{array}$ & $\begin{array}{l}\text { Resist. } \\
\text { falta } \\
\text { (ohms) }\end{array}$ & $\begin{array}{l}\text { Ângulo de } \\
\text { Incidência } \\
\text { (graus) }\end{array}$ & $\begin{array}{c}\text { Tipo de } \\
\text { Falta }\end{array}$ & $\begin{array}{c}\text { Pré- } \\
\text { Localização } \\
\text { (1/2 - metade) }\end{array}$ & $\begin{array}{c}\text { Distância } \\
\text { Estimada } \\
(\mathbf{k m})\end{array}$ & $\begin{array}{l}\text { Erro } \\
\text { Abs. } \\
\text { (km) }\end{array}$ & $\begin{array}{c}\text { Erro } \\
\text { (\%) }\end{array}$ \\
\hline 10 & 0 & 0 & AT & 1 & 12,71 & 2,71 & 1,81 \\
\hline 10 & 50 & 0 & AT & 1 & 14,13 & 4,13 & 2,76 \\
\hline 10 & 100 & 0 & AT & 1 & 12,71 & 2,71 & 1,81 \\
\hline 25 & 0 & 0 & AT & 1 & 25,46 & 0,46 & 0,31 \\
\hline 25 & 50 & 0 & AT & 1 & 25,46 & 0,46 & 0,31 \\
\hline 25 & 100 & 0 & AT & 1 & 25,46 & 0,46 & 0,31 \\
\hline 40 & 0 & 0 & AT & 1 & 42,42 & 2,42 & 1,61 \\
\hline 40 & 50 & 0 & AT & 1 & 42,42 & 2,42 & 1,61 \\
\hline 40 & 100 & 0 & AT & 1 & 8,49 & 31,51 & 21,01 \\
\hline 55 & 0 & 0 & AT & 1 & 59,37 & 4,37 & 2,92 \\
\hline 55 & 50 & 0 & AT & 1 & 59,37 & 4,37 & 2,92 \\
\hline 55 & 100 & 0 & $\mathrm{AT}$ & 1 & 14,13 & 40,87 & 27,24 \\
\hline 70 & 0 & 0 & $\mathrm{AT}$ & 2 & 77,90 & 7,90 & 5,26 \\
\hline 70 & 50 & 0 & AT & 2 & 77,90 & 7,90 & 5,26 \\
\hline 70 & 100 & 0 & AT & 2 & 128,78 & 58,78 & 39,19 \\
\hline 75 & 0 & 0 & AT & 1 & 79,17 & 4,17 & 2,78 \\
\hline 75 & 50 & 0 & AT & 1 & 79,17 & 4,17 & 2,78 \\
\hline 75 & 100 & 0 & AT & 1 & 79,17 & 4,17 & 2,78 \\
\hline 80 & 0 & 0 & AT & 2 & 76,48 & 3,52 & 2,35 \\
\hline 80 & 50 & 0 & AT & 1 & 73,52 & 6,48 & 4,32 \\
\hline 80 & 100 & 0 & AT & 2 & 76,48 & 3,52 & 2,35 \\
\hline 95 & 0 & 0 & AT & 2 & 93,45 & 1,55 & 1,03 \\
\hline 95 & 50 & 0 & AT & 2 & 93,45 & 1,55 & 1,03 \\
\hline 95 & 100 & 0 & AT & 2 & 93,45 & 1,55 & 1,03 \\
\hline 110 & 0 & 0 & AT & 2 & 107,58 & 2,42 & 1,61 \\
\hline 110 & 50 & 0 & AT & 2 & 107,58 & 2,42 & 1,61 \\
\hline 110 & 100 & 0 & AT & 2 & 107,58 & 2,42 & 1,61 \\
\hline 125 & 0 & 0 & AT & 2 & 124,56 & 0,44 & 0,30 \\
\hline 125 & 50 & 0 & AT & 2 & 121,72 & 3,28 & 2,19 \\
\hline 125 & 100 & 0 & AT & 2 & 124,56 & 0,44 & 0,30 \\
\hline 140 & 0 & 0 & AT & 2 & 138,69 & 1,31 & 0,87 \\
\hline 140 & 50 & 0 & AT & 2 & 141,51 & 1,51 & 1,01 \\
\hline 140 & 100 & 0 & $\mathrm{AT}$ & 2 & 131,62 & 8,38 & 5,58 \\
\hline \multicolumn{7}{|c|}{ Erro médio (\%) } & 4,54 \\
\hline
\end{tabular}


TABELA 99 - Efeito da imprecisão de -5\% nos parâmetros L e C da linha de transmissão considerando faltas fase-terra com ângulo de incidência da falta de $90^{\circ}$.

\begin{tabular}{|c|c|c|c|c|c|c|c|}
\hline $\begin{array}{c}\text { Distância } \\
\text { Real } \\
(\mathbf{k m})\end{array}$ & $\begin{array}{l}\text { Resist. } \\
\text { falta } \\
\text { (ohms) }\end{array}$ & $\begin{array}{l}\text { Ângulo de } \\
\text { Incidência } \\
\text { (graus) }\end{array}$ & $\begin{array}{c}\text { Tipo de } \\
\text { Falta }\end{array}$ & $\begin{array}{c}\text { Pré- } \\
\text { Localização } \\
\text { (1/2 - metade) }\end{array}$ & $\begin{array}{c}\text { Distância } \\
\text { Estimada } \\
(\mathbf{k m})\end{array}$ & $\begin{array}{l}\text { Erro } \\
\text { Abs. } \\
(\mathbf{k m})\end{array}$ & Erro \\
\hline 10 & 0 & 90 & AT & 1 & 14,13 & 4,13 & 2,76 \\
\hline 10 & 50 & 90 & AT & 1 & 14,13 & 4,13 & 2,76 \\
\hline 10 & 100 & 90 & AT & 1 & 14,13 & 4,13 & 2,76 \\
\hline 25 & 0 & 90 & AT & 1 & 25,46 & 0,46 & 0,31 \\
\hline 25 & 50 & 90 & AT & 1 & 22,62 & 2,38 & 1,59 \\
\hline 25 & 100 & 90 & AT & 1 & 22,62 & 2,38 & 1,59 \\
\hline 40 & 0 & 90 & AT & 1 & 42,42 & 2,42 & 1,61 \\
\hline 40 & 50 & 90 & AT & 1 & 42,42 & 2,42 & 1,61 \\
\hline 40 & 100 & 90 & AT & 1 & 42,42 & 2,42 & 1,61 \\
\hline 55 & 0 & 90 & AT & 1 & 56,55 & 1,55 & 1,03 \\
\hline 55 & 50 & 90 & AT & 1 & 56,55 & 1,55 & 1,03 \\
\hline 55 & 100 & 90 & $\mathrm{AT}$ & 1 & 62,21 & 7,21 & 4,81 \\
\hline 70 & 0 & 90 & $\mathrm{AT}$ & 1 & 73,52 & 3,52 & 2,35 \\
\hline 70 & 50 & 90 & $\mathrm{AT}$ & 1 & 73,52 & 3,52 & 2,35 \\
\hline 70 & 100 & 90 & AT & 1 & 73,52 & 3,52 & 2,35 \\
\hline 75 & 0 & 90 & AT & 2 & 70,83 & 4,17 & 2,78 \\
\hline 75 & 50 & 90 & AT & 2 & 70,83 & 4,17 & 2,78 \\
\hline 75 & 100 & 90 & AT & 2 & 70,83 & 4,17 & 2,78 \\
\hline 80 & 0 & 90 & AT & 2 & 76,48 & 3,52 & 2,35 \\
\hline 80 & 50 & 90 & AT & 2 & 76,48 & 3,52 & 2,35 \\
\hline 80 & 100 & 90 & AT & 2 & 76,48 & 3,52 & 2,35 \\
\hline 95 & 0 & 90 & AT & 2 & 90,63 & 4,37 & 2,92 \\
\hline 95 & 50 & 90 & AT & 2 & 90,63 & 4,37 & 2,92 \\
\hline 95 & 100 & 90 & AT & 2 & 90,63 & 4,37 & 2,92 \\
\hline 110 & 0 & 90 & AT & 2 & 109,00 & 1,00 & 0,66 \\
\hline 110 & 50 & 90 & AT & 2 & 109,00 & 1,00 & 0,66 \\
\hline 110 & 100 & 90 & AT & 2 & 109,00 & 1,00 & 0,66 \\
\hline 125 & 0 & 90 & AT & 2 & 124,54 & 0,46 & 0,31 \\
\hline 125 & 50 & 90 & AT & 2 & 124,54 & 0,46 & 0,31 \\
\hline 125 & 100 & 90 & AT & 2 & 124,54 & 0,46 & 0,31 \\
\hline 140 & 0 & 90 & AT & 2 & 138,69 & 1,31 & 0,87 \\
\hline 140 & 50 & 90 & AT & 2 & 138,69 & 1,31 & 0,87 \\
\hline 140 & 100 & 90 & AT & 2 & 141,51 & 1,51 & 1,01 \\
\hline \multicolumn{7}{|c|}{ Erro médio (\%) } & 1,83 \\
\hline
\end{tabular}




\section{APÊNDICE B - Resultados dos testes para o circuito duplo}

Este apêndice tem por objeto ilustrar outros resultados referentes às simulações sobre o sistema duplo de transmissão proposto, com o intuito de confirmar a aplicabilidade, confiabilidade e precisão do algoritmo de localização de faltas proposto.

\section{B1. Técnica que utiliza dados de dois terminais}

Nas Tabelas (100-106) são mostrados resultados obtidos pelo algoritmo referentes a diversas situações faltosas aplicadas na linha entre os barramentos E-F, a fim de se verificar o comportamento do algoritmo frente ao efeito do acoplamento mutuo entre fases imposto por esse tipo de sistema;

As Tabelas (107-108) trazem resultados referentes a testes onde foram consideradas faltas em diversos pontos do circuito duplo (circuito 1 e 2) objetivando-se verificar o comportamento do localizador em casos de faltas dentro e fora da sua área de cobertura.

No que segue, Apêndice B2, são apresentados diferentes resultados obtidos pela técnica que utiliza dados registrados em um terminal, aplicada agora sobre um linha de transmissão dupla. Os resultados são mostrados através de tabelas como segue:

Nas Tabelas (109-115) são apresentados resultados referentes a diversas situações faltosas aplicadas na linha entre os barramentos E-F, visando-se verificar o comportamento do algoritmo frente ao efeito do acoplamento mutuo entre fases imposto por esse tipo de sistema;

Por fim, as Tabelas (116-117) demonstram resultados de testes aplicados com o intuito de se verificar o comportamento da técnica que utiliza dados de um terminal em casos de faltas dentro e fora da sua área de cobertura..

É importante ressaltar que, os dados em destaque (..), representam casos onde o localizador apresentou uma grande imprecisão, devido a fatores descritos anteriormente. 
TABELA 100 - Resultados para faltas fase-fase (AB) com ângulo de incidência de $0^{\circ}$, aplicadas na linha $E-F$.

\begin{tabular}{cccccc}
\hline $\begin{array}{c}\text { Distância } \\
\text { Real } \\
(\mathbf{k m})\end{array}$ & $\begin{array}{c}\text { Angulo de } \\
\text { Incidência } \\
\text { (graus) }\end{array}$ & $\begin{array}{c}\text { Tipo de } \\
\text { Falta }\end{array}$ & $\begin{array}{c}\text { Distância } \\
\text { Estimada } \\
\text { (km) }\end{array}$ & $\begin{array}{c}\text { Erro } \\
\text { Abs. } \\
\mathbf{( k m )}\end{array}$ & $\begin{array}{c}\text { Erro } \\
\mathbf{( \% )}\end{array}$ \\
\hline 10 & 0 & $\mathrm{AB}$ & 8,64 & 1,36 & 0,91 \\
\hline 25 & 0 & $\mathrm{AB}$ & 24,56 & 0,44 & 0,29 \\
\hline 40 & 0 & $\mathrm{AB}$ & 40,48 & 0,48 & 0,32 \\
\hline 55 & 0 & $\mathrm{AB}$ & 56,41 & 1,41 & 0,94 \\
\hline 70 & 0 & $\mathrm{AB}$ & 69,7 & 0,3 & 0,20 \\
\hline 75 & 0 & $\mathrm{AB}$ & 75 & 0 & 0,00 \\
\hline 80 & 0 & $\mathrm{AB}$ & 80,3 & 0,3 & 0,20 \\
\hline 95 & 0 & $\mathrm{AB}$ & 93,58 & 1,42 & 0,95 \\
\hline 110 & 0 & $\mathrm{AB}$ & 109,52 & 0,48 & 0,32 \\
\hline 125 & 0 & $\mathrm{AB}$ & 125,44 & 0,44 & 0,29 \\
\hline 140 & 0 & $\mathrm{AB}$ & 141,36 & 1,36 & 0,91 \\
\hline \multicolumn{7}{c}{ Erro médio (\%) } & & & $\mathbf{0 , 4 8}$ \\
\hline
\end{tabular}

TABELA 102 - Resultados para faltas trifásicas $(A B C)$ com ângulo de incidência de $0^{\circ}$, aplicadas na linha $E-F$.

\begin{tabular}{cccccc}
\hline $\begin{array}{c}\text { Distância } \\
\text { Real } \\
\mathbf{( k m )}\end{array}$ & $\begin{array}{c}\text { Angulo de } \\
\text { Incidência } \\
\text { (graus) }\end{array}$ & $\begin{array}{c}\text { Tipo de } \\
\text { Falta }\end{array}$ & $\begin{array}{c}\text { Distância } \\
\text { Estimada } \\
\mathbf{( k m )}\end{array}$ & $\begin{array}{c}\text { Erro } \\
\text { Abs. } \\
\mathbf{( k m )}\end{array}$ & Erro \\
$\mathbf{( \% )}$
\end{tabular}

TABELA 101 - Resultados para faltas fase-fase (AB) com ângulo de incidência de $90^{\circ}$, aplicadas na linha $E-F$.

\begin{tabular}{cccccc}
\hline $\begin{array}{c}\text { Distância } \\
\text { Real } \\
\mathbf{( k m )}\end{array}$ & $\begin{array}{c}\text { Angulo de } \\
\text { Incidência } \\
\text { (graus) }\end{array}$ & $\begin{array}{c}\text { Tipo de } \\
\text { Falta }\end{array}$ & $\begin{array}{c}\text { Distância } \\
\text { Estimada } \\
\mathbf{( k m )}\end{array}$ & $\begin{array}{c}\text { Erro } \\
\text { Abs. } \\
\mathbf{( k m )}\end{array}$ & $\begin{array}{c}\text { Erro } \\
\mathbf{( \% )}\end{array}$ \\
\hline 10 & 90 & $\mathrm{AB}$ & 11,29 & 1,29 & 0,86 \\
\hline 25 & 90 & $\mathrm{AB}$ & 24,56 & 0,44 & 0,29 \\
\hline 40 & 90 & $\mathrm{AB}$ & 40,5 & 0,5 & 0,33 \\
\hline 55 & 90 & $\mathrm{AB}$ & 53,77 & 1,23 & 0,82 \\
\hline 70 & 90 & $\mathrm{AB}$ & 68,35 & 1,65 & 1,10 \\
\hline 75 & 90 & $\mathrm{AB}$ & 75 & 0 & 0,00 \\
\hline 80 & 90 & $\mathrm{AB}$ & 82,97 & 2,97 & 1,98 \\
\hline 95 & 90 & $\mathrm{AB}$ & 96,23 & 1,23 & 0,82 \\
\hline 110 & 90 & $\mathrm{AB}$ & 109,5 & 0,5 & 0,33 \\
\hline 125 & 90 & $\mathrm{AB}$ & 125,44 & 0,44 & 0,29 \\
\hline 140 & 90 & $\mathrm{AB}$ & 138,71 & 1,29 & 0,86 \\
\hline \multicolumn{7}{c}{} & Erro médio $\mathbf{( \% )}$ & & & $\mathbf{0 , 7 0}$ \\
\hline
\end{tabular}

TABELA 103 - Resultados para faltas trifásicas $(A B C)$ com ângulo de incidência de $90^{\circ}$, aplicadas na linha $E-F$.

\begin{tabular}{cccccc}
\hline $\begin{array}{c}\text { Distância } \\
\text { Real } \\
(\mathbf{k m})\end{array}$ & $\begin{array}{c}\text { Angulo de } \\
\text { Incidência } \\
\text { (graus) }\end{array}$ & $\begin{array}{c}\text { Tipo de } \\
\text { Falta }\end{array}$ & $\begin{array}{c}\text { Distância } \\
\text { Estimada } \\
\mathbf{( k m )}\end{array}$ & $\begin{array}{c}\text { Erro } \\
\text { Abs. } \\
\mathbf{( k m )}\end{array}$ & Erro \\
$\mathbf{( \% )}$
\end{tabular}


TABELA 104 - Resultados para faltas fase-terra (AT) com ângulo de incidência de $90^{\circ}$ e resistência de falta de 0, 50 e $100 \mathrm{ohms,} \mathrm{aplicadas} \mathrm{na} \mathrm{linha} \mathrm{E-F.}$

\begin{tabular}{|c|c|c|c|c|c|c|}
\hline $\begin{array}{c}\text { Distância } \\
\text { Real } \\
\text { (km) }\end{array}$ & $\begin{array}{c}\text { Resist. } \\
\text { falta } \\
(\text { ohms })\end{array}$ & $\begin{array}{c}\text { Ângulo de } \\
\text { Incidência } \\
\text { (graus) }\end{array}$ & $\begin{array}{c}\text { Tipo de } \\
\text { Falta }\end{array}$ & $\begin{array}{c}\text { Distância } \\
\text { Estimada } \\
\text { (km) }\end{array}$ & $\begin{array}{l}\text { Erro } \\
\text { Abs. } \\
(\mathbf{k m})\end{array}$ & $\begin{array}{l}\text { Erro } \\
(\%)\end{array}$ \\
\hline 10 & 0 & 90 & AT & 11,29 & 1,29 & 0,86 \\
\hline 10 & 50 & 90 & AT & 11,29 & 1,29 & 0,86 \\
\hline 10 & 100 & 90 & AT & 11,29 & 1,29 & 0,86 \\
\hline 25 & 0 & 90 & AT & 24,56 & 0,44 & 0,29 \\
\hline 25 & 50 & 90 & AT & 24,56 & 0,44 & 0,29 \\
\hline 25 & 100 & 90 & AT & 24,56 & 0,44 & 0,29 \\
\hline 40 & 0 & 90 & AT & 40,5 & 0,5 & 0,33 \\
\hline 40 & 50 & 90 & AT & 40,5 & 0,5 & 0,33 \\
\hline 40 & 100 & 90 & AT & 37,83 & 2,17 & 1,45 \\
\hline 55 & 0 & 90 & AT & 53,76 & 1,24 & 0,83 \\
\hline 55 & 50 & 90 & AT & 53,76 & 1,24 & 0,83 \\
\hline 55 & 100 & 90 & AT & 53,76 & 1,24 & 0,83 \\
\hline 70 & 0 & 90 & AT & 67,03 & 2,97 & 1,98 \\
\hline 70 & 50 & 90 & AT & 67,03 & 2,97 & 1,98 \\
\hline 70 & 100 & 90 & AT & 67,03 & 2,97 & 1,98 \\
\hline 75 & 0 & 90 & AT & 75 & 0 & 0,00 \\
\hline 75 & 50 & 90 & AT & 75 & 0 & 0,00 \\
\hline 75 & 100 & 90 & AT & 75 & 0 & 0,00 \\
\hline 80 & 0 & 90 & AT & 82,96 & 2,96 & 1,97 \\
\hline 80 & 50 & 90 & AT & 82,96 & 2,96 & 1,97 \\
\hline 80 & 100 & 90 & AT & 80,3 & 0,3 & 0,20 \\
\hline 95 & 0 & 90 & AT & 96,23 & 1,23 & 0,82 \\
\hline 95 & 50 & 90 & AT & 96,23 & 1,23 & 0,82 \\
\hline 95 & 100 & 90 & $\mathrm{AT}$ & 96,23 & 1,23 & 0,82 \\
\hline 110 & 0 & 90 & AT & 109,5 & 0,5 & 0,33 \\
\hline 110 & 50 & 90 & AT & 109,5 & 0,5 & 0,33 \\
\hline 110 & 100 & 90 & AT & 109,5 & 0,5 & 0,33 \\
\hline 125 & 0 & 90 & AT & 125,43 & 0,43 & 0,29 \\
\hline 125 & 50 & 90 & AT & 125,43 & 0,43 & 0,29 \\
\hline 125 & 100 & 90 & AT & 122,79 & 2,21 & 1,47 \\
\hline 140 & 0 & 90 & AT & 138,71 & 1,29 & 0,86 \\
\hline 140 & 50 & 90 & AT & 138,71 & 1,29 & 0,86 \\
\hline 140 & 100 & 90 & AT & 138,71 & 1,29 & 0,86 \\
\hline \multicolumn{6}{|c|}{ Erro médio (\%) } & 0,79 \\
\hline
\end{tabular}


TABELA 105 - Resultados para faltas fase-fase-terra (ABT) com ângulo de incidência de $0^{\circ}$ e resistência de falta de 0, 50 e 100 ohms, aplicadas na linha E-F.

\begin{tabular}{|c|c|c|c|c|c|c|}
\hline $\begin{array}{c}\text { Distância } \\
\text { Real } \\
\text { (km) }\end{array}$ & $\begin{array}{l}\text { Resist. } \\
\text { falta } \\
\text { (ohms) }\end{array}$ & $\begin{array}{c}\text { Ângulo de } \\
\text { Incidência } \\
\text { (graus) }\end{array}$ & $\begin{array}{c}\text { Tipo de } \\
\text { Falta }\end{array}$ & $\begin{array}{c}\text { Distância } \\
\text { Estimada } \\
(\mathbf{k m})\end{array}$ & $\begin{array}{l}\text { Erro } \\
\text { Abs. } \\
\text { (km) }\end{array}$ & $\begin{array}{l}\text { Erro } \\
(\%)\end{array}$ \\
\hline 10 & 0 & 0 & ABT & 8,64 & 1,36 & 0,91 \\
\hline 10 & 50 & 0 & $\mathrm{ABT}$ & 8,64 & 1,36 & 0,91 \\
\hline 10 & 100 & 0 & $\mathrm{ABT}$ & 8,64 & 1,36 & 0,91 \\
\hline 25 & 0 & 0 & ABT & 24,56 & 0,44 & 0,29 \\
\hline 25 & 50 & 0 & ABT & 24,56 & 0,44 & 0,29 \\
\hline 25 & 100 & 0 & ABT & 24,56 & 0,44 & 0,29 \\
\hline 40 & 0 & 0 & $\mathrm{ABT}$ & 40,48 & 0,48 & 0,32 \\
\hline 40 & 50 & 0 & $\mathrm{ABT}$ & 40,48 & 0,48 & 0,32 \\
\hline 40 & 100 & 0 & $\mathrm{ABT}$ & 40,48 & 0,48 & 0,32 \\
\hline 55 & 0 & 0 & ABT & 56,41 & 1,41 & 0,94 \\
\hline 55 & 50 & 0 & ABT & 56,41 & 1,41 & 0,94 \\
\hline 55 & 100 & 0 & ABT & 56,41 & 1,41 & 0,94 \\
\hline 70 & 0 & 0 & $\mathrm{ABT}$ & 69,7 & 0,3 & 0,20 \\
\hline 70 & 50 & 0 & $\mathrm{ABT}$ & 69,7 & 0,3 & 0,20 \\
\hline 70 & 100 & 0 & $\mathrm{ABT}$ & 69,7 & 0,3 & 0,20 \\
\hline 75 & 0 & 0 & $\mathrm{ABT}$ & 75 & 0 & 0,00 \\
\hline 75 & 50 & 0 & $\mathrm{ABT}$ & 75 & 0 & 0,00 \\
\hline 75 & 100 & 0 & $\mathrm{ABT}$ & 75 & 0 & 0,00 \\
\hline 80 & 0 & 0 & $\mathrm{ABT}$ & 80,3 & 0,3 & 0,20 \\
\hline 80 & 50 & 0 & $\mathrm{ABT}$ & 80,3 & 0,3 & 0,20 \\
\hline 80 & 100 & 0 & $\mathrm{ABT}$ & 80,3 & 0,3 & 0,20 \\
\hline 95 & 0 & 0 & $\mathrm{ABT}$ & 93,58 & 1,42 & 0,95 \\
\hline 95 & 50 & 0 & ABT & 93,58 & 1,42 & 0,95 \\
\hline 95 & 100 & 0 & $\mathrm{ABT}$ & 93,58 & 1,42 & 0,95 \\
\hline 110 & 0 & 0 & $\mathrm{ABT}$ & 109,52 & 0,48 & 0,32 \\
\hline 110 & 50 & 0 & ABT & 109,52 & 0,48 & 0,32 \\
\hline 110 & 100 & 0 & ABT & 109,52 & 0,48 & 0,32 \\
\hline 125 & 0 & 0 & ABT & 125,44 & 0,44 & 0,29 \\
\hline 125 & 50 & 0 & $\mathrm{ABT}$ & 125,44 & 0,44 & 0,29 \\
\hline 125 & 100 & 0 & $\mathrm{ABT}$ & 125,44 & 0,44 & 0,29 \\
\hline 140 & 0 & 0 & ABT & 141,35 & 1,35 & 0,90 \\
\hline 140 & 50 & 0 & $\mathrm{ABT}$ & 141,35 & 1,35 & 0,90 \\
\hline 140 & 100 & 0 & $\mathrm{ABT}$ & 141,35 & 1,35 & 0,90 \\
\hline \multicolumn{6}{|c|}{ Erro médio (\%) } & 0,48 \\
\hline
\end{tabular}


TABELA 106 - Resultados para faltas fase-fase-terra (ABT) com ângulo de incidencia de $90^{\circ}$ e resistência de falta de 0, 50 e $100 \mathrm{ohms,} \mathrm{aplicadas} \mathrm{na} \mathrm{linha} E-F$.

\begin{tabular}{|c|c|c|c|c|c|c|}
\hline $\begin{array}{c}\text { Distância } \\
\text { Real } \\
\text { (km) }\end{array}$ & $\begin{array}{c}\text { Resist. } \\
\text { falta } \\
\text { (ohms) }\end{array}$ & $\begin{array}{c}\text { Ângulo de } \\
\text { Incidência } \\
\text { (graus) }\end{array}$ & $\begin{array}{c}\text { Tipo de } \\
\text { Falta }\end{array}$ & $\begin{array}{c}\text { Distância } \\
\text { Estimada } \\
(\mathbf{k m})\end{array}$ & $\begin{array}{l}\text { Erro } \\
\text { Abs. } \\
(\mathrm{km})\end{array}$ & $\begin{array}{l}\text { Erro } \\
(\%)\end{array}$ \\
\hline 10 & 0 & 90 & ABT & 11,29 & 1,29 & 0,86 \\
\hline 10 & 50 & 90 & ABT & 11,29 & 1,29 & 0,86 \\
\hline 10 & 100 & 90 & ABT & 11,29 & 1,29 & 0,86 \\
\hline 25 & 0 & 90 & ABT & 24,56 & 0,44 & 0,29 \\
\hline 25 & 50 & 90 & ABT & 24,56 & 0,44 & 0,29 \\
\hline 25 & 100 & 90 & ABT & 24,56 & 0,44 & 0,29 \\
\hline 40 & 0 & 90 & ABT & 40,5 & 0,5 & 0,33 \\
\hline 40 & 50 & 90 & ABT & 40,5 & 0,5 & 0,33 \\
\hline 40 & 100 & 90 & ABT & 40,5 & 0,5 & 0,33 \\
\hline 55 & 0 & 90 & ABT & 53,76 & 1,24 & 0,83 \\
\hline 55 & 50 & 90 & ABT & 53,76 & 1,24 & 0,83 \\
\hline 55 & 100 & 90 & ABT & 53,76 & 1,24 & 0,83 \\
\hline 70 & 0 & 90 & ABT & 68,35 & 1,65 & 1,10 \\
\hline 70 & 50 & 90 & ABT & 68,35 & 1,65 & 1,10 \\
\hline 70 & 100 & 90 & ABT & 68,35 & 1,65 & 1,10 \\
\hline 75 & 0 & 90 & ABT & 75 & 0 & 0,00 \\
\hline 75 & 50 & 90 & ABT & 75 & 0 & 0,00 \\
\hline 75 & 100 & 90 & ABT & 75 & 0 & 0,00 \\
\hline 80 & 0 & 90 & ABT & 82,96 & 2,96 & 1,97 \\
\hline 80 & 50 & 90 & ABT & 82,96 & 2,96 & 1,97 \\
\hline 80 & 100 & 90 & ABT & 82,96 & 2,96 & 1,97 \\
\hline 95 & 0 & 90 & ABT & 96,23 & 1,23 & 0,82 \\
\hline 95 & 50 & 90 & ABT & 96,23 & 1,23 & 0,82 \\
\hline 95 & 100 & 90 & ABT & 96,23 & 1,23 & 0,82 \\
\hline 110 & 0 & 90 & $\mathrm{ABT}$ & 109,5 & 0,5 & 0,33 \\
\hline 110 & 50 & 90 & ABT & 109,5 & 0,5 & 0,33 \\
\hline 110 & 100 & 90 & $\mathrm{ABT}$ & 109,5 & 0,5 & 0,33 \\
\hline 125 & 0 & 90 & ABT & 125,44 & 0,44 & 0,29 \\
\hline 125 & 50 & 90 & ABT & 125,44 & 0,44 & 0,29 \\
\hline 125 & 100 & 90 & $\mathrm{ABT}$ & 125,44 & 0,44 & 0,29 \\
\hline 140 & 0 & 90 & $\mathrm{ABT}$ & 138,71 & 1,29 & 0,86 \\
\hline 140 & 50 & 90 & ABT & 138,71 & 1,29 & 0,86 \\
\hline 140 & 100 & 90 & $\mathrm{ABT}$ & 138,71 & 1,29 & 0,86 \\
\hline \multicolumn{6}{|c|}{ Erro médio (\%) } & $\mathbf{0 , 7 0}$ \\
\hline
\end{tabular}


TABELA 107 - Resultados referentes a situações de faltas aplicadas nas linhas do circuito 1.

\begin{tabular}{|c|c|c|c|c|c|c|c|}
\hline $\begin{array}{c}\text { Circuito } 1 \\
\text { Linha }\end{array}$ & $\begin{array}{c}\text { Distância } \\
\text { Real } \\
\text { (km) }\end{array}$ & $\begin{array}{c}\text { Resist. } \\
\text { falta } \\
\text { (ohms) }\end{array}$ & $\begin{array}{c}\text { Ângulo de } \\
\text { Incidência } \\
\text { (graus) }\end{array}$ & $\begin{array}{c}\text { Tipo de } \\
\text { Falta }\end{array}$ & $\begin{array}{c}\text { Distância } \\
\text { Estimada } \\
\quad(\mathbf{k m})\end{array}$ & $\begin{array}{l}\text { Erro } \\
\text { Abs. } \\
\text { (km) }\end{array}$ & $\begin{array}{l}\text { Erro } \\
(\%)\end{array}$ \\
\hline \multirow{9}{*}{ D-E } & 10 & 0 & 90 & AT & FAC* & - & - \\
\hline & 10 & 50 & 90 & AT & FAC & - & - \\
\hline & 10 & 100 & 90 & AT & FAC & - & - \\
\hline & 40 & 0 & 90 & AT & FAC & - & - \\
\hline & 40 & 50 & 90 & AT & FAC & - & - \\
\hline & 40 & 100 & 90 & AT & FAC & - & - \\
\hline & 60 & 0 & 90 & AT & FAC & - & - \\
\hline & 60 & 50 & 90 & AT & FAC & - & - \\
\hline & 60 & 100 & 90 & AT & FAC & - & - \\
\hline \multirow{9}{*}{ E-F } & 20 & 0 & 90 & $\mathrm{AB}$ & 20,59 & 0,59 & 0,40 \\
\hline & 20 & 50 & 90 & $\mathrm{AB}$ & 20,59 & 0,59 & 0,40 \\
\hline & 20 & 100 & 90 & $\mathrm{AB}$ & 20,59 & 0,59 & 0,40 \\
\hline & 80 & 0 & 90 & $\mathrm{AB}$ & 81,65 & 1,65 & 1,10 \\
\hline & 80 & 50 & 90 & $\mathrm{AB}$ & 81,65 & 1,65 & 1,10 \\
\hline & 80 & 100 & 90 & $\mathrm{AB}$ & 81,65 & 1,65 & 1,10 \\
\hline & 130 & 0 & 90 & $\mathrm{AB}$ & 129,41 & 0,59 & 0,40 \\
\hline & 130 & 50 & 90 & $\mathrm{AB}$ & 129,41 & 0,59 & 0,40 \\
\hline & 130 & 100 & 90 & $\mathrm{AB}$ & 129,41 & 0,59 & 0,40 \\
\hline \multirow{9}{*}{ F-G } & 10 & 0 & 90 & AT & FAC & - & - \\
\hline & 10 & 50 & 90 & AT & FAC & - & - \\
\hline & 10 & 100 & 90 & AT & FAC & - & - \\
\hline & 50 & 0 & 90 & AT & FAC & - & - \\
\hline & 50 & 50 & 90 & AT & FAC & - & - \\
\hline & 50 & 100 & 90 & AT & FAC & - & - \\
\hline & 80 & 0 & 90 & AT & FAC & - & - \\
\hline & 80 & 50 & 90 & AT & FAC & - & - \\
\hline & 80 & 100 & 90 & AT & FAC & - & - \\
\hline
\end{tabular}

*FAC = Fora da Área de Cobertura do Localizador 
TABELA 108 - Resultados referentes a situações de faltas aplicadas nas linhas do circuito 2.

\begin{tabular}{|c|c|c|c|c|c|c|c|}
\hline $\begin{array}{c}\text { Circuito } 2 \\
\text { Linha }\end{array}$ & $\begin{array}{c}\text { Distância } \\
\text { Real } \\
\text { (km) }\end{array}$ & $\begin{array}{c}\text { Resist. } \\
\text { falta } \\
\text { (ohms) }\end{array}$ & $\begin{array}{c}\text { Ângulo de } \\
\text { Incidência } \\
\text { (graus) }\end{array}$ & $\begin{array}{c}\text { Tipo de } \\
\text { Falta }\end{array}$ & $\begin{array}{l}\text { Distância } \\
\text { Estimada } \\
\quad(\mathbf{k m})\end{array}$ & $\begin{array}{l}\text { Erro } \\
\text { Abs. } \\
\text { (km) }\end{array}$ & $\begin{array}{l}\text { Erro } \\
(\%)\end{array}$ \\
\hline \multirow{9}{*}{ D-H } & 10 & 0 & 90 & AT & FAC* & - & - \\
\hline & 10 & 50 & 90 & AT & FAC & - & - \\
\hline & 10 & 100 & 90 & AT & FAC & - & - \\
\hline & 40 & 0 & 90 & AT & FAC & - & - \\
\hline & 40 & 50 & 90 & AT & FAC & - & - \\
\hline & 40 & 100 & 90 & AT & FAC & - & - \\
\hline & 60 & 0 & 90 & AT & FAC & - & - \\
\hline & 60 & 50 & 90 & AT & FAC & - & - \\
\hline & 60 & 100 & 90 & AT & FAC & - & - \\
\hline \multirow{9}{*}{$\mathrm{H}-\mathrm{I}$} & 20 & 0 & 90 & AT & FAC & - & - \\
\hline & 20 & 50 & 90 & AT & FAC & - & - \\
\hline & 20 & 100 & 90 & AT & FAC & - & - \\
\hline & 80 & 0 & 90 & AT & FAC & - & - \\
\hline & 80 & 50 & 90 & AT & FAC & - & - \\
\hline & 80 & 100 & 90 & AT & FAC & - & - \\
\hline & 130 & 0 & 90 & AT & FAC & - & - \\
\hline & 130 & 50 & 90 & AT & FAC & - & - \\
\hline & 130 & 100 & 90 & AT & FAC & - & - \\
\hline \multirow{9}{*}{ I-G } & 10 & 0 & 90 & AT & FAC & - & - \\
\hline & 10 & 50 & 90 & AT & FAC & - & - \\
\hline & 10 & 100 & 90 & AT & FAC & - & - \\
\hline & 50 & 0 & 90 & AT & FAC & - & - \\
\hline & 50 & 50 & 90 & AT & FAC & - & - \\
\hline & 50 & 100 & 90 & AT & FAC & - & - \\
\hline & 80 & 0 & 90 & AT & FAC & - & - \\
\hline & 80 & 50 & 90 & AT & FAC & - & - \\
\hline & 80 & 100 & 90 & AT & FAC & - & - \\
\hline
\end{tabular}

*FAC = Fora da Área de Cobertura do Localizador 


\section{B2. Técnica que utiliza dados de um terminal aplicada ao circuito duplo de transmissão}

TABELA 109 - Resultados para faltas fase-terra (AT) com ângulo de incidência de $0^{\circ}$ e resistência de falta de 0, 50 e $100 \mathrm{ohms,} \mathrm{aplicadas} \mathrm{sobre} \mathrm{linha} \mathrm{E-F.}$

\begin{tabular}{|c|c|c|c|c|c|c|c|}
\hline $\begin{array}{c}\text { Distância } \\
\text { Real } \\
\text { (km) }\end{array}$ & $\begin{array}{c}\text { Resist. } \\
\text { falta } \\
(\text { ohms })\end{array}$ & $\begin{array}{c}\text { Ângulo de } \\
\text { Incidência } \\
\text { (graus) }\end{array}$ & $\begin{array}{c}\text { Tipo de } \\
\text { Falta }\end{array}$ & $\begin{array}{c}\text { Pré- } \\
\text { Localização } \\
\text { (1/2 - seção) }\end{array}$ & $\begin{array}{c}\text { Distância } \\
\text { Estimada } \\
\quad(\mathbf{k m})\end{array}$ & $\begin{array}{l}\text { Erro } \\
\text { Abs. } \\
(\mathbf{k m})\end{array}$ & $\begin{array}{l}\text { Erro } \\
(\%) \\
\end{array}$ \\
\hline 10 & 0 & 0 & AT & 1 & 10,61 & 0,61 & 0,41 \\
\hline 10 & 50 & 0 & AT & 1 & 7,96 & 2,04 & 1,36 \\
\hline 10 & 100 & 0 & AT & 1 & 10,61 & 0,61 & 0,41 \\
\hline 25 & 0 & 0 & AT & 1 & 26,53 & 1,53 & 1,02 \\
\hline 25 & 50 & 0 & AT & 1 & 26,53 & 1,53 & 1,02 \\
\hline 25 & 100 & 0 & AT & 1 & 26,53 & 1,53 & 1,02 \\
\hline 40 & 0 & 0 & AT & 1 & 39,82 & 0,18 & 0,12 \\
\hline 40 & 50 & 0 & AT & 1 & 39,82 & 0,18 & 0,12 \\
\hline 40 & 100 & 0 & AT & 1 & 71,67 & 31,67 & 21,11 \\
\hline 55 & 0 & 0 & AT & 1 & 53,1 & 1,9 & 1,27 \\
\hline 55 & 50 & 0 & AT & 1 & 53,1 & 1,9 & 1,27 \\
\hline 55 & 100 & 0 & AT & 1 & 53,1 & 1,9 & 1,27 \\
\hline 70 & 0 & 0 & AT & 1 & 69,02 & 0,98 & 0,65 \\
\hline 70 & 50 & 0 & AT & 1 & 21,23 & 48,77 & 32,51 \\
\hline 70 & 100 & 0 & AT & 1 & 21,23 & 48,77 & 32,51 \\
\hline 75 & 0 & 0 & AT & 2 & 70,36 & 4,64 & 3,09 \\
\hline 75 & 50 & 0 & AT & 2 & 70,36 & 4,64 & 3,09 \\
\hline 75 & 100 & 0 & AT & 2 & 120,79 & 45,79 & 30,53 \\
\hline 80 & 0 & 0 & AT & 2 & 80,97 & 0,97 & 0,65 \\
\hline 80 & 50 & 0 & AT & 2 & 76,99 & 3,01 & 2,01 \\
\hline 80 & 100 & 0 & AT & 2 & 78,33 & 1,67 & 1,11 \\
\hline 95 & 0 & 0 & AT & 2 & 136,71 & 41,71 & 27,81 \\
\hline 95 & 50 & 0 & AT & 2 & 96,91 & 1,91 & 1,27 \\
\hline 95 & 100 & 0 & AT & 2 & 96,91 & 1,91 & 1,27 \\
\hline 110 & 0 & 0 & AT & 2 & 107,53 & 2,47 & 1,65 \\
\hline 110 & 50 & 0 & AT & 2 & 107,53 & 2,47 & 1,65 \\
\hline 110 & 100 & 0 & AT & 2 & 110,18 & 0,18 & 0,12 \\
\hline 125 & 0 & 0 & AT & 2 & 123,46 & 1,54 & 1,03 \\
\hline 125 & 50 & 0 & AT & 2 & 123,46 & 1,54 & 1,03 \\
\hline 125 & 100 & 0 & AT & 2 & 123,46 & 1,54 & 1,03 \\
\hline 140 & 0 & 0 & AT & 2 & 142,05 & 2,05 & 1,37 \\
\hline 140 & 50 & 0 & $\mathrm{AT}$ & 2 & 139,38 & 0,62 & 0,41 \\
\hline 140 & 100 & 0 & AT & 2 & 142,05 & 2,05 & 1,37 \\
\hline \multicolumn{7}{|c|}{ Erro médio (\%) } & 5,35 \\
\hline
\end{tabular}


TABELA 110 - Resultados para faltas fase-terra (AT) com ângulo de incidência de $90^{\circ}$ e resistência de

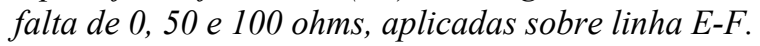

\begin{tabular}{|c|c|c|c|c|c|c|c|}
\hline $\begin{array}{c}\text { Distância } \\
\text { Real } \\
\text { (km) }\end{array}$ & $\begin{array}{c}\text { Resist. } \\
\text { falta } \\
\text { (ohms) }\end{array}$ & $\begin{array}{c}\text { Ângulo de } \\
\text { Incidência } \\
\text { (graus) }\end{array}$ & $\begin{array}{c}\text { Tipo de } \\
\text { Falta }\end{array}$ & $\begin{array}{c}\text { Pré- } \\
\text { Localização } \\
(1 / 2 \text { - seção) }\end{array}$ & $\begin{array}{c}\text { Distância } \\
\text { Estimada } \\
\text { (km) }\end{array}$ & $\begin{array}{l}\text { Erro } \\
\text { Abs. } \\
(\mathbf{k m})\end{array}$ & $\begin{array}{l}\text { Erro } \\
(\%)\end{array}$ \\
\hline 10 & 0 & 90 & AT & 1 & 10,62 & 0,62 & 0,41 \\
\hline 10 & 50 & 90 & AT & 1 & 10,62 & 0,62 & 0,41 \\
\hline 10 & 100 & 90 & AT & 1 & 10,62 & 0,62 & 0,41 \\
\hline 25 & 0 & 90 & AT & 1 & 23,9 & 1,1 & 0,73 \\
\hline 25 & 50 & 90 & AT & 1 & 23,9 & 1,1 & 0,73 \\
\hline 25 & 100 & 90 & AT & 1 & 45,13 & 20,13 & 13,42 \\
\hline 40 & 0 & 90 & AT & 1 & 42,47 & 2,47 & 1,65 \\
\hline 40 & 50 & 90 & AT & 1 & 42,47 & 2,47 & 1,65 \\
\hline 40 & 100 & 90 & AT & 1 & 42,47 & 2,47 & 1,65 \\
\hline 55 & 0 & 90 & AT & 1 & 55,74 & 0,74 & 0,49 \\
\hline 55 & 50 & 90 & AT & 1 & 55,74 & 0,74 & 0,49 \\
\hline 55 & 100 & 90 & AT & 1 & 55,74 & 0,74 & 0,49 \\
\hline 70 & 0 & 90 & AT & 1 & 66,36 & 3,64 & 2,43 \\
\hline 70 & 50 & 90 & AT & 1 & 66,36 & 3,64 & 2,43 \\
\hline 70 & 100 & 90 & AT & 1 & 69,02 & 0,98 & 0,65 \\
\hline 75 & 0 & 90 & AT & 2 & 71,67 & 3,33 & 2,22 \\
\hline 75 & 50 & 90 & AT & 2 & 71,67 & 3,33 & 2,22 \\
\hline 75 & 100 & 90 & AT & 2 & 71,67 & 3,33 & 2,22 \\
\hline 80 & 0 & 90 & AT & 2 & 83,63 & 3,63 & 2,42 \\
\hline 80 & 50 & 90 & AT & 2 & 83,63 & 3,63 & 2,42 \\
\hline 80 & 100 & 90 & AT & 2 & 83,63 & 3,63 & 2,42 \\
\hline 95 & 0 & 90 & AT & 2 & 94,26 & 0,74 & 0,49 \\
\hline 95 & 50 & 90 & AT & 2 & 94,26 & 0,74 & 0,49 \\
\hline 95 & 100 & 90 & AT & 2 & 94,26 & 0,74 & 0,49 \\
\hline 110 & 0 & 90 & AT & 2 & 110,19 & 0,19 & 0,13 \\
\hline 110 & 50 & 90 & AT & 2 & 110,19 & 0,19 & 0,13 \\
\hline 110 & 100 & 90 & AT & 2 & 110,19 & 0,19 & 0,13 \\
\hline 125 & 0 & 90 & AT & 2 & 123,45 & 1,55 & 1,03 \\
\hline 125 & 50 & 90 & AT & 2 & 123,45 & 1,55 & 1,03 \\
\hline 125 & 100 & 90 & AT & 2 & 123,45 & 1,55 & 1,03 \\
\hline 140 & 0 & 90 & AT & 2 & 139,38 & 0,62 & 0,41 \\
\hline 140 & 50 & 90 & AT & 2 & 139,38 & 0,62 & 0,41 \\
\hline 140 & 100 & 90 & AT & 2 & 139,38 & 0,62 & 0,41 \\
\hline \multicolumn{7}{|c|}{ Erro médio (\%) } & 1,46 \\
\hline
\end{tabular}


TABELA 111 - Resultados para faltas fase-fase-terra (ABT) com ângulo de incidência de $0^{\circ}$ e resistência de falta de 0, 50 e $100 \mathrm{ohms,} \mathrm{aplicadas} \mathrm{sobre} \mathrm{linha} \mathrm{E-F.}$

\begin{tabular}{|c|c|c|c|c|c|c|}
\hline $\begin{array}{c}\text { Distância } \\
\text { Real } \\
\text { (km) }\end{array}$ & $\begin{array}{c}\text { Resist. } \\
\text { falta } \\
(\text { ohms })\end{array}$ & $\begin{array}{c}\text { Ângulo de } \\
\text { Incidência } \\
\text { (graus) }\end{array}$ & $\begin{array}{c}\text { Tipo de } \\
\text { Falta }\end{array}$ & $\begin{array}{c}\text { Distância } \\
\text { Estimada } \\
\quad(\mathbf{k m})\end{array}$ & $\begin{array}{l}\text { Erro } \\
\text { Abs. } \\
(\mathbf{k m})\end{array}$ & $\begin{array}{l}\text { Erro } \\
(\%) \\
\end{array}$ \\
\hline 10 & 0 & 0 & ABT & 7,97 & 2,03 & 1,35 \\
\hline 10 & 50 & 0 & ABT & 7,97 & 2,03 & 1,35 \\
\hline 10 & 100 & 0 & ABT & 7,97 & 2,03 & 1,35 \\
\hline 25 & 0 & 0 & ABT & 26,53 & 1,53 & 1,02 \\
\hline 25 & 50 & 0 & ABT & 26,53 & 1,53 & 1,02 \\
\hline 25 & 100 & 0 & ABT & 26,53 & 1,53 & 1,02 \\
\hline 40 & 0 & 0 & ABT & 39,82 & 0,18 & 0,12 \\
\hline 40 & 50 & 0 & ABT & 39,82 & 0,18 & 0,12 \\
\hline 40 & 100 & 0 & ABT & 39,82 & 0,18 & 0,12 \\
\hline 55 & 0 & 0 & ABT & 53,1 & 1,9 & 1,27 \\
\hline 55 & 50 & 0 & ABT & 53,1 & 1,9 & 1,27 \\
\hline 55 & 100 & 0 & ABT & 53,1 & 1,9 & 1,27 \\
\hline 70 & 0 & 0 & ABT & 69,02 & 0,98 & 0,65 \\
\hline 70 & 50 & 0 & ABT & 69,02 & 0,98 & 0,65 \\
\hline 70 & 100 & 0 & ABT & 69,02 & 0,98 & 0,65 \\
\hline 75 & 0 & 0 & ABT & 79,64 & 4,64 & 3,09 \\
\hline 75 & 50 & 0 & ABT & 79,64 & 4,64 & 3,09 \\
\hline 75 & 100 & 0 & ABT & 79,64 & 4,64 & 3,09 \\
\hline 80 & 0 & 0 & ABT & 79,64 & 0,36 & 0,24 \\
\hline 80 & 50 & 0 & ABT & 79,64 & 0,36 & 0,24 \\
\hline 80 & 100 & 0 & ABT & 79,64 & 0,36 & 0,24 \\
\hline 95 & 0 & 0 & ABT & 92,91 & 2,09 & 1,39 \\
\hline 95 & 50 & 0 & ABT & 92,91 & 2,09 & 1,39 \\
\hline 95 & 100 & 0 & ABT & 92,91 & 2,09 & 1,39 \\
\hline 110 & 0 & 0 & ABT & 111,49 & 1,49 & 0,99 \\
\hline 110 & 50 & 0 & ABT & 111,49 & 1,49 & 0,99 \\
\hline 110 & 100 & 0 & ABT & 111,49 & 1,49 & 0,99 \\
\hline 125 & 0 & 0 & ABT & 124,76 & 0,24 & 0,16 \\
\hline 125 & 50 & 0 & ABT & 124,76 & 0,24 & 0,16 \\
\hline 125 & 100 & 0 & ABT & 124,76 & 0,24 & 0,16 \\
\hline 140 & 0 & 0 & ABT & 7,95 & 132,05 & 88,03 \\
\hline 140 & 50 & 0 & ABT & 138,03 & 1,97 & 1,31 \\
\hline 140 & 100 & 0 & ABT & 138,03 & 1,97 & 1,31 \\
\hline \multicolumn{6}{|c|}{ Erro médio (\%) } & 3,68 \\
\hline
\end{tabular}


TABELA 112 - Resultados para faltas fase-fase-terra (ABT) com ângulo de incidencia de $90^{\circ}$ e resistência de falta de 0, 50 e 100 ohms, aplicadas sobre linha E-F.

\begin{tabular}{|c|c|c|c|c|c|c|}
\hline $\begin{array}{c}\text { Distância } \\
\text { Real } \\
\text { (km) }\end{array}$ & $\begin{array}{c}\text { Resist. } \\
\text { falta } \\
\text { (ohms) }\end{array}$ & $\begin{array}{c}\text { Ângulo de } \\
\text { Incidência } \\
\text { (graus) }\end{array}$ & $\begin{array}{c}\text { Tipo de } \\
\text { Falta }\end{array}$ & $\begin{array}{c}\text { Distância } \\
\text { Estimada } \\
(\mathbf{k m})\end{array}$ & $\begin{array}{l}\text { Erro } \\
\text { Abs. } \\
\text { (km) }\end{array}$ & $\begin{array}{l}\text { Erro } \\
(\%)\end{array}$ \\
\hline 10 & 0 & 90 & ABT & 10,61 & 0,61 & 0,41 \\
\hline 10 & 50 & 90 & ABT & 10,61 & 0,61 & 0,41 \\
\hline 10 & 100 & 90 & ABT & 10,61 & 0,61 & 0,41 \\
\hline 25 & 0 & 90 & ABT & 23,9 & 1,1 & 0,73 \\
\hline 25 & 50 & 90 & ABT & 23,9 & 1,1 & 0,73 \\
\hline 25 & 100 & 90 & ABT & 23,9 & 1,1 & 0,73 \\
\hline 40 & 0 & 90 & ABT & 42,47 & 2,47 & 1,65 \\
\hline 40 & 50 & 90 & ABT & 42,47 & 2,47 & 1,65 \\
\hline 40 & 100 & 90 & ABT & 42,47 & 2,47 & 1,65 \\
\hline 55 & 0 & 90 & ABT & 55,74 & 0,74 & 0,49 \\
\hline 55 & 50 & 90 & ABT & 55,74 & 0,74 & 0,49 \\
\hline 55 & 100 & 90 & ABT & 55,74 & 0,74 & 0,49 \\
\hline 70 & 0 & 90 & ABT & 69,02 & 0,98 & 0,65 \\
\hline 70 & 50 & 90 & ABT & 69,02 & 0,98 & 0,65 \\
\hline 70 & 100 & 90 & ABT & 69,02 & 0,98 & 0,65 \\
\hline 75 & 0 & 90 & ABT & 71,67 & 3,33 & 2,22 \\
\hline 75 & 50 & 90 & ABT & 71,67 & 3,33 & 2,22 \\
\hline 75 & 100 & 90 & ABT & 71,67 & 3,33 & 2,22 \\
\hline 80 & 0 & 90 & ABT & 82,29 & 2,29 & 1,53 \\
\hline 80 & 50 & 90 & ABT & 82,29 & 2,29 & 1,53 \\
\hline 80 & 100 & 90 & ABT & 82,29 & 2,29 & 1,53 \\
\hline 95 & 0 & 90 & ABT & 95,56 & 0,56 & 0,37 \\
\hline 95 & 50 & 90 & ABT & 95,56 & 0,56 & 0,37 \\
\hline 95 & 100 & 90 & ABT & 95,56 & 0,56 & 0,37 \\
\hline 110 & 0 & 90 & ABT & 114,14 & 4,14 & 2,76 \\
\hline 110 & 50 & 90 & ABT & 114,14 & 4,14 & 2,76 \\
\hline 110 & 100 & 90 & ABT & 114,14 & 4,14 & 2,76 \\
\hline 125 & 0 & 90 & ABT & 127,42 & 2,42 & 1,61 \\
\hline 125 & 50 & 90 & ABT & 127,42 & 2,42 & 1,61 \\
\hline 125 & 100 & 90 & ABT & 127,42 & 2,42 & 1,61 \\
\hline 140 & 0 & 90 & ABT & 140,69 & 0,69 & 0,46 \\
\hline 140 & 50 & 90 & ABT & 140,69 & 0,69 & 0,46 \\
\hline 140 & 100 & 90 & ABT & 140,69 & 0,69 & 0,46 \\
\hline \multicolumn{6}{|c|}{ Erro médio (\%) } & 1,17 \\
\hline
\end{tabular}


TABELA 113 - Resultados para faltas fase-fase (AB) com ângulo de incidência de $90^{\circ}$, aplicadas sobre linha $E-F$.

\begin{tabular}{cccccc}
\hline $\begin{array}{c}\text { Distância } \\
\text { Real } \\
(\mathbf{k m})\end{array}$ & $\begin{array}{c}\text { Âng. de } \\
\text { Incid. } \\
\text { (graus) }\end{array}$ & $\begin{array}{c}\text { Tipo de } \\
\text { Falta }\end{array}$ & $\begin{array}{c}\text { Distância } \\
\text { Estimada } \\
(\mathbf{k m})\end{array}$ & $\begin{array}{c}\text { Erro } \\
\text { Abs. } \\
\mathbf{( k m )}\end{array}$ & $\begin{array}{c}\text { Erro } \\
\mathbf{( \% )}\end{array}$ \\
\hline 10 & 90 & $\mathrm{AB}$ & 10,62 & 0,62 & 0,41 \\
\hline 25 & 90 & $\mathrm{AB}$ & 23,9 & 1,1 & 0,73 \\
\hline 40 & 90 & $\mathrm{AB}$ & 42,47 & 2,47 & 1,65 \\
\hline 55 & 90 & $\mathrm{AB}$ & 55,74 & 0,74 & 0,49 \\
\hline 70 & 90 & $\mathrm{AB}$ & 69,02 & 0,98 & 0,65 \\
\hline 75 & 90 & $\mathrm{AB}$ & 71,67 & 3,33 & 2,22 \\
\hline 80 & 90 & $\mathrm{AB}$ & 82,29 & 2,29 & 1,53 \\
\hline 95 & 90 & $\mathrm{AB}$ & 95,56 & 0,56 & 0,37 \\
\hline 110 & 90 & $\mathrm{AB}$ & 114,14 & 4,14 & 2,76 \\
\hline 125 & 90 & $\mathrm{AB}$ & 127,42 & 2,42 & 1,61 \\
\hline 140 & 90 & $\mathrm{AB}$ & 140,69 & 0,69 & 0,46 \\
\hline \multicolumn{7}{c}{ Erro médio (\%) } & & & $\mathbf{1 , 1 7}$ \\
\hline
\end{tabular}

TABELA 114 - Resultados para faltas trifásicas (ABC) com ângulo de incidência de $0^{\circ}$, aplicadas sobre linha $E-F$.

\begin{tabular}{|c|c|c|c|c|c|}
\hline $\begin{array}{c}\text { Distância } \\
\text { Real } \\
\text { (km) }\end{array}$ & $\begin{array}{l}\text { Âng. de } \\
\text { Incid. } \\
\text { (graus) }\end{array}$ & $\begin{array}{c}\text { Tipo de } \\
\text { Falta }\end{array}$ & $\begin{array}{c}\text { Distância } \\
\text { Estimada } \\
\quad(\mathbf{k m})\end{array}$ & $\begin{array}{l}\text { Erro } \\
\text { Abs. } \\
\text { (km) }\end{array}$ & $\begin{array}{l}\text { Erro } \\
(\%)\end{array}$ \\
\hline 10 & 0 & $\mathrm{ABC}$ & 7,97 & 2,03 & 1,35 \\
\hline 25 & 0 & $\mathrm{ABC}$ & 26,53 & 1,53 & 1,02 \\
\hline 40 & 0 & $\mathrm{ABC}$ & 39,82 & 0,18 & 0,12 \\
\hline 55 & 0 & $\mathrm{ABC}$ & 53,1 & 1,9 & 1,27 \\
\hline 70 & 0 & $\mathrm{ABC}$ & 69,02 & 0,98 & 0,65 \\
\hline 75 & 0 & $\mathrm{ABC}$ & 74,32 & 0,68 & 0,45 \\
\hline 80 & 0 & $\mathrm{ABC}$ & 79,64 & 0,36 & 0,24 \\
\hline 95 & 0 & $\mathrm{ABC}$ & 92,9 & 2,1 & 1,40 \\
\hline 110 & 0 & $\mathrm{ABC}$ & 111,49 & 1,49 & 0,99 \\
\hline 125 & 0 & $\mathrm{ABC}$ & 124,76 & 0,24 & 0,16 \\
\hline 140 & 0 & $\mathrm{ABC}$ & 138,03 & 1,97 & 1,31 \\
\hline \multicolumn{5}{|c|}{ Erro médio (\%) } & $\mathbf{0 , 8 2}$ \\
\hline
\end{tabular}

TABELA 115 - Resultados para faltas trifásicas (ABC) com ângulo de incidência de $90^{\circ}$, aplicadas sobre linha $E-F$.

\begin{tabular}{|c|c|c|c|c|c|}
\hline $\begin{array}{c}\text { Distância } \\
\text { Real } \\
\text { (km) }\end{array}$ & $\begin{array}{l}\text { Âng. de } \\
\text { Incid. } \\
\text { (graus) }\end{array}$ & $\begin{array}{c}\text { Tipo de } \\
\text { Falta }\end{array}$ & $\begin{array}{c}\text { Distância } \\
\text { Estimada } \\
\quad(\mathbf{k m})\end{array}$ & $\begin{array}{l}\text { Erro } \\
\text { Abs. } \\
\text { (km) }\end{array}$ & Erro \\
\hline 10 & 90 & $\mathrm{ABC}$ & 10,62 & 0,62 & 0,41 \\
\hline 25 & 90 & $\mathrm{ABC}$ & 23,9 & 1,1 & 0,73 \\
\hline 40 & 90 & $\mathrm{ABC}$ & 42,47 & 2,47 & 1,65 \\
\hline 55 & 90 & $\mathrm{ABC}$ & 55,74 & 0,74 & 0,49 \\
\hline 70 & 90 & $\mathrm{ABC}$ & 66,36 & 3,64 & 2,43 \\
\hline 75 & 90 & $\mathrm{ABC}$ & 71,67 & 3,33 & 2,22 \\
\hline 80 & 90 & $\mathrm{ABC}$ & 82,29 & 2,29 & 1,53 \\
\hline 95 & 90 & $\mathrm{ABC}$ & 95,56 & 0,56 & 0,37 \\
\hline 110 & 90 & $\mathrm{ABC}$ & 108,83 & 1,17 & 0,78 \\
\hline 125 & 90 & $\mathrm{ABC}$ & 127,42 & 2,42 & 1,61 \\
\hline 140 & 90 & $\mathrm{ABC}$ & 140,69 & 0,69 & 0,46 \\
\hline \multicolumn{5}{|c|}{ Erro médio (\%) } & 1,15 \\
\hline
\end{tabular}


TABELA 116 - Resultados referentes a situações de faltas aplicadas nas linhas do circuito 1, utilizando dados registrados localmente.

\begin{tabular}{|c|c|c|c|c|c|c|c|}
\hline $\begin{array}{c}\text { Circuito } 1 \\
\text { Linha }\end{array}$ & $\begin{array}{c}\text { Distância } \\
\text { Real } \\
\text { (km) }\end{array}$ & $\begin{array}{c}\text { Resist. } \\
\text { falta } \\
(\text { ohms })\end{array}$ & $\begin{array}{l}\text { Ângulo de } \\
\text { Incidência } \\
\text { (graus) }\end{array}$ & $\begin{array}{c}\text { Tipo de } \\
\text { Falta }\end{array}$ & $\begin{array}{c}\text { Distância } \\
\text { Estimada } \\
\quad(\mathbf{k m})\end{array}$ & $\begin{array}{l}\text { Erro } \\
\text { Abs. } \\
(\mathbf{k m})\end{array}$ & $\begin{array}{r}\text { Erro } \\
(\%)\end{array}$ \\
\hline \multirow{9}{*}{ D-E } & 10 & 0 & 90 & AT & FAC* & - & - \\
\hline & 10 & 50 & 90 & AT & FAC & - & - \\
\hline & 10 & 100 & 90 & AT & FAC & - & - \\
\hline & 40 & 0 & 90 & AT & FAC & - & - \\
\hline & 40 & 50 & 90 & AT & FAC & - & - \\
\hline & 40 & 100 & 90 & AT & FAC & - & - \\
\hline & 60 & 0 & 90 & AT & FAC & - & - \\
\hline & 60 & 50 & 90 & AT & FAC & - & - \\
\hline & 60 & 100 & 90 & AT & FAC & - & - \\
\hline \multirow{9}{*}{ E-F } & 20 & 0 & 90 & $\mathrm{AB}$ & 18,58 & 1,42 & 0,95 \\
\hline & 20 & 50 & 90 & $\mathrm{AB}$ & 18,58 & 1,42 & 0,95 \\
\hline & 20 & 100 & 90 & $\mathrm{AB}$ & 18,58 & 1,42 & 0,95 \\
\hline & 80 & 0 & 90 & $\mathrm{AB}$ & 82,29 & 2,29 & 1,53 \\
\hline & 80 & 50 & 90 & $\mathrm{AB}$ & 82,29 & 2,29 & 1,53 \\
\hline & 80 & 100 & 90 & $\mathrm{AB}$ & 82,29 & 2,29 & 1,53 \\
\hline & 130 & 0 & 90 & $\mathrm{AB}$ & 130,07 & 0,07 & 0,05 \\
\hline & 130 & 50 & 90 & $\mathrm{AB}$ & 130,07 & 0,07 & 0,05 \\
\hline & 130 & 100 & 90 & $\mathrm{AB}$ & 130,07 & 0,07 & 0,05 \\
\hline \multirow{9}{*}{ F-G } & 10 & 0 & 90 & AT & $\overline{F F A C}$ & - & - \\
\hline & 10 & 50 & 90 & AT & FAC & - & - \\
\hline & 10 & 100 & 90 & AT & FAC & - & - \\
\hline & 50 & 0 & 90 & AT & FAC & - & - \\
\hline & 50 & 50 & 90 & AT & FAC & - & - \\
\hline & 50 & 100 & 90 & AT & FAC & - & - \\
\hline & 80 & 0 & 90 & AT & FAC & - & - \\
\hline & 80 & 50 & 90 & AT & FAC & - & - \\
\hline & 80 & 100 & 90 & AT & FAC & - & - \\
\hline
\end{tabular}


TABELA 117 - Resultados referentes a situações de faltas aplicadas nas linhas do circuito 2, utilizando dados registrados localmente.

\begin{tabular}{|c|c|c|c|c|c|c|c|}
\hline $\begin{array}{c}\text { Circuito } 2 \\
\text { Linha }\end{array}$ & $\begin{array}{c}\text { Distância } \\
\text { Real } \\
\text { (km) }\end{array}$ & $\begin{array}{l}\text { Resist. } \\
\text { falta } \\
\text { (ohms) }\end{array}$ & $\begin{array}{c}\text { Ângulo de } \\
\text { Incidência } \\
\text { (graus) }\end{array}$ & $\begin{array}{c}\text { Tipo de } \\
\text { Falta }\end{array}$ & $\begin{array}{c}\text { Distância } \\
\text { Estimada } \\
\quad(\mathbf{k m})\end{array}$ & $\begin{array}{l}\text { Erro } \\
\text { Abs. } \\
\text { (km) }\end{array}$ & $\begin{array}{l}\text { Erro } \\
(\%)\end{array}$ \\
\hline \multirow{9}{*}{ D-H } & 10 & 0 & 90 & AT & FAC* & - & - \\
\hline & 10 & 50 & 90 & AT & FAC & - & - \\
\hline & 10 & 100 & 90 & $\mathrm{AT}$ & FAC & - & - \\
\hline & 40 & 0 & 90 & AT & FAC & - & - \\
\hline & 40 & 50 & 90 & AT & FAC & - & - \\
\hline & 40 & 100 & 90 & AT & FAC & - & - \\
\hline & 60 & 0 & 90 & AT & FAC & - & - \\
\hline & 60 & 50 & 90 & AT & FAC & - & - \\
\hline & 60 & 100 & 90 & AT & FAC & - & - \\
\hline \multirow{9}{*}{$H-I$} & 20 & 0 & 90 & AT & FAC & - & - \\
\hline & 20 & 50 & 90 & AT & FAC & - & - \\
\hline & 20 & 100 & 90 & AT & FAC & - & - \\
\hline & 80 & 0 & 90 & AT & FAC & - & - \\
\hline & 80 & 50 & 90 & AT & FAC & - & - \\
\hline & 80 & 100 & 90 & AT & FAC & - & - \\
\hline & 130 & 0 & 90 & AT & FAC & - & - \\
\hline & 130 & 50 & 90 & AT & FAC & - & - \\
\hline & 130 & 100 & 90 & AT & FAC & - & - \\
\hline \multirow{9}{*}{ I-G } & 10 & 0 & 90 & AT & FAC & - & - \\
\hline & 10 & 50 & 90 & AT & FAC & - & - \\
\hline & 10 & 100 & 90 & AT & FAC & - & - \\
\hline & 50 & 0 & 90 & AT & FAC & - & - \\
\hline & 50 & 50 & 90 & AT & FAC & - & - \\
\hline & 50 & 100 & 90 & AT & FAC & - & - \\
\hline & 80 & 0 & 90 & AT & FAC & - & - \\
\hline & 80 & 50 & 90 & AT & FAC & - & - \\
\hline & 80 & 100 & 90 & AT & FAC & - & - \\
\hline
\end{tabular}

